\title{
Uranium-Series Radionuclide Records of Paleoceanographic and Sedimentary Changes in the Arctic Ocean
}

\author{
by \\ Sharon Susanna Hoffmann \\ B.A., Columbia University, 1999 \\ Submitted in partial fulfillment of the requirements for the degree of \\ Doctor of Philosophy \\ at the \\ MASSACHUSETTS INSTITUTE OF TECHNOLOGY \\ and the \\ WOODS HOLE OCEANOGRAPHIC INSTITUTION
}

February, 2009

(C)Sharon Susanna Hoffmann, 2009.

All rights reserved.

The author hereby grants MIT and WHOI permission to reproduce and distribute paper and electronic copies of this thesis document in whole or in part.

Signature of Author:

Joint Program in Oceanography

Massachusetts Institute of Technology

Woods Hole Oceanographic Institution

September 23, 2008

Certified by:

Jerry F. McManus

Associate Scientist

Thesis Advisor

Accepted by:

Bradford H. Hager

Co-Chair, Joint Committee for Marine Geology and Geophysics Massachusetts Institute of Technology 


\title{
Uranium-series Radionuclide Records of Paleoceanographic and Sedimentary Changes in the Arctic Ocean
}

\author{
by \\ Sharon Susanna Hoffmann \\ Submitted to the MIT/WHOI Joint Program \\ on September 23, 2008 in Partial Fulfillment of the \\ Requirements for the Degree of Doctor of Philosophy in \\ Marine Geology
}

\begin{abstract}
The radionuclides ${ }^{231} \mathrm{~Pa}$ and ${ }^{230} \mathrm{Th}$, produced in the water column and removed from the ocean by particle scavenging and burial in sediments, offer a means for paleoceanographers to examine past dynamics of both water column and sedimentary processes. I show for the first time that a state of balance exists between ${ }^{230}$ Th production and burial in the Central Arctic basins, based on measured sedimentary ${ }^{230} \mathrm{Th}_{\mathrm{xs}}$ inventories in box cores, establishing this nuclide's utility as a paleoceanographic indicator of sedimentary processes and as a normalization tool. I present the first ${ }^{230} \mathrm{Th}$-normalized particle fluxes calculated for the central Arctic: vertical particle fluxes were extremely low during the late glacial, rose during the deglaciation due to particle inputs from shelf inundation, increased productivity and ice-rafted debris, and fell again following the establishment of interglacial conditions. A major event of lateral sediment redistribution, inferred from surplus ${ }^{230} \mathrm{Th}_{\mathrm{xs}}$ inventories, occurred in the Makarov Basin during the deglaciation and may have been due to destabilization of slope and shelf sediments as sea level rose.

I present the first high-resolution, radiocarbon-dated downcore records of sedimentary ${ }^{231}{ }^{\mathrm{Pa}} /{ }^{230} \mathrm{Th}$ from the Arctic Ocean. Low ratios indicate that ${ }^{231} \mathrm{~Pa}$ was exported from all sites during the late glacial period, with export decreasing during the deglaciation and Holocene. ${ }^{231} \mathrm{~Pa} /{ }^{230} \mathrm{Th}$ measurements in cores from three continental slope sites show no evidence for a ${ }^{231} \mathrm{~Pa}$ sink related to boundary scavenging on the continental slopes. Holocene ${ }^{231} \mathrm{~Pa} /{ }^{230} \mathrm{Th}$ ratios show a very significant variation by depth, with strong export of ${ }^{231} \mathrm{~Pa}$ at deep sites but little or no export at shallow sites, a result which echoes findings for the South Atlantic and the Pacific. The Arctic thus appears fundamentally similar to other ocean basins in its ${ }^{231} \mathrm{~Pa}$ and ${ }^{230} \mathrm{Th}$ dynamics, despite its peculiar qualities of sea ice cover, low particle flux, and relatively isolated deep waters.

Thesis Supervisor: Jerry F. McManus

Title: Associate Scientist, Woods Hole Oceanographic Institution
\end{abstract}




\section{Table of Contents}

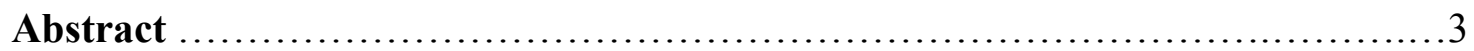

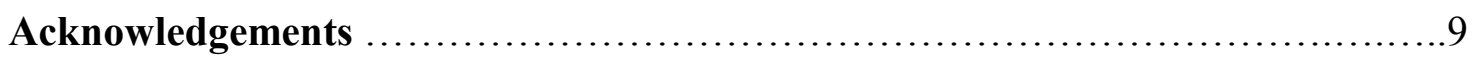

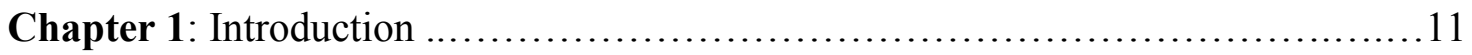

Chapter 2: Is There a ${ }^{230} \mathrm{Th}$ Deficit in Arctic Sediments? ..........................21

Abstract.........................................................21

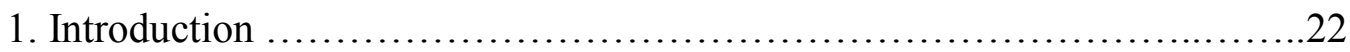

2. Methods and Sources...........................................26

3. Results:

3.1 Core ${ }^{230}$ Th profiles and inventories...........................28

4. Discussion:

4.1 Previous estimates of Arctic ${ }^{230}$ Th burial

4.2 Holocene budgets of ${ }^{230} \mathrm{Th}$ and modern evidence for scavenging...33

4.3 Glacial sedimentation rates and implications for ongoing..........36 ${ }^{230}$ Th scavenging

4.4: High ${ }^{230} \mathrm{Th}$ inventories in deglacial sediments....................36

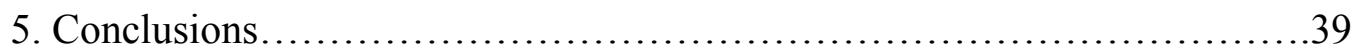

References..........................................................41

Table...........................................................45

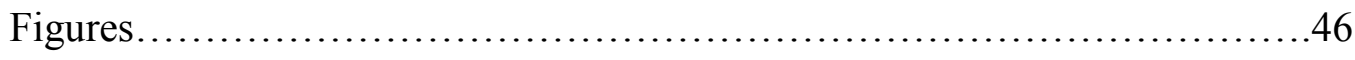

Chapter 3: A History of Sedimentation in the Central Arctic in the Last 35,000.....51 Years from Sedimentary ${ }^{230} \mathrm{Th}_{\mathrm{xs}}$ Records

Abstract..........................................................51

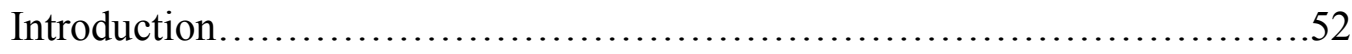

Methods........................................................55 
Results:

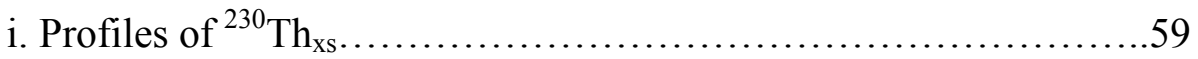

ii. ${ }^{230} \mathrm{Th}_{\mathrm{xs}}$ inventories from the Eurasian Basin, $\mathrm{BC} 26,28,32 \ldots \ldots \ldots 60$

iii. New inventory calculations from Amerasian Basin cores, ........61 $\mathrm{BC} 08,16,17$ and 20

iv. Vertical sedimentation fluxes from ${ }^{230} \mathrm{Th}_{\mathrm{xs}}$ and total.............62 sedimentation fluxes

v. Uranium-238 and thorium-232 ..............................64

Discussion:

Inventories:

i. ${ }^{230} \mathrm{Th}_{\mathrm{xs}}$ inventories from the Eurasian Basin....................64

ii. ${ }^{230} \mathrm{Th}_{\mathrm{xs}}$ inventories from the Amerasian Basin...................67

${ }^{230}{ }^{T} h_{x s}$-normalized sediment fluxes and total mass accumulation rates

iii. Glacial ${ }^{230}$ Th deposition...................................69

iv. Deglacial sediment fluxes.................................... 73

v. Deglacial ${ }^{230}$ Th and lateral transport..........................74

vi. Holocene ${ }^{230} \mathrm{Th}_{\mathrm{xs}}$ and MARs................................ 77

vii. Relationship of foraminiferal $\delta^{18} \mathrm{O}$ and surface conditions..........78 to particle fluxes

Conclusions.......................................................81

References......................................................8 83

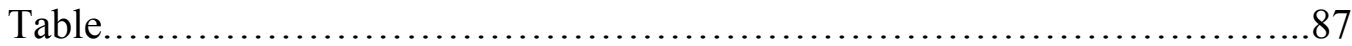

Figures.............................................................. 88 
Chapter 4. Extensive Deglacial Sediment Redistribution in the Western Arctic as ...105 Determined by Excess Thorium- ${ }^{230}$

Abstract............................................................ 105

Introduction........................................................ 106

Materials and Methods................................................ 107

Results............................................................... 111

Discussion............................................................ 112

Table................................................................. 120

Figures............................................................ 121

References.......................................................... 124

Chapter 5: ${ }^{231} \mathrm{~Pa}$ Deposition and Export in the Central Arctic........................ 127 Since the Last Glaciation

Abstract.................................................................. 127

Introduction..................................................... 127

Materials and Methods..................................................131

Results................................................................. 132

Discussion:

History of late glacial, deglacial, and Holocene Pa deposition

i. Late glacial records....................................135

ii. Deglacial records..................................136

iii. Holocene records.................................... 137

Factors controlling export and burial of ${ }^{231} \mathrm{~Pa}$

iv. Particle fluxes to the Central Arctic seafloor................138

v. Particle type and fractionation between ${ }^{231} \mathrm{~Pa}$ and ${ }^{230} \mathrm{Th} . \ldots \ldots . .139$

vi. Boundary scavenging............................... 140 
Conclusions...................................................... 146

References........................................................ 148

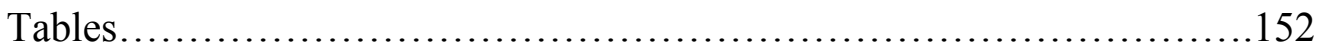

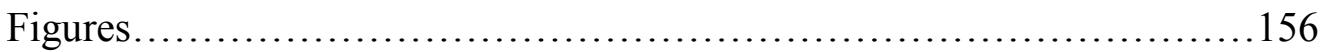

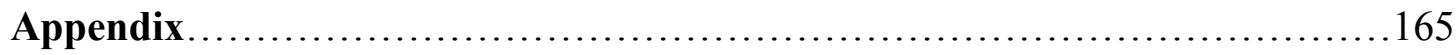

Table A.1: Core Locations and Water Depths......................... 165

Table A.2: Radiocarbon Dates and Calibrated Ages.......................166

Figure A.1: BC 20 Coarse Fraction in Two Subcores: Darby et al. (1997) ..168 and This Study

Table A.3: Nuclide Measurements, all cores............................169

Table A.4: Stable Isotopic Measurements, $\delta^{13} \mathrm{C}$ and $\delta^{18} \mathrm{O} \ldots \ldots \ldots \ldots \ldots \ldots . . \ldots 178$

Table A.5: ${ }^{230}$ Th-Normalized Mass Flux, Mass Accumulation Rate,........192 and Focusing Factors

Table A.6: Th and Pa Replicate Data for Error Analysis...................200

Figure A. 2: Replicate Standard Deviations for ${ }^{230} \mathrm{Th}$ and ${ }^{231} \mathrm{~Pa} /{ }^{230} \mathrm{Th} . \ldots \ldots . .202$

Table A.7: ${ }^{230}$ Th-normalized Fluxes of Planktonic Foraminifera, ...........203 BC 07, 16, 17

Table A.8 Biogenic Silica \% in PL-94-AR Samples......................204

Figure A.3: ${ }^{231} \mathrm{~Pa} /{ }^{230} \mathrm{Th}$ ratios from this study, Moran et al. (2005) and ......205 Scholten et al. (1995).

Figure A.4: Biogenic Opal weight $\%$ measurements and ${ }^{231} \mathrm{~Pa} /{ }^{230} \mathrm{Th} . . . \ldots . .206$

Figure A.5: Water Column Dissolved Silica and Conservative Properties...207 


\section{Acknowledgements}

My graduate work has been funded by NSF grants OCE-0402565 and OCE0550637 to Jerry McManus, ARC-0520073 to Bill Curry, and OCE-0118126 to Daniel McCorkle. My graduate education was also supported by an IODP Schlanger Ocean Drilling Fellowship, WHOI Fellowships from the WHOI Academic Programs Office, and an MIT Presidential Fellowship.

Thank you first to Jerry McManus, for his patience, time, and support as my thesis advisor. His expertise, advice, and mini-Socratic dialogues have greatly enhanced this work. He made time for me when he had no time at all to spare. Thanks also to Dan McCorkle, who advised my first generals project, and who has continued to be a great help in my graduate career. Bill Curry has been a source of support and information and good sense; Olivier Marchal has been extremely helpful and kind with statistics and modeling questions and good ideas about protactinium. Ed Boyle has been an excellent committee member and source of thesis advice. Thanks to Laura Robinson, who kindly agreed to chair my committee, whose excellent comments helped to improve this thesis, and who has been wonderfully supportive during the writing-up phase.

This thesis would never have been possible without Susan Brown-Leger, who managed and organized the new clean lab and taught me how to process samples for radionuclide analysis. Dave Schneider and Scot Birdwhistell provided invaluable assistance with the Element2 ICP-MS. Summer Praetorius picked forams for radiocarbon dating; Rindy Ostermann prepared and ran foram samples for stable isotope mass spectrometry. Delia Oppo, Lloyd Keigwin, Bill Thompson, Candace Major, Marti Jeglinski, and Karen Bice have helped me as well in the course of graduate study. Gerard Bond and Rusty Lotti-Bond gave me my introduction to paleoceanographic research, and I will always be grateful to them.

Many thanks to the Academic Programs Office and the people in it, especially Julia Westwater, Marsha Gomes, and Ronni Schwartz! They do an immense amount for the Joint Program Students and can't really be thanked enough.

I have many friends to thank for their support while I worked on this project. I thank Matt Jackson for an absurd amount of time spent sitting in the Captain Kidd at inappropriate hours on school nights. Abby Fusaro and Trish Gregg have been wonderful sources of support, silliness, and song. Lynne Elkins is the finest officemate in history. Asher Siebert is still the only person who can get me to dance decently. Jo Muller has been a great friend and labmate and commiserator over protactinium spreadsheets. Fern Gibbons took care of me at AGU and tells me stories about her dog and her bees. Dave Stuebe, Jonathan Blythe, Heidi Marsella, Anna Maria Skulladottir, Fareeha Iqbal, Annette Hynes, Kate Buckman, Mark Rapo, Ariane Verdy, Nick Drenzek, Mea Cook, Rose Came, Dave Lund, Matt Makou, Sheri Simmons, Elizabeth Senecal, Stephanie Desprat, Danielle Dreilinger, Wren Montgomery, and Phil Stanton have all been great friends. Thanks also are due to my friends from Schola Cantorum of Falmouth, the Woods Hole Cantata, and the Falmouth Chorale, for great music, paper airplane throwing in the BBC, and for helping me feel like I have lived in Falmouth the last few years, rather than in Clark. 
Finally, I must thank my family: my parents, who have given me unswerving support and love, and my grandparents, aunts, uncles, and cousins, for loving me and asking me, "So how's your work?" And, thanks to my fiancé, Hunter Oates, for everything. Just everything. 


\section{Chapter 1}

\section{Introduction}

The Arctic region today is a bellwether of global climate change. Warming temperatures, disappearing sea ice, and thawing permafrost all signal major climatic and environmental upheavals afoot in the region, and invite geoscientists to study these shifts and the Arctic's role in the global climate. Paleoclimatology and paleoceanography play a vital role in this study, by helping to establish the natural range of variability in oceanic and environmental conditions in the past, and patterns of regional change that may help us to predict future behavior of the Arctic climate system.

However, due to its remoteness and harsh conditions, the Arctic has been one of the ocean basins least studied by paleoceanographers. Sediment cores from this region present a number of obstacles to study. Sedimentation rates in the deep basins are generally low compared to the rates seen in many Atlantic sediment drift cores that have been studied by paleoceanographers, limiting the resolution achievable in Arctic records, and apparent gaps in sedimentation complicate efforts to constrain ages in records (Poore et al., 1999). Foraminifera, used for generating radiocarbon ages and stable isotope records, can be rare or absent in some regions and time periods (e.g. Darby et al., 1997, Poore et al., 1999). Furthermore, stable oxygen isotope records, often used in core records from other oceans to provide stratigraphic information during the Quaternary, are difficult to correlate between the Arctic and the rest of the globe. In much of the world 
ocean, age models for cores can be constructed from benthic or planktonic foraminiferal $\delta^{18} \mathrm{O}$ and assigned ages through correlation to ice core records or Milankovich orbitallyforced insolation curves. However, Arctic planktonic foraminiferal $\delta^{18} \mathrm{O}$ signals appear to track local changes in meltwater and near-surface salinity, rather than global temperature trends and ice volume (Stein et al., 1994; Spielhagen et al., 1994; Norgaard-Pedersen et al., 1998; Poore et al., 1999).

Several studies have attempted to get around these difficulties in constraining sedimentation in the Arctic basins by measuring the activity of the radionuclide ${ }^{230} \mathrm{Th}$ in sediments. This extremely particle-reactive isotope is produced at a known constant rate in seawater by decay of ${ }^{234} \mathrm{U}$, and is removed from the water column by adsorption to sinking particles and subsequent burial in sediments. Local removal of ${ }^{230} \mathrm{Th}$ from the water column to the sediments has been shown to roughly balance local production in the water column in much of the world ocean (Henderson et al., 1999; Yu et al., 2001). If this is the case in the Arctic, then we should be able to use the production rate of ${ }^{230} \mathrm{Th}$ in the water column there to estimate its rate of input to the sea floor, and in some cases use the shape of the ${ }^{230} \mathrm{Th}$ profile measured in sediments to estimate the rate at which those sediments accumulated (Broecker and van Donk, 1970). Where the production and burial of ${ }^{230} \mathrm{Th}$ are in balance, ${ }^{230} \mathrm{Th}$ can also be used as a normalizing tool to determine fluxes of other chemical species and sedimentary components to the seafloor.

However, it was long thought that the Arctic Ocean represented an exception to the rule of balanced ${ }^{230} \mathrm{Th}$ budgets. The first Arctic water column measurements (Bacon et al., 1989) of dissolved ${ }^{230} \mathrm{Th}$ and its sister nuclide ${ }^{231} \mathrm{~Pa}$, produced by decay of ${ }^{235} \mathrm{U}$, 
showed unusually high concentrations compared to other ocean basins. These results were interpreted as consistent with slow scavenging of these nuclides by particles, and with inefficient removal of ${ }^{230} \mathrm{Th}$ and ${ }^{231} \mathrm{~Pa}$ from the water column. Sedimentary records of ${ }^{230} \mathrm{Th}$ (Ku and Broecker, 1967; Finkel et al., 1977; Somayajulu et al., 1989; Huh et al., 1997) from the Arctic were interpreted as indicative of very low ( $\mathrm{mm} / \mathrm{kyr}$ ) sedimentation rates and major deficits of ${ }^{230} \mathrm{Th}$ relative to the water column production. An imbalance between production and burial would preclude the use of ${ }^{230} \mathrm{Th}$ as a normalizing tool for studying input of sediment components and chemical species such as ${ }^{231} \mathrm{~Pa}$ to the seafloor. No previous study has attempted to interpret ${ }^{230} \mathrm{Th}$ or ${ }^{231} \mathrm{~Pa}$ as a paleoceanographic tool for this reason.

${ }^{231} \mathrm{~Pa}$ is less particle reactive and has a longer residence time in seawater than ${ }^{230} \mathrm{Th}$, allowing it to be exported away from regions of low particle flux either by eddy diffusion, as seen in the Pacific (Yang et al., 1986) or by advection of water masses, as seen in the Atlantic (Yu et al., 1996; Moran et al., 2002; McManus et al., 2004). The ratio of ${ }^{231} \mathrm{~Pa}$ to ${ }^{230} \mathrm{Th}$ in sediments, assuming balanced local budgets of ${ }^{230} \mathrm{Th}$, has been shown to be a useful dynamical proxy for deep water advection in the Atlantic Ocean (Yu et al., 1996; McManus et al., 2004, Gherardi et al., 2005; Hall et al., 2006), as well as an indicator of paleoproductivity (Bradtmiller et al., 2007) in tropical seas. For my thesis work, I chose to investigate the potential of these nuclides as paleoceanographic tools in Arctic sediments.

In Chapter 2, I show that the assumption of imbalance between Arctic ${ }^{230} \mathrm{Th}$ production and deposition is largely incorrect: no pervasive sedimentary deficit of ${ }^{230} \mathrm{Th}_{\mathrm{xs}}$ 
exists in Western Arctic sediments. I combine published ${ }^{230} \mathrm{Th}_{\mathrm{xs}}$ records (the subscript "xs" denotes excess ${ }^{230} \mathrm{Th}$, derived from the water column, and unsupported by radiodecay within the sediment grains) with radiocarbon dates $\left({ }^{230} \mathrm{Th}_{\mathrm{xs}}\right.$ data, Huh et al., 1997; radiocarbon dates, Darby et al. 1997; Poore et al. 1999) as an independent means of age control, to calculate the amount of ${ }^{230} \mathrm{Th}_{\mathrm{xs}}$ deposited in sediments at five Western Arctic sites during the Holocene (11 ka-present), deglacial (15-11 ka), and late glacial (35-15 ka). My calculations show that Holocene and late glacial sedimentary inventories of ${ }^{230} \mathrm{Th}_{\mathrm{xs}}$ largely balanced the amount of ${ }^{230} \mathrm{Th}$ that would have been produced in the water column above these sites during the accumulation of the sediments. In the deglacial sections of the cores, far from a deficit, we found a surplus of ${ }^{230} \mathrm{Th}_{\mathrm{xs}}$ relative to what could have been produced locally in the water column during deposition of those sediments. This chapter overturns the previously accepted idea of inefficient ${ }^{230} \mathrm{Th}$ scavenging and burial in the Arctic, and establishes that ${ }^{230} \mathrm{Th}$ budgets were relatively well balanced during the Holocene and late glacial. This finding permits the use of sedimentary ${ }^{230} \mathrm{Th}_{\mathrm{xs}}$ as a paleoceanographic indicator of particle fluxes and lateral sediment redistribution, and as a normalizing tool to study the behavior of ${ }^{231} \mathrm{~Pa}$ in the Arctic.

In Chapter 3, I present new ICP-MS measurements of ${ }^{230} \mathrm{Th}_{\mathrm{xs}}$ in seven Arctic sediment cores forming a transect from the Mendeleev Ridge to the Nansen Basin, four cores in the Western Arctic and three in the Eastern Arctic. I use these measurements to produce the first records of ${ }^{230} \mathrm{Th}$-normalized vertical particle flux to the Arctic seafloor, reflecting changes in surface conditions, such as ice cover, that affect productivity and 
terrigenous particle supply. My results show that particle fluxes were low during the late glacial, when the Arctic was covered in thick sea ice with few leads, and rose at the deglaciation, when collapsing ice sheets, increased open water area for productivity, and flooded shelves all resulted in increased particle supply to the central ocean.

Chapter 4 focuses on a particularly noteworthy feature of our records: a deglacial interval of high sedimentation rates and surplus ${ }^{230} \mathrm{Th}_{\mathrm{xs}}$ inventory found in all our Western Arctic cores, which is shown to be due to a major sediment redistribution event in the Makarov Basin. ${ }^{230} \mathrm{Th}_{\mathrm{xs}}$ inventories in all our Makarov Basin cores are far too high to reflect only local ${ }^{230} \mathrm{Th}$ production in the water column; lateral transport from elsewhere in the basin of sediments carrying ${ }^{230} \mathrm{Th}_{\mathrm{xs}}$ must have been responsible for the high observed sedimentation rates at that time. We suggest that a possible source for the redistributed sediments is the wide Siberian shelf adjacent to the Makarov Basin, which had been subaerially exposed during the glacial lowstand and was subsequently flooded during the deglacial sea level rise. This finding suggests that caution should be used in interpreting other paleoproxies from the same interval, as it is possible that they may have been transported with the sediments and may not reflect conditions at the coring site.

In chapter 5 I present the first high-resolution ${ }^{231} \mathrm{~Pa} /{ }^{230} \mathrm{Th}$ records from the Arctic. Ratios of ${ }^{231} \mathrm{~Pa}{ }^{230} \mathrm{Th}$ lower than the water column production ratio of 0.093 in our records indicate that ${ }^{231} \mathrm{~Pa}$ has been exported from the deep central basins continuously over the last $35 \mathrm{kyr}$. However, samples from three sites on the continental slopes of the Arctic did not show ratios elevated above the production ratio, suggesting that ${ }^{231} \mathrm{~Pa}$ is not 
imported to these sites and removed by boundary scavenging. We find a strong relationship between ${ }^{231} \mathrm{~Pa} /{ }^{230} \mathrm{Th}$ values and water depth, with shallower cores consistently giving higher ratios than deeper cores through the late glacial, deglacial and Holocene, an observation consistent with published coretop ratios from both the Arctic (Moran et al., 2005) and from other ocean basins (Scholten et al., 2008). This suggests that the Holocene and present-day relationship of ratio to water depth is not dependent on environmental or oceanographic conditions peculiar to the Arctic, such as sea ice, reduced particle flux, or isolated deep waters. However, the slope of the late glacial ratio/water depth relationship is lower than during the Holocene, indicating that differing past conditions could drive changes in ${ }^{231} \mathrm{~Pa}$ scavenging, particularly at shallower sites. These ${ }^{231} \mathrm{~Pa}$ results and the ${ }^{230} \mathrm{Th}$ results in Chapter 2 indicate that particle scavenging behavior in the Arctic, far from being the special case it once was supposed to be, is remarkably similar to what is observed in the rest of the world ocean.

The cores analyzed in this thesis lie within the Makarov, Amundsen and Nansen Basins of the Arctic Ocean. Future directions for work on ${ }^{230} \mathrm{Th}$ and ${ }^{231} \mathrm{~Pa}$ include expanding the dataset to cores from the Canada Basin, the largest sub-basin of the Arctic Ocean, and the most isolated in its deeper reaches. The bottom waters of the Canada Basin do not appear to have communicated with the surface for at least 400 years (Schlosser et al., 1997) and are very homogenized in their physical characteristics (Timmermans et al., 2003), indicating isolation from other deep water masses as well. In such a closed-off basin with long residence times of water, does the relationship of ${ }^{231} \mathrm{~Pa}$ export with depth that we find for the other Arctic basins hold true, or might the ${ }^{231} \mathrm{~Pa}$ 
produced in the deep Canada Basin remain there, leading to high ${ }^{231} \mathrm{~Pa} /{ }^{230} \mathrm{Th}$ ratios even in the deepest cores?

This study concentrated on the last 35,000 years of the paleoceanographic record. The half-lives of ${ }^{230} \mathrm{Th}$ and ${ }^{231} \mathrm{~Pa}$ are 75,380 years and 32,760 years respectively; much longer records can be constructed from them. Did ${ }^{231} \mathrm{~Pa} /{ }^{230} \mathrm{Th}$ during the last interglacial, Marine Isotope Stage 5e, resemble modern ratios? As the global climate began to slide towards glacial conditions, how did Arctic particle fluxes and scavenging respond? As our understanding of Arctic sediment stratigraphy improves, and identification of previous climatic periods in the sediments becomes more sure, we may be able to extend our records back in time and to answer these questions. We can also examine major sedimentation changes, such as the sedimentation rate change following Marine Isotope Stage 5 seen in Lomonosov Ridge cores (Jakobsson et al., 2000): are such changes related to vertical particle fluxes, and thus to surface conditions, or to lateral sediment transport in nepheloid layers?

Finally, although this study concluded that between 30 and $40 \%$ of ${ }^{231} \mathrm{~Pa}$ produced in the Central Arctic over the past $35 \mathrm{kyr}$ has been exported from the deep central basins, it did not positively identify a sink for that ${ }^{231} \mathrm{~Pa}$. Future work might focus on cores in high-particle-flux regions such as the Laptev Sea continental slope, to look for boundary scavenging there. If ${ }^{231} \mathrm{~Pa}$ is exported out of the Arctic Basin entirely, through the deep conduit of the Fram Strait, analyzing cores from the strait and the high North Atlantic might show evidence for importation of ${ }^{231} \mathrm{~Pa}$. Tracing the ${ }^{231} \mathrm{~Pa}$ that is lost from the Central Arctic will be an important next step for understanding radionuclide behavior in 
this region, and may also improve our understanding of ${ }^{231} \mathrm{~Pa}$ budgets in the far north Atlantic region.

\section{References}

Bacon, M.P., Huh, C.-A., Moore, R.M., 1989. Vertical profiles of some natural radionuclides over the Alpha Ridge, Arctic Ocean. Earth Planet. Sci. Lett. 95, 1522.

Bradtmiller, L.I., R. F. Anderson, M.Q. Fleisher and L. H. Burckle (2007), Opal burial in the equatorial Atlantic Ocean over the last 30kyr: implications for glacialinterglacial changes in the ocean silicon cycle. Paleoceanography, 22, PA4216, doi:10.1029/2007PA001443

Broecker, W.S., van Donk, J., 1970. Insolation changes, ice volumes and the O18 record in deep-sea cores. Rev. Geophys. Space Phys. 8, 69-198.

Darby, D.A., Bischof, J.F., Jones, G.A., 1997. Radiocarbon chronology of depositional regimes in the western Arctic Ocean. Deep-Sea Res. II 44, 1745-1757.

Finkel, R., Krishnaswami, S., Clark, D.L., 1977. ${ }^{10}$ Be in Arctic Ocean sediments. Earth Planet. Sci. Lett. 35, 199-204.

Gherardi, J.-M., Labeyrie, L., McManus, J.M., Francois, R., Skinner, L.C., Cortijo, E., 2005. Evidence from the Northeastern Atlantic basin for variability in the rate of the meridional overturning circulation through the last deglaciation. Earth Planet. Sci. Lett., v. 240, p. 710-723.

Hall, I.R., Moran, S.B., Zahn, R., Knutz, P.C., Shen, C.-C., Edwards, R.L., 2006. Accelerated drawdown of meridional overturning in the late-glacial Atlantic triggered by transient pre-H event freshwater perturbation. Geophys. Res. Lett., v. 333, L16616, doi:10.1029/2006GL026239.

Henderson, G.M., Heinze, C., Anderson, R.F., Winguth, A.M.E., 1999. Global distribution of the ${ }^{230}$ Th flux to ocean sediments constrained by GCM modeling. Deep-Sea Res. I 46, 1861-1893.

Huh, C.-A. , Pisias, N.G., Kelley, J.M., Maiti, T.C., Grantz, A., 1997. Natural radionuclides and plutonium in sediments from the western Arctic Ocean: sedimentation rates and pathways of radionuclides. Deep-Sea Res. II 44, 17251743.

Jakobsson, M., Løvlie, R., Al-Hanbali, H., Arnold, E., Backman, J., Mörth, M., 2000. Manganese and color cycles in Arctic Ocean sediments constrain Pleistocene chronology. Geology 28, 23-26.

$\mathrm{Ku}$, T.-L., Broecker, W.S., 1967. Rates of sedimentation in the Arctic Ocean. Prog. Oceanog. 4, 95-104.

McManus, J.F., Francois, R., Gherardi, J.-M., Keigwin, L.D., Brown-Leger, S., 2004.

Collapse and rapid resumption of Atlantic meridional circulation linked to deglacial climate changes. Nature 428, 834-837. 
Moran, S.B., Shen, C.-C., Edmonds, H.N., Weinstein, S.E., Smith, J.N., Edwards, R.L., 2002. Dissolved and particulate ${ }^{231} \mathrm{~Pa}$ and ${ }^{230} \mathrm{Th}$ in the Atlantic Ocean: constraints on intermediate/deep water age, boundary scavenging, and ${ }^{231} \mathrm{~Pa} /{ }^{230} \mathrm{Th}$ fractionation. Earth Planet. Sci. Lett. 203, 999-1014.

Moran, S.B., Shen, C.-C., Edwards, R.L., Edmonds, H.N., Scholten, J.C., Smith, J.N., $\mathrm{Ku}, \mathrm{T} .-\mathrm{L} ., 2005 .{ }^{231} \mathrm{~Pa}$ and ${ }^{230} \mathrm{Th}$ in surface sediments of the Arctic Ocean: Implications for ${ }^{231} \mathrm{~Pa} /{ }^{230} \mathrm{Th}$ fractionation, boundary scavenging, and advective export. Earth Planet. Sci. Lett., v. 234, p. 235-248.

Norgaard-Pedersen, N., R.F. Spielhagen, J. Thiede, and H. Kassens, 1998. Central Arctic surface ocean environment during the past 80,000 years. Paleoceanography v. 13, p. 193-204.

Poore, R.Z., Osterman, L., Curry, W.B., Phillips, R.L., 1999a. Late Pleistocene and Holocene meltwater events in the western Arctic Ocean. Geology 27, 759-762.

Schlosser, P., Kromer, B., Ekwurzel, B., Bönisch,G., McNichol, A., Schneider, R., von Reden, K., Östlund, H.G., Swift, J.H., 1997. The first trans-Arctic 14C section: Comparison of the mean ages of the deep waters in the Eurasian and Canadian basins of the Arctic Ocean. Nucl.Instrum. Methods, 123B, 431-437.

Scholten, J.C., Fietzke, J., Mangini, A., Garbe- Schönberg, C.-D., Eisenhauer, A., Schneider, R., Stoffers, P., 2008. Advection and scavenging: Effects on ${ }^{230} \mathrm{Th}$ and ${ }^{231} \mathrm{~Pa}$ distribution off Southwest Africa. Earth Planet. Sci. Lett., v. 271, p. 159169.

Somayajulu, B.L.K., Sharma, P., Herman, Y., 1989. Thorium and uranium isotopes in Arctic sediments, in: Herman,Y. (Ed.), The Arctic Seas: Climatology, Oceanography, Geology and Biology. Van Nostrand Reinhold Co., New York, pp. 571-579.

Spielhagen,R.F., Erlenkeuser, H., 1994. Stable oxygen and carbon isotopes in planktic foraminifers from Arctic Ocean surface sediments: reflection of the low salinity surface water layer. Mar. Geol. v. 119, p. 227-250.

Stein, R., S.-I. Nam, C. Schubert, C. Vogt, D. Futterer, and J. Heinemeier, 1994. The last deglaciation event in the eastern central Arctic Ocean. Science v. 264, p. 692-696.

Timmermans, M.-L., C. Garrett, and E. Carmack, 2003: The thermohaline structure and evolution of the deep waters in the Canada Basin, Arctic Ocean. Deep-Sea Res., 50A, 1305-1321.

Yang, H.-S., Nozaki, Y., Sakai, H., Masuda, A., 1986. The distribution of ${ }^{230} \mathrm{Th}$ and ${ }^{231} \mathrm{~Pa}$ in the deep-sea surface sediments of the Pacific Ocean. Geochim. Cosmochim. Acta 50, 81-89.

Yu, E.-F., Francois, R., Bacon, M.P., 1996. Similar rates of modern and last- glacial ocean thermohaline circulation inferred from radiochemical data. Nature 379, 689-694.

Yu, E.-F., Francois, R., Bacon, M.P., Fleer, A.P., 2001. Fluxes of ${ }^{230}$ Th and ${ }^{231} \mathrm{~Pa}$ to the deep sea: implications for the interpretation of excess ${ }^{230} \mathrm{Th}$ and ${ }^{231} \mathrm{~Pa} /{ }^{230} \mathrm{Th}$ profiles in sediments. Earth Planet. Sci. Lett. 191, 219-230. 


\section{Chapter 2}

\section{Is There a ${ }^{230}$ Thorium Deficit in Arctic Sediments?}

Reprinted with permission of Elsevier Ltd.

Hoffmann, S.S. and J.F. McManus, 2007. Is There a ${ }^{230}$ Thorium Deficit in Arctic

Sediments? Earth Planet. Sci. Lett. v. 258, p. 516-527.

\section{ABSTRACT}

In most of the global ocean, the radionuclide thorium-230 is removed from the water column by adsorption onto particles and deposition in seafloor sediments at a rate approximately in balance with its local production by the decay of uranium dissolved in seawater, allowing its use in assessing rates of marine processes. However, several previous studies have suggested that the flux of ${ }^{230} \mathrm{Th}$ to the sediments of the Central Arctic is far too small to balance its production in the overlying water column. If this is so, ${ }^{230} \mathrm{Th}$ produced in the low particle-flux Central Arctic basins would be deposited elsewhere, either by boundary scavenging at the margins or by export from the Arctic to lower latitudes. In order to evaluate this possibility, we compare the expected ${ }^{230} \mathrm{Th}$ production and measured inventories for five sites in the Western Arctic, combining previously published ${ }^{230}$ Th data with reported AMS radiocarbon dates, and find no evidence for a substantial deficit of

${ }^{230} \mathrm{Th}$ in these sediments. Instead, we find evidence for near balance in the ${ }^{230} \mathrm{Th}$ budget during both the Holocene and late glacial periods. These intervals are 
separated by a brief deglacial period of apparently higher sedimentation rates and

${ }^{230} \mathrm{Th}$ deposition. During the Holocene, the average sedimentary inventory of ${ }^{230} \mathrm{Th}$ at these sites is largely within $30 \%$ of the water column production, in good agreement with observations and model results from other ocean basins.

\section{Introduction}

Uranium-234 is well mixed in the global ocean (Henderson and Anderson, 2003) and decays at a constant rate to produce thorium-230. This particle-reactive radionuclide is primarily removed locally by scavenging to sediments, rather than by transportation through advection or eddy diffusion (Anderson et al., 1983). The excess of ${ }^{230} \mathrm{Th}$ $\left({ }^{230} \mathrm{Th}_{\mathrm{xs}}\right)$ in sediments, unsupported by uranium decay in the crystal lattices or in authigenic grain coatings of sediments, is thus assumed to be derived from the water column. The extreme particle reactivity and constant production of ${ }^{230} \mathrm{Th}$ allow it to be used to estimate sediment fluxes to the seafloor (e.g. Francois et al., 1990; Francois et al., 2004), as a chronometer (Broecker and van Donk, 1970), or as a normalizer to which the behavior of other isotopes, such as ${ }^{231} \mathrm{~Pa}$, can be compared (Asmus et al., 1999; Kumar et al., 1993; Yu et al., 1996). Excess ${ }^{230} \mathrm{Th}$ in sediments can be a powerful tool to investigate sedimentary processes such as sediment focusing or winnowing (Suman and Bacon, 1989). Sediment trap studies (Yu et al., 2001) and modeling (Henderson et al., 1999) support the conclusion that most ${ }^{230} \mathrm{Th}$ production in the water column is balanced locally by deposition, and that net advective or eddy diffusive transport of ${ }^{230} \mathrm{Th}$ away from its production site is minimal for much of the open ocean. Production and removal 
over most of the global ocean are estimated to agree to within 30\% (Henderson et al., 1999). In the Atlantic, with possible spatially limited exceptions, the agreement appears to be even better, to near $10 \%$ (Yu et al., 2001).

The Arctic may be an exception to this rule. Sedimentation rates are low in the deep central basins, due in part to the sea ice cover, which both blocks windborne terrigenous particles and keeps productivity low. Traditionally, sedimentation rates here, most determined from paleomagnetic polarity measurements in cores, have been estimated to be on the scale of $\mathrm{mm} / \mathrm{kyr}$ (e.g. Clark et al., 1980). With such low particle fluxes, ${ }^{230} \mathrm{Th}$ might remain in the water column longer, and thus be susceptible to transport to the shelf edge or to other basins. However, recent studies reinterpreting paleomagnetic data, and using other methods such as biostratigraphy and geophysical sensing of depth to bedrock, indicate that long-term Arctic sedimentation rates are often higher, on the cm/kyr scale (e.g. Backman et al., 2005; Backman et al., 2004). Such sedimentation rates are similar to those of the mid-Pacific (Anderson et al., 2006) but lower than rates in many Atlantic cores.

Excess ${ }^{230} \mathrm{Th}$ could be a powerful tool to examine sedimentation rates in the Arctic if its budget is found to be in balance there. For example, a significant increase in sedimentation rate during Marine Isotope Stages 4 through 1 has been observed in cores from Lomonosov Ridge (Jakobsson et al., 2000). ${ }^{230} \mathrm{Th}_{\mathrm{xs}}$ has the potential to provide insight into the causes of such changes, through Th-normalized sediment flux estimates and sediment focusing studies. If the overall water column and sedimentary ${ }^{230} \mathrm{Th}$ budget appears to be in balance, ${ }^{230} \mathrm{Th}$ may be used to look for sedimentation irregularities such 
as turbidites or hiatuses, both of which are concerns in Arctic stratigraphy (Grantz et al., 1996; Poore et al., 1999). Excess ${ }^{230}$ Th measurements can also provide a rough check on chronology for stratigraphies in Arctic cores: if excess $\mathrm{Th}$ is present in a sample, the sample age must be less than five half lives of ${ }^{230} \mathrm{Th}$, roughly $380 \mathrm{kyr}$. The ${ }^{230} \mathrm{Th}$ budget of the Arctic is also of interest to paleoceanographers, who use thorium-230 and protactinium-231 to investigate thermohaline overturning rates in the North Atlantic (Gherardi et al., 2005; McManus et al., 2004; Yu et al., 1996). Recent work on ${ }^{230}$ Th and ${ }^{231} \mathrm{~Pa}$ in the water column (Edmonds et al., 1998; Edmonds et al., 2004; Scholten et al., 1995) and in surface sediments (Moran et al., 2005) of the Arctic has done a great deal to improve our understanding of the behavior of these nuclides in the Arctic, including the possibility of their export to the Atlantic. Downcore sedimentary studies to establish the history of the Arctic budgets and distribution will be key to using these nuclides as paleoproxies in the Atlantic. The fate of ${ }^{230} \mathrm{Th}$ in the Arctic also has implications for our understanding of the paths of anthropogenic radionuclides in this region: if the extremely particle-reactive ${ }^{230} \mathrm{Th}$ can be exported, it is likely that less reactive nuclides, such as the naturally-occurring ${ }^{231} \mathrm{~Pa}$ and anthropogenic plutonium isotopes, may be exported from the region as well.

All previous studies of ${ }^{230} \mathrm{Th}$ in Arctic sediments (Finkel et al., 1977; Herman et al., 1989; Huh et al., 1997; Ku and Broecker, 1967; Somayajulu et al., 1989; see section 4.1 for further discussion) have concluded that a significant imbalance between production and sediment burial exists, resulting in large deficits of sedimentary ${ }^{230} \mathrm{Th}_{\mathrm{xs}}$ relative to the water column production. Several of these studies used ${ }^{230} \mathrm{Th}_{\mathrm{xs}}$ to estimate 
sediment accumulation rates, which were then used to calculate apparent ${ }^{230} \mathrm{Th}_{\mathrm{xs}}$ accumulation rates. This approach works when sedimentation rates are constant and ${ }^{230} \mathrm{Th}_{\mathrm{xs}}$ measurements show exponential decay profiles, but can be complicated by changing sedimentation rates.

The addition of an independent constraint on chronology and sedimentation rate, such as radiocarbon dates, can help to better interpret the features of the ${ }^{230} \mathrm{Th}_{\mathrm{xs}}$ profiles, as well as rates of ${ }^{230} \mathrm{Th}$ deposition. We have revisited the Arctic ${ }^{230} \mathrm{Th}_{\mathrm{xs}}$ budget using the best available independent dating tool, radiocarbon measured by AMS in planktic foraminifera. We use ${ }^{230} \mathrm{Th}_{\mathrm{xs}}$ data from Huh et al. (1997) and radiocarbon dates acquired for the late glacial, deglacial, and Holocene periods in the same box cores by Darby et al. (1997) and by Poore et al. (1999a, 1999b) to calculate sedimentary ${ }^{230}$ Th inventories for comparison to water column ${ }^{230} \mathrm{Th}$ production rates for five sites in the Western Arctic (Table 1). These radiocarbon dates suggest sedimentation rates in the $\mathrm{cm} / \mathrm{kyr}$, rather than $\mathrm{mm} / \mathrm{kyr}$, range, for the period following the Last Glacial Maximum. Our calculations suggest that there is no substantial ${ }^{230} \mathrm{Th}$ deficit in these cores relative to the predicted water column production. Instead we find that in this region the ${ }^{230} \mathrm{Th}$ budget has generally been in balance during the glacial and Holocene, with a brief deglacial pulse of rapid ${ }^{230}$ Th deposition. This finding appears to hold true for both the modest sediment accumulation rates that characterize the Holocene and for the much slower accumulation rates associated with the glacial sections. 


\section{Methods and Sources}

The ${ }^{230} \mathrm{Th}$ and radiocarbon data (Huh et al., 1997; Darby et al., 1997, Poore et al., 1999a and 1999b) used in this study were generated from sediments from sites cored on cruise AOS 94 of the USCGC Polar Sea (locations in Table 1; map, Figure 1). These sites sit on the Mendeleev Ridge and nearby Wrangel Abyssal Plain, at depths from 1000 to over $3000 \mathrm{~m}$, lying underneath the interior of the Beaufort Gyre circulation (Poore et al., 199a). Sediments consist of silty IRD-bearing muds with varying amounts of foraminifera present (Darby et al., 1997; Poore et al., 1999a). From each box core, a subcore was sampled at high resolution, and the samples were digested and analyzed for ${ }^{230} \mathrm{Th}$ and ${ }^{232} \mathrm{Th}$, using methods described in (Huh et al., 1997). ${ }^{232} \mathrm{Th}$ measurements were used to estimate uranium contents and hence supported crystal lattice ${ }^{230} \mathrm{Th}$ contents of the samples, which were subtracted from the total measured ${ }^{230} \mathrm{Th}$ to estimate excess ${ }^{230} \mathrm{Th}$ (Huh et al., 1997). Supported detrital ${ }^{230} \mathrm{Th}$ activities were between 1 and $2 \mathrm{dpm} / \mathrm{g}$ for almost all samples, roughly the same magnitude as the smallest calculated excess contents. No estimate for possible authigenic $U$ in these sediments was available. Sediment density was measured on a salt-free basis (Huh et al., 1997).

Other subcores from the same box cores were analyzed for ${ }^{14} \mathrm{C}$ dates on planktonic foraminifera by Darby et al. (1997) and by Poore et al. (1999a, 1999b). We converted the radiocarbon dates to calendar years using the CALIB 5.0 calibration program (Stuiver et al., 2005) and Marine04 calibration dataset (Hughen et al., 2004) for samples whose radiocarbon ages were less than $21,880 \mathrm{yr}$, and using the calibration curve of Fairbanks et al. (2005) for older samples. Calendar ages calculated for comparison 
using the Fairbanks calibration for samples younger than 21,880 yr did not differ from the CALIB-calculated ages by more than 3\%. In addition to the reservoir age of $440 \mathrm{yr}$ used by both Darby et al. (1997) and Poore et al. (1999a, 1999b), we assumed an additional reservoir age offset $(\Delta \mathrm{R})$ of $250 \mathrm{yr}$ due to the blocking of gas exchange in the Central Arctic by sea ice (Mangerun and Gulliksen, 1975; Curry, personal communication). We constructed age models by linear interpolation between dated intervals in the cores. Where dates from two subcores of the same box core are available, in $\mathrm{BC} 16$ and $\mathrm{BC} 17$, it is clear that different subcores can have slightly different dates for the same sample depth (Figure 2), resulting in differing age models. For these two box cores, we have calculated ${ }^{230} \mathrm{Th}$ inventories and sedimentation rates twice, using age models from both published radiocarbon stratigraphies. Sensitivity tests indicate that our ${ }^{230} \mathrm{Th}$ budget calculations are not significantly altered by small differences to the age models.

Using the age models described above, we corrected the ${ }^{230} \mathrm{Th}_{\mathrm{xs}}$ data of Huh et al. (1997) for radioactive decay to estimate the excess ${ }^{230} \mathrm{Th}$ concentration at the time of sediment deposition. These corrected concentrations were then multiplied by the sample sediment densities and adjusted for the sampling interval to obtain ${ }^{230} \mathrm{Th}_{\mathrm{xs}}$ inventories for each 1-2 $\mathrm{cm}$ interval in the core. The cumulative expected inventories, assuming that all ${ }^{230} \mathrm{Th}$ produced in the water column was scavenged to the seafloor at each site, were calculated using the equation of Suman and Bacon (1989) : production $\left(\mathrm{dpm} \mathrm{cm}{ }^{-2} \mathrm{ky}^{-1}\right)=$ $0.00263 *$ water column depth $(\mathrm{m})$. 
In this paper, we define the Holocene as encompassing the last $11 \mathrm{kyr}$, the deglacial as the period between $15 \mathrm{kyr}$ and $11 \mathrm{kyr}$, and the glacial period as before 15 kyr. The glacial sections of the box cores in this paper thus include both Marine Isotope Stage 3 and Stage 2 sediments.

\section{Results}

\subsection{Core ${ }^{230}$ Th profiles and inventories}

As noted by Huh et al. (1997), ${ }^{230} \mathrm{Th}_{\mathrm{xs}}$ concentrations generally decline down each core, then increase to a subsurface maximum before decreasing again (Fig. 2). Subsurface maxima occur between 33 and $15 \mathrm{ka}$, although they appear within only a few closely spaced samples in each core. Below this interval in each core, ${ }^{230} \mathrm{Th}_{\mathrm{xs}}$ concentrations begin to decrease again, with at least one more small increase at depth. In all cases there is measurable excess ${ }^{230} \mathrm{Th}$ in the deepest samples analyzed.

When the decay-corrected ${ }^{230} \mathrm{Th}_{\mathrm{xs}}$ profiles are plotted by their age models (Figure 3), their structure can be interpreted in light of sedimentation rate changes as well as global changes occurring through the glacial, deglacial, and Holocene. The age models in the deepest part of the core include reported dates close to or beyond the sensitivity limit of radiocarbon dating, and thus cannot be considered as strong as the Holocene age models. However, the upper parts of the glacial sections are within the radiocarbon dating range, allowing us to make some interpretations of this part of the record. ${ }^{230} \mathrm{Th}_{\mathrm{xs}}$ glacial concentrations vary in the cores but tend to be high just before the deglacial, suggesting low sedimentation rates at this time. In cores $\mathrm{BC} 16,17,19$, and 20 , the oldest dated interval with a deglacial date has a ${ }^{230} \mathrm{Th}_{\mathrm{xs}}$ concentration higher than Holocene samples, 
which drops off steeply in younger deglacial samples. ${ }^{230} \mathrm{Th}_{\mathrm{xs}}$ values then rise again through the Holocene.

The integrated sum of the predicted ${ }^{230} \mathrm{Th}$ production in the overlying seawater increases down each core at a constant rate over time (Figure 4). The cumulative measured sedimentary inventory increases down each core and can be compared to the production. In each core the two curves, predicted and measured decay-corrected inventory of ${ }^{230} \mathrm{Th}$, have similar values in the Holocene section, although $\mathrm{BC} 08$ appears to have an episode of rapid sediment and ${ }^{230} \mathrm{Th}_{\mathrm{xs}}$ accumulation in its Holocene interval which substantially increases its measured inventory. Below the Holocene section, the measured total exceeds the predicted production in $\mathrm{BC} 08,16$, and 17 , and is close to the predicted production in BC 19 and 20, due largely to an apparent rise in ${ }^{230} \mathrm{Th}$ deposition during the deglacial period. Below 12-15 ka, the slopes of the two cumulative curves become similar again, indicating similar rates of production and deposition. There is no systematic deficit evident in the cumulative measurements, and only limited intervals where there is evidence of a deficit in any given core. The more general relationship is of a measured inventory similar to the predicted one, with an overall excess that is primarily driven by the rapid increase in burial between 15 and $12 \mathrm{ka}$. With the exception of the 8ka event in $\mathrm{BC} 08$, the past 10,000 years appear to have been a relatively stable sedimentary environment in the Western Arctic, with no large changes in ${ }^{230} \mathrm{Th}$ deposition or sedimentation rates. The average Holocene inventory of all five cores is $110 \%$ of production, with a standard error of $20 \%$ (Table 1 ). If $\mathrm{BC} 08$, with its anomalous 
Holocene ${ }^{230} \mathrm{Th}$ burial event, is omitted from these calculations, the average measured/predicted Holocene inventory ratio is $95 \%$, with a standard error of $11 \%$.

A compressed glacial section, possibly containing a hiatus thought to correspond to the Last Glacial Maximum, has been previously noted in these cores (Darby et al., 1997; Poore et al., 1999a). Figure 2 shows the jump in a few $\mathrm{cm}$ from ages predating the LGM, in MIS 3, to deglacial-aged samples (15-11 ka). The increased ${ }^{230} \mathrm{Th}_{\mathrm{xs}}$ concentrations from the glacial sections of these box cores (Figure 3) are consistent with lower sediment accumulation rates. However, the cumulative glacial ${ }^{230} \mathrm{Th}_{\mathrm{xs}}$ inventories from $\mathrm{BC} 16$ and $\mathrm{BC} 17$ show no missing ${ }^{230} \mathrm{Th}_{\mathrm{xs}}$, while the other three cores show only a modest deficit in their glacial sections. The average measured/predicted inventory ratio for the glacial period in the five cores is $93 \%$, with a standard error of $14 \%$. These results suggest that there is no substantial hiatus involving removal of sediment or cessation of sedimentation in this region. Rather, sedimentation appears to have continued at a greatly reduced rate.

In BC 16, Poore et al. (1999a, 1999b) report an age reversal, which in our age model affects the modeled ages of samples within the glacial period, but does not affect the assignation of samples to the glacial or deglacial periods. In $\mathrm{BC} 17$, an age reversal reported by Darby et al. (1997) makes identification of the boundary between glacial and deglacial sediments difficult, and hence we have not attempted to calculate glacial and deglacial inventories using this age model. 


\section{Discussion}

\subsection{Previous Estimates of Arctic ${ }^{230}$ Th Burial}

The few studies of ${ }^{230} \mathrm{Th}_{\mathrm{xs}}$ sediment inventories in the Arctic that have been published have each come to the conclusion that a sedimentary ${ }^{230} \mathrm{Th}_{\mathrm{xs}}$ deficit exists. $\mathrm{Ku}$ and Broecker (1967) first suggested that the ${ }^{230} \mathrm{Th}_{\mathrm{xs}}$ concentrations they measured in sandy layers of core T3-63-1 from the Alpha Ridge were lower than would be expected from a purely radioactive-decay-driven profile, possibly due to a lack of suitable particles to scavenge water column ${ }^{230} \mathrm{Th}$ effectively. Resolution of this profile was roughly 3 samples per $10 \mathrm{~cm}$, and the sedimentation rate derived from the profile was $0.21 \mathrm{~cm} / \mathrm{kyr}$. Finkel et al.'s study (1977) of ${ }^{10} \mathrm{Be}$ and ${ }^{230} \mathrm{Th}$ in cores from the Chukchi Plain and the Alpha Ridge, sampled at $10 \mathrm{~cm}$ intervals, found rising and falling downcore ${ }^{230} \mathrm{Th}$ concentrations in several cores. Somayajulu et al. (1989) and Herman et al. (1989) calculated very low sedimentation rates from decay-curve fits to ${ }^{230} \mathrm{Th}_{\mathrm{xs}}$ profiles in the top $25 \mathrm{~cm}$ of sediment at a number of sites in the central Arctic, with resolution varying from 2 to $5 \mathrm{~cm}$. Combining these sedimentation rates, which ranged from 0.8 to $5 \mathrm{~mm} / \mathrm{kyr}$, with ${ }^{230} \mathrm{Th}_{\mathrm{xs}}$ inventories for their samples, they calculated ${ }^{230} \mathrm{Th}$ accumulation rates that were between 2 and $20 \%$ of the expected water column production.

The most thorough study of ${ }^{230} \mathrm{Th}_{\mathrm{xs}}$ in Arctic sediments, by Huh et al. (1997), used box cores from a transect across the Western Arctic. This study produced measurements of excess ${ }^{230} \mathrm{Th}$ every one to two $\mathrm{cm}$ in the top $30 \mathrm{~cm}$ from ten sites, greatly improving resolution over the previous studies. As noted in section 3.1, the profiles had subsurface minima and maxima which did not conform to exponential decay 
models, and in all cores excess ${ }^{230} \mathrm{Th}_{\mathrm{xs}}$ was present at the bottom of the profile. The ${ }^{230} \mathrm{Th}_{\mathrm{xs}}$ budget was estimated in two ways. From exponential regressions of the upper parts of the profiles above the subsurface ${ }^{230} \mathrm{Th}_{\mathrm{xs}}$ maxima and from correlation of these maxima between cores, Huh et al. calculated rough sedimentation rates which were extremely low, between 0.019 and $0.189 \mathrm{~cm} / \mathrm{kyr}$ for all sites except a shallow shelf site. These sedimentation rates were then multiplied by coretop ${ }^{230} \mathrm{Th}_{\mathrm{xs}}$ concentrations to estimate the ${ }^{230} \mathrm{Th}$ fluxes to the sea floor. Sedimentary fluxes were also calculated by measuring the inventories of ${ }^{230} \mathrm{Th}_{\mathrm{xs}}$ in the cores, and assuming that ${ }^{230} \mathrm{Th}$ deposition rates must balance the decay rate of these inventories. Using these methods, Huh et al. found that the ${ }^{230} \mathrm{Th}_{\mathrm{xs}}$ measured in these cores could account, on average, for less than half the expected production of ${ }^{230} \mathrm{Th}$ in the water column, with burial/production ratios ranging between 0.06 to 0.62 . They suggested that the ${ }^{230} \mathrm{Th}$ that was "missing" from the central basin sediments was probably exported in the water column to continental margins, where particle fluxes are often higher, and removed from the water column there, a process known as boundary scavenging.

Thus, all previous studies have concluded that there is a buried ${ }^{230} \mathrm{Th}_{\mathrm{xs}}$ deficit in Arctic sediments, with only $2-62 \%$ of expected ${ }^{230} \mathrm{Th}$ water column production balanced by flux into the sediments. Each study, however, assumed a constant sedimentation rate, at least for the upper portions of the profiles. The ${ }^{230} \mathrm{Th}_{\mathrm{xs}}$ concentration in sediment often depends more on dilution and concentration by changing sedimentation rates than on decay (e.g. Bacon, 1984; McManus et al., 1998), as evidenced by subsurface maxima and minima in most downcore profiles in the Arctic. This deviation from standard 
exponential decay profiles can hamper efforts to estimate sedimentation rates from ${ }^{230} \mathrm{Th}_{\mathrm{xs}}$ by altering the slopes of the profiles which are used to fit the decay curves. In addition, the Huh et al. approach of balancing the entire sedimentary inventory of ${ }^{230} \mathrm{Th}_{\mathrm{xs}}$ against production may have underestimated the total inventory, as none of the measured box core profiles actually reaches zero excess Th at depth, suggesting that part of the total buried inventory remains unsampled.

\subsection{Holocene budgets of ${ }^{230}$ Th and modern evidence for scavenging}

Overall, the calculations of production and burial in this study are much closer than previous estimates of ${ }^{230} \mathrm{Th}$ flux to the sediments and ${ }^{230} \mathrm{Th}$ production that were not constrained by radiocarbon. Rather than being anomalous, at these sites in the central Western Arctic, the production and deposition of ${ }^{230} \mathrm{Th}$ over the last $10 \mathrm{kyr}$ has proceeded in a similar fashion to the rest of the world's ocean. Although the limited range of ${ }^{14} \mathrm{C}$ dating precludes its use to determine whether the Arctic ${ }^{230} \mathrm{Th}$ budget has always been in near balance, the Holocene estimate discussed here can be considered robust. This is an interval for which the decay correction for ${ }^{230} \mathrm{Th}_{\mathrm{xs}}$ is negligible, there are abundant foraminifera for ${ }^{14} \mathrm{C}$ dating, there is relatively little uncertainty in the conversion to calendar age, and the radionuclide data are resolved every $\mathrm{cm}$.

This finding has implications for other areas of Arctic research. Arctic Ocean cycling of other particle-reactive nuclides, particularly anthropogenic ones, is likely to proceed similarly to cycling in other basins. The ability of Arctic particle fluxes to effectively scavenge ${ }^{230} \mathrm{Th}$ suggests that they may also play a role in the scavenging and 
removal of other elements. The increase through the Holocene in ${ }^{230} \mathrm{Th}_{\mathrm{xs}}$ concentration is intriguing, and could be related to a number of factors, including particle type changes or a sedimentation rate slowdown. It presents an interesting question for Holocene paleoceanography.

Present-day water column measurements may provide insight into thorium cycling in the premodern Holocene. The first study of Arctic water column ${ }^{230} \mathrm{Th}$ and ${ }^{231} \mathrm{~Pa}$ (Bacon et al., 1989), from a site at the Alpha Ridge, found higher concentrations of ${ }^{231} \mathrm{~Pa}$ and ${ }^{230} \mathrm{Th}$ in the water column than have been found in other oceans and interpreted this as evidence of reduced scavenging at the site. However, subsequent water column measurements indicate that ${ }^{230} \mathrm{Th}$ and ${ }^{231} \mathrm{~Pa}$ concentrations vary from basin to basin within the Arctic, with highest values at the Alpha Ridge and Makarov Basin (Scholten et al., 1995), and lower values in the Beaufort Sea (Edmonds et al., 1998), and in the Amundsen and Nansen Basins (Cochran et al., 1995). These variations may reflect differences in particle fluxes or types, water mass residence times in the basins, or fractionation of $\mathrm{Th}$ and $\mathrm{Pa}$ between dissolved and particulate species. Differences in these various influences can allow the effective scavenging of ${ }^{230} \mathrm{Th}$ at differing seawater concentrations. Models of scavenging behavior based on water column measurements in the Canada Basin indicate that Th is highly scavenged there (Edmonds et al., 1998; Trimble et al., 2004), consistent with our findings that ${ }^{230} \mathrm{Th}$ has been efficiently removed from the water column to the sediments during the interglacial. Our new estimates of ${ }^{230} \mathrm{Th}$ burial thus bring sedimentary evidence into agreement with water column evidence for effective scavenging in this region. 
Our calculations indicate that no removal of ${ }^{230} \mathrm{Th}$ from the central Western Arctic is required to balance the thorium budget there. However, if ${ }^{230} \mathrm{Th}$ is exported at all from the region, where might it be going? Two possibilities are to the boundaries of the deep Arctic basins, and to the Atlantic through Fram Strait. Calculations of ${ }^{230}$ Th export through Fram Strait (Moran et al., 2005), based on water column concentrations and advection rates, suggest that only $10 \%$ of the ${ }^{230} \mathrm{Th}$ produced in the Arctic may be lost from the basin to the Atlantic. This is consistent with our conclusion that most ${ }^{230} \mathrm{Th}$ in the western central Arctic is being buried in sediments locally.

The broad shelf seas of the Arctic, although high in productivity and particles, are not a likely sink of ${ }^{230} \mathrm{Th}$, as most ${ }^{230} \mathrm{Th}$ production occurs in the deep basins. Isopycnal mixing is therefore unlikely to bring much ${ }^{230} \mathrm{Th}$ up to the near-surface shelves. However, scavenging along the deeper continental slope at the edges of the deep basins is a possibility. Huh et al. (1997) noted the possibility of boundary scavenging of ${ }^{230} \mathrm{Th}$ in one high-accumulation rate core from the Chukchi slope, and measurements of lead-210 in Arctic sediments have shown evidence for boundary scavenging of this element as well (Smith et al., 2003). Recent water column and coretop studies (Edmonds et al., 2004; Moran et al., 2005) of Arctic ${ }^{230} \mathrm{Th}$ and ${ }^{231} \mathrm{~Pa}$, which is more sensitive to boundary scavenging than thorium, do not show the pattern of high marginal ${ }^{231} \mathrm{~Pa} /{ }^{230} \mathrm{Th}$ ratios considered typical of boundary scavenging in other basins (e.g. Yang et al., 1986), although they note that boundary scavenging may nevertheless occur in this region. While boundary scavenging thus is a possible sink of Arctic thorium, we have shown it is not required to balance the ${ }^{230} \mathrm{Th}$ budget in the central western Arctic. 


\subsection{Glacial sedimentation rates and implications for ongoing ${ }^{230}$ Th scavenging}

Our findings of relatively balanced budgets at these sites prior to the deglaciation are important for understanding longer-term thorium cycle dynamics in the Arctic. A balance that holds during interglacial conditions might not be expected to hold when ice cover is thicker and productivity is lowered, driving particle fluxes to a minimum as occurred during the late glacial. However, the measured inventories and estimated production for the period just before the deglaciation, when sedimentation rates were at their lowest, suggest that ${ }^{230} \mathrm{Th}$ was nevertheless scavenged by the few particles that did fall. In fact, the lowest ratio of measured inventory to production that we calculated for the glacial, 0.65 for $\mathrm{BC} 20$, is higher than the highest previous estimate of the Arctic ${ }^{230}$ Th burial / production relationship (Huh et al., 1997). Our findings of a generally balanced Arctic ${ }^{230} \mathrm{Th}$ budget thus are not dependent on sedimentation rate: the balance holds when particle fluxes are relatively high (for the Arctic), and when they are relatively low. Our calculations also suggest that, despite the large change in age between deglacial and glacial samples only a few centimeters apart, there may have been no true lapse in sedimentation at that time. The cores contain a very highly compressed late-glacial section, rather than a substantial hiatus.

\subsection{High ${ }^{230}$ Th inventories in deglacial sediments}

Thorium burial during the deglacial period (roughly 15-11 ka) differs greatly from the relatively balanced budgets of the Holocene and glacial periods bracketing the deglacial. During the deglaciation, the sediment accumulation rate increased and the

${ }^{230} \mathrm{Th}$ concentration in sediments declined from their glacial values (Figure 3 ). While 
these two observations are consistent with dilution of buried ${ }^{230} \mathrm{Th}_{\mathrm{xs}}$ by greater amounts of settling particles, the deglacial ${ }^{230} \mathrm{Th}_{\mathrm{xs}}$ inventories of these cores nevertheless appear to be higher than required to balance the expected production during this relatively brief interval. Burial / production ratios range between 2.3 and 6.8, all greater than the "balanced" ratio of 1. While the high ${ }^{230} \mathrm{Th}_{\mathrm{xs}}$ concentrations seen at the start of the deglacial in several cores contribute to this imbalance, they do not account for all of the extra deglacial ${ }^{230} \mathrm{Th}_{\mathrm{xs}}$, and other contributing processes must be considered. Because this event is the single notable departure from a balanced ${ }^{230} \mathrm{Th}$ budget for these Arctic sites, it merits additional discussion.

One possible explanation for the transient increase in ${ }^{230} \mathrm{Th}$ flux is that bioturbation has redistributed clay particles and ${ }^{230} \mathrm{Th}_{\mathrm{xs}}$ in the sediment column. During the late glacial period, particle fluxes were extremely low, and the accumulating sediments had very high excess ${ }^{230} \mathrm{Th}$ concentrations (Figure 3). If bioturbation later mixed some of these particles upward into deglacial sediments accumulating more rapidly above them, it would raise the ${ }^{230} \mathrm{Th}_{\mathrm{xs}}$ concentration, and thus apparent flux, within the more rapidly accumulating deglacial sediments. A slight stratigraphic offset between the radiocarbon-dated subcores and the subcores analyzed for ${ }^{230} \mathrm{Th}_{\mathrm{xs}}$ might also result in samples being assigned to the deglacial in our calculations which might be older than our age models suggest. Similarly, abundant foraminifera accumulating above glacial sediment might be mixed downward, shifting downcore the apparent sedimentation rate transition inferred from radiocarbon ages. Mixing by bioturbation in the Arctic varies from core to core and is often limited (BC17 is relatively unbioturbated, 
for example), but may extend to a depth of 2-4 cm (Clough et al., 1997), allowing for the possibility of sediment mixing out of the compressed high-Th glacial section.

A strong possibility is lateral transport of sediments to these sites. The assumption that local deposition and production balance each other requires that sediments accumulate only by vertical sinking of particles. If sediments from other parts of the basin were re-suspended and transported to these sites to be re-deposited, the ${ }^{230} \mathrm{Th}$ adsorbed onto these laterally transported sediments would boost the sediment inventory above local ${ }^{230} \mathrm{Th}$ production (Suman and Bacon, 1989). The much higher deglacial sedimentation rates apparent in these cores relative to the Holocene possibly reflect such a lateral input of sediments. Oxygen isotope measurements (Poore et al., 1999a) suggest that the onset of this change coincides with Meltwater Pulse 1a, the largest deglacial melting episode, during which global sea level rose more than 20 meters (Fairbanks, 1989). The flooding of circum-Arctic shelves may have increased sediment availability and destabilized the shelf-breaks, leading to episodic re-deposition in the central basins. Such an event could account for the similar sedimentation pattern occurring at very different depths along the slope and basin. A similar jump in ${ }^{230} \mathrm{Th}$ accumulation in $\mathrm{BC}$ 08 occurred around 8000 years ago, although it is difficult to know if similar processes apply in the case of that younger event. If sediment focusing might be responsible for high deglacial inventories, we must consider the possibility that it may also contribute to the Holocene and glacial inventories, producing the appearance of balance in the ${ }^{230} \mathrm{Th}$ budgets for these times. Circulation in the intermediate and deep waters of the Arctic is strongly steered by topography (Anderson et al., 1989; Jones et al., 1995; Woodgate et 
al., 2001; Woodgate et al., 2007); deep eddies have also been suggested to occur (Woodgate et al., 2001). Such water mass movements could redistribute sediments along the continental slope. We cannot rule the possibility out; however, it seems unlikely that focusing occurs throughout the Holocene at just the rates needed to produce the impression of a balanced thorium budget at five sites whose depths differ by up to 2000 m.

\section{Conclusions}

(i) A comparison of measured sedimentary inventories of ${ }^{230} \mathrm{Th}_{\mathrm{xs}}$ with ${ }^{230} \mathrm{Th}$ production during the time of sediment accumulation, as estimated from radiocarbon dating, indicates that the ${ }^{230} \mathrm{Th}$ budget at each of five sites in the western Arctic is far closer to being in balance than was previously estimated. This region therefore appears similar to much of the world ocean in the cycling of this particle-reactive element.

(ii) Holocene ${ }^{230} \mathrm{Th}$ production is largely balanced by burial in sediments, as was late glacial production, indicating that effective scavenging of thorium is not dependent on high sedimentation rates.

(iii) Deglacial ${ }^{230} \mathrm{Th}_{\mathrm{xs}}$ burial appears to have occurred at a faster rate than production, suggesting that another process was at work during this time, possibly sediment focusing, or that there are slight stratigraphic uncertainties in the cores due to bioturbation or age model creation.

(iv) If export is not required to balance the Arctic ${ }^{230} \mathrm{Th}$ budget, we may also now be able to use the behavior and sediment accumulation of thorium as a normalizer, to understand 
the sedimentation processes of the Arctic and the scavenging processes which affect the less particle-reactive radionuclides, such as ${ }^{231} \mathrm{~Pa}$ (Edmonds et al., 2004; Moran et al., 2005; Yu et al., 1996). This finding has important implications for our understanding of the cycling of reactive elements in the Arctic Ocean, and for paleoceanographic studies as well.

Acknowledgements: We thank C.-A. Huh for generously sharing sedimentary ${ }^{230} \mathrm{Th}$ data. Reviews by H. Edmonds and G. Henderson greatly improved this paper, as did an anonymous review of an earlier draft. We thank W. Curry for his assistance with the manuscript and with maps, R. Francois and O. Marchal for valuable discussions, and N. Goodkin and M. Jackson for their comments on the manuscript. We acknowledge support from NSF grants ARC-0520073 to W. Curry, and OCE-0402565 and OCE-0550637 to J. McManus. S. Hoffmann was supported by a JOI Schlanger Ocean Drilling Fellowship. 


\section{References cited}

Anderson, L.G., Jones, E.P., Koltermann, K.P., Schlosser, P., Swift, J.H., Wallace, D.W.R., 1989. The first oceanographic section across the Nansen Basin in the Arctic Ocean. Deep-Sea Res. 36, 475-482.

Anderson, R.F., Bacon, M.P., Brewer, P.G., 1983. Removal of ${ }^{230}$ Th and ${ }^{231} \mathrm{~Pa}$ from the open ocean. Earth Planet. Sci. Lett. 62, 7-23.

Anderson, R.F., Fleisher, M.Q., Lao, Y., 2006. Glacial-interglacial variability in the delivery of dust to the central equatorial Pacific Ocean. Earth Planet. Sci. Lett. 242, 406-414.

Asmus, T., Frank, M., Koschmieder, C., Frank, N., Gersonde, R., Kuhn, G., Mangini, A., 1999. Variations of biogenic particle flux in the southern Atlantic section of the Zone during the late Quaternary: Evidence from sedimentary ${ }^{231} \mathrm{~Pa}_{\mathrm{ex}}$ and ${ }^{230} \mathrm{Th}_{\mathrm{ex}}$. Mar. Geol. 159, 63-78.

Backman, J., Jakobsson, M., Løvlie, R., Polyak, L., Febo, L.A., 2004. Is the central Arctic Ocean a sediment starved basin? Quat. Sci. Rev. 23, 1435-1454.

Backman, J., Moran, K., Moore, T., King, J., Gattacecca, J., Brinkhuis, H., Matthiessen, J., Jakobsson, M., Paelike, H., O’Regan, M., Frank, M., Kubik, P., 2005. Cenozoic ridge crest sediments from the Central Arctic Ocean yield $\mathrm{cm} / \mathrm{ka}$-scale sedimentation rates. EOS Trans. AGU, 86(52) Fall Meeting Suppl., Abstr. PP51C-0607.

Bacon, M.P., 1984. Glacial to interglacial changes in carbonate and clay sedimentation in the Atlantic Ocean estimated from ${ }^{230}$ Th measurements. Isotope Geosci. 2, 97111.

Bacon, M.P., Huh, C.-A., Moore, R.M., 1989. Vertical profiles of some natural radionuclides over the Alpha Ridge, Arctic Ocean. Earth Planet. Sci. Lett. 95, 1522.

Broecker, W.S., van Donk, J., 1970. Insolation changes, ice volumes and the O18 record in deep-sea cores. Rev. Geophys. Space Phys. 8, 69-198.

Clark, D.L., Whitman, R.R., Morgan, K.A., Mackay, S.D., 1980. Stratigraphy and glacialmarine sediments of the Basin, central Arctic Ocean. Geol. Soc. Am. Spec. Pap. 181, 1-57.

Clough, L.M., Ambrose, W.G., Cochran, J.K., Barnes, C., Renaud, P.E., Aller, R.C., 1997. Infaunal density, biomass and bioturbation in the sediments of the Arctic Ocean. Deep-Sea Res. II 44, 1683-1704.

Cochran, J.K., Hirschberg, D.J., Livingston, H.D., Buesseler, K.O., Key, R.M., 1995. Natural and anthropogenic radionuclide distributions in the Nansen Basin, Arctic Ocean: Scavenging rates and circulation timescales. Deep-Sea Res. II 42, 14951517.

Darby, D.A., Bischof, J.F., Jones, G.A., 1997. Radiocarbon chronology of depositional regimes in the western Arctic Ocean. Deep-Sea Res. II 44, 17451757. 
Edmonds, H.N., Moran, S.B., Hoff, J.A., Smith, J.N., Edwards, R.L., 1998. Protactinium231 and Thorium-230 abundances and high scavenging rates in the Western Arctic Ocean. Science 280, 405-407.

Edmonds, H.N., Moran, S.B., Cheng, H., Edwards, R.L., 2004. ${ }^{230} \mathrm{Th}$ and ${ }^{231} \mathrm{~Pa}$ in the Arctic Ocean: implications for particle fluxes and basin-scale $\mathrm{Th} / \mathrm{Pa}$ fractionation. Earth Planet. Sci. Lett. 227, 155-167.

Fairbanks, R.G., 1989. A 17,000-year glacio-eustatic sea level record: Influence of glacial melting rates on the Younger Dryas event and deep-ocean circulation, Nature 342, 637-642.

Fairbanks, R.G., Mortlock, R.A., Chiu, T.-C., Cao, L., Kaplan, A., Guilderson, T.P., Fairbanks, T.W., Bloom, A.L., 2005. Marine radiocarbon calibration curve spanning 0 to 50,000 years B.P. based on paired ${ }^{230} \mathrm{Th} /{ }^{234} \mathrm{U} /{ }^{238} \mathrm{U}$ and ${ }^{14} \mathrm{C}$ dates on pristine corals. Quat. Sci. Rev. 24, 1781-1796.

Finkel, R., Krishnaswami, S., Clark, D.L., 1977. ${ }^{10}$ Be in Arctic Ocean sediments. Earth Planet. Sci. Lett. 35, 199-204.

Francois, R., Bacon, M.P., Suman, D.O., 1990. Thorium-230 profiling in deep sea sediments: High-resolution records of flux and dissolution of carbonate in the equatorial Atlantic during the last 24,000 years. Paleoceanography 5, 761-787.

Francois, R., Frank, M., Rutgers van der Loeff, M.M., Bacon, M.P., 2004. ${ }^{230} \mathrm{Th}$ normalization: An essential tool for interpreting sedimentary fluxes during the late Quaternary. Paleoceanography 19, PA1018, doi:10.1029/2003PA000939.

Grantz, A., Phillips, R.L., Mullen, M.W., Starratt, S.W., Jones, G.A., Naidu, A.S., Finney, B.P., 1996. Character, paleoenvironment, rate of accumulation, and evidence for seismic triggering of Holocene turbidites, Canada Abyssal Plain, Arctic Ocean. Mar. Geol. 133, 51-73.

Henderson, G.M., Heinze, C., Anderson, R.F., Winguth, A.M.E., 1999. Global distribution of the ${ }^{230}$ Th flux to ocean sediments constrained by GCM modeling. Deep-Sea Res. I 46, 1861-1893.

Henderson, G.M., Anderson, R.F., 2003. The U-series toolbox for paleoceanography. Rev. Mineral. Geochem. 52, 493-531.

Hughen, K.A., Baillie, M.G.L., Bard, E., Bayliss, A., Beck, J.W., Bertrand, C.J.H., Blackwell, P.G., Buck, C.E., Burr, G.S., Cutler, K.B., Damon, P.E., Edwards, R.L., Fairbanks, R.G., Friedrich, M., Guilderson, T.P., Kromer, B., McCormac, F.G., Manning, S.W., Bronk Ramsey, C., Reimer, P.J., Reimer, R.W., Remmele, S., Southon, J.R., Stuiver, M., Talamo, S., Taylor, F.W., van der Plicht, J., Weyhenmeyer, C.E., 2004. Marine04 Marine radiocarbon age calibration, 26 - 0 ka BP. Radiocarbon 46, 1059-1086.

Herman, Y., Osmond, J.K., Somayajulu, B.L.K., 1989. Late Neogene Arctic paleoceanography: micropaleontology, stable isotopes, and chronology, in: Herman,Y. (Ed.), The Arctic Seas: Climatology, Oceanography, Geology and Biology. Van Nostrand Reinhold Co., New York, pp. 581-655. 
Huh, C.-A. , Pisias, N.G., Kelley, J.M., Maiti, T.C., Grantz, A., 1997. Natural radionuclides and plutonium in sediments from the western Arctic Ocean: sedimentation rates and pathways of radionuclides. Deep-Sea Res. II 44, $1725-$ 1743.

Jakobsson, M., Løvlie, R., Al-Hanbali, H., Arnold, E., Backman, J., Mörth, M., 2000. Manganese and color cycles in Arctic Ocean sediments constrain Pleistocene chronology. Geology 28, 23-26.

Jones, E.P., Rudels, B., Anderson, L.G., 1995. Deep waters of the Arctic Ocean: origins and circulation. Deep-Sea Res. I 42, 737-760.

Ku, T.-L., Broecker, W.S., 1967. Rates of sedimentation in the Arctic Ocean. Prog. Oceanog. 4, 95-104.

Kumar, N., Gwiazda, R., Anderson, R.F., Froelich, P.N., 1993. ${ }^{231} \mathrm{~Pa} /{ }^{230} \mathrm{Th}$ ratios in sediments as a proxy for past changes in Southern Ocean productivity. Nature $362,45-48$.

Mangerud, J., Gulliksen, S., 1975. Apparent radiocarbon ages of recent marine shells from Norway, Spitsbergen, and Arctic Canada. Quat. Res. 5 (1975) 263-273.

McManus, J.F., Anderson, R.F., Broecker, W.S., Fleisher, M.Q., Higgins, S.M., 1998. Radiometrically determined sedimentary fluxes in the sub-polar North Atlantic during the last 140,000 years. Earth Planet. Sci. Lett. 155, 29-43.

McManus, J.F., Francois, R., Gherardi, J.-M., Keigwin, L.D., Brown-Leger, S., 2004. Collapse and rapid resumption of Atlantic meridional circulation linked to deglacial climate changes. Nature 428, 834-837.

Moran, S.B., Shen, C.-C., Edwards, R.L., Edmonds, H.N., Scholten, J.C., Smith, J.N., $\mathrm{Ku}, \mathrm{T} .-\mathrm{L} ., 2005 .{ }^{231} \mathrm{~Pa}$ and ${ }^{230} \mathrm{Th}$ in surface sediments of the Arctic Ocean: implications for ${ }^{231} \mathrm{~Pa} /{ }^{230} \mathrm{Th}$ fractionation, boundary scavenging, and advective export. Earth Planet. Sci. Lett. 234, 235-248.

Poore, R.Z., Osterman, L., Curry, W.B., Phillips, R.L., 1999a. Late Pleistocene and Holocene meltwater events in the western Arctic Ocean. Geology 27, 759-762.

Poore, R.Z., Ostermann, D.R., McGeehin, J., 1999b. Stable isotope data and AMS 14C dates from Arctic Ocean Section 1994 surface sediment transect and box core samples from the Mendeleyev Ridge area. USGS Open-File Report 99-48.

Scholten, J.C., Rutgers van der Loeff, M.M., Michel, A., 1995. Distribution of ${ }^{230} \mathrm{Th}$ and ${ }^{231} \mathrm{~Pa}$ in the water column in relation to the ventilation of the deep Arctic basins. Deep-Sea Res. II 42, 1519-1531.

Smith, J.N., Moran, S.B., Macdonald, R.W., 2003. Shelf-basin interactions in the Arctic Ocean based on ${ }^{210} \mathrm{~Pb}$ and $\mathrm{Ra}$ isotope tracer distributions. Deep-Sea Res. I 50, 387-416.

Somayajulu, B.L.K., Sharma, P., Herman, Y., 1989. Thorium and uranium isotopes in Arctic sediments, in: Herman,Y. (Ed.), The Arctic Seas: Climatology, Oceanography, Geology and Biology. Van Nostrand Reinhold Co., New York, pp. 571-579.

Stuiver, M., Reimer, P.J., Reimer, R.W., 2005. Calib 5.0, WWW Program and Documentation. 
Suman, D.O., Bacon, M.P., 1989. Variations in Holocene sedimentation in the North American Basin determined from ${ }^{230} \mathrm{Th}$ measurements. Deep-Sea Res. 36, 869878.

Trimble, S.M., Baskaran, M., Porcelli, D., 2004. Scavenging of thorium isotopes in the Canada Basin of the Arctic Ocean. Earth Planet. Sci. Lett. 222, 915-932.

Woodgate, R.A., Aagaard, K., Muench, R.D., Gunn, J., Björk, G., Rudels, B., Roach, A.T., Schauer, U., 2001. The Arctic Ocean Boundary Current along the Eurasian slope and the adjacent Lomonosov Ridge: Water mass properties, transports and transformations from moored instruments. Deep-Sea Res. I 48, 1757-1792.

Woodgate, R.A., Aagaard, K., Swift, J.H., Smethie, W.M., Falkner, K.K., 2007. Atlantic water circulation over the Mendeleev Ridge and Chukchi Borderland from thermohaline intrusions and water mass properties. J. Geophys. Res. 112, C02005, doi:10.1029/2005JC003416.

Yang, H.-S., Nozaki, Y., Sakai, H., Masuda, A., 1986. The distribution of ${ }^{230} \mathrm{Th}$ and ${ }^{231} \mathrm{~Pa}$ in the deep-sea surface sediments of the Pacific Ocean. Geochim. Cosmochim. Acta 50, 81-89.

Yu, E.-F., Francois, R., Bacon, M.P., 1996. Similar rates of modern and last- glacial ocean thermohaline circulation inferred from radiochemical data. Nature 379, 689-694.

Yu, E.-F., Francois, R., Bacon, M.P., Fleer, A.P., 2001. Fluxes of ${ }^{230} \mathrm{Th}$ and ${ }^{231} \mathrm{~Pa}$ to the deep sea: implications for the interpretation of excess ${ }^{230} \mathrm{Th}$ and ${ }^{231} \mathrm{~Pa} /{ }^{230} \mathrm{Th}$ profiles in sediments. Earth Planet. Sci. Lett. 191, 219-230. 


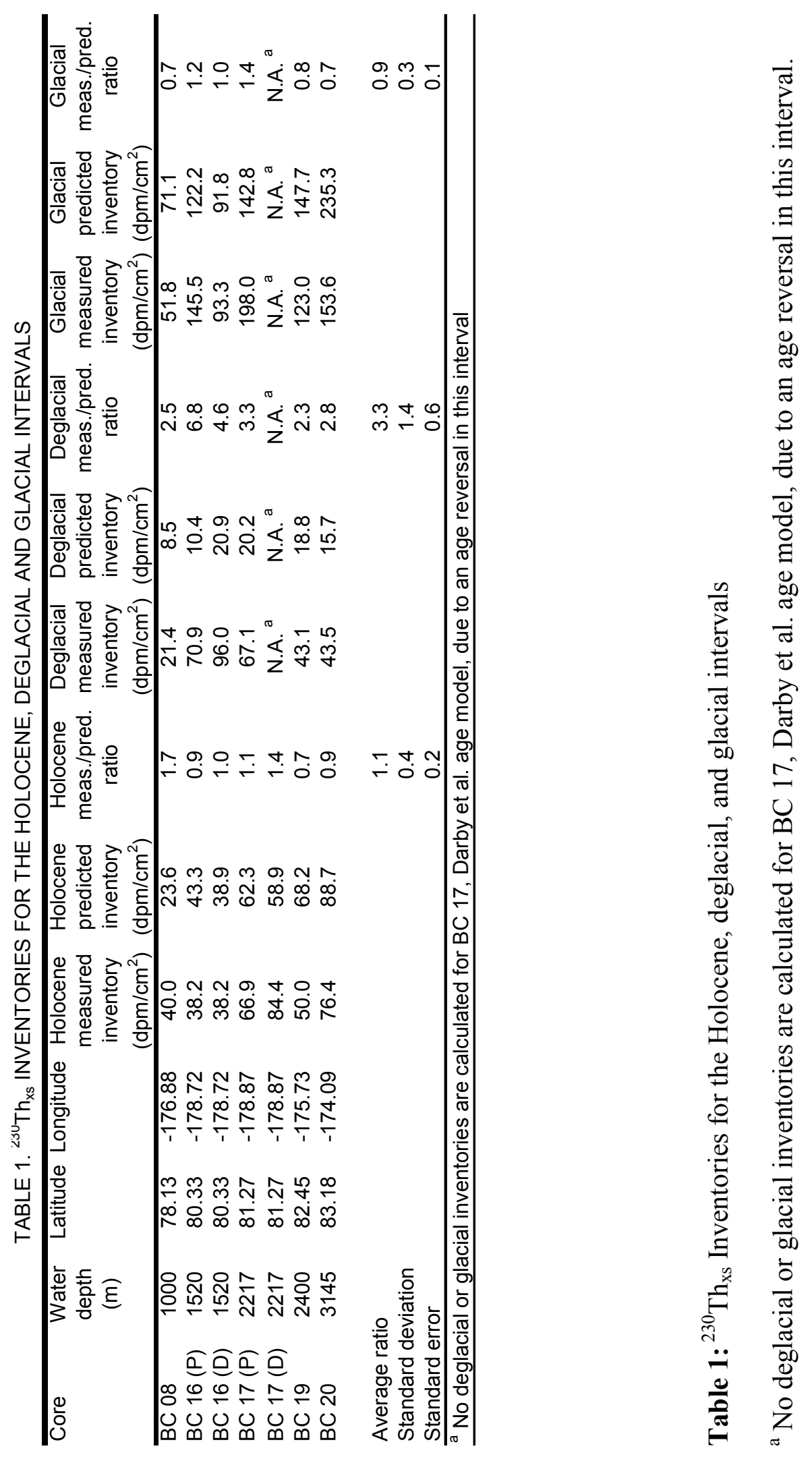




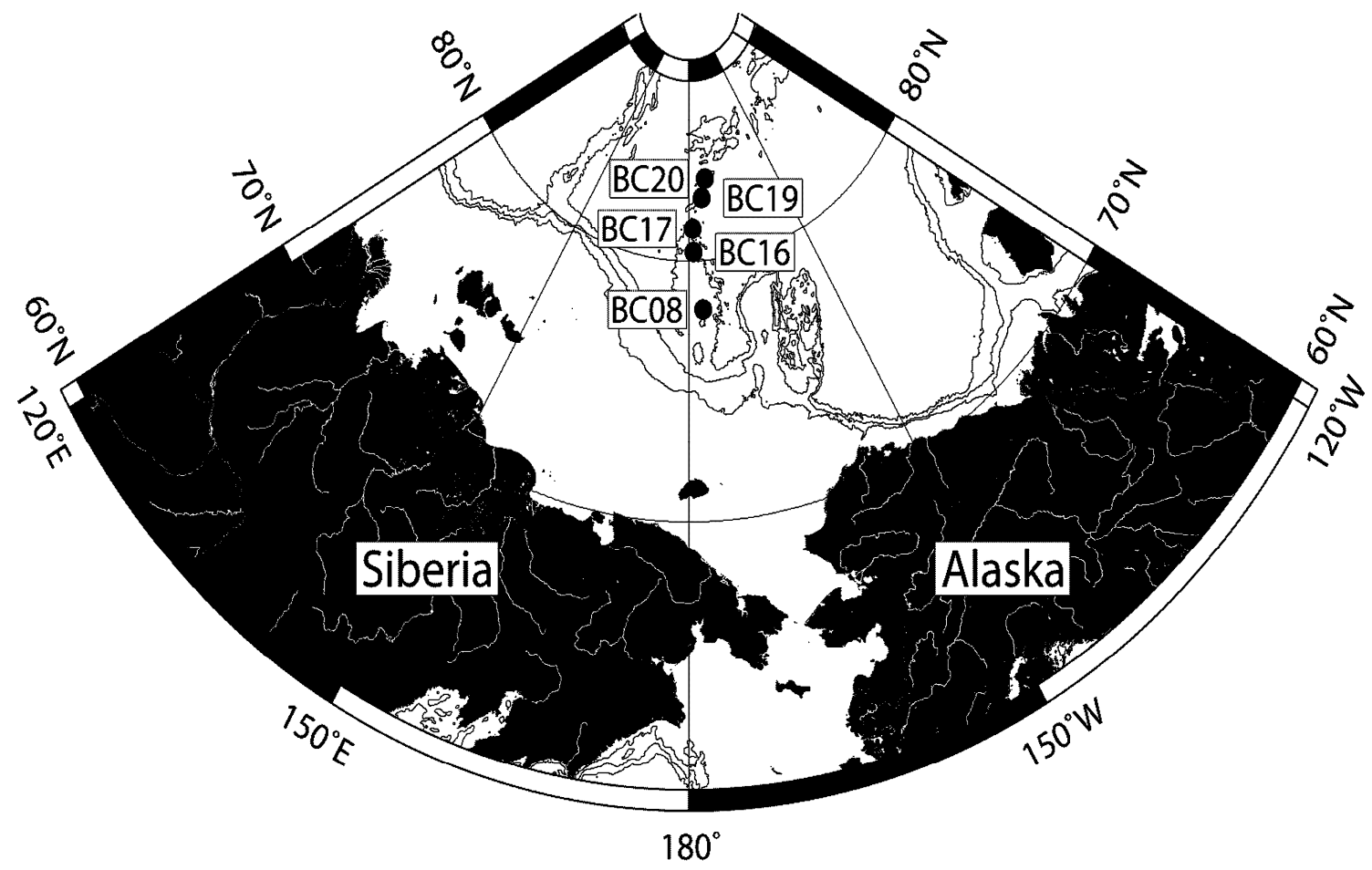

Figure 1: Locations of Arctic Ocean Section 1994 box cores studied in this paper. 

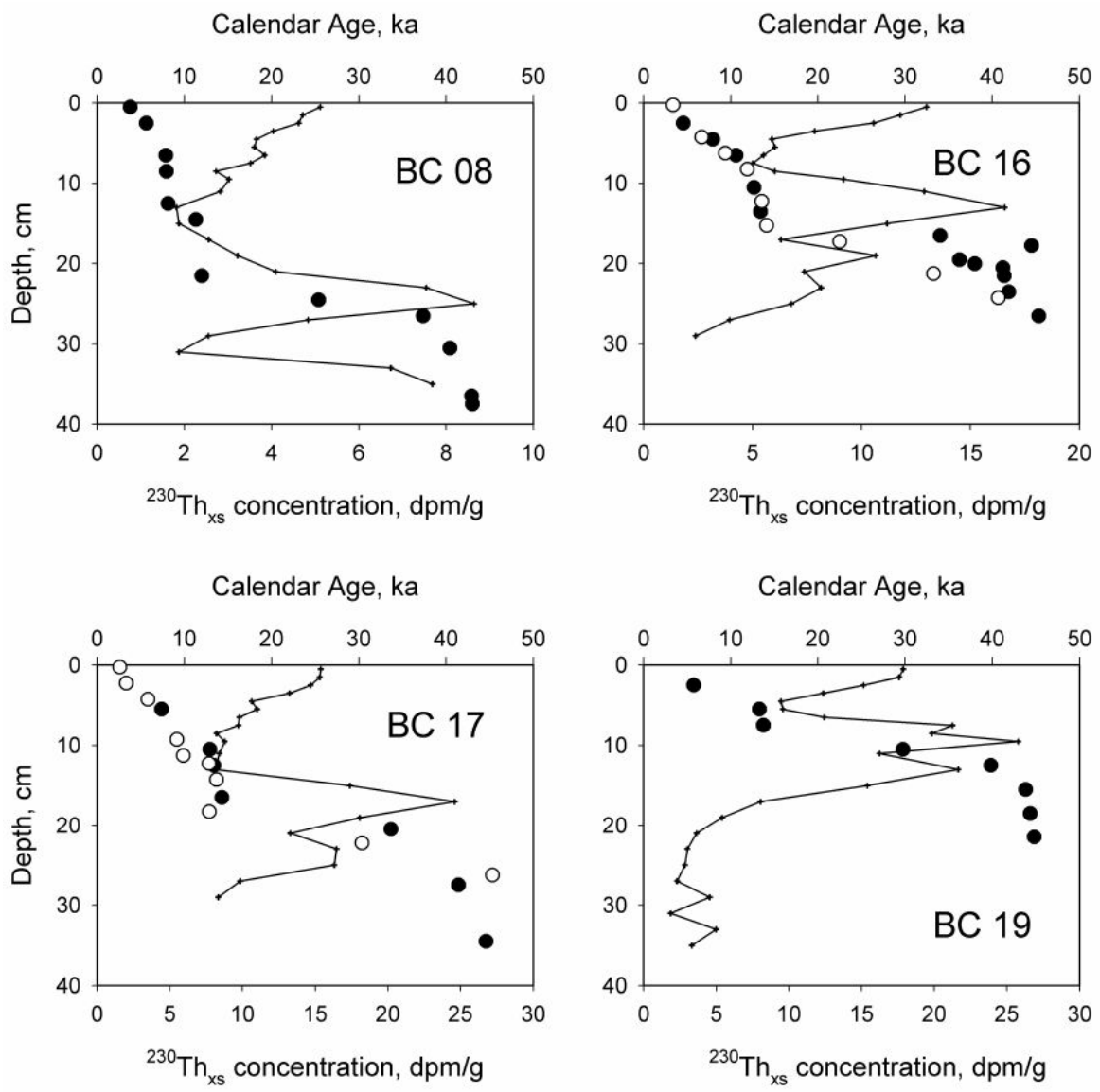

Calendar Age, ka
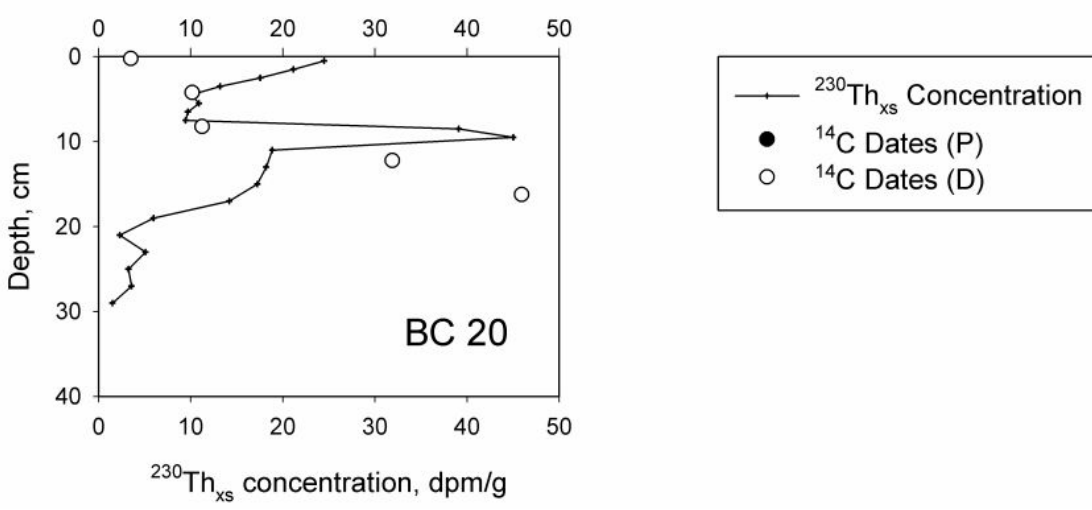

Figure 2: Data used in this study. ${ }^{230} \mathrm{Th}_{\mathrm{xs}}$ profiles reported by Huh et al. (1997), uncorrected for decay since burial. Radiocarbon data from Poore et al. (1999a, 1999b) (“14 C dates (P)" in legend) and from Darby et al. (1997) (“'14 C dates (D)"), calibrated to calendar years as explained in section 2 . 

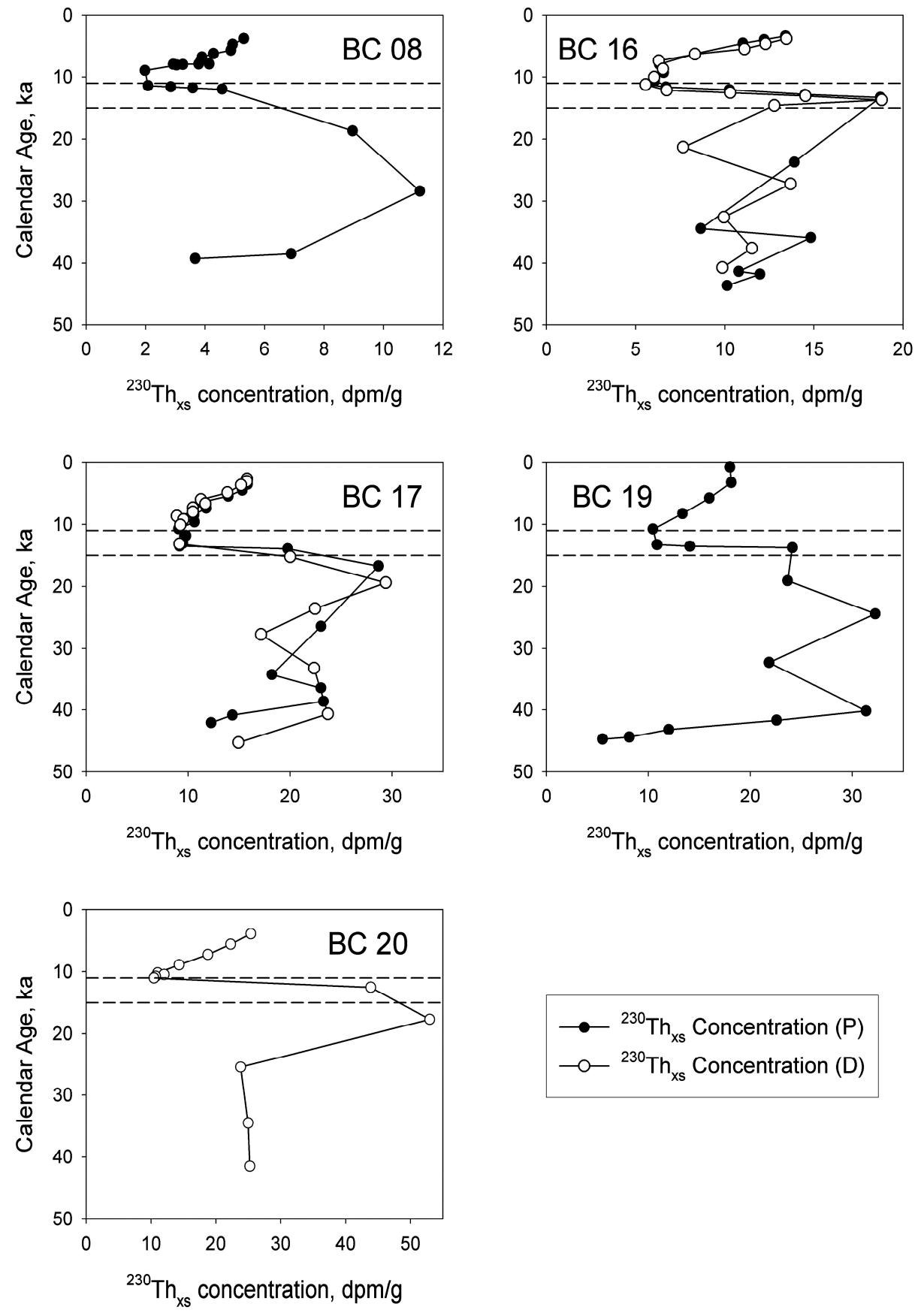

$$
\begin{aligned}
& \multimap{ }^{230} \mathrm{Th}_{\mathrm{xs}} \text { Concentration (P) } \\
& \multimap-{ }^{230} \mathrm{Th}_{\mathrm{xs}} \text { Concentration (D) }
\end{aligned}
$$

Figure 3: ${ }^{230} \mathrm{Th}_{\mathrm{xs}}$ profiles, corrected for decay since burial, plotted with age models based on Poore et al. (1999a, 1999b) dates (P) and Darby et al. (1997) dates (D). Dashed horizontal lines at 11 and $15 \mathrm{kyr}$ mark the boundaries between the Holocene, deglacial, and glacial periods. 


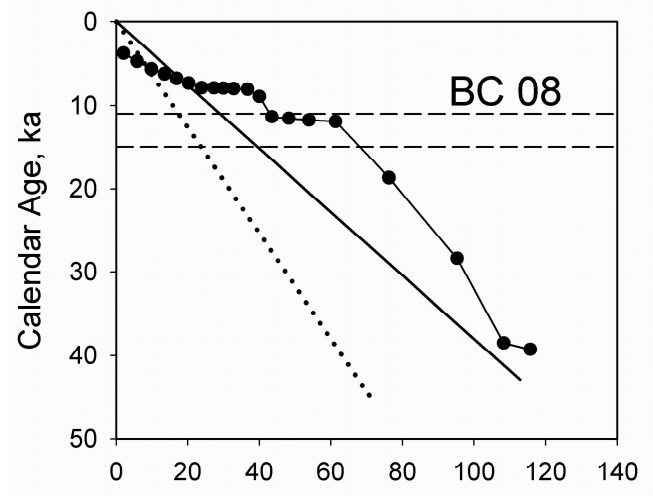

Cumulative ${ }^{230} \mathrm{Th}$ Inventory, dpm/ $/ \mathrm{cm}^{2}$
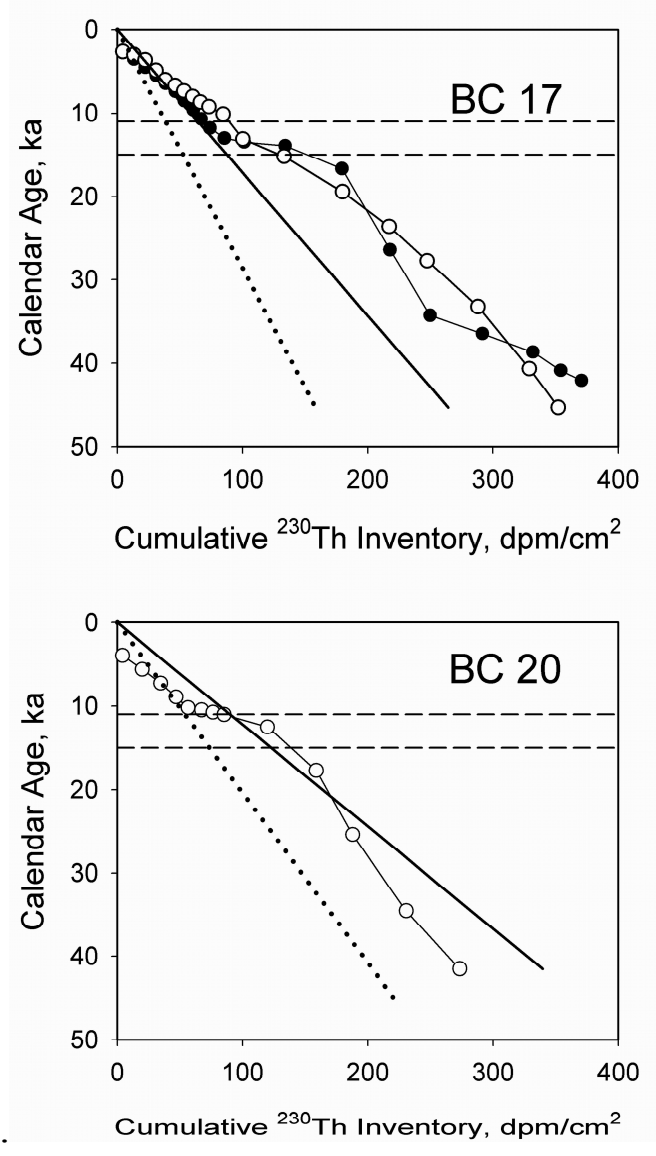

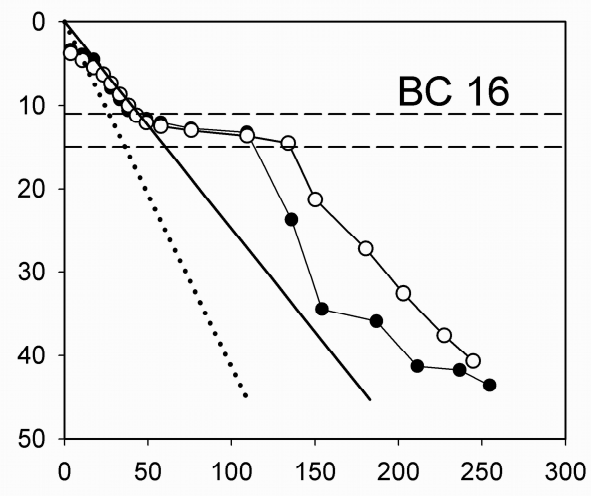

Cumulative ${ }^{230}$ Th Inventory, $\mathrm{dpm} / \mathrm{cm}^{2}$

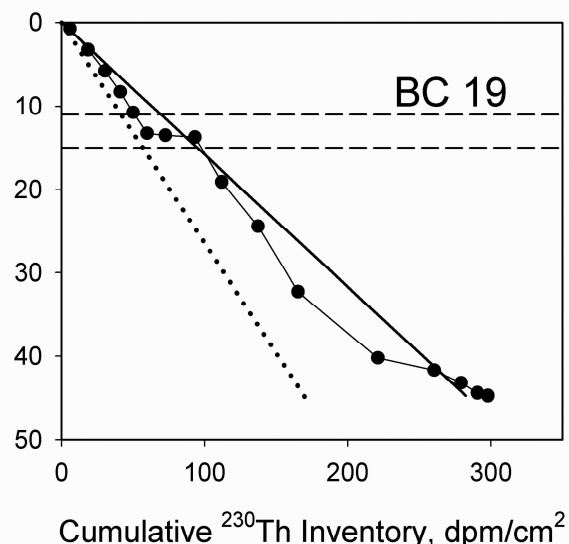

Cumulative ${ }^{230} \mathrm{Th}$ Inventory, $\mathrm{dpm} / \mathrm{cm}^{2}$

Figure 4: ${ }^{230} \mathrm{Th}_{\mathrm{xs}}$ cumulative downcore measured inventory and cumulative production, plotted against calendar-year age models. Dashed horizontal lines at 11 and $15 \mathrm{kyr}$ mark the boundaries between the Holocene, deglacial, and glacial periods. The dotted line marks $60 \%$ of cumulative production, previously the highest estimated ratio of burial to production. The calculated cumulative measured inventories are higher than this $60 \%$ benchmark even during times of extremely low sedimentation rate. 


\section{Chapter 3}

\section{A History of Sedimentation in the Central Arctic in the Last 35,000 Years from Sedimentary ${ }^{230} \mathrm{Th}_{\mathrm{xs}}$ Records}

Abstract: ${ }^{230}{ }^{2} h_{x s}$ in sediments provides a constant flux proxy to investigate deposition rates of various sedimentary components at the seafloor. We present ${ }^{230} \mathrm{Th}_{\mathrm{xs}}$ profiles from seven sites in a transect from the Amerasian Basin to the Eurasian Basin, to examine the sedimentary history of the central deep Arctic basins over the past $35 \mathrm{kyr}$ and its connection to climatic conditions. Sedimentary inventories of ${ }^{230} \mathrm{Th}_{\mathrm{xs}}$ in cores from the Lomonosov Ridge to the Nansen Basin in the Eurasian Basin indicate balanced rates of production and burial of ${ }^{230} \mathrm{Th}$ during the Holocene. ${ }^{230}$ Th-normalized sediment mass fluxes from all cores indicate variable particle fluxes during the glacial period, typically showing high fluxes prior to $35 \mathrm{ka}$ and extremely low fluxes during the late glacial (35-15 ka). A deglacial or early Holocene rise in vertical sedimentation followed, which dwindled through the Holocene. In the Makarov Basin, ${ }^{230} \mathrm{Th}_{\mathrm{xs}}$ accumulation rates show that sediment focusing accompanied this deglacial jump in vertical sediment flux. Deglacial peaks in both lateral and vertical sediment delivery to these core sites coincided with depleted $\delta^{18} O$ signals in planktonic foraminifera which may reflect increased meltwater input to the Arctic from ice sheets. In the Eastern Arctic, peaks in 
vertical sedimentation flux occurred later, at the very end of the deglacial and start of the Holocene, and were not accompanied by large changes in lateral sedimentation. Our results suggest that collapse of the northern hemisphere ice sheets ringing the Arctic basins, deglacial breakup of the perennial ice pack, and drowning of the wide Siberian shelves as sea level rose allowed increased input of particles to the Arctic ocean.

\section{Introduction}

${ }^{234} \mathrm{U}$, conservative and well-mixed in seawater, decays at a known rate to produce ${ }^{230} \mathrm{Th}$ in the water column of the world ocean (Henderson and Anderson, 2003). ${ }^{230} \mathrm{Th}$, unlike its parent, is highly insoluble and particle-reactive, and is removed from the water column by adsorption to settling particles and subsequent burial in seafloor sediments (Anderson et al., 1983a). In much of the world ocean, the rate of ${ }^{230} \mathrm{Th}$ removal to sediments at any given location approximately balances the rate of its production in the local water column above (Henderson et al., 1999; Yu et al., 2001). The activity of the thorium so delivered to the seafloor, unsupported by $U$ decay within the crystal lattices of sediment particles, is referred to as excess $\mathrm{Th}\left({ }^{230} \mathrm{Th}_{\mathrm{xs}}\right)$. The approximate balance between the rate of burial and the known, constant rate of production in seawater allows the use of ${ }^{230} \mathrm{Th}$, measured in core sediments and corrected for radiodecay since deposition, to estimate rates of input to the seafloor of bulk sediments, sedimentary components such as clay, carbonates, and ice-rafted debris (IRD), and chemical species such as other radionuclides (Bacon, 1984; Francois et al., 1990; Francois et al., 2004). When 
combined with independent age control, such as radiocarbon measurements, ${ }^{230} \mathrm{Th}$ contents of sediments can also allow us to identify lateral sediment transportation (Suman and Bacon, 1989), which can have important implications for understanding records of other paleoceanographic proxies such as alkenones or grain size measurements.

Water column studies of ${ }^{230} \mathrm{Th}$ in the Arctic basins suggested varying rates of nuclide scavenging by particles, ranging from very slow at the Alpha Ridge and Makarov Basin (Bacon et al., 1989; Scholten et al., 1995; Edmonds et al., 2004) to rates comparable to the rest of the world ocean in the Nansen Basin and the Canada Basin (Cochran et al., 1995; Scholten et al., 1995; Edmonds et al., 1998; Trimble et al., 2004). Other studies measured ${ }^{230} \mathrm{Th}_{\mathrm{xs}}$ in downcore sediments, generally as a method of estimating sedimentation rates (Ku \& Broecker, 1967; Finkel et al., 1977; Somayajulu et al., 1989; Huh et al., 1997). These studies all noted that their ${ }^{230} \mathrm{Th}_{\mathrm{xs}}$ profiles in the Arctic basins did not resemble classic radiodecay profiles, instead revealing substantial subsurface peaks, but did not attempt to interpret these peaks in detail as paleoceanographic signals. Estimates of sedimentary ${ }^{230} \mathrm{Th}_{\mathrm{xs}}$ inventories from these studies, in conjunction with the Bacon et al. (1989) water column study from Alpha Ridge, established the idea that low particle fluxes in the central Arctic basins were insufficient to fully scavenge ${ }^{230} \mathrm{Th}$ and that consequently between 40 and $98 \%$ of ${ }^{230} \mathrm{Th}$ produced in the deep central Arctic was exported in the water column to areas of higher particle flux, such as slope environments. It has now been shown that in the Western Arctic, this does not appear to be the case for the Holocene, and that efficient scavenging occurred even during times of extremely low sedimentation rate during the late glacial 
period as well (Hoffmann and McManus, 2007). Deglacial sediments, far from a deficit, contained ${ }^{230} \mathrm{Th}_{\mathrm{xs}}$ far exceeding the amount produced in the water column during their interval of deposition, most likely due to accumulation of remobilized ${ }^{230}$ Th-bearing sediments from elsewhere (Chapter 4.)

Our finding of a general Holocene balance in ${ }^{230} \mathrm{Th}$ production and burial, and our rejection of a widespread ${ }^{230} \mathrm{Th}_{\mathrm{xs}}$ deficit in Arctic sediments due to inefficient particle scavenging, encourage the use ${ }^{230} \mathrm{Th}_{\mathrm{xs}}$ in Arctic sediments to derive information on sedimentation patterns and redistribution, which no published studies have heretofore done. High particle fluxes and rapid sedimentation dilute the ${ }^{230} \mathrm{Th}$ buried at the seafloor; while low particle fluxes concentrate ${ }^{230} \mathrm{Th}$ from the water column on each particle and result in peaks of ${ }^{230} \mathrm{Th}_{\mathrm{xs}}$ concentration in core records. Where lateral transport has remobilized sediments that acquired ${ }^{230} \mathrm{Th}_{\mathrm{xs}}$ elsewhere in the basin, the ${ }^{230} \mathrm{Th}$ inventories between dated horizons will show more ${ }^{230} \mathrm{Th}_{\mathrm{xs}}$ than can have been produced locally by uranium decay. Where sediments have been winnowed away, ${ }^{230} \mathrm{Th}$ inventories will show a deficit relative to how much ${ }^{230} \mathrm{Th}_{\mathrm{xs}}$ would have been produced in the water column over the winnowing site during original deposition. Using ${ }^{230} \mathrm{Th}_{\mathrm{xs}}$ measurements alone, it is difficult to distinguish between sedimentary ${ }^{230} \mathrm{Th}_{\mathrm{xs}}$ deficits due to loss of sediment by winnowing and deficits caused by reduced local scavenging of water column ${ }^{230} \mathrm{Th}$; however, sedimentary grain size analyses or ${ }^{231} \mathrm{~Pa}_{\mathrm{xs}}$ measurements may help to give clues about the processes that cause sedimentary deficits.

We have constructed records of sedimentary ${ }^{230} \mathrm{Th}_{\mathrm{xs}}$ in seven box cores from the deep Arctic basins at water depths ranging from 1 to $3.5 \mathrm{~km}$, in a transect running from 
the Mendeleev Ridge in the western Arctic across Lomonosov Ridge to the Nansen Basin in the eastern Arctic. We combine these records with ${ }^{14} \mathrm{C}$ dates, stable isotope measurements, and foraminiferal counts to construct a picture of Arctic sedimentation patterns and their relationship to oceanographic changes over the past 35,000 years. Chief questions prompting this study include:

i: $\mathrm{Do}^{230} \mathrm{Th}_{\mathrm{xs}}$ inventories balance production in cores from the eastern basins?

ii: Can any regional or depth-related differences in overall sedimentation patterns be discerned from our records?

iii: How do Arctic sedimentation changes and thorium deposition relate to climatic and oceanographic changes such as glaciation, deglaciation, and meltwater inputs?

\section{Methods}

Sediments for this study were sampled from subcores of box cores taken as part of the 1994 Arctic Ocean Section USCGC Polar Sea cruise (locations in Table 1, mapped in Figure 1). Cores were chosen to give an East-West transect across the deep Arctic basins and to give a depth transect in the Western Arctic. Each core was sampled for radionuclide analyses in half-cm-thick layers spaced at $1-\mathrm{cm}$ intervals except $\mathrm{BC} 17$, which was sampled every half-cm for a higher-resolution record.

\section{Core chronologies}

Radiocarbon dates for BC 26 were obtained on samples of $\sim 800$ specimens of Neogloboquadrina pachyderma sinistral, at the NOSAMS AMS facility at the Woods 
Hole Oceanographic Institution. Age models for BC 08, 16, and 17 are derived from radiocarbon dates in Poore et al. (1999a, b); BC 20 from Darby et al. (1997), and BC 28 and 32 from R. Poore, unpublished data (W. Curry, personal communication). Radiocarbon ages younger than 22,000 years were calibrated to calendar years using the Calib 5.1 program and the Intcal 94 marine carbon calibration data set (Hughen et al., 2004; Stuiver and Reimer, 2005). Older ages were converted to calendar years using the calibration program of Fairbanks et al. (2005.) All ages were corrected for a standard reservoir age of 440 years (Darby et al., 1997; Poore et al., 1999a) and a further $\Delta \mathrm{R}$ correction of 250 years to approximate the effect of perennial ice cover on air-sea gas exchange (Mangerud \& Gulliksen, 1975). Calibrated radiocarbon ages are given in Appendix Table 2. As we do not know how $\Delta \mathrm{R}$ changed in the past, we have applied the same correction to all ages. Dated samples for all cores except BC 20 came from the same subcores analyzed for radionuclides. Coarse fraction weight percent records from our subcore of BC 20 and the dated subcore of Darby et al. (1997) suggest no major stratigraphic differences between the cores (Appendix, Fig. A.1). Total mass accumulation rates (MARs) representing both vertical and lateral sediment deposition were calculated for each core by multiplying radiocarbon age model-based sedimentation rates by sample bulk density. These estimates of sediment delivery rate to our sites are independent of the ${ }^{230} \mathrm{Th}$-normalized sediment mass fluxes.

${ }^{230}$ Th measurements and corrections

Sediment samples were pulverized, spiked with ${ }^{229} \mathrm{Th}$, and digested in $\mathrm{HClO}_{4}, \mathrm{HF}$ and $\mathrm{HNO}_{3}$. Aliquots were further spiked with ${ }^{229} \mathrm{Th}$ and ${ }^{236} \mathrm{U}$ and set aside for ${ }^{232} \mathrm{Th} /{ }^{238} \mathrm{U}$ 
analysis. The remaining sample was coprecipitated with iron oxides by $\mathrm{NH}_{4} \mathrm{OH}$, redissolved in $\mathrm{HCl}$, and purified by anion column chromatography (Choi et al., 2001). Samples were analyzed for ${ }^{229} \mathrm{Th},{ }^{230} \mathrm{Th},{ }^{232} \mathrm{Th},{ }^{236} \mathrm{U}$, and ${ }^{238} \mathrm{U}$ on a Thermo-Finnegan Element 2 inductively-coupled plasma mass spectrometer (ICP-MS) at the Woods Hole Oceanographic Institution. Measured ${ }^{232} \mathrm{Th}$ concentrations were multiplied by an assumed ${ }^{238} \mathrm{U} /{ }^{232}$ Th ratio of 0.6 , typical of Arctic and Atlantic sediments (Henderson and Anderson, 2003; McManus et al., 2004; Moran et al., 2005; this study, see Discussion) to estimate ${ }^{238} \mathrm{U}$ activity within the crystal lattice, and hence supported ${ }^{230} \mathrm{Th}$ activity assuming secular equilibrium. These estimates of detrital ${ }^{238} \mathrm{U}$ activity were assumed to be free of the influence of authigenic U. Measured ${ }^{238} \mathrm{U} /{ }^{232} \mathrm{Th}$ ratios were used to determine the presence of authigenic ${ }^{238} \mathrm{U}$ in sediments (suggested by measured ratios above 0.7 ), and to make corrections for ingrown ${ }^{230} \mathrm{Th}$. Supported and ingrown ${ }^{230} \mathrm{Th}$ activities were subtracted from the total measured ${ }^{230} \mathrm{Th}$ to give unsupported excess activity, assumed to be derived from the water column. These resulting ${ }^{230} \mathrm{Th}_{\mathrm{xs}}$ concentrations were then corrected for radioactive decay since deposition according to radiocarbon-derived age models. Replicates of ${ }^{230} \mathrm{Th}$ measurements gave an average standard deviation of $0.3 \mathrm{dpm} / \mathrm{g}\left(\left(\right.\right.$ mean S.D./measured $\left.\left.{ }^{230} \mathrm{Th}\right)=2.5 \%\right)$; average standard deviation between individual replicates was within 3\%. Machine counting errors were within $1 \%$ for the ${ }^{230}$ Th ICP-MS measurements, and error introduced by age-correction of ${ }^{230} \mathrm{Th}_{\mathrm{xs}}$ is less than $1 \%$ for an age error of 400 years, and less than $2 \%$ for an age error of up to 2000 years. Average variation introduced by different estimations of supported ${ }^{230} \mathrm{Th}$ activity within the samples is $\sim 3 \%$. ${ }^{230} \mathrm{Th}_{\mathrm{xs}}$-normalized sediment mass fluxes to the 
seafloor were calculated according to the equation $\mathrm{F}=\beta \mathrm{z} /{ }^{230} \mathrm{Th}_{\mathrm{xs}}$, (Francois et al., 2004) where $\beta$ is the production rate of ${ }^{230} \mathrm{Th}$ in seawater $\left(0.0267 \mathrm{dpm} / \mathrm{m}^{3} / \mathrm{kyr}\right)$, $\mathrm{z}$ is the water depth of the site (m), and our reported $\mathrm{F}$ is in units of $\mathrm{g} / \mathrm{cm}^{2} / \mathrm{kyr}$.

We calculated sample and core inventories of ${ }^{230} \mathrm{Th}_{\mathrm{xs}}$ for Eastern Arctic cores according to methods set forth in Hoffmann and McManus (2007). Inventories for each sampling interval downcore were calculated from ${ }^{230} \mathrm{Th}_{\mathrm{xs}}$ concentration and estimated or measured sediment density (data provided by C.-A. Huh); these sample inventories were then summed to produce inventories for the Holocene (defined as $<11 \mathrm{ka}$ ), deglacial (15$11 \mathrm{ka})$, and late glacial (35-15 ka) intervals. Samples older than $35 \mathrm{ka}$ were not included in glacial inventories as their radiocarbon ages are less reliable than those of younger samples. Sediment density values from Huh et al. (1997) were measured on different subcores than were sampled for our ${ }^{230} \mathrm{Th}_{\mathrm{xs}}$ records. A composite average density profile modeled from the Huh data was constructed for cores with no original density data.

Stable isotope measurements are from Poore et al. (1999a, b) for cores BC 08, 16, and 17; and from R. Poore, unpublished data (W. Curry, personal communication) for BC 20, 28 and 32. These measurements were obtained on $\sim 6$ specimens per sample of the polar planktonic foraminifer $N$. pachyderma sinistral (>125 $\mu \mathrm{m}$ size fraction), using a Finnegan MAT252 mass spectrometer at the Woods Hole Oceanographic Institution. Stable isotope measurements from core BC 26 (this study) were analyzed on $\sim 10$ specimens of $N$. pachyderma sinistral (>150 $\mu$ m size fraction), at WHOI. Records of $N$. pachyderma sinistral, in numbers per gram of sediment, for cores $\mathrm{BC} 08,16$, and 17 are from Poore et al. (1999b). 


\section{Results}

i. $\quad$ Profiles of ${ }^{230} \mathrm{Th}_{x s}$

Our measurements of bulk ${ }^{230} \mathrm{Th},{ }^{232} \mathrm{Th},{ }^{238} \mathrm{U}$, and age-corrected ${ }^{230} \mathrm{Th}_{\mathrm{xs}}$ are presented in Appendix Table A.3. Profiles of ${ }^{230} \mathrm{Th}_{\mathrm{xs}}$ in cores from the Amerasian and Eurasian basins (West and East Arctic) are presented in Figure 2a and b, graphed by depth in core, and in $2 \mathrm{c}$ and $\mathrm{d}$, graphed on an age scale. Several features are common to all profiles except BC 26. Generally, late glacial-age concentrations are high, rising to peaks just at or below the beginning of the deglaciation. Cores $\mathrm{BC} 16$ and 17 show an additional earlier peak within the glacial section, prior to $35 \mathrm{ka}$. Above the deglacial/glacial boundary (defined here as the horizon of the deepest radiocarbon date between 15 and $11 \mathrm{ka}),{ }^{230} \mathrm{Th}_{\mathrm{xs}}$ concentration rapidly drops to low values through the rest of the deglacial section (defined as $15-11 \mathrm{kyr}$ ). Concentrations then rise slowly through the Holocene sections.

Core BC 26 shows near-zero concentrations of ${ }^{230} \mathrm{Th}_{\mathrm{xs}}$ in the lower part of the core, rising to several minor subsurface peaks and a final near-surface peak (Figure $2 b$ ). This near-surface peak is only slightly larger than the subsurface peaks, unlike other cores where subsurface peaks dwarf the surface concentration. Radiocarbon dates indicate that the ${ }^{230} \mathrm{Th}_{\mathrm{xs}}$-free sediments and the deepest subsurface peak in the deep part of the core predate the last $38 \mathrm{kyr}$ (Figure 2d). Another subsurface peak and subsequent drop to somewhat lower ${ }^{230} \mathrm{Th}_{\mathrm{xs}}$ concentrations occur during an interval of relatively rapid sediment deposition preceding the LGM. Above this peak and drop, sediments date to the 
very latest glacial and early deglacial. A small near-surface peak, dated to the Holocene, is consistent with Holocene ${ }^{230} \mathrm{Th}$ records from the other cores in this study.

ii. ${ }^{230}{ }^{2} h_{x s}$ Inventories from the Eurasian Basin, BC 26, 28 and 32

Sedimentary ${ }^{230} \mathrm{Th}_{\mathrm{xs}}$ inventories are smaller than production of ${ }^{230} \mathrm{Th}$ in the water column during the Holocene in $\mathrm{BC}$ 26, 28, and 32 (Table 1, Figure 3). However, the rates at which ${ }^{230} \mathrm{Th}_{\mathrm{xs}}$ was deposited at the seafloor at these sites match the rates of production well, on average to within $30 \%$ (Figure 4a). BC 28 has a good match of measured inventory to production for most of the upper part of the core (figure 3), with a small apparent deficit in glacial-dated sediments. In this it resembles western Arctic cores (Hoffmann and McManus, 2007); however, neither it nor BC 32 have a large increase in ${ }^{230} \mathrm{Th}_{\mathrm{xs}}$ inventory during the deglaciation as the western cores do (Hoffmann and McManus, 2007, also see Chapter 4). In BC 26, the burial rate in ${ }^{230}$ Th in the Holocene is similar to the production rate near the coretop, but appears much slower than production in the glacial section of the core, except at the rapid-sedimentation event between 28 and $25 \mathrm{ka}$. BC 28 shows an increase in ${ }^{230} \mathrm{Th}_{\mathrm{xs}}$ burial rate at the deglaciation, a feature common to all our Makarov cores (see next section and chapter 4). However, the rise in burial rate in $\mathrm{BC} 28$ comes at the end of the deglaciation (11 kyr), later than in the Western Arctic where the increase is seen as early as $15 \mathrm{kyr}$, and is at least 3 times smaller. In $\mathrm{BC} 32$, burial rates rise above the production rate in the Holocene, averaging $\sim 30 \%$ higher than production after $8 \mathrm{ka}$. 
iii. New inventory calculations from Amerasian Basin cores, $B C$ 08, 16, 17, and 20

Our previous calculations of ${ }^{230} \mathrm{Th}_{\mathrm{xs}}$ inventories in cores from the Mendeleev Ridge and Makarov Basin (Hoffmann \& McManus, 2007) were based on published thorium concentration data (Huh et al., 1997) and published radiocarbon dates (Poore et al., 1999a, b; Darby et al., 1997), measured on separate subcores of the same box cores. Our new ${ }^{230} \mathrm{Th}_{\mathrm{xs}}$ profiles were measured on the same subcores of $\mathrm{BC} 08,16$, and 17 that were dated by Poore et al. (1999a,b). To eliminate any possible small subcore-to-subcore stratigraphic discrepancies that might affect our assignment of sample inventories to different age periods, we have recalculated inventories for these cores, as well as from our new ${ }^{230} \mathrm{Th}_{\mathrm{xs}}$ analyses on $\mathrm{BC} 20$ (Table 1). Although some inventory totals have changed, the overall pattern is consistent with our previous findings: ${ }^{230} \mathrm{Th}$ budgets appear balanced during the Holocene to within 30\% (Figure 3). Sediment focusing appears to deliver extra ${ }^{230} \mathrm{Th}_{\mathrm{xs}}$ to the core sites during times of peak accumulation during the deglacial (measured/produced ratios $>>1$ in Figure 3). Late glacial results vary somewhat between cores. BC 16 appears to have a ${ }^{230} \mathrm{Th}_{\mathrm{xs}}$ inventory smaller than total production during its glacial section (35-15 kyr): its late glacial burial rates vary between $33 \%$ to $65 \%$ of the production rate. In $\mathrm{BC} 08$, early in the $35-15 \mathrm{kyr}$ interval burial rates are lower than production rates, but in the later part of that interval the burial rates rise and match the production rate. BC 17 displays broadly similar rates of production and burial during the glacial interval, with slightly lower rates during the start of the interval than at the end. $\mathrm{BC} 20$ shows a late glacial burial rate averaging about $63 \%$ of the production rate. In each core, ${ }^{230} \mathrm{Th}_{\mathrm{xs}}$ deposition rises sharply at the deglacial far above 
the production rate, in an event associated with sediment focusing (discussed further in Chapter 4). A second event of sediment focusing occurred at $8 \mathrm{ka}$ in $\mathrm{BC} 08$, contributing roughly $45 \%$ of the total ${ }^{230} \mathrm{Th}_{\mathrm{xs}}$ Holocene inventory in that core. The ${ }^{230} \mathrm{Th}_{\mathrm{xs}}$ budget for the Holocene interval after this event balances well, however, with the measured inventory constituting $94 \%$ of the predicted production (Table 1)

iv. Vertical sedimentation fluxes from ${ }^{230} T h_{x s}$ and total sedimentation fluxes

${ }^{230}$ Th-normalized sediment fluxes, representing vertical sedimentation (sinking from the water column), are presented in Figures $5 \mathrm{a}$ and $\mathrm{b}$. In cores $\mathrm{BC} 08$, 16, and 17 sediment flux peaks appear at the bottom of the analyzed section, deposited prior to 35 kyr. Particle fluxes in all cores are extremely low, between 0.25 and $0.4 \mathrm{~g} / \mathrm{cm}^{2} / \mathrm{kyr}$, during the late glacial. Sediment mass fluxes jump by factors of 2-7 at the deglacial in all Western Arctic cores and in the late deglacial / early Holocene in the Eastern cores, subsequently declining throughout the Holocene to values between 0.35 and 0.75 $\mathrm{g} / \mathrm{cm}^{2} / \mathrm{kyr}$. In most Western Arctic cores, we find that Th-normalized sediment mass fluxes begin to rise slightly after the first radiocarbon date marking the base of the deglacial period in each core. Th-normalized fluxes then remain high until the end of the deglaciation in the Western Arctic. The timing of this deglacial jump varies slightly among the cores. In the Western Arctic (BC 08, 16, 17, 20) the ${ }^{230}$ Th-normalized sediment flux rises between 14 and $11 \mathrm{kyr}$; in the Eastern Arctic cores BC 28 and 32, the rise comes in the earliest Holocene: at $10 \mathrm{kyr}$ in $\mathrm{BC} 32$ and beginning at $10.5 \mathrm{kyr}$ in $\mathrm{BC}$ 28 (Figure 5b). A smaller deglacial rise in ${ }^{230} \mathrm{Th}$-normalized sedimentation flux appears 
in BC 26 at $14 \mathrm{kyr}$, and all fluxes in that core are significantly smaller than those seen at BC 28 nearby.

Mass accumulation rates (MARs), calculated from total sedimentation rates as derived from radiocarbon dates, are also plotted in Figure 5. A match between the ${ }^{230} \mathrm{Th}$ normalized mass fluxes and the MAR, which represents total mass deposition from both vertical particle flux and lateral sediment transport, is consistent with completely vertical delivery of sediments to the core site, with minimal horizontal focusing or winnowing. In BC 08, 16, and 17 from the Mendeleev Ridge, MARs are high in the oldest part of our records, between 45 and $35 \mathrm{kyr}$. These ages are at the limit of the age range datable by ${ }^{14} \mathrm{C}$, and sediment accumulation estimates based on these dates have a large associated uncertainty. These early peaks in MAR accompany rises in ${ }^{230} \mathrm{Th}$-normalized sediment mass flux. During the later glacial period, $35-15 \mathrm{kyr}$, the MAR is small in all four Makarov Basin cores, consistent with the low ${ }^{230}$ Th-normalized flux records records. MARs rise sharply at the deglaciation in these cores, indicating sedimentation rate changes up to four or five times larger than can be seen in the ${ }^{230} \mathrm{Th}$-normalized sediment mass flux records. $\mathrm{BC} 08$ has a second high-MAR event at $8 \mathrm{ka}$, following its deglacial event at 12 kyr. During the Holocene, MARs in the Western Arctic largely match ${ }^{230}$ Thnormalized mass fluxes.

In the cores from the Eastern Arctic, MARs and ${ }^{230}$ Th-normalized mass fluxes resemble each other through the late glacial, deglacial, and Holocene sections of $\mathrm{BC} 28$, and in the deglacial and Holocene sections of BC 32. MARs substantially lower than the vertical mass flux are found in the late glacial section of $\mathrm{BC} 32$, and in most of the record 
from $\mathrm{BC} 26$. In BC 26, only just prior to the LGM do we see a jump in MAR, and in the later Holocene the MAR approaches the vertical mass flux.

\section{v. Uranium-238 and thorium-232}

Appendix Table A.3 presents concentrations of ${ }^{238} \mathrm{U}$ and ${ }^{232} \mathrm{Th}$ in our samples. These isotopes primarily represent the detrital component of sediments, and are used to calculate supported activity of ${ }^{230} \mathrm{Th}$ in our samples for correction of the ${ }^{230} \mathrm{Th}_{\mathrm{xs}}$ signal. As in the Atlantic, ${ }^{238} \mathrm{U} /{ }^{232} \mathrm{Th}$ ratios in our Arctic samples fall mostly between 0.5 and 0.7 (Figure 6). Ratios higher than this may indicate the presence of authigenic ${ }^{238} U$ in sediments, requiring additional corrections for ingrown ${ }^{230} \mathrm{Th}$. The average ${ }^{238} \mathrm{U} /{ }^{232} \mathrm{Th}$ for our samples is $\sim 0.65$. We find ratios well above 0.7 only in the deeper section of BC 26 , where carbonate content and excess ${ }^{230} \mathrm{Th}$ both drop to nil. These samples also gave the lowest ${ }^{238} \mathrm{U}$ and ${ }^{232} \mathrm{Th}$ activities in our sample set. Several cores (BC 17, 20 and 32 in particular) show slightly lower ratios during the late glacial than during the Holocene, while $\mathrm{BC} 08$ shows a distinct peak in ratios during an early Holocene sediment focusing event, suggesting that the source of that laterally-transported sediment may differ from the source of sediments usually reaching that site.

\section{Discussion}

\section{Inventories}

i. ${ }^{230} \mathrm{Th}_{x \mathrm{~s}}$ Inventories from the Eurasian Basin

Our ability to interpret ${ }^{230} \mathrm{Th}_{\mathrm{xs}}$ as a constant flux proxy depends on the assumption that production and deposition of ${ }^{230} \mathrm{Th}_{\mathrm{xs}}$ occur at similar rates. ${ }^{230} \mathrm{Th}$ burial has been 
shown to balance production within $30 \%$, over $70 \%$ of the world ocean (Henderson et al., 1999, Yu et al., 2001). This assumption is also verified for Holocene sediments at sites in the Western Arctic (Hoffmann and McManus, 2007). To expand our regional understanding of seawater and sedimentary ${ }^{230} \mathrm{Th}$ budgets, we calculated inventories of ${ }^{230} \mathrm{Th}_{\mathrm{xs}}$ for three cores in the Central and Eastern Arctic: BC 26, atop the Lomonosov Ridge, BC 28 nearby on the Amundsen Basin slope of the Lomonosov Ridge, and BC 32 close to the Gakkel Ridge on the floor of the Nansen Basin. The ratios of our measured Holocene, deglacial, and late glacial inventories to estimated water column production for these intervals are shown in Figure 3, revealing a general balance for both eastern and western cores in the Holocene, and strong deficits of ${ }^{230} \mathrm{Th}$ in $\mathrm{BC} 16$ and 32 during the glacial. During the deglacial, eastern cores differed from their western counterparts in that only one Eastern core, BC 28, showed any surplus deglacial ${ }^{230}$ Th inventory; all Western Arctic cores have large excesses of ${ }^{230} \mathrm{Th}_{\mathrm{xs}}$ in their deglacial sections, leading to measured/produced ratios much greater than 1 (Figure 3).

In figure $4 \mathrm{a}$, we compare our cumulative measured inventories in the eastern cores to what we estimate the total cumulative inventory would be at each measured point in the core if burial rates perfectly balanced the rate of ${ }^{230} \mathrm{Th}$ production in the water column above each site. We also plot burial rate compared to production rate, where the burial rate is the slope of the cumulative inventory plot, to eliminate offsets due to coretop loss or sediment focusing. Where the slopes of the cumulative downcore measured and predicted inventory lines are similar, we infer that the rate of burial does 
indeed balance the rate of production, even if the cumulative inventory plot is offset from the predicted inventory.

We find that in all three eastern cores (BC 26, 28, and 32), the slopes of the measured cumulative inventory and predicted inventory from production match well in the Holocene, indicating a balance between the rates of production and burial. At each coretop there is an offset between the two cumulative inventory profiles, which could result from loss of surface sediment during coring: each core has a nonzero coretop age, and the difference between the measured and predicted inventories in each core is similar to the ${ }^{230} \mathrm{Th}_{\mathrm{xs}}$ production expected for each site in the time since the coretop age. $\mathrm{BC} 28$ shows a slight increase in the rate of burial at the deglacial. Between 35 and $15 \mathrm{kyr}$ in each core, a deficit in the measured ${ }^{230} \mathrm{Th}_{\mathrm{xs}}$ inventory is seen below that expected from ${ }^{230}$ Th production. BC 28 has only a slight deficit and a slightly smaller rate of burial; BC 26 and 32 have much larger differences between the rates of production and burial. In BC 26 , an event of rapid sedimentation between 28 and $25 \mathrm{ka}$ appears to have been a time of rapid ${ }^{230} \mathrm{Th}$ burial, sandwiched within a glacial section of otherwise slow ${ }^{230} \mathrm{Th}$ deposition.

A large glacial-age deficit of ${ }^{230} \mathrm{Th}_{\mathrm{xs}}$ exists in $\mathrm{BC} 32$ - our calculations suggest that as little as $25 \%$ of water column production at this site was buried in the sediments prior to 20 kyr ago. This is profoundly different from most late glacial Th inventories in Western Arctic cores and in $\mathrm{BC} 28$, and could suggest that Th scavenging and/or particle flux dynamics in the Nansen Basin differed significantly from these processes in other parts of the Arctic at that time. Sediment winnowing from this site during the glacial could also 
produce an apparent lack of ${ }^{230} \mathrm{Th}_{\mathrm{xs}}$ sufficient to balance production during the time these sediments were deposited. Evidence from ${ }^{231} \mathrm{~Pa} /{ }^{230} \mathrm{Th}$ profiles suggests that scavenging of ${ }^{231} \mathrm{~Pa}$, which is less particle-reactive than ${ }^{230} \mathrm{Th}$ and is thus more likely to be exported from a region of low particle flux, was not considerably different between the glacial, deglacial, and Holocene in that core, which may support the winnowing explanation (Chapter 5). However, the relative effects of winnowing and reduced scavenging efficiency cannot yet be separated and definitively tested.

\section{ii. ${ }^{230} \mathrm{Th}_{x \mathrm{~s}}$ Inventories from the Amerasian Basin}

We produced new inventory calculations for Western Arctic cores BC 08, 16, 17, and 20, using new ${ }^{230} \mathrm{Th}_{\mathrm{xs}}$ data from ICP-MS analysis (Figure $4 \mathrm{~b}$ ) measured on the same subcores on which the radiocarbon age model was constructed for the first three cores. These inventories confirm our previous conclusion that Holocene ${ }^{230} \mathrm{Th}$ budgets were largely in balance between sediments and water column. Deglacial deposition of ${ }^{230} \mathrm{Th}_{\mathrm{xs}}$ significantly outpaced production in the water column however (see high deglacial measured/production inventory ratios in Figure $3 ;{ }^{230} \mathrm{Th}$ deposition rates in Figure $4 \mathrm{~b}$ ), suggesting that lateral transport of sediments may be needed to understand this interval in the sedimentary record. During the late glacial, in all cores but $\mathrm{BC} 16$, rates of ${ }^{230} \mathrm{Th}_{\mathrm{xs}}$ burial in Western Arctic cores appear similar to rates of production to within $40 \%$ (Figure 4b), suggesting that the scavenging efficiency of lowered particle fluxes at that time was not severely reduced. Our lowest ratios of burial to production, $\sim 0.6$, are higher than almost all previous estimates of the supposed ${ }^{230} \mathrm{Th}_{\mathrm{xs}}$ deficit in Arctic sediments (Ku and 
Broecker, 1967; Somayajulu et al., 1989, Huh et al., 1997). In BC 16, however, the late glacial ${ }^{230} \mathrm{Th}_{\mathrm{xs}}$ burial rate appears to be only half the rate of production, possibly indicating either winnowing or reduced scavenging. This could also be related to bioturbation of high- ${ }^{230} \mathrm{Th}_{\mathrm{xs}}$ glacial sediments into the deglacial section (see Discussion section v). ${ }^{230} \mathrm{Th}_{\mathrm{xs}}$ concentrations approach zero at the bottom of the records in $\mathrm{BC} 16$ and 17 , and below $\sim 18 \mathrm{~cm}$ in BC 26 . It is possible that these sediments with little excess ${ }^{230} \mathrm{Th}$ represent ancient ( $>300 \mathrm{kyr}$ ) sediments from which all ${ }^{230} \mathrm{Th}_{\mathrm{xs}}$ has decayed away, as these samples are older than the age range reliably dateable by radiocarbon. However, this would require a long hiatus in sedimentation over $300 \mathrm{kyr}$, which is unlikely given general sedimentation rates in the Arctic. More likely, the low excess values in these cores represent instances of strong dilution of ${ }^{230} \mathrm{Th}_{\mathrm{xs}}$ by large sediment fluxes, combined with radioactive decay.

\section{${ }^{230} \mathrm{Th}_{\mathrm{xs}}$-normalized sediment fluxes and total mass accumulation rates}

${ }^{230} \mathrm{Th}_{\mathrm{xs}}$ normalization gives us an estimate of the vertical particle rain rate at the seafloor, which is most likely related to surface environmental and climatic conditions: open water, productivity, and wind-blown and ice-rafted terrigenous particle supply. The total mass accumulation rate (MAR), combining vertical and lateral sediment supply, is calculated from radiocarbon date-based linear sedimentation rates and sediment density records. Differences between these two estimates of sediment mass delivery rates to a core site may reflect either inefficient ${ }^{230} \mathrm{Th}$ scavenging or lateral sediment transport. If $\mathrm{Th}_{\mathrm{xs}}$-normalized flux exceeds the MAR, either sediment has been winnowed away, 
reducing the apparent MAR, or ${ }^{230} \mathrm{Th}$ may have been inefficiently scavenged by particles, reducing the ${ }^{230} \mathrm{Th}_{\mathrm{xs}}$ concentration in the sediments and thus increasing the calculated ${ }^{230} \mathrm{Th}$-normalized mass flux. MARs exceeding the ${ }^{230} \mathrm{Th}_{\mathrm{xs}}$-normalized flux may indicate sediment focusing at the core site, or dissolved ${ }^{230} \mathrm{Th}$ import to the local water column increasing the amount of ${ }^{230} \mathrm{Th}$ scavenged. We examine changes in the vertical and total sediment supply to our sites in the western and eastern basins of the Arctic, between the glacial, deglacial and Holocene intervals, using ${ }^{230} \mathrm{Th}_{\mathrm{xs}}$-normalized mass fluxes and MARs in each of our cores (figures $5 a$ and $b$ ).

\section{iii. Glacial ${ }^{230}$ Th Deposition}

In the Western Arctic, ${ }^{230} \mathrm{Th}_{\mathrm{xs}}$-normalized mass fluxes are high at the base of the record in $\mathrm{BC} 08,16$, and 17 (figure 5a), corresponding to low ${ }^{230} \mathrm{Th}_{\mathrm{xs}}$ concentrations. Dates for these sediments are quite old, $35-45 \mathrm{ka}$, on the cusp of the range dateable by radiocarbon. These sediments therefore could be significantly older, and the low ${ }^{230} \mathrm{Th}_{\mathrm{xs}}$ concentrations due to insufficient decay corrections to our measured ${ }^{230} \mathrm{Th}_{\mathrm{xs}}$. If, however, these dates are accurate, our data suggest a time of heightened vertical particle fluxes preceding the LGM, coincident with a time of increased MAR in these three cores. The mid-Weichselian Interstade is known from Siberian permafrost records of insect and pollen assemblages (Wetterich et al., in press). During this time, from $\sim 48-35 \mathrm{ka}$, summer temperatures in Siberia near the present-day Laptev Sea shoreline were higher even than today (Kienast et al., 2005). It is possible that the Siberian shelf region was warmer at that time than during the Last Glacial Maximum, and experienced higher particle fluxes 
due to more seasonally open water, melting out of IRD, or terrigenous particle supply from rivers and exposed shelves. However, planktonic foraminiferal fluxes (figure 7) at this time, calculated by multiplying counts of $N$. pachyderma sinistral per gram (Poore et al., 1999b) by the bulk sediment ${ }^{230} \mathrm{Th}_{\mathrm{xs}}$-normalized sediment flux, decrease when the sediment flux rises. This could indicate either that productivity did not rise during this time (or that our sediments do not in fact date to this warmer interval), or that supply of other types of particle increased.

In the Eastern Arctic, $\mathrm{BC} 28$ shows a slight increase in ${ }^{230}$ Th-normalized mass flux around $30 \mathrm{kyr}$ (Figure 5b). BC 32 shows very little change in sedimentation prior to and during the LGM, possibly due to low sedimentation rates and low temporal resolution. Our record from BC 26 has little or no excess ${ }^{230} \mathrm{Th}$ prior to $\sim 38 \mathrm{kyr}$, resulting in very high calculated Th-normalized sediment fluxes; we do not know whether this represents truly high fluxes or whether these sediments are much older than the horizons above which do contain ${ }^{230} \mathrm{Th}_{\mathrm{xs}}$. The deep, zero-excess samples in $\mathrm{BC} 26$ are also barren of foraminifera, and most have very high coarse fraction content by weight, which could indicate winnowing of fine fraction away from the site. It has been suggested that a thick ice sheet or deep-draft icebergs covered this part of the Arctic during previous glaciations (Jakobsson et al., 2001; Polyak et al., 2001; Kristoffersen, 2004), and during MIS 6 may have planed off the shallowest parts of Lomonosov Ridge, nearby to our sites. If thick ice again covered the Lomonosov Ridge at times during MIS 4-2, this could reduce the amount of water column above the site, and thus reduce local production of ${ }^{230} \mathrm{Th}_{\mathrm{xs}}$. Without any means of dating, it is difficult to interpret these low ${ }^{230} \mathrm{Th}_{\mathrm{xs}}$ values and the 
corresponding high fluxes. BC 26 does have a sudden increase in MAR and in ${ }^{230} \mathrm{Th}$ normalized sediment mass flux prior to the LGM, between 28 and $25 \mathrm{ka}$. Such an event has not been seen in any of our other cores, or in other cores from Lomonosov Ridge (Norgaard-Pedersen et al., 1998, 2003). Above this, ${ }^{230} \mathrm{Th}_{\mathrm{xs}}$ in the late glacial section of the core indicates a strong deficit relative to production, which may be due to a sedimentation hiatus (see Chapter 5 for the ${ }^{231} \mathrm{~Pa} /{ }^{230} \mathrm{Th}$ record from this core), winnowing, or reduction of the water column by thick floating ice sheets.

During the later glacial, the Arctic is thought to have been ice-locked, with few areas of open water (Bradley and England, 2008). Reduced insolation and open water led to reduced productivity, reflected in our cores by low fluxes of planktonic foraminifera (figure 7). Lowered sea level (Fairbanks, 1989) left the wide Siberian shelves high and dry (e.g. Bauch et al., 2005), reducing the area of sea ice production and the amount of sediments entrained in that sea ice. Reduced input of warm Atlantic waters to the Arctic (Knies et al., 1999) may have cooled the subsurface waters, hindering melting of icebergs and thus slowing deposition of ice-rafted debris. All of these factors may have contributed to drastically lowering sedimentation rates across the Western Arctic (Darby et al., 1997; Poore et al., 1999) and north of $84^{\circ} \mathrm{N}$ in the Eastern Arctic (NorgaardPedersen et al., 1998, 2003).

Our records of vertical particle flux from ${ }^{230} \mathrm{Th}_{\mathrm{xs}}$ are consistent with this view of the late glacial Arctic environment. ${ }^{230} \mathrm{Th}_{\mathrm{xs}}$-normalized particle mass fluxes are low in all cores, ranging between 0.2 and $0.5 \mathrm{~g} / \mathrm{cm}^{2} / \mathrm{kyr}$. Agreement with MARs is good for the later part of the glacial (25-15 kyr) in BC 08, and 17, after $20 \mathrm{kyr}$ in $\mathrm{BC} 28$, and from 32- 
$22 \mathrm{kyr}$ in $\mathrm{BC} 20$. In BC 16 and 32, the entire late glacial period is characterized by a ${ }^{230}$ Th-normalized mass flux higher than the age-model-derived MAR. This disagreement between the two estimates of sediment accumulation could be due to sediment winnowing or a depositional hiatus, which would lower the apparent MAR and sedimentary inventory of ${ }^{230} \mathrm{Th}_{\mathrm{xs}}$ (as noted in the discussion of inventories for these two cores) but not affect the concentration of ${ }^{230} \mathrm{Th}_{\mathrm{xs}}$ in an individual sample. Or, it could be due to inefficient scavenging of ${ }^{230} \mathrm{Th}$ from the water column by very low particle fluxes. BC 16 is located nearby to $\mathrm{BC} 08$ and 17 , which do not lack ${ }^{230} \mathrm{Th}_{\mathrm{xs}}$ from the LGM; it most likely experienced a degree of scavenging from the water column similar to these other cores. We therefore believe sediment winnowing may provide the best explanation for the disagreement between ${ }^{230} \mathrm{Th}_{\mathrm{xs}}$-normalized fluxes and MARs at that site. ${ }^{231} \mathrm{~Pa}$ evidence from BC 32 (Chapter 5) suggests that particle scavenging of radionuclides did not differ greatly between the LGM and the Holocene, which may also suggest a winnowing explanation at that site.

Average ${ }^{230}$ Th-normalized sediment fluxes (Figure 8 ) at all of our sites are relatively similar during the late glacial, clustered around $0.4 \mathrm{~g} / \mathrm{cm}^{2} / \mathrm{kyr}$. Vertical sediment supply seems to be relatively constant in the Central Arctic, from west to east, and was low even at $\mathrm{BC} 08$ nearest the shelf. This may suggest that particle-rain gradients were minimal in the water column at that time, consistent with the suggestion that the surface of the Arctic north of $84^{\circ} \mathrm{N}$ was covered by thick, unbroken ice that impeded productivity and IRD deposition (Norgaard-Pedersen et al., 2003; Bradley and England, 2008). The lack of strong particle gradients suggests that boundary scavenging, such as is 
seen for radionuclides in the Pacific (Anderson et al., 1983b) due to particle gradients between central basins and gyres, may not have occurred during the glacial. The similar rates of ${ }^{230} \mathrm{Th}$ production and burial at four of our cores $(\mathrm{BC} 08,17,20,28)$ during the late glacial are consistent with this supposition, as they suggest little lateral export of ${ }^{230} \mathrm{Th}$ in the water column above these sites. However, the average late glacial ${ }^{230} \mathrm{Th}-$ normalized fluxes from the three sites where we see a glacial deficit in ${ }^{230} \mathrm{Th}_{\mathrm{xs}}$ inventory, BC 16, 26 and 32, are slightly higher than fluxes at the other sites, which could be a sign of reduced scavenging of ${ }^{230} \mathrm{Th}$ in the water column at these sites.

\section{iv. Deglacial Sediment Fluxes}

${ }^{230} \mathrm{Th}_{\mathrm{xs}}$-normalized particle mass fluxes increase sharply within the deglacial sections of all cores in the Western Arctic, corresponding to drops in the concentration of ${ }^{230} \mathrm{Th}_{\mathrm{xs}}$. Foraminiferal fluxes (Figure 7), normalized to ${ }^{230} \mathrm{Th}_{\mathrm{xs}}$, also rise sharply at the deglacial in $\mathrm{BC} 16$ and 17, suggesting increased productivity and more open water above these sites at the deglacial. This increase in vertical sediment supply to our sites is also likely due to increased input of terrigenous particles, consistent with deglacial/early Holocene increases in ${ }^{230} \mathrm{Th}$-normalized flux of ${ }^{232} \mathrm{Th}$, derived from the terrigenous detrital component of the sediments, to the seafloor (Figure 9a and b). As sea level rose (Fairbanks, 1989), the broad Siberian shelves were flooded (e.g., Bauch et al., 2005), which may have destabilized and remobilized sediments from the shelf-slope break. If sediments were transported out to our sites in surface currents or in sea ice formed on the newly-flooded shelves, these particles would reach our sites by sinking vertically and 
increase the ${ }^{230} \mathrm{Th}$-normalized flux. ${ }^{230} \mathrm{Th}_{\mathrm{xs}}$-normalized sediment fluxes also rise in our Eastern cores BC 28 and 32, and slightly in BC 26. However, in 28 and 32, the peak appears to come a little bit later than in the Western Arctic, with the largest increase coming around $10 \mathrm{ka}$; the increase in vertical particle flux in these cores is thus better considered an early Holocene change rather than a deglacial change.

Age-model-derived MARs increase sharply at the deglacial in our four Western Arctic cores (Figure 5a), giving much higher estimates for the rate of sediment input to these sites than do our ${ }^{230} \mathrm{Th}$-normalized fluxes. This, and our ${ }^{230} \mathrm{Th}_{\mathrm{xs}}$ inventories from the deglacial sections of these cores, suggest another side to deglacial sedimentation in addition to vertical flux: major lateral sediment redistribution in the Makarov Basin at this time. ${ }^{230} \mathrm{Th}_{\mathrm{xs}}$ inventories in deglacial-dated sediments are much too large to be attributed only to local ${ }^{230} \mathrm{Th}$ production in seawater. We do not find evidence for a similar event at our sites in the Eastern Arctic. MARs in BC 26 are generally lower than the ${ }^{230}$ Th- normalized sediment fluxes, suggesting winnowing of sediments from the ridge crest, while in BC 28 the rise in early Holocene MAR agrees well with the ${ }^{230} \mathrm{Th}$ normalized sediment flux, an indication of minimal lateral sediment redistribution.

\section{v. Deglacial ${ }^{230}$ Th and lateral transport}

In three of the Western Arctic cores (BC 08, 16, 17), the base of the dated deglacial interval of high MAR overlaps with the falling ${ }^{230} \mathrm{Th}_{\mathrm{xs}}$ concentrations following the glacial ${ }^{230} \mathrm{Th}_{\mathrm{xs}}$ peak, which presumably reflects low glacial sedimentation rates. Thus it appears that ${ }^{230}$ Th-normalized vertical sediment fluxes begin to rise slightly after the 
onset of high mass accumulation rates. This apparent lag of the ${ }^{230}$ Th-normalized sediment fluxes is consistent with bioturbation, which might mix high- ${ }^{230} \mathrm{Th}_{\mathrm{xs}}$ glacial sediments into newly accumulating low- ${ }^{230} \mathrm{Th}_{\mathrm{xs}}$ deglacial sediments. Bioturbation has been shown to mix surface sediments in these cores to depths of several $\mathrm{cm}$ (Clough et al., 1997), and appears responsible for blurred contacts between layers in BC 16, although this is less of an issue in BC 17 (Poore et al., 1999a). LGM sediments in the Central Arctic contain very few foraminifera (Darby et al., 1997; Poore et al., 1999a,b; Norgaard-Pedersen et al., 2003). Bioturbation could therefore create a mixed deglacial/glacial ${ }^{230} \mathrm{Th}_{\mathrm{xs}}$ concentration profile over several $\mathrm{cm}$ between the glacial and deglacial core sections without producing older radiocarbon ages: few older foraminifera are present to be mixed upwards (Peng and Broecker, 1984). Deglacial-aged forams could be mixed downwards into the glacial section, however, leading to the appearance of deglacial ages and $\delta^{18} \mathrm{O}$ signals within sediments which otherwise show a glacial signal in thorium concentration.

However, we do not believe that our deglacial sediment focusing signal is merely an artifact of bioturbation. Cores from the Eastern Arctic today show rates of bioturbation similar to cores from the Western Arctic (Clough et al., 1997), yet do not show similar intervals of rapid apparent sedimentation rate (Darby et al., 1997; Norgaard-Pedersen et al., 1998). Furthermore, few reversals in radiocarbon age are seen at the deglacial in our cores: only one published age model, that of Darby et al. (1997) for BC 17, includes a deglacial age reversal, but the coarse fraction weight percent record for that subcore 
shows an uncharacteristic peak in the dated interval, suggesting that a discrete burrow may disrupt the record at that depth in that subcore.

The high ${ }^{230} \mathrm{Th}_{\mathrm{xs}}$ inventories at the base of the deglacial inventory are not responsible for the entire surplus inventory of ${ }^{230} \mathrm{Th}_{\mathrm{xs}}$ which we consider evidence for lateral focusing of sediment to these sites. Even if we assume that our lowest measured ${ }^{230} \mathrm{Th}_{\mathrm{xs}}$ concentrations from the deglacial represent the true deglacial thorium signal, and assign those values to the entire deglacial section of each core (see sensitivity test in Table 1), we still find that ${ }^{230} \mathrm{Th}_{\mathrm{xs}}$ inventories remain higher than the expected production from the water column, requiring an additional input of ${ }^{230} \mathrm{Th}$ to these sites through lateral sedimentary transport.

Another possibility to explain the pattern of Th deposition in the rapidlyaccumulating deglacial sections is that lateral transportation and deposition of sediment, which influenced the MAR, did just barely lead changes in productivity and ice rafting, which influenced the ${ }^{230}$ Th-normalized sediment mass flux. A box model of particle scavenging, aggregation and sinking (Thomas et al., 2006) suggests that ${ }^{230} \mathrm{Th}$ adsorbed to sinking particles appears to equilibrate with the last water mass that the particles come in contact with before deposition. Sediments traveling in nepheloid layers thus may still show ${ }^{230} \mathrm{Th}$ signals characteristic of their final deposition locale. If this is the case, then when sediment particles in a deep current enter a region with small vertical particle fluxes (and hence high ${ }^{230} \mathrm{Th}$ concentration in the water column), those particles may equilibrate and adsorb large amounts of ${ }^{230} \mathrm{Th}$ before deposition, leading to high ${ }^{230} \mathrm{Th}$ concentrations at the base of the deglacial high-MAR event. However, surface conditions as revealed by 
stable isotopic records from planktonic foraminifera (Poore et al., 1999a and b) change when the MAR changes, rather than when the ${ }^{230} \mathrm{Th}$ changes, suggesting that surface conditions likely to lead to higher vertical particle fluxes do not lag behind the change in deep lateral transportation. Bioturbation is thus a likelier explanation for the offset between the deglacial ages and the rise of ${ }^{230} \mathrm{Th}$-normalized fluxes.

vi. Holocene ${ }^{230} T h_{x s}$ and MARs

In the Western Arctic, following the end of the deglaciation at $\sim 11 \mathrm{ka},{ }^{230} \mathrm{Th}_{\mathrm{xs}}$ normalized mass flux in $\mathrm{BC} 16,17$, and 20 drops off gradually throughout the Holocene section (figure 5a). ${ }^{230} \mathrm{Th}_{\mathrm{xs}}$-normalized fluxes of planktonic foraminifera (fig 7), which jumped during the deglacial, remain high but variable through the Holocene in $\mathrm{BC} 16$ and 17. In $\mathrm{BC} 08$, which contains a second interval of sediment focusing at $8 \mathrm{ka}$, the foram flux remains high until this event, drops off sharply within the focused sedimentary interval, and then drops gently through the remainder of the Holocene. Our results suggest that productivity remained relatively high by central Arctic standards through the Holocene, possibly due to seasonally open leads in the ice.

In the Eastern Arctic, ${ }^{230} \mathrm{Th}$-normalized sediment mass fluxes and MARs peak in the earliest Holocene in BC 28 and 32, dropping off thereafter (Figure 5b). Overall agreement between ${ }^{230}$ Th-normalized flux and MAR is reasonably good, especially compared to the peak differences in the Western Arctic. Although some sediment redistribution may have occurred at our eastern sites during the early Holocene, it was minimal. No intervals of very high (by central Arctic standards) sedimentation rates, as 
determined by multiple horizons dated by radiocarbon to the deglacial, are obvious in Eastern Arctic cores as they are in Makarov Basin cores (Norgaard-Pedersen et al., 1998). If sediment redistribution occurred, it was not on a rapid and regional scale, as the focusing event in the Makarov Basin was.

Average ${ }^{230}$ Th-normalized mass fluxes in the late Holocene (6 ka-present) in the Eurasian Basin (BC 28 and 32) are approximately $0.75 \mathrm{~g} / \mathrm{cm}^{2} / \mathrm{kyr}$, while average mass fluxes in the Makarov Basin are around $0.42 \mathrm{~g} / \mathrm{cm}^{2} / \mathrm{kyr}$ (figure 8). Slightly higher sediment accumulation in the Eastern Arctic than in the Western is consistent with longterm regional trends in sedimentation (Sellén \& Jakobssen, 2008). Our eastern Arctic average sediment fluxes are an order of magnitude lower than wintertime fluxes found by Fahl and Nöthig (2007) in sediment traps next to the Lomonosov Ridge; however, their sediment traps are located very close to the Laptev Shelf break, a major source of sediments both carried in sea ice and in discharge from the Lena River. Fahl and Nöthig (2007) found a higher sediment flux in their deep trap than in their shallow trap, suggesting that lateral sediment transport along Lomonosov Ridge does occur at least on shorter timescales, despite our well-balanced overall Holocene ${ }^{230}$ Th-normalized fluxes and MARs in $\mathrm{BC} 28$ on the flank of the ridge further away from the shelf.

vii. Relationship of foraminiferal $\delta^{18} O$ and surface conditions to particle fluxes

We compare our ${ }^{230} \mathrm{Th}$-normalized mass fluxes to records of surface and nearsurface oceanographic conditions derived from planktonic foraminiferal stable oxygen records (figures 10a and 10b), to understand shifts in sedimentation patterns in a larger 
paleoceanographic context. Planktonic oxygen stable isotopes from the Arctic are thought to record surface or near-surface salinity, particularly meltwater inputs from isotopically light land-based ice (Stein et al., 1994; Norgaard-Pedersen et al., 1998; Poore et al., 1999a). A meltwater peak in the Western Arctic at $~ 14$ kyr has been suggested to coincide with Meltwater Pulse 1a (Poore et al., 1999a) during the deglaciation; a foraminiferal $\mathrm{Ba} / \mathrm{Ca}$ record from $\mathrm{BC} 17$ (Hall and Chan, 2004) suggests that the meltwater from this event originated from the Laurentide Ice Sheet and was transported to the sea through the Mackenzie River system. Meltwater events have also been observed in $\delta^{18} \mathrm{O}$ records from the Eastern Arctic (Stein et al., 1994; Norgaard-Pedersen et al., 1998) but are smaller in magnitude than in the Western Arctic. In general, Western Arctic $\delta^{18} \mathrm{O}$ values during the glacial are isotopically depleted, and become enriched over the course of the deglaciation and Holocene (opposite to the global ice-volume effect on $\delta^{18} \mathrm{O}$ ), while Eastern Arctic $\delta^{18} \mathrm{O}$ records are enriched during the glacial and depleted in the Holocene. This gradient between east and west may be due to increased presence of salty, isotopically enriched Atlantic Water on the eastern side of the basin closer to Fram Strait, and to the Beaufort Gyre circulation in the Western Arctic, which may trap meltwater and river runoff in that basin while in the East, the Transpolar Drift drives export of freshwater out of the basin (Spielhagen et al., 1994).

Comparison of our ${ }^{230} \mathrm{Th}$-normalized sediment mass fluxes to $\delta^{18} \mathrm{O}$ records shows a general similarity in the Western Arctic cores: depletions in $\delta^{18} \mathrm{O}$ indicating meltwater peaks, generally coincident with sharp rises in MAR, occur slightly downcore from the ${ }^{230}$ Th-normalized sediment mass flux, although given the high sedimentation rates during 
these intervals this implies a time offset of only a few centuries at most. At BC 28 on the Lomonosov Ridge, $\delta^{18} \mathrm{O}$ is depleted at $11 \mathrm{kyr}$ just before the rise in Th-normalized mass flux, shows a small enrichment corresponding to the peak of the mass flux, and is slightly depleted again above the mass flux peak. Errors associated with age model construction are too small to explain the apparent lag of this change behind similar changes in the Western Arctic, which occur between 15 and 12 ka. BC 32 shows little isotopic variation preceding the ${ }^{230}$ Th-normalized mass flux peak, and a trend towards enrichment which begins during the peak in mass flux. $\delta^{18} \mathrm{O}$ in BC 26 was enriched during the glacial, became depleted during the rapid sedimentation rate increase in that core at $28 \mathrm{ka}$, and then slowly became slightly more enriched over the remainder of the record in that core, with one depletion event in the late Holocene.

Our Makarov Basin records in cores BC 08, 16, 17 and 20 suggest that both vertical and lateral sediment supply to the seafloor increased at the same time that Laurentide Ice Sheet meltwater flooded the surface of the western Arctic during the deglaciation. Productivity may have remained relatively high by central Arctic standards through the Holocene, possibly due to seasonally open leads in the ice, in contrast to the much more ice-choked conditions of the late glacial. Bulk particle fluxes that peaked during the deglacial, when shelves were first becoming inundated and ice sheets were collapsing, may have decreased through the Holocene as the ice sheets disappeared and as sea-level-driven shelf sediment destabilization tapered off. It is unclear why our sites in the Eastern Arctic experience an increase in ${ }^{230} \mathrm{Th}_{\mathrm{xs}}$-normalized mass flux and MAR at the start of the Holocene, rather than during the deglacial as in the Makarov Basin, and 
why at $\mathrm{BC} 28$ the jump in ${ }^{230}$ Th-normalized mass flux occurs out of phase with meltwater-driven $\delta^{18} \mathrm{O}$ depletions.

\section{Conclusions}

We measured ${ }^{230} \mathrm{Th}_{\mathrm{xs}}$ in cores from a transect across the Central Arctic in order to examine ${ }^{230} \mathrm{Th}$ budgets, Th-normalized vertical particle fluxes, and lateral sediment transport in this region over the past $35 \mathrm{kyr}$. Inventories and burial rates of ${ }^{230} \mathrm{Th}_{\mathrm{xs}}$ from cores in the Eastern Arctic confirm that production and removal of this nuclide from the water column in the Central Arctic are balanced to the same degree as in the rest of the world ocean. Scavenging by particles in the water column is an efficient means of removing ${ }^{230} \mathrm{Th}$ from a site, relative to water column transport away from a site by advection and eddy diffusion. ${ }^{230} \mathrm{Th}_{\mathrm{xs}}$ in sediments is therefore useful as a paleoceanographic indicator of vertical and lateral sedimentation.

We found that ${ }^{230} \mathrm{Th}_{\mathrm{xs}}$-normalized sediment mass fluxes are generally low during the late glacial, supporting the idea that the Arctic Ocean surface was choked with thick ice. Sedimentary deficits of ${ }^{230} \mathrm{Th}_{\mathrm{xs}}$ during the late glacial in some cores suggest either local sedimentary winnowing or less efficient particle scavenging of ${ }^{230} \mathrm{Th}$. Large amounts of ${ }^{230} \mathrm{Th}_{\mathrm{xs}}$ in deglacial sediments in the Makarov Basin, in excess of water column production, suggest a major sediment redistribution event during deglaciation. In the Makarov Basin, vertical particle fluxes rose during the deglaciation, while in the Amundsen and Nansen Basins fluxes rose at the start of the Holocene, most likely due to a combination of increased productivity, more open waters, increased iceberg supply of 
sediments, and rising sea level drowning the Arctic shelves. Particle fluxes subsequently dropped through the Holocene, possibly reflecting decreased input of terrigenous particles once deglacial sea level rise and ice sheet collapse were complete. 


\section{References}

Anderson, R.F., Bacon, M.P., Brewer, P.G., 1983a. Removal of ${ }^{230} \mathrm{Th}$ and ${ }^{231} \mathrm{~Pa}$ from the open ocean. Earth Planet. Sci. Lett. 62, 7-23.

Anderson, R.F., Bacon, M.P., Brewer, P.G., 1983b. Removal of ${ }^{230} \mathrm{Th}$ and ${ }^{231} \mathrm{~Pa}$ at ocean margins. Earth Planet. Sci. Lett., v. 66, p. 73-90.

Bacon, M.P., 1984. Glacial to interglacial changes in carbonate and clay sedimentation in the Atlantic Ocean estimated from ${ }^{230} \mathrm{Th}$ measurements. Isotope Geoscience v. 2, p. 97-11.

Bacon, M.P., C.-A. Huh, and R.M. Moore, 1989. Vertical profiles of some natural radionuclides over the Alpha Ridge, Arctic Ocean. Earth and Planetary Science Letters v. 95, p. 15-22.

Bauch, H.A., Mueller-Lupp, T., Taldenkova, E., Spielhagen, R.F., Kassens, H., Grootes, P.M., Thiede, J., Heinemeier, J., Petryashov, V.V., 2005. Chronology of the Holocene transgression at the North Siberian margin. Global Planet. Change 31, 125-139.

Bradley, R.S., England, J.H., 2008. The Younger Dryas and the sea of ancient ice. Quat. Res. In press.

Choi, M.S., R. Francois, K. Sims, M.P. Bacon, S. Brown-Leger, A.P. Fleer, L. Ball, D. Schneider, S. Pichat, 2001. Rapid determination of ${ }^{230} \mathrm{Th}$ and ${ }^{231} \mathrm{~Pa}$ in seawater by desolvated micro-nebulization Inductively Coupled Plasma magnetic sector mass spectrometry. Marine Chemistry v. 76, p. 99-112.

Clough, L.M., Ambrose, W.G., Cochran, J.K., Barnes, C., Renaud, P.E., Aller, R.C., 1997. Infaunal density, biomass and bioturbation in the sediments of the Arctic Ocean. Deep-Sea Res. II 44, 1683-1704.

Cochran, J.K., D.J. Hirschberg, H.D. Livingston, K.O. Buesseler, and R.M. Key, 1995. Natural and antropogenic radionuclide distributions in the Nansen Basin, Arctic Ocean: Scavenging rates and circulation timescales. Deep-Sea Research II v. 42, p. $1495-1517$.

Darby, D.A., J.F. Bischof, and G.A. Jones, 1997. Radiocarbon chronology of depositional regimes in the western Arctic Ocean. Deep-Sea Research II v. 44, p. 1745-1757.

Edmonds, H.N., S.B. Moran, J.A. Hoff, J.N. Smith, and R.L. Edwards, 1998. Protactinium-231 and Thorium-230 abundances and high scavenging rates in the Western Arctic Ocean. Science v. 280, p. 405-407.

Edmonds, H.N., S.B. Moran, H. Cheng, R.L. Edwards, 2004. ${ }^{230} \mathrm{Th}$ and ${ }^{231} \mathrm{~Pa}$ in the Arctic Ocean: implications for particle fluxes and basin-scale $\mathrm{Th} / \mathrm{Pa}$ fractionation. Earth and Planetary Science Letters v. 227, p. 155-167.

Fahl, K. and Nöthig, E.-M., 2007. Lithigenic and biogenic particle fluxes on the Lomonosov Ridge (central Arctic Ocean) and their relevance for sediment accumulation: Vertical vs. lateral transport. Deep-Sea Research I v. 54, p. 12561272. 
Fairbanks, R.G., 1989. A 17,000-year glacio-eustatic sea level record: Influence of glacial melting rates on the Younger Dryas event and deep-ocean circulation, Nature 342, 637-642.

Fairbanks, R.G., Mortlock, R.A., Chiu, T.-C., Cao, L., Kaplan, A., Guilderson, T.P., Fairbanks, T.W., Bloom, A.L., 2005. Marine radiocarbon calibration curve spanning 0 to 50,000 years B.P. based on paired ${ }^{230} \mathrm{Th} /{ }^{234} \mathrm{U} /{ }^{238} \mathrm{U}$ and ${ }^{14} \mathrm{C}$ dates on pristine corals. Quat. Sci. Rev. 24, 1781-1796.

Finkel, R., Krishnaswami, S., Clark, D.L., 1977. ${ }^{10}$ Be in Arctic Ocean sediments. Earth Planet. Sci. Lett. 35, 199-204.

Francois, R., M.P. Bacon, and D.O. Suman, 1990. Thorium ${ }^{230}$ profiling in deep sea sediments: High-resolution records of flux and dissolution of carbonate in the equatorial Atlantic during the last 24,000 years. Paleoceanography v. 5, p. 761787.

Francois, R., M. Frank, M.M. Rutgers van der Loeff, and M.P. Bacon, 2004. ${ }^{230} \mathrm{Th}$ normalization: An essential tool for interpreting sedimentary fluxes during the late Quaternary. Paleoceanography v. 19, PA1018, doi:10.1029/2003PA000939.

Hall, J.J. and L.-H. Chan, 2004. Ba/Ca in Neogloboquadrina pachyderma as an indicator of deglacial meltwater discharge into the western Arctic Ocean. Paleoceanography v. 19, PA1017, doi:10.1029/2003PA000910.

Henderson, G.M., C. Heinze, R.F. Anderson, and A.M.E. Winguth, 1999. Global distribution of the ${ }^{230} \mathrm{Th}$ flux to ocean sediments constrained by GCM modeling. Deep-Sea Research I v. 46, p. 1861-1893.

Henderson, G.M., Anderson, R.F., 2003. The U-series toolbox for paleoceanography. Rev. Mineral. Geochem. 52, 493-531.

Hoffmann, S.S. and J.F. McManus, 2007. Is There a ${ }^{230}$ Thorium Deficit in Arctic Sediments? Earth Planet. Sci. Lett. v. 258, p. 516-527.

Hughen, K.A., Baillie, M.G.L., Bard, E., Bayliss, A., Beck, J.W., Bertrand, C.J.H., Blackwell, P.G., Buck, C.E., Burr, G.S., Cutler, K.B., Damon, P.E., Edwards, R.L., Fairbanks, R.G., Friedrich, M., Guilderson, T.P., Kromer, B., McCormac, F.G., Manning, S.W., Bronk Ramsey, C., Reimer, P.J., Reimer, R.W., Remmele, S., Southon, J.R., Stuiver, M., Talamo, S., Taylor, F.W., van der Plicht, J., Weyhenmeyer, C.E., 2004. Marine04 Marine radiocarbon age calibration, 26 - 0 ka BP. Radiocarbon 46, 1059-1086.

Huh, C.-A., N.G. Pisias, J.M. Kelley, T.C. Maiti, and A. Grantz, 1997. Natural radionuclides and plutonium in sediments from the western Arctic Ocean: sedimentation rates and pathways of radionuclides. Deep-Sea Research II v. 44, p. 1725-1743.

Jakobsson, M., Løvlie, R., Arnold, E. M., Backman, J., Polyak, L., Knutsen, J.O., Musatov, E., 2001. Pleistocene stratigraphy and paleoenvironmental variation from Lomonosov Ridge sediments, central Arctic Ocean, Global and Planetary Change, v. 31, no. 1-4, p. 1-21.

Kienast, F., Schirrmeister, L., Siegert, C., Tarasov, P., 2005. Paleobotanical evidence for warm summers in the East Siberian Arctic during the last cold stage. Quat. Res. V. 63, p. 283-300. 
Knies, J., Vogt, C., Stein, R., 1999. Late Quaternary growth and decay of the Svalbard/Barents Sea ice sheet and paleoceanographic evolution in the adjacent Arctic Ocean. Geo-Marine Letters, v. 18, p. 195-202.

Kristoffersen, Y., Coakley, B., Jokat, W., Edwards, M., Brekke, H., Gjengedal, J., 2004. Seabed erosion on the Lomonosov Ridge, central Arctic Ocean: A tale of deep draft icebergs in the Eurasia Basin and the influence of Atlantic water inflow on iceberg motion? Paleoceanography, v. 19, PA3006, doi:10.1029/2003PA000985.

$\mathrm{Ku}$, T.-L., Broecker, W.S., 1967. Rates of sedimentation in the Arctic Ocean. Prog. Oceanog. 4, 95-104.

Mangerud, J., Gulliksen, S., 1975. Apparent radiocarbon ages of recent marine shells from Norway, Spitsbergen, and Arctic Canada. Quat. Res. 5 (1975) 263-273.

McManus, J.F., Francois, R., Gherardi, J.-M., Keigwin, L.D., Brown-Leger, S., 2004. Collapse and rapid resumption of Atlantic meridional circulation linked to deglacial climate changes. Nature 428, 834-837.

Moran, S.B., Shen, C.-C., Edwards, R.L., Edmonds, H.N., Scholten, J.C., Smith, J.N., Ku, T.-L., 2005. ${ }^{231} \mathrm{~Pa}$ and ${ }^{230} \mathrm{Th}$ in surface sediments of the Arctic Ocean: Implications for ${ }^{231} \mathrm{~Pa} /{ }^{230} \mathrm{Th}$ fractionation, boundary scavenging, and advective export. Earth Planet. Sci. Lett., v. ${ }^{234}$, p. 235-248.

Norgaard-Pedersen, N., R.F. Spielhagen, J. Thiede, and H. Kassens, 1998. Central Arctic surface ocean environment during the past 80,000 years. Paleoceanography v. 13, p. 193-204.

Norgaard-Pedersen, N., R.F. Spielhagen, H. Erlenkeuser, P.M. Grootes, J. Heinemeier, and J. Knies, 2003. Arctic Ocean during the Last Glacial Maximum: Atlantic and polar domains of surface water mass distribution and ice cover. Paleoceanography v. 18, 1063 doi:10.1029/2002PA000781.

Ostermann, D.R., Curry, W.B., 2000. Inter-lab mass spectrometer calibration programs. IGBP PAGES/World Data Center A for Paleoclimatology Data Contribution Series \#1999-065. NOAA/NGDC Paleoclimatology Program, Boulder CO.

Peng, T.-H., Broecker, W.S., 1984. The impacts of bioturbation on the age difference benthic and planktonic foraminifera in deep sea sediments. Nuclear Instruments \& Methods in Physics Research, Section B: Beam Interactions with Materials and Atoms, vol.233 [B5], pp.346-352.

Polyak, L., Edwards, M.H., Coakley, B.J., Jakobsson, M., 2001. Ice shelves in the Pleistocene Arctic Ocean inferred from glaciogenic deep-sea bedforms. Nature v. 410, p. 453-456.

Poore, R.Z., L. Ostermann, W.B. Curry, and R.L. Phillips, 1999a. Late Pleistocene and Holocene meltwater events in the western Arctic Ocean. Geology v. 27, p. 759762.

Poore, R.Z., Ostermann, D.R., McGeehin, J., 1999b. Stable isotope data and AMS 14C dates from Arctic Ocean Section 1994 surface sediment transect and box core samples from the Mendeleyev Ridge area. USGS Open-File Report 99-48.

Scholten, J.C., M.M. Rutgers van der Loeff, and A. Michel, 1995. Distribution of ${ }^{230} \mathrm{Th}$ and ${ }^{231} \mathrm{~Pa}$ in the water column in relation to the ventilation of the deep Arctic basins. Deep-Sea Research II v. 42, p. 1519-1531. 
Séllen, E., Jakobsson, M., Backman, J., 2008. Different sedimentary regimes between the Amerasian and Eurasian basins, Arctic Ocean. Global and Planetary Change, v. 61, p. 275-284.

Somayajulu, B.L.K., Sharma, P., Herman, Y., 1989. Thorium and uranium isotopes in Arctic sediments, in: Herman,Y. (Ed.), The Arctic Seas: Climatology, Oceanography, Geology and Biology. Van Nostrand Reinhold Co., New York, pp. 571-579.

Spielhagen,R.F., Erlenkeuser, H., 1994. Stable oxygen and carbon isotopes in planktic foraminifers from Arctic Ocean surface sediments: reflection of the low salinity surface water layer. Mar. Geol. v. 119, p. 227-250.

Stein, R., S.-I. Nam, C. Schubert, C. Vogt, D. Futterer, and J. Heinemeier, 1994. The last deglaciation event in the eastern central Arctic Ocean. Science v. 264, p. 692-696.

Stuiver, M., Reimer, P.J., Reimer, R.W., 2005. Calib 5.0, WWW Program and Documentation.

Suman, D.O., and M.P. Bacon, 1989. Variations in Holocene sedimentation in the North American Basin determined from ${ }^{230} \mathrm{Th}$ measurements. Deep-Sea Research v. 36, p. 869-878.

Thomas, A., Henderson, G., Robinson, L., 2006. Interpretation of the ${ }^{231} \mathrm{~Pa} /{ }^{230} \mathrm{Th}$ paleocirculation proxy: New water-column measurements from the southwest Indian Ocean. Earth Planet. Sci. Lett., v. 241, p. 493-504.

Trimble, S.M., M. Baskaran, D. Porcelli, 2004. Scavenging of thorium isotopes in the Canada Basin of the Arctic Ocean. Earth and Planetary Science Letters v. 222, p. 915-932.

Wetterich, S., Kuzmina, S., Andreev, A.A., Kienast, F., Meyer, H., Schirrmeister, L., Kuznetsova, T., Sierralta, M., in press. Paleoenvironmental dynamics inferred from late Quaternary permafrost deposits on Kurungnakh Island, Lena Delta, Northeast Siberia, Russia. Quat. Sci. Rev., in press.

Yu, E.-F., R. Francois, M.P. Bacon, and A.P. Fleer, 2001. Fluxes of ${ }^{230} \mathrm{Th}$ and ${ }^{231} \mathrm{~Pa}$ to the deep sea: implications for the interpretation of excess ${ }^{230} \mathrm{Th}$ and ${ }^{231} \mathrm{~Pa}{ }^{230} \mathrm{Th}$ profiles in sediments. Earth and Planetary Science Letters v. 191, p. 219-230. 


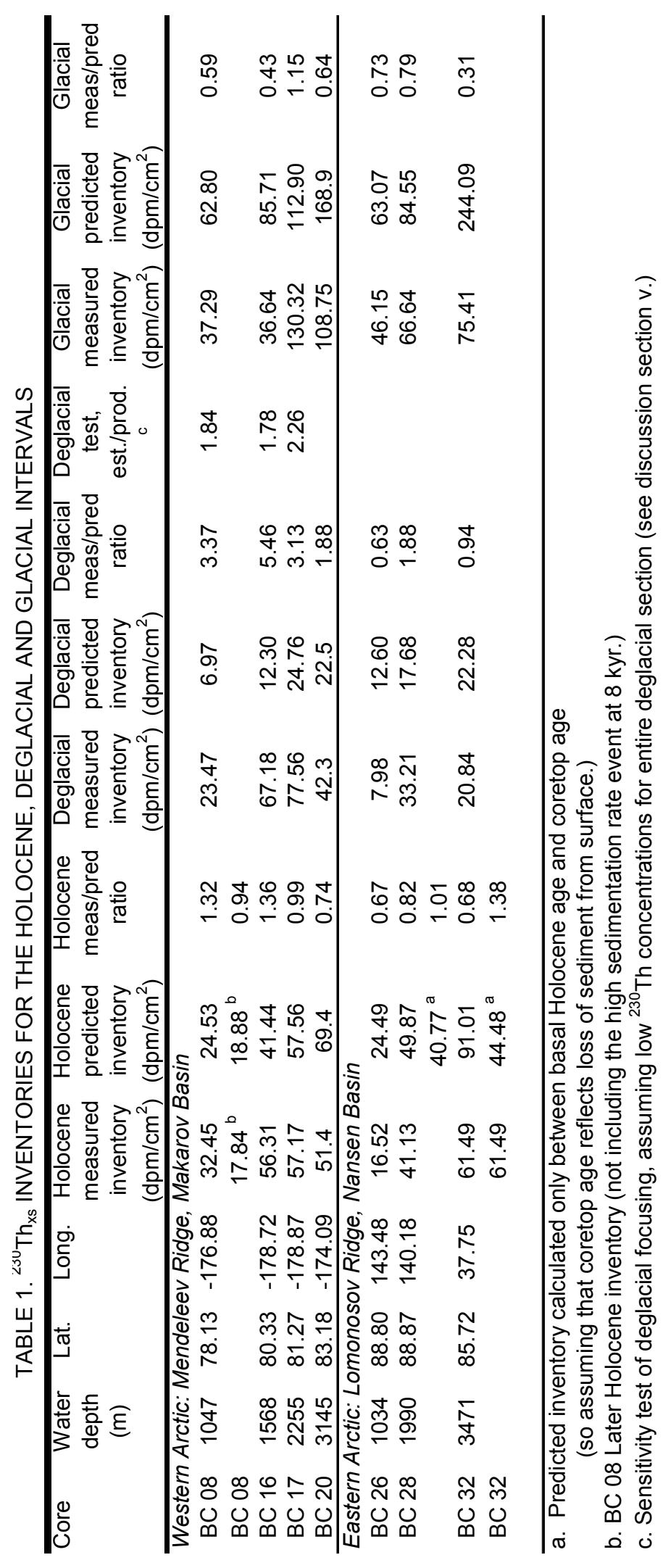




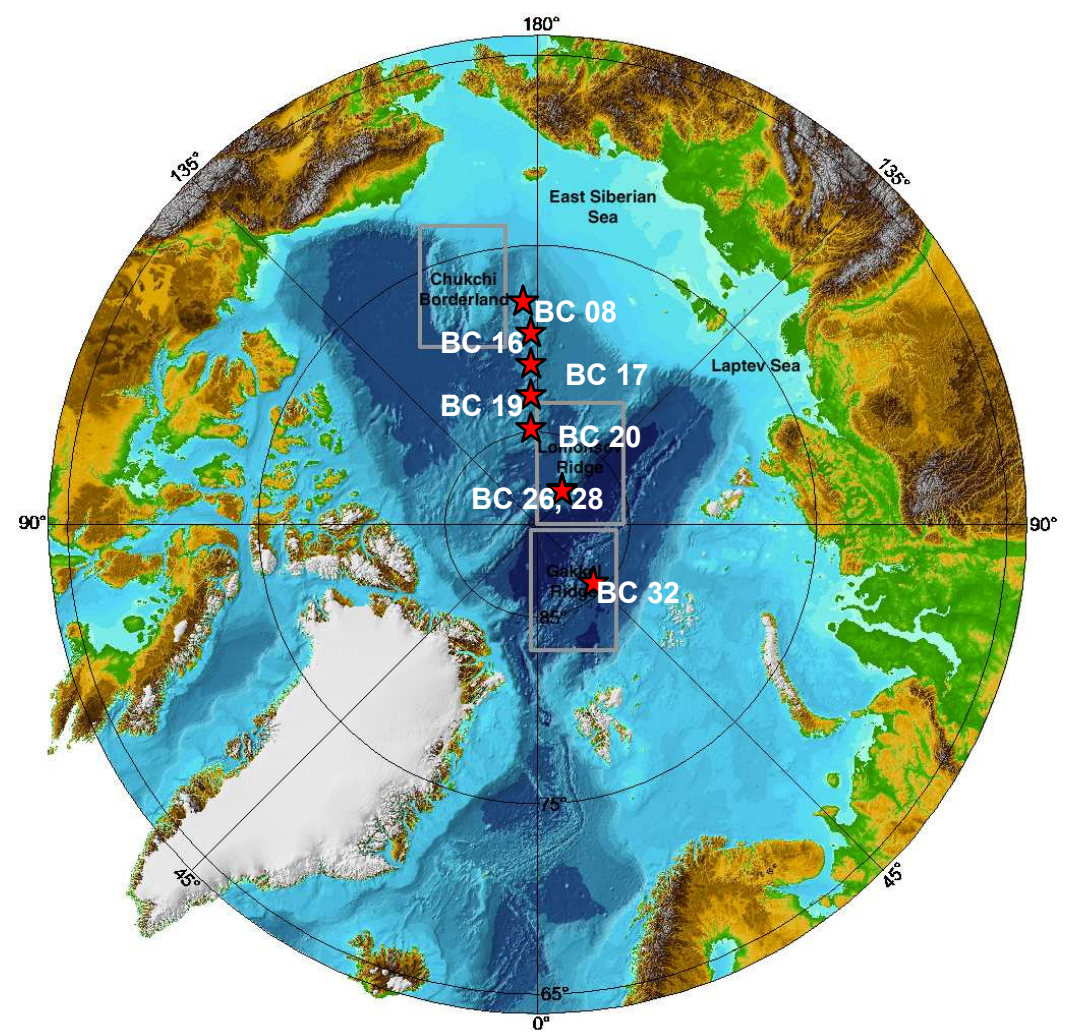

Figure 1: Locations of cores used in this study. Coordinates and water depths are included in Table 1. 

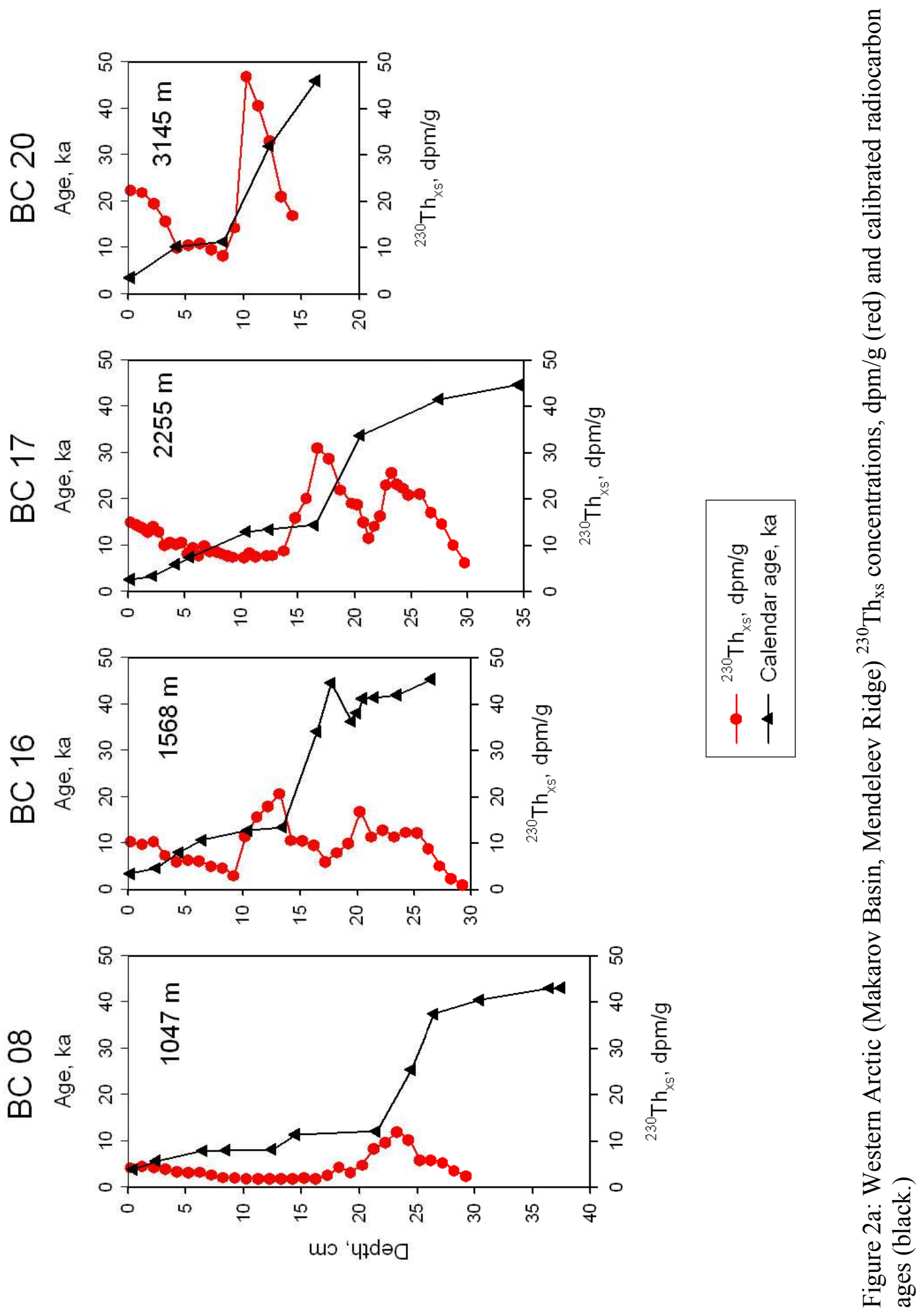

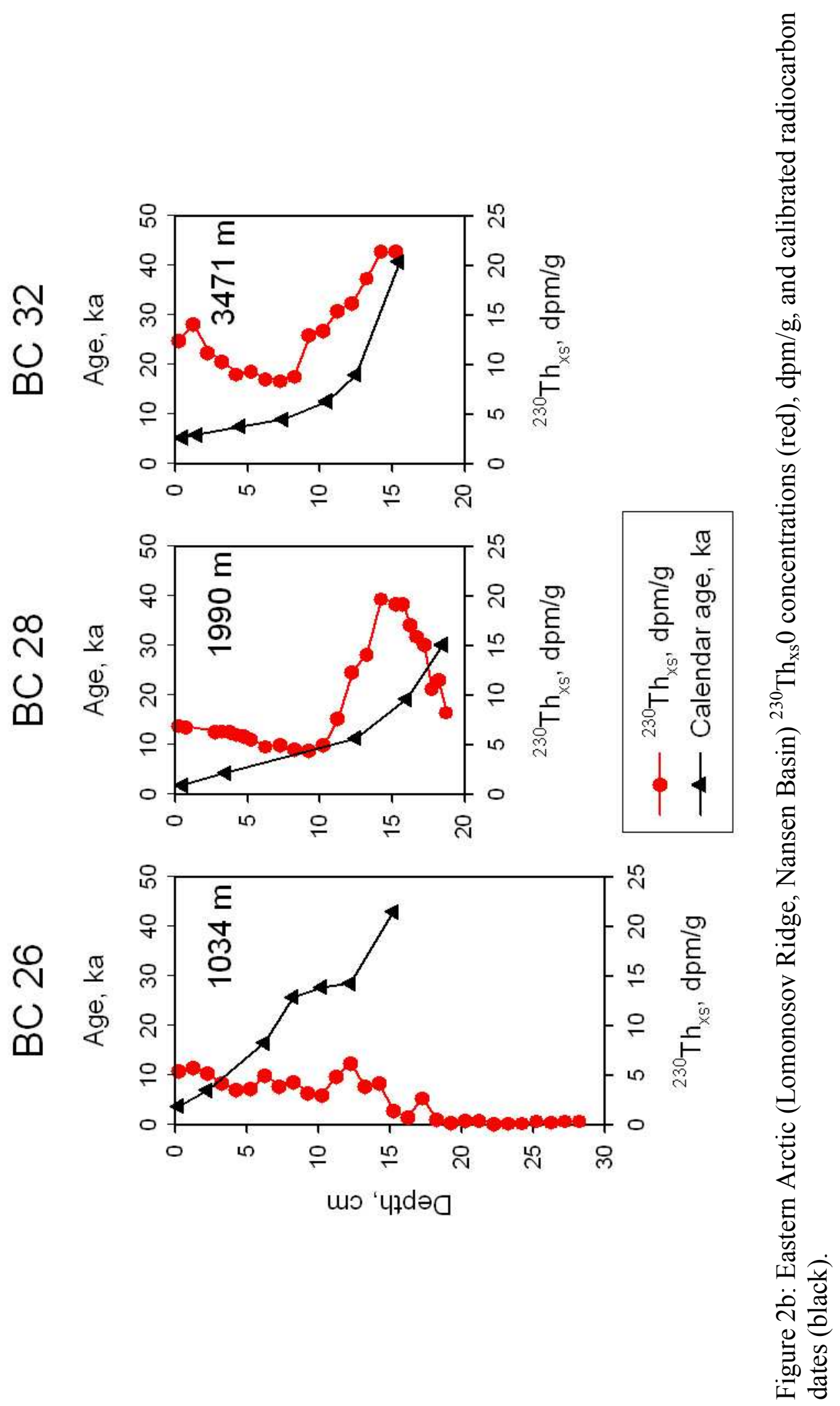

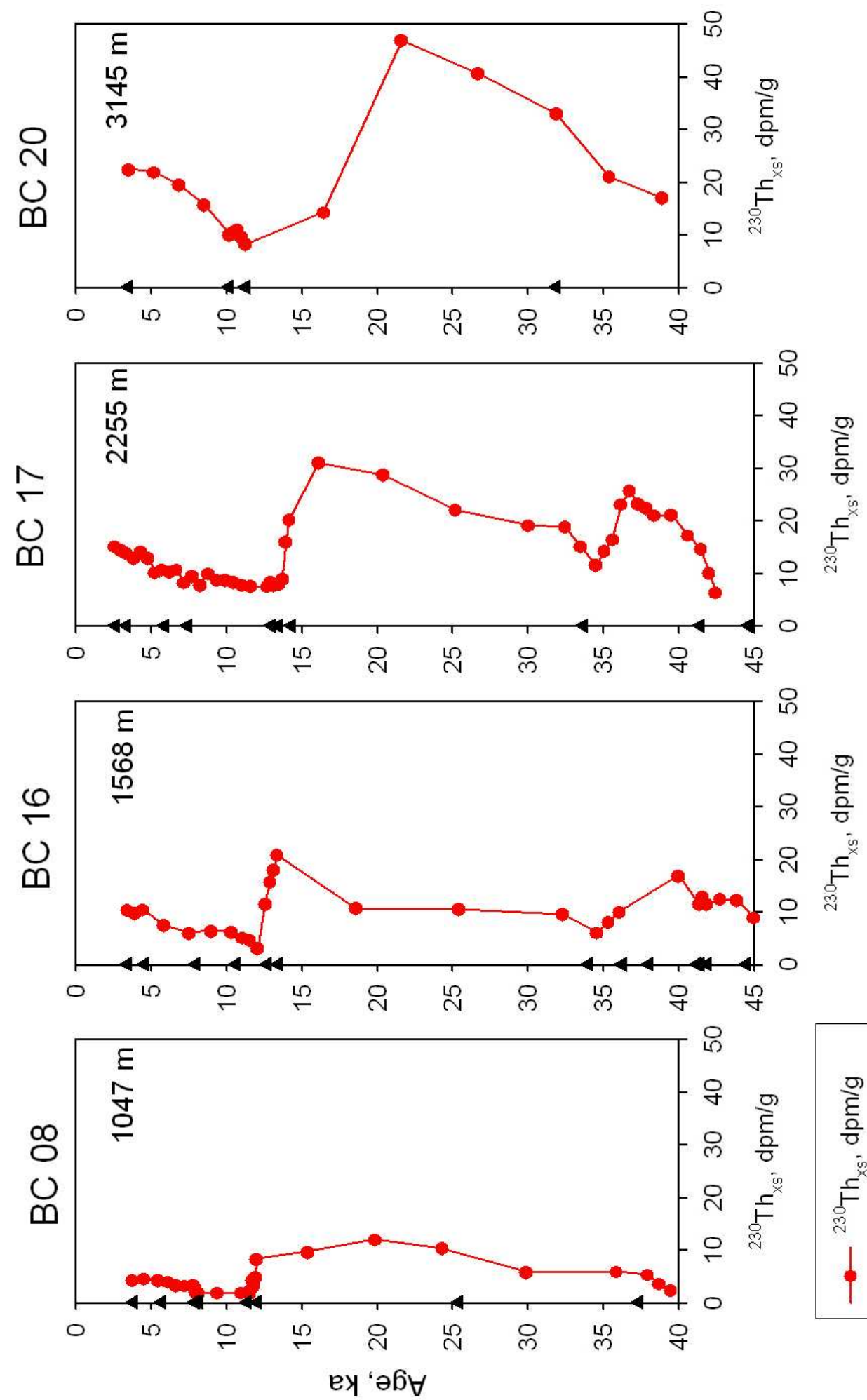

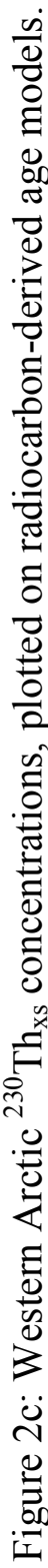




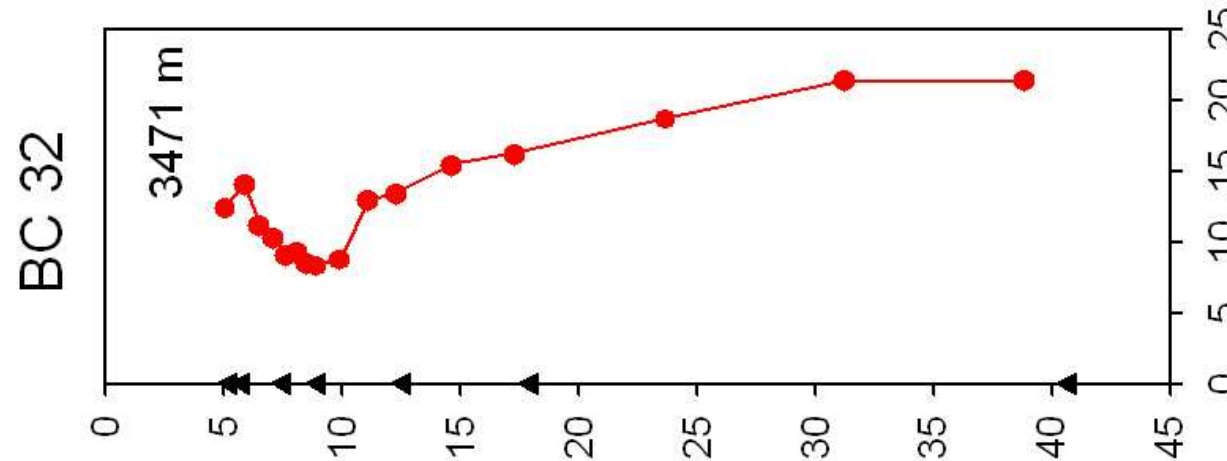

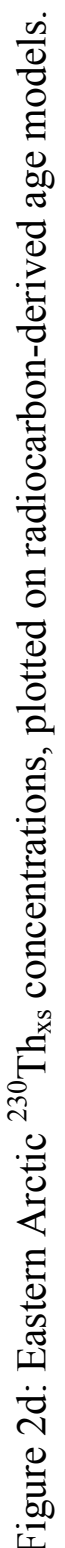

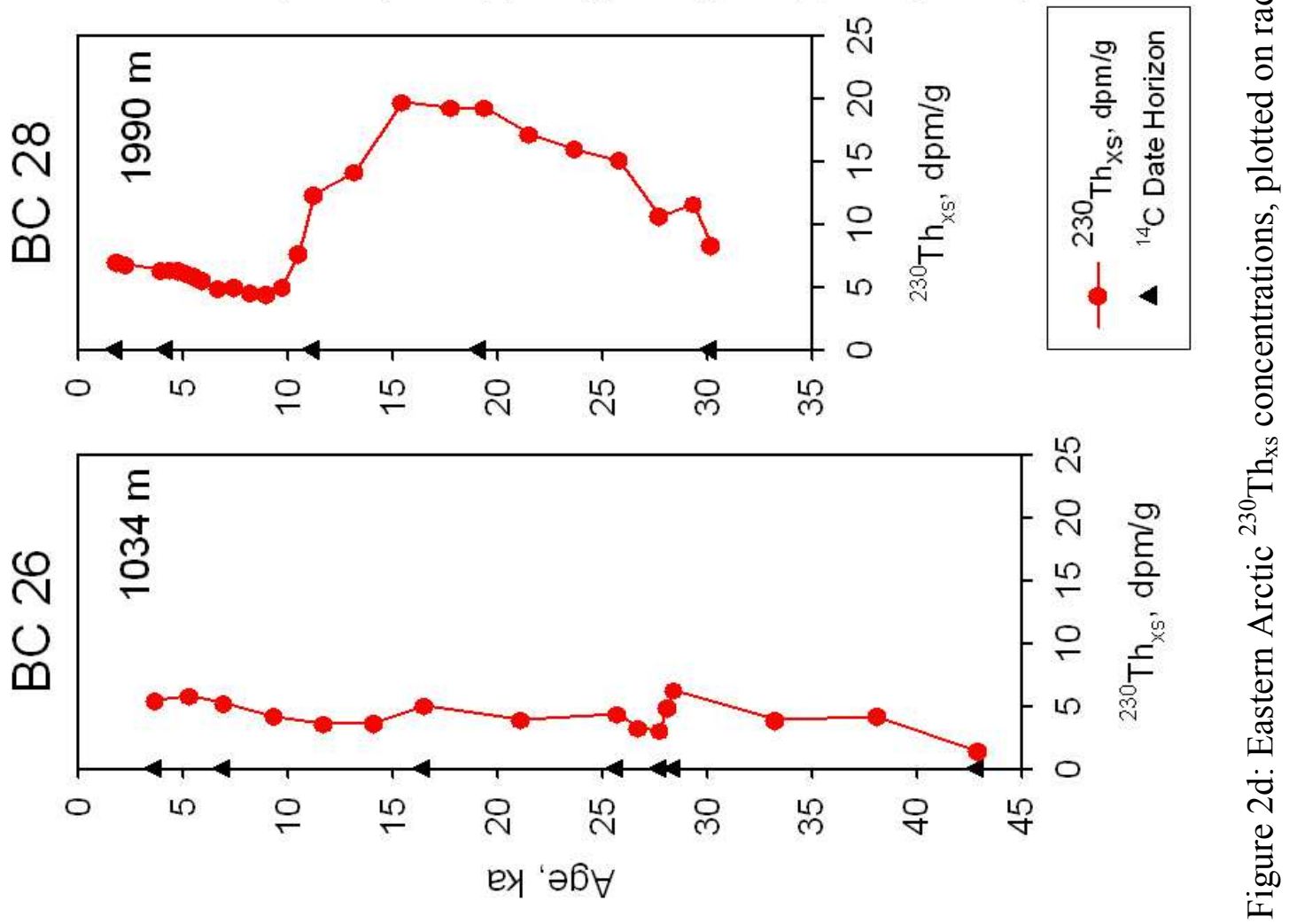




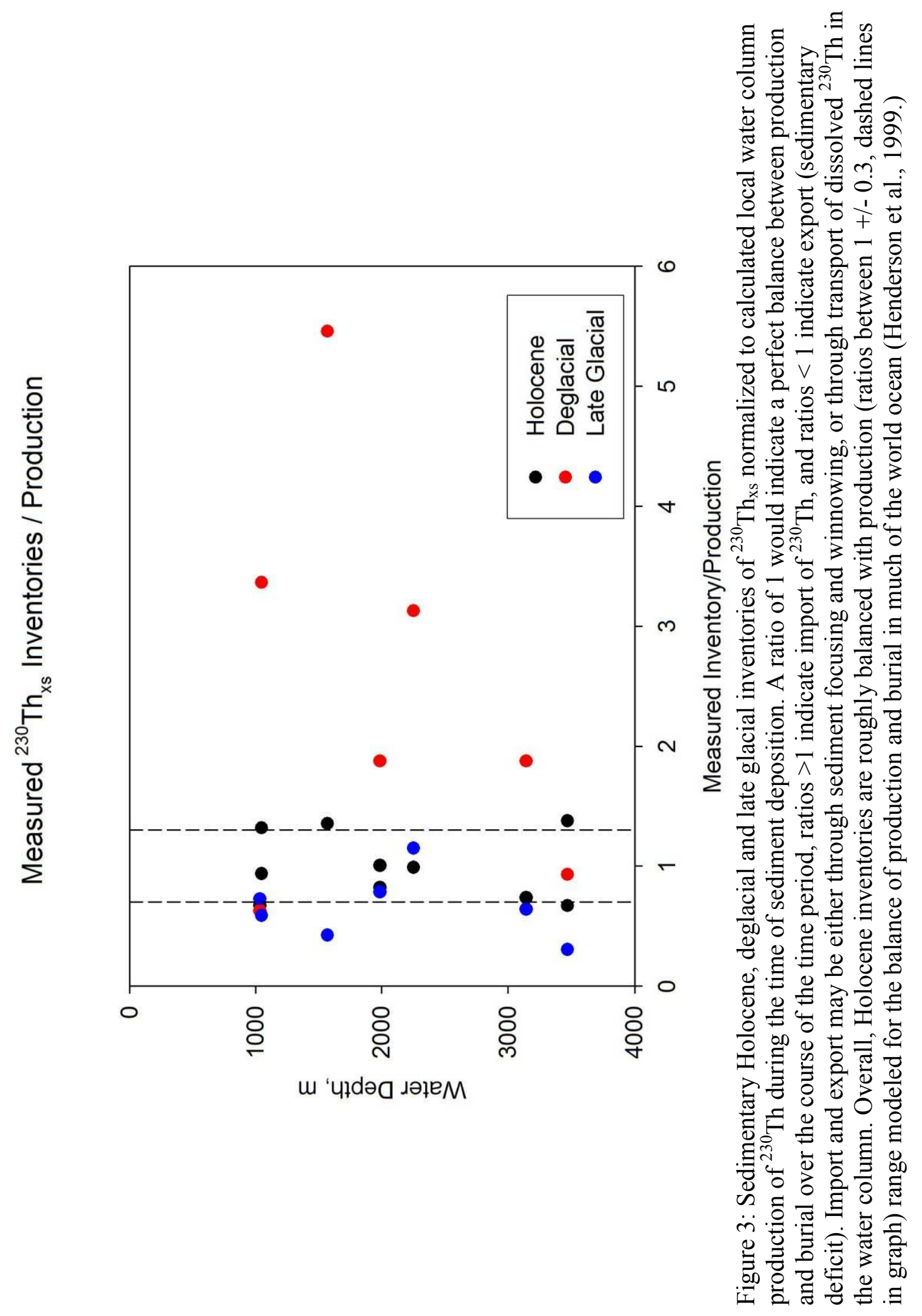



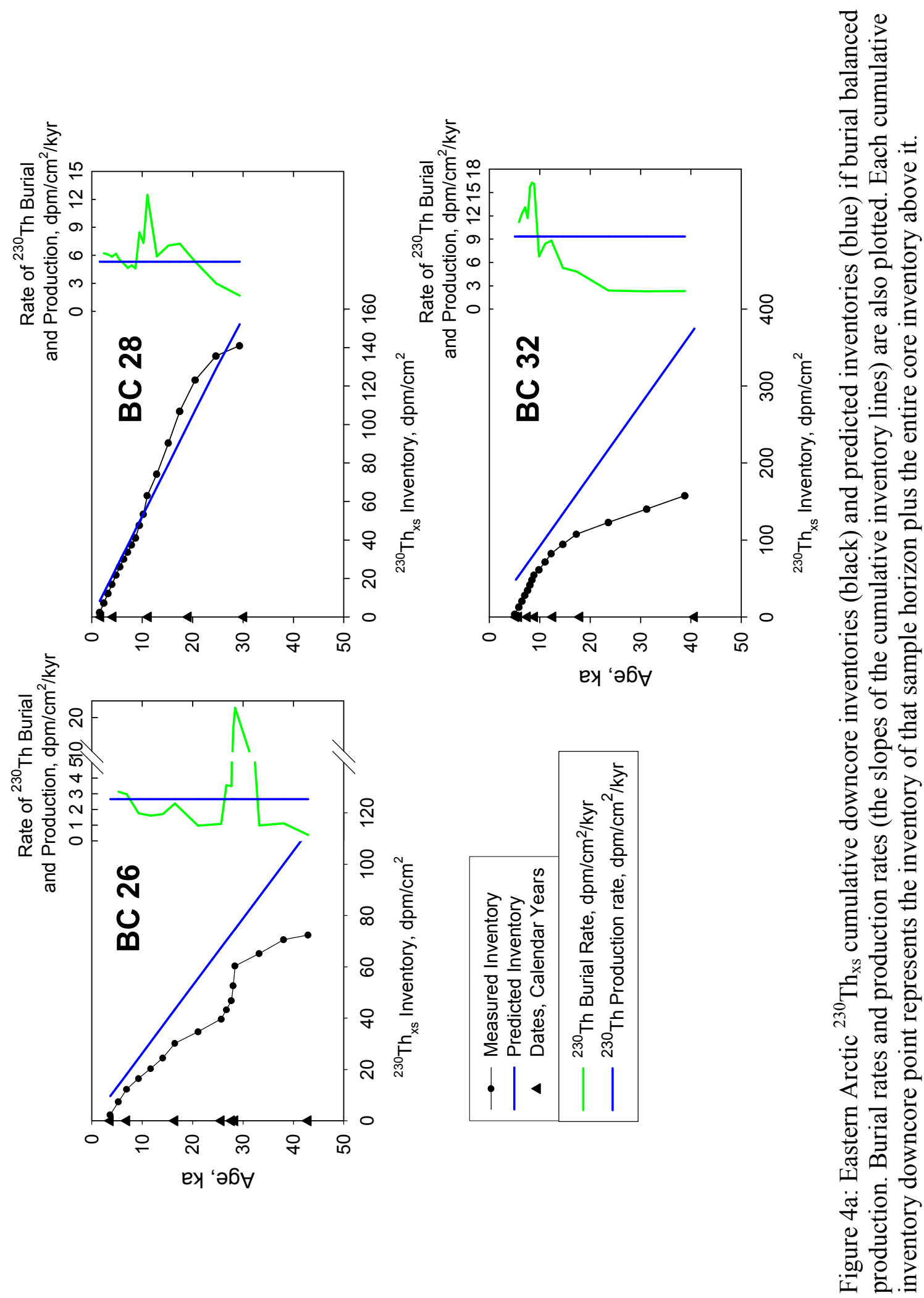

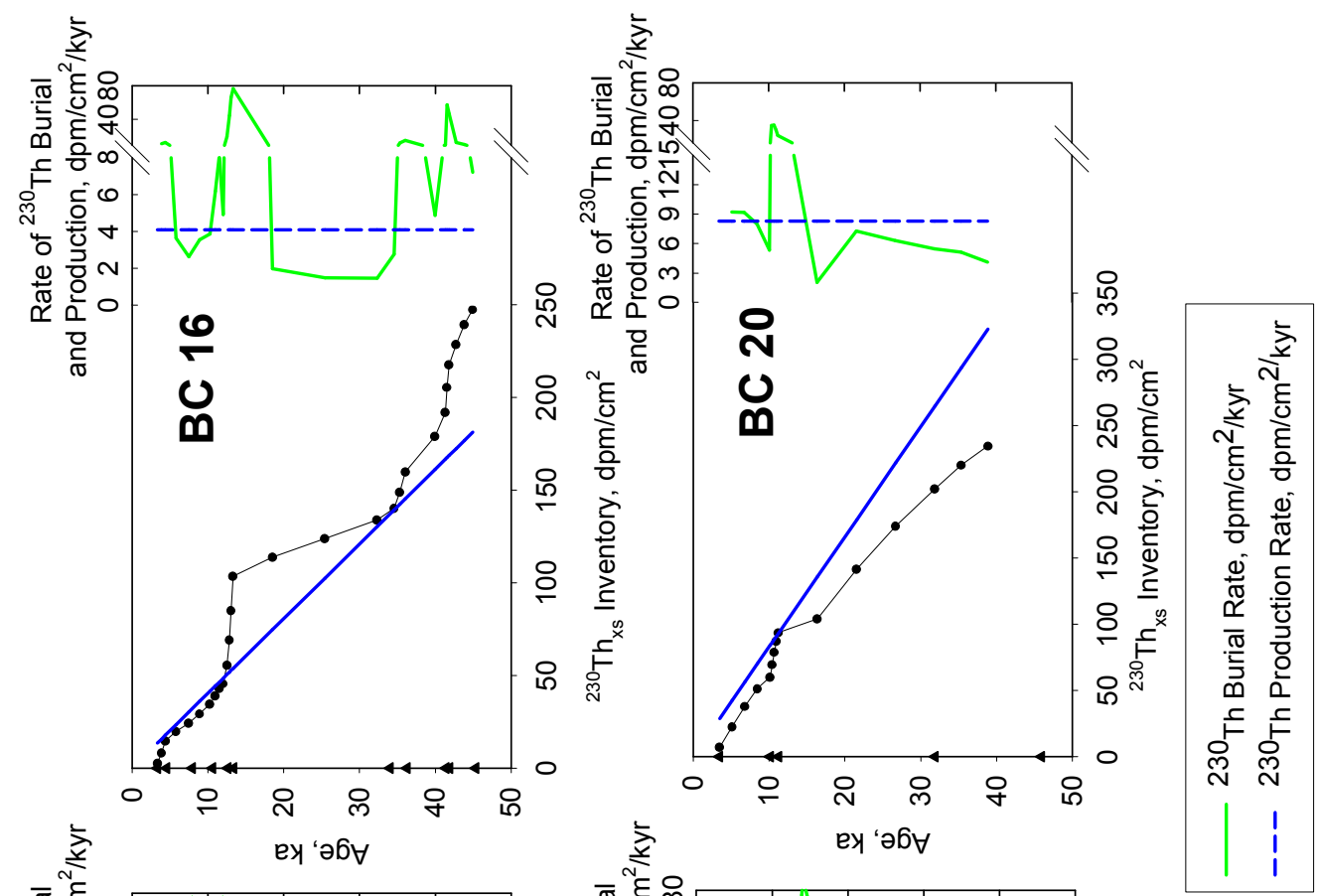

总

를

寻

(ِ)

르응

कै 음

응 을

을 主

ఏ

7 o

.

चृ

르윰

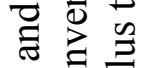

중

총 옹

늘

ช छ

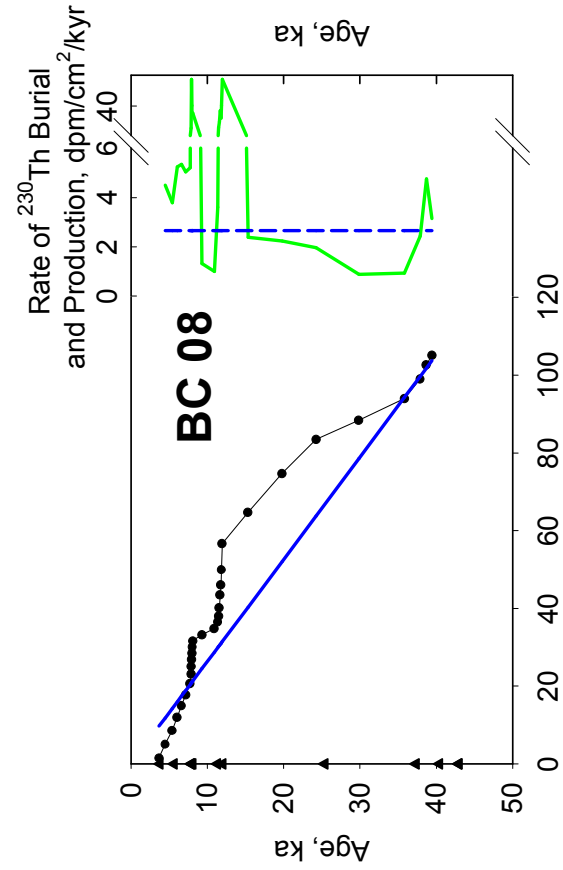

)

党

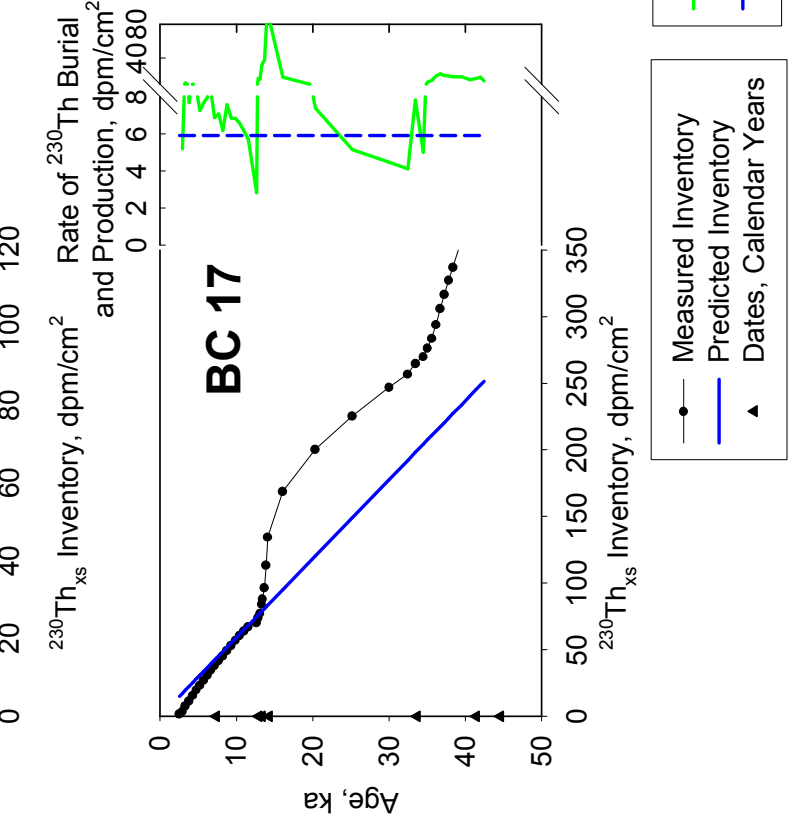

을 छ

费范

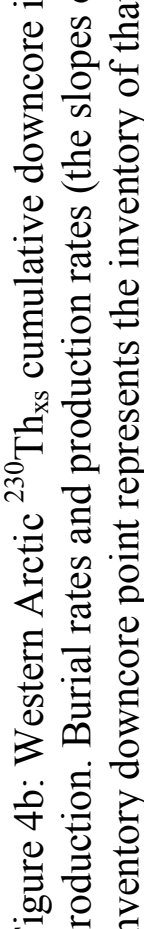

玒 


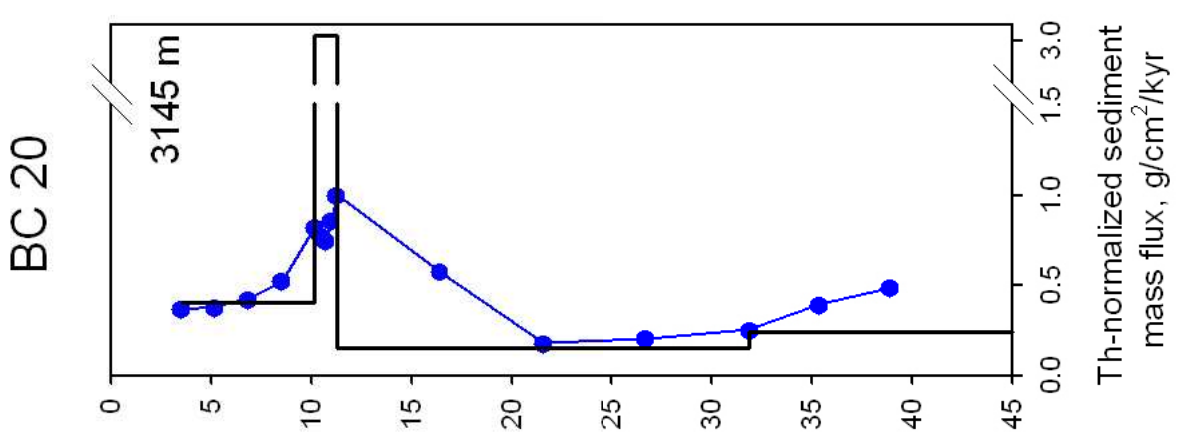

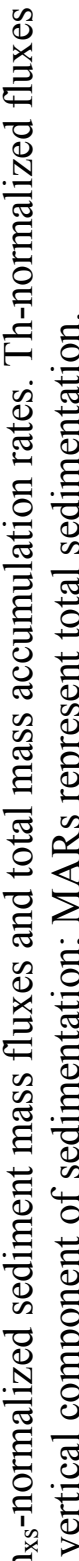
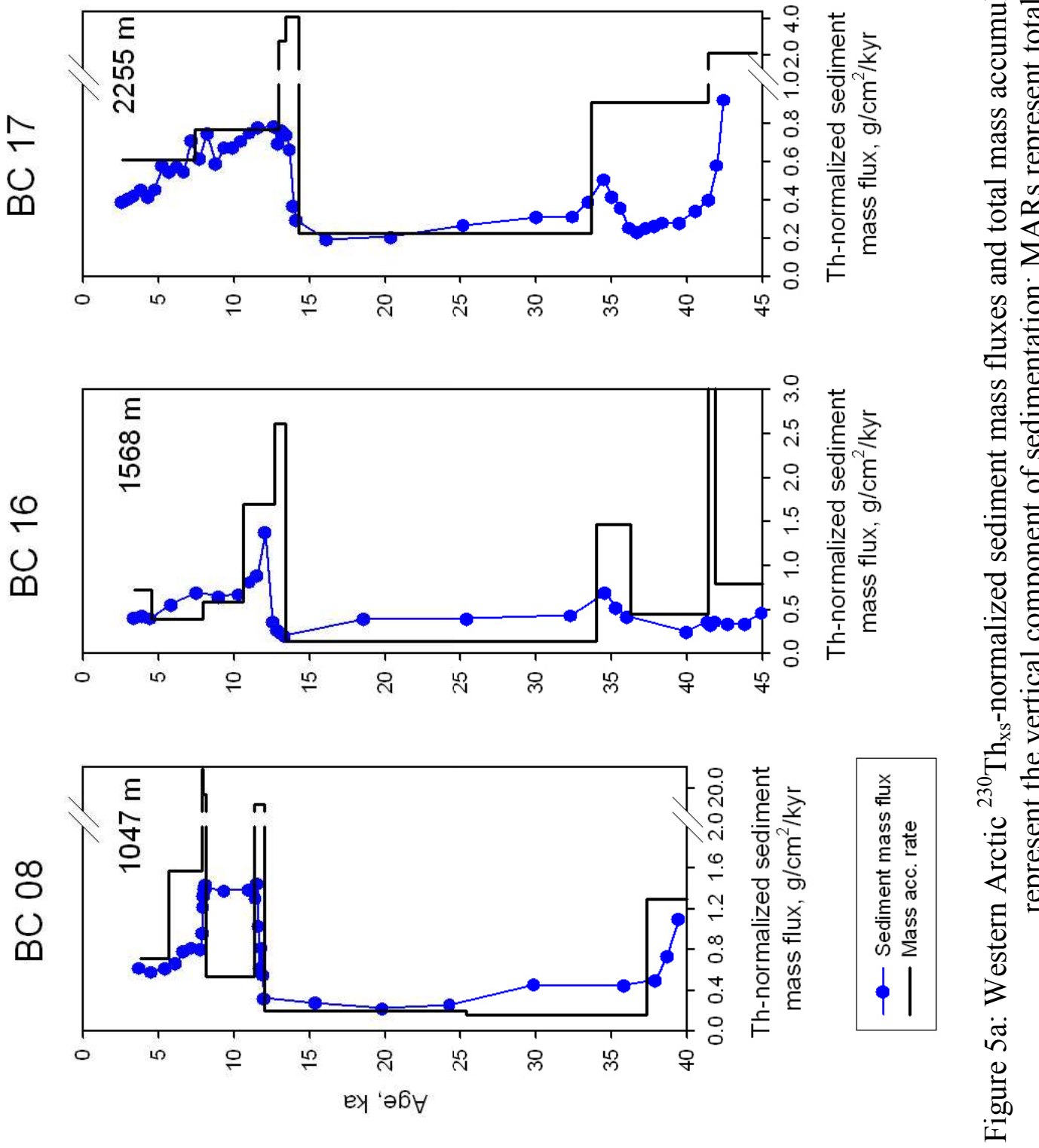


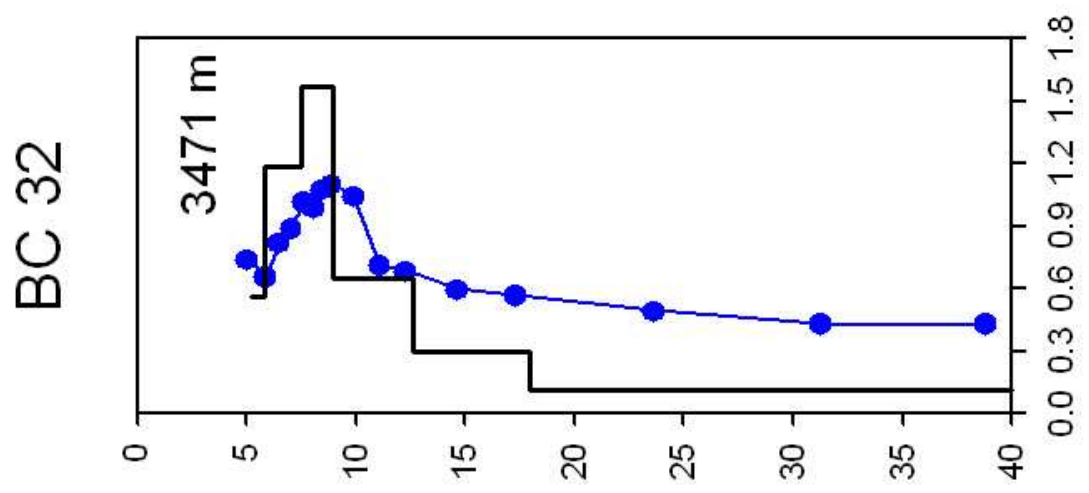

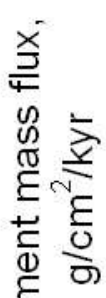
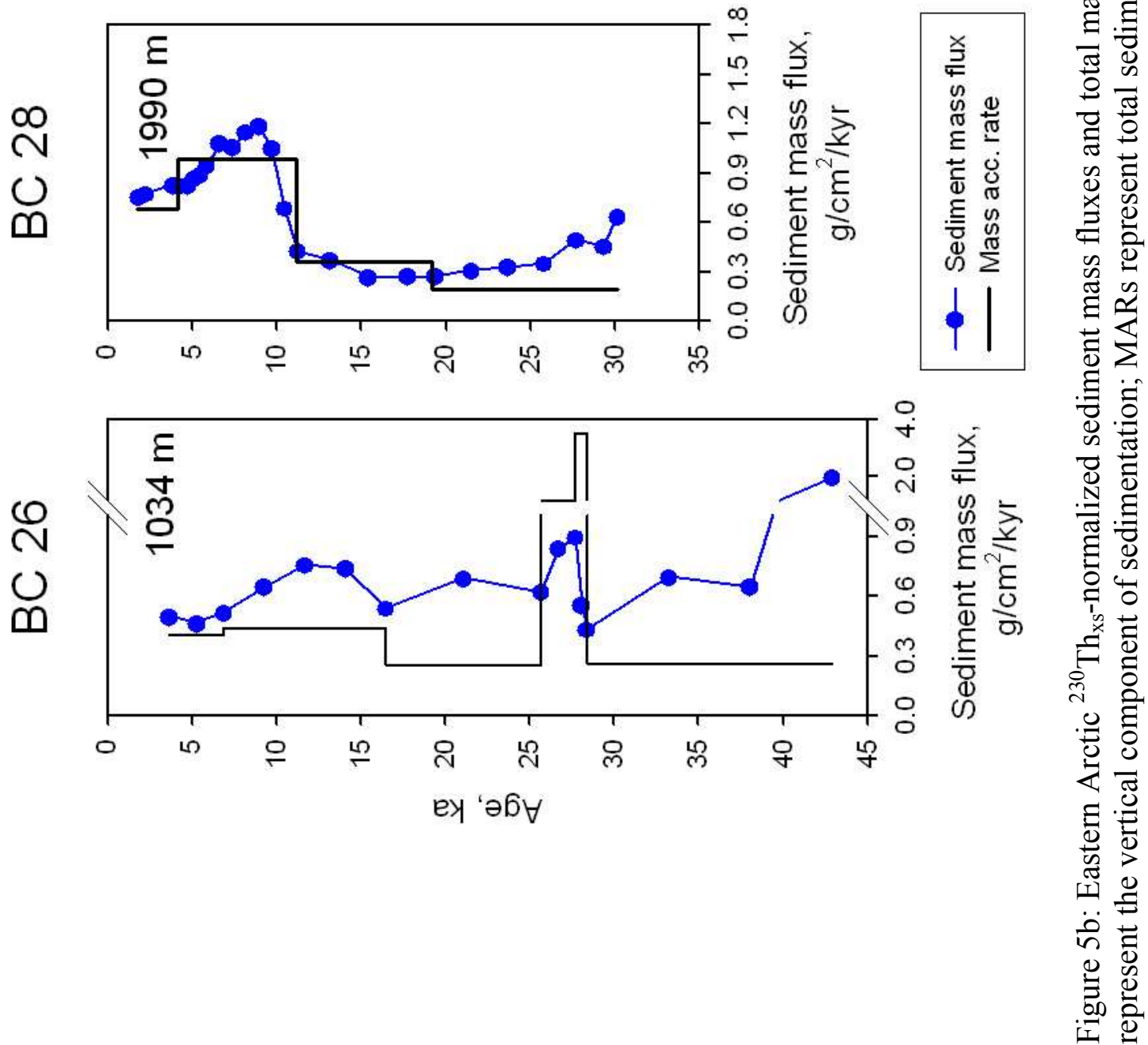


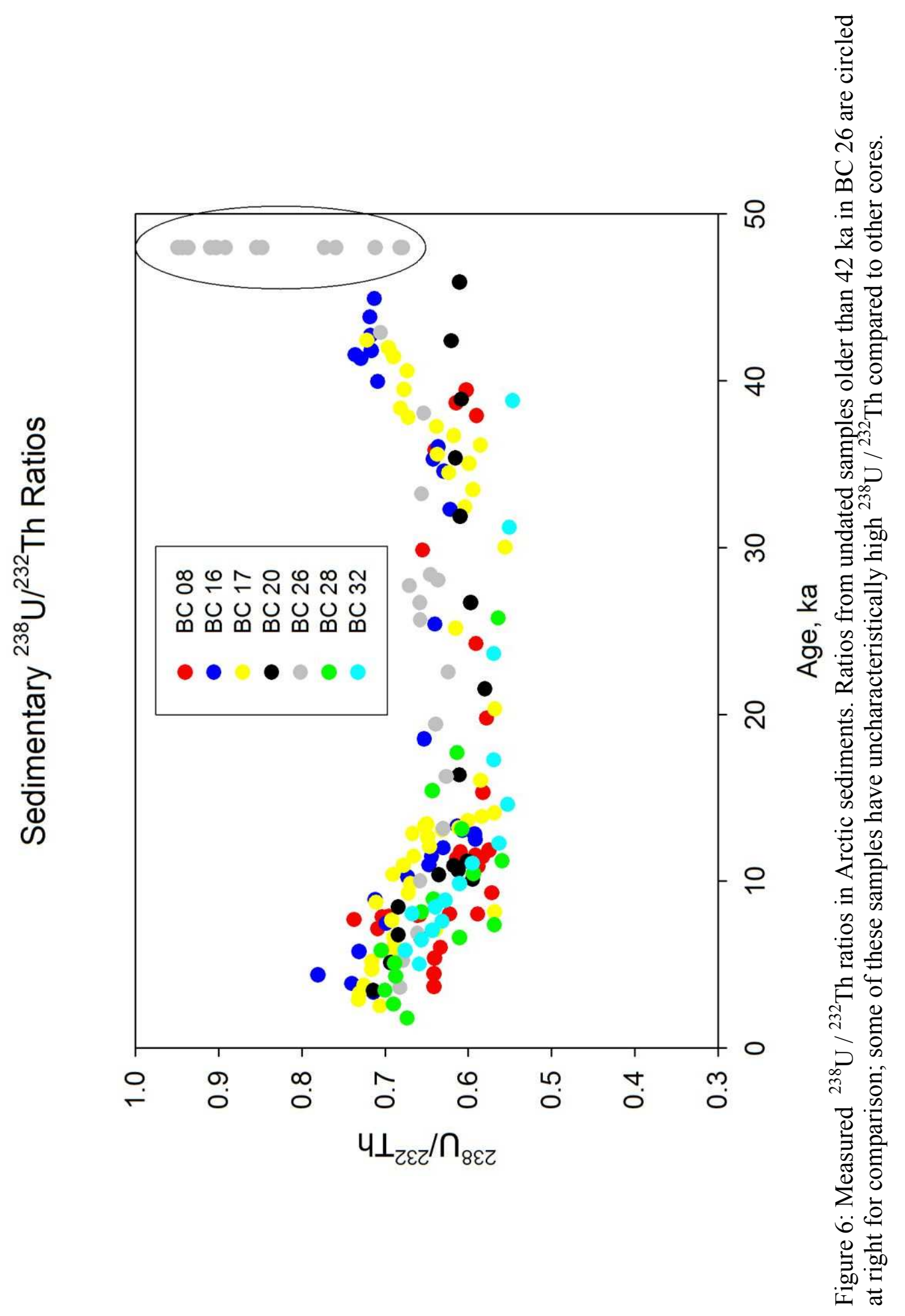



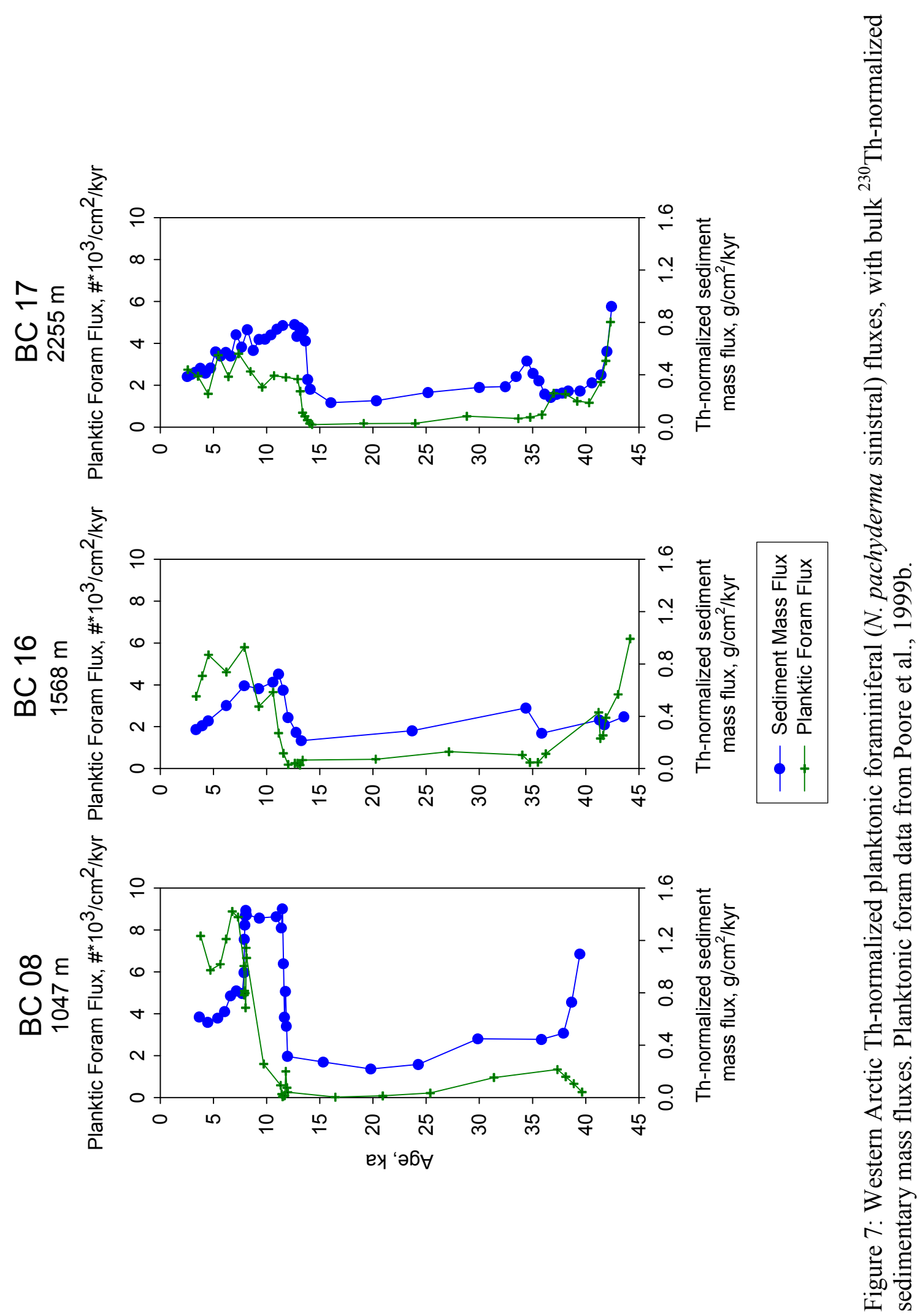

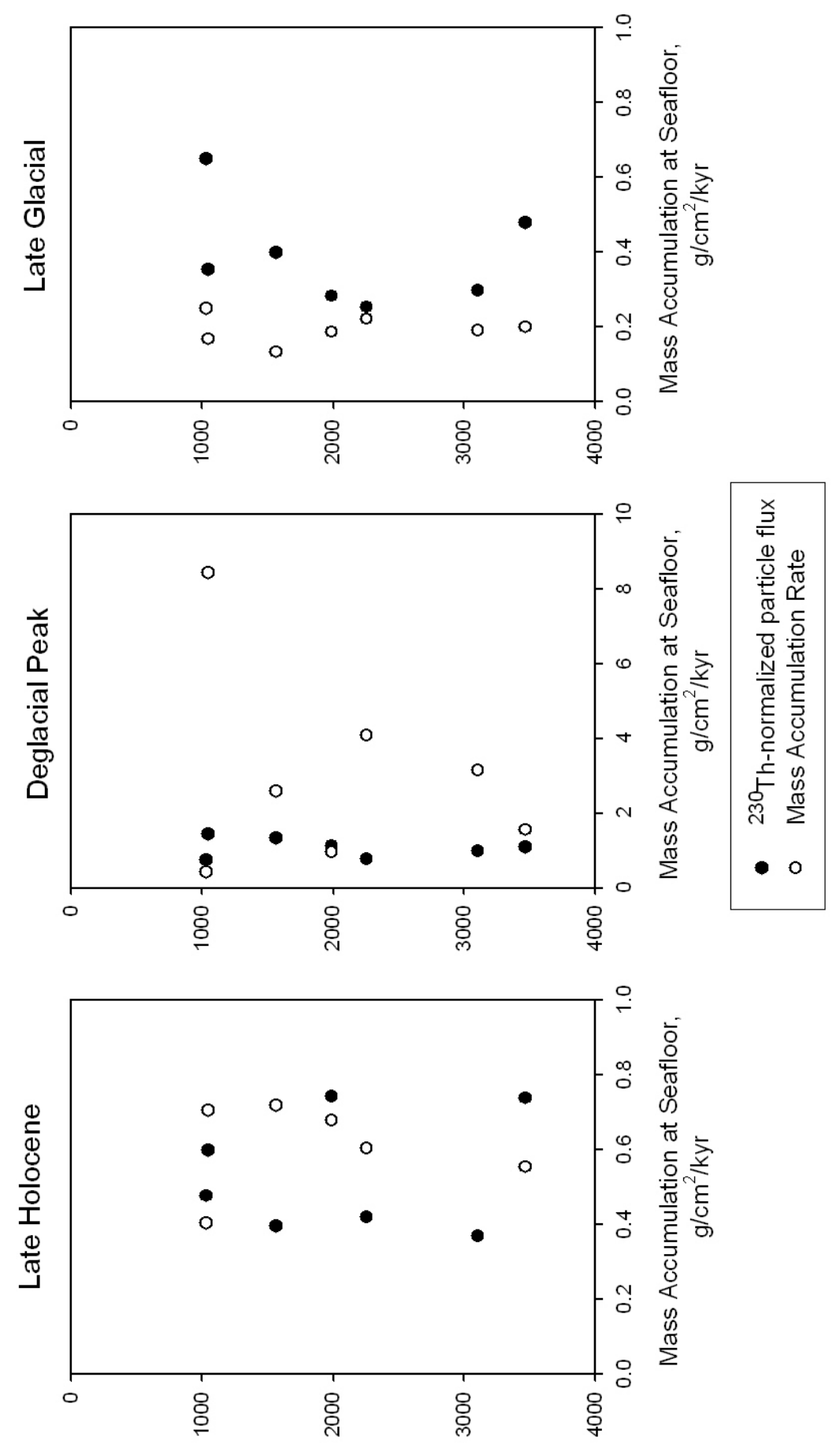

u 'प7dә0 ıәғем

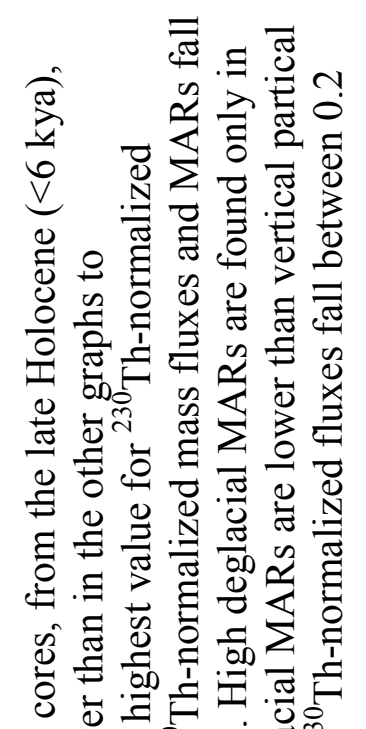

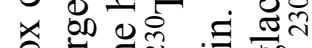

츠

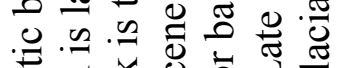

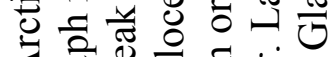
ব 전

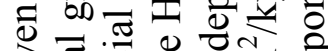

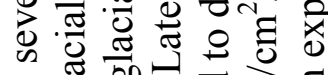
ప क्ठ

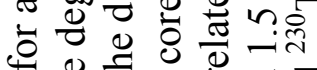

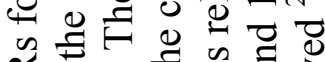

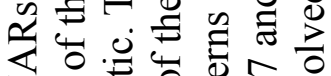
¿0.0

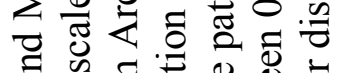
స

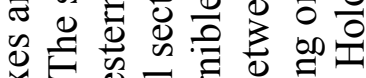

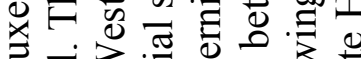

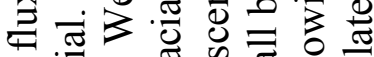

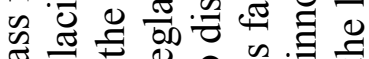
ส

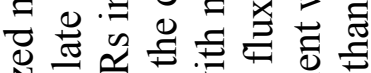

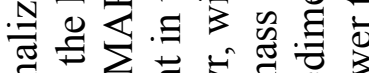

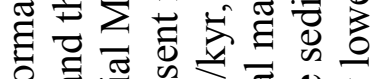

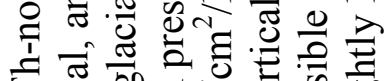

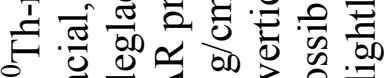
ह

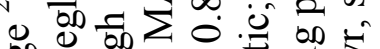

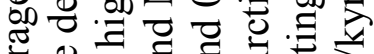

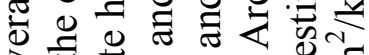

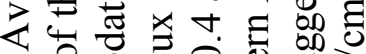
$\therefore \circ$ 다워 0 की

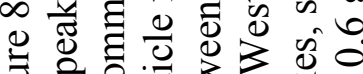

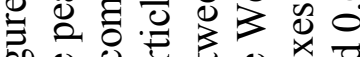

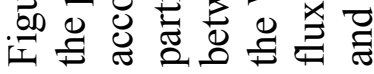




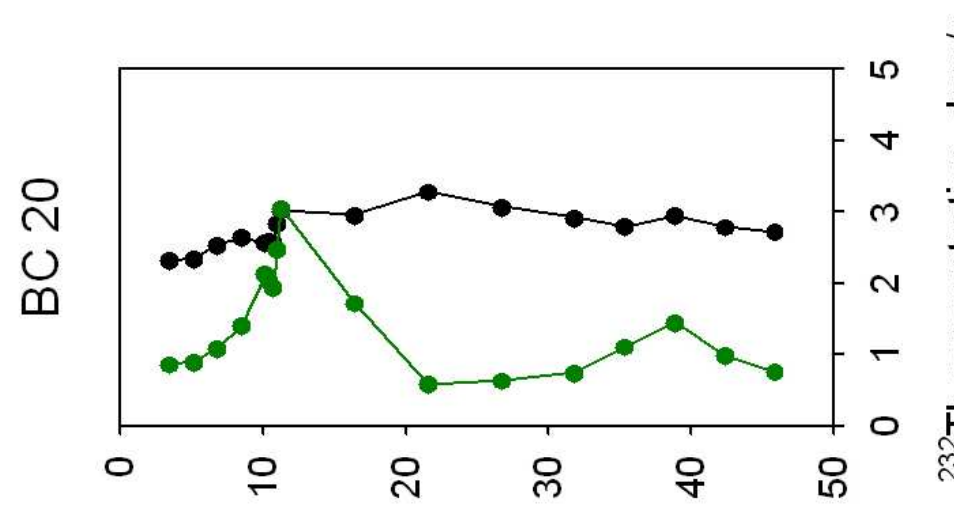

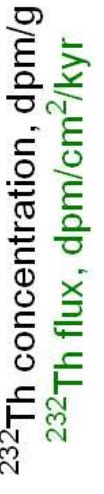
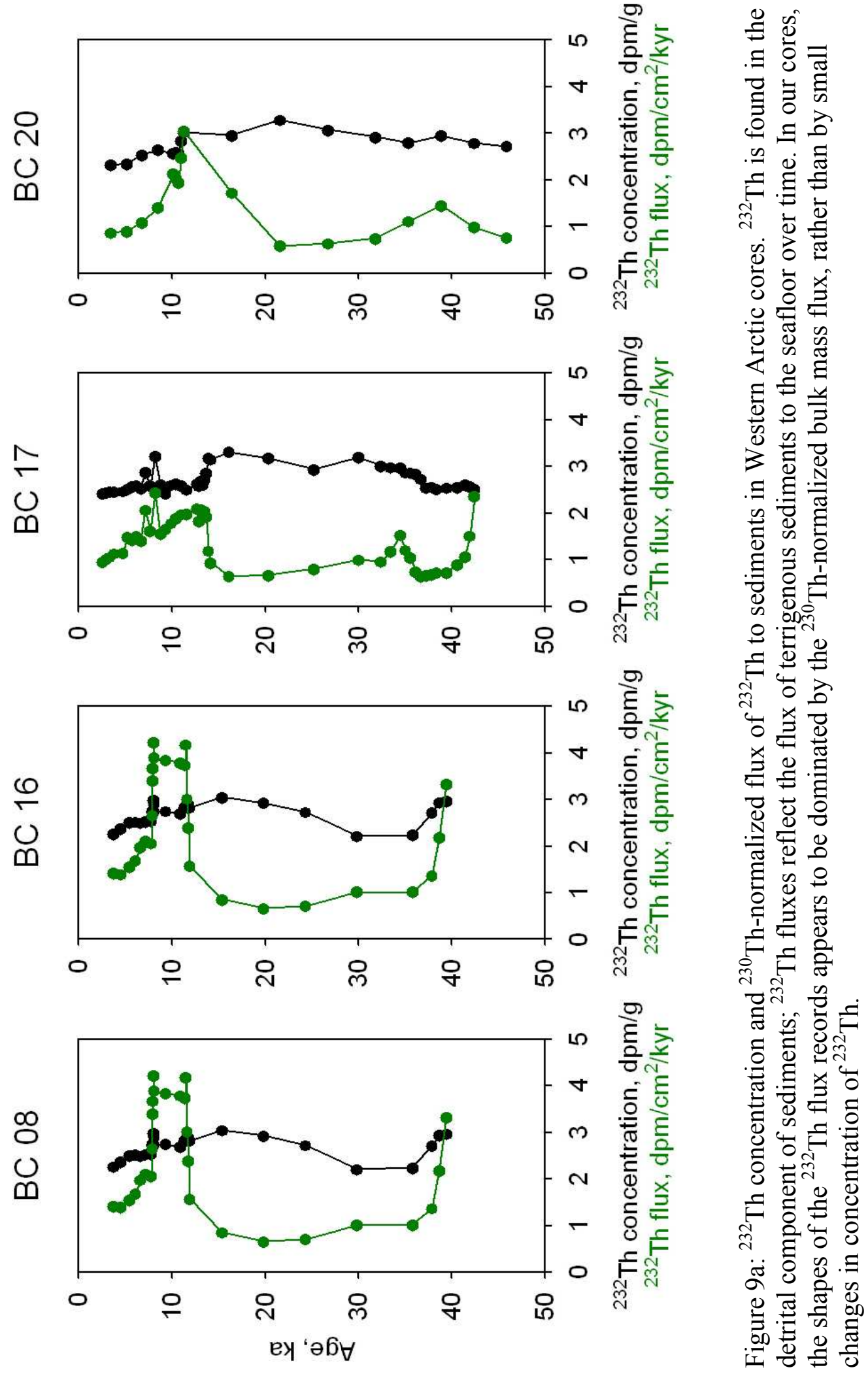


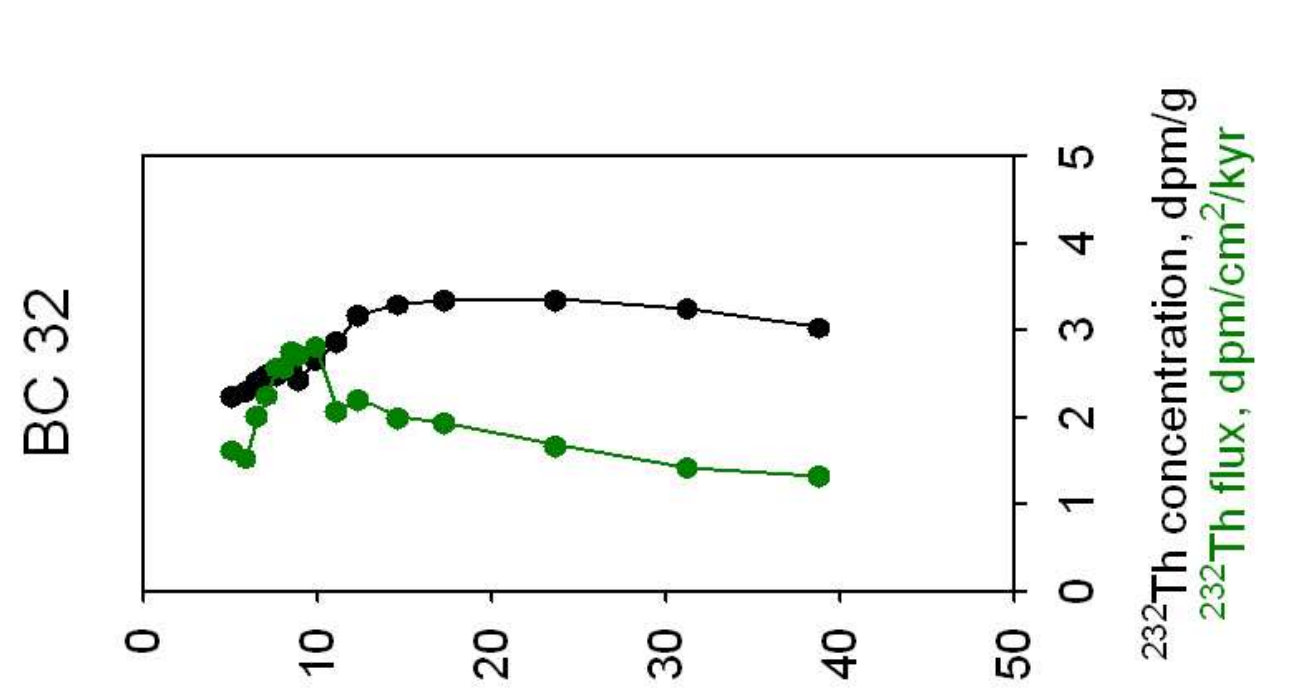

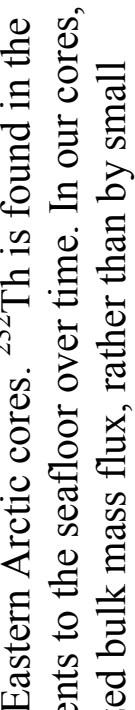

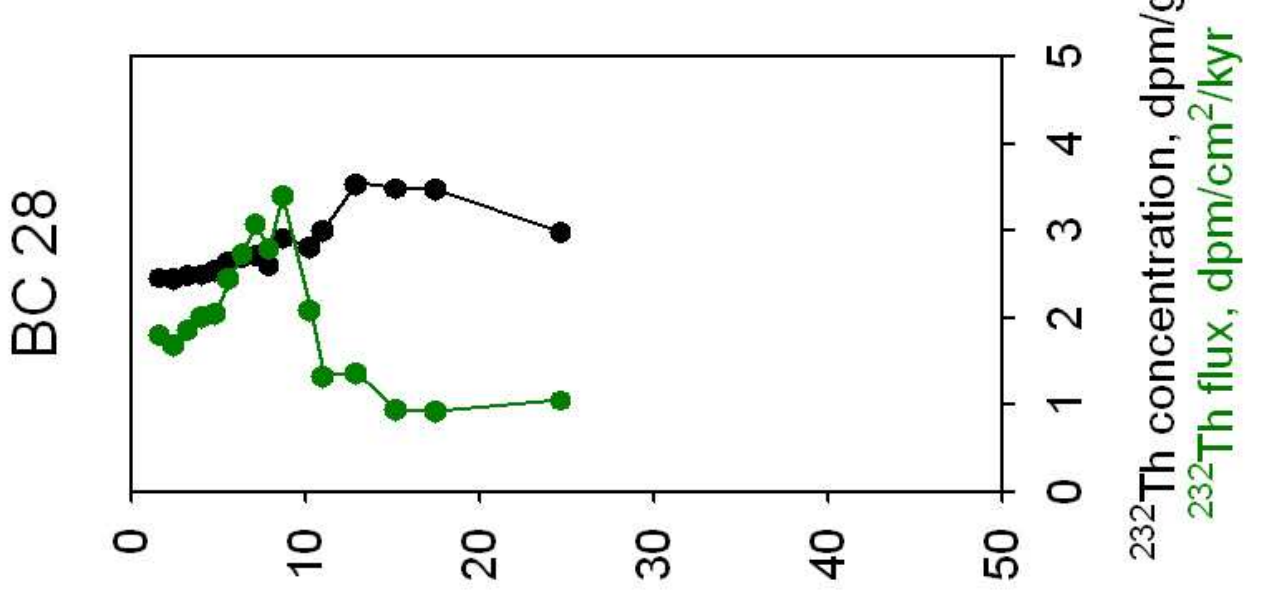

$\exists$ Nㅗ

的氜

造出

噇主

를

สิ

능 옹

远

马्ठ

는

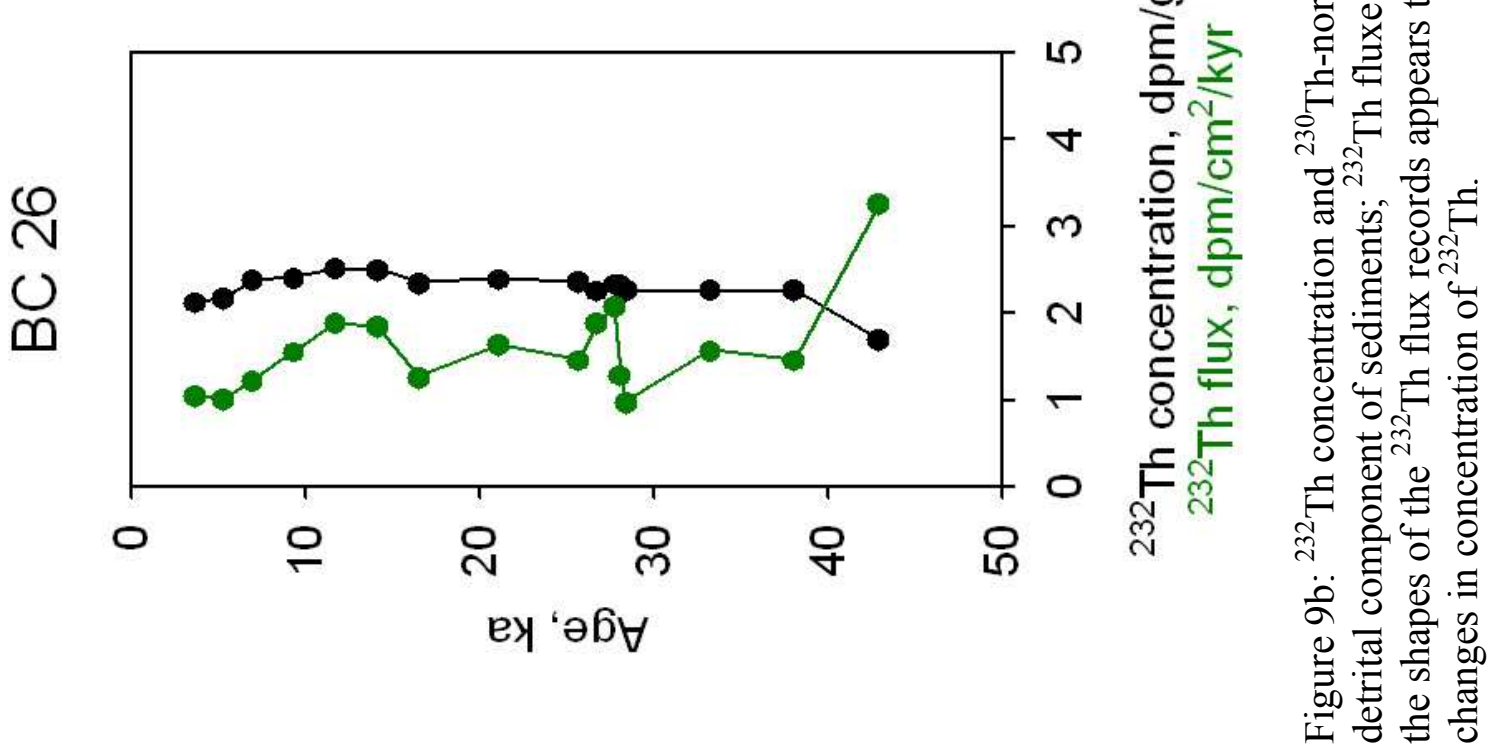




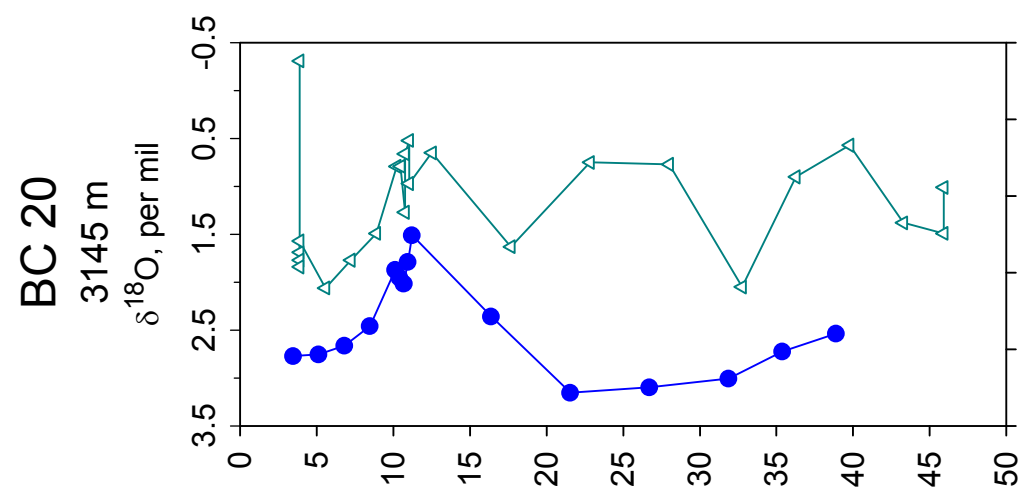

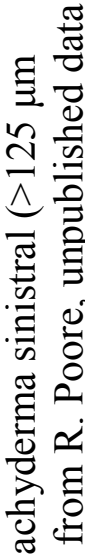
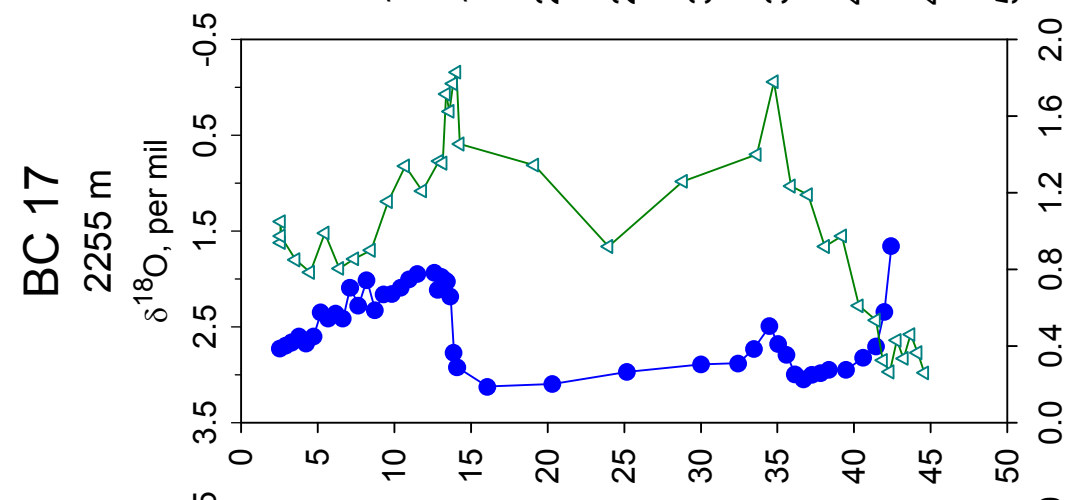

2.ㅇ

구유

ํํำ

थ

के

ర్ల
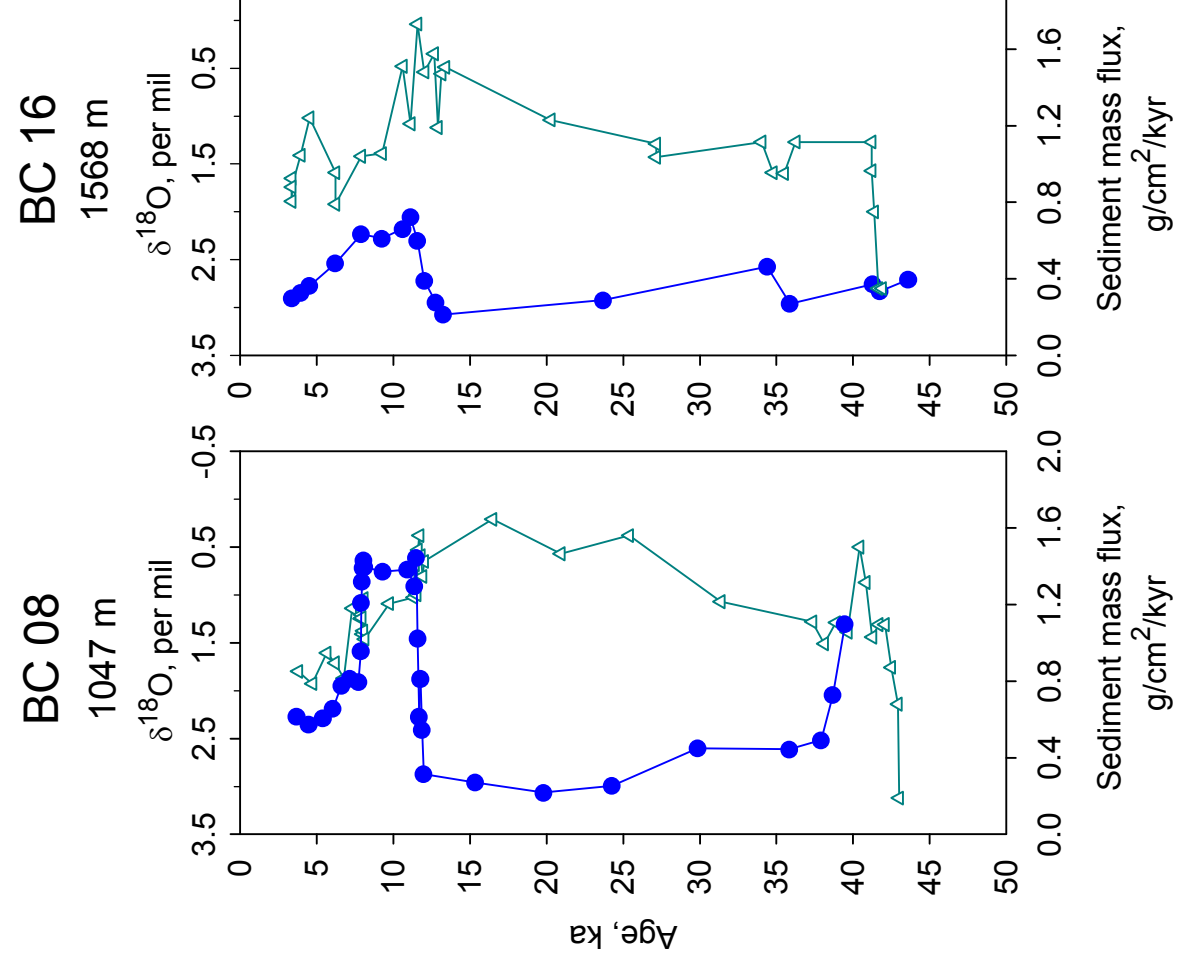

$0 \dot{0}$

$\infty$ o

䨌

Ð

पू :

¿

륭

洁

㛡

그

큰

$\exists$

它

I

항.

on

훙

元

잉 중

is

$3 \dot{\bar{D}}$

远兽

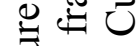

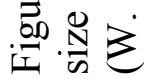




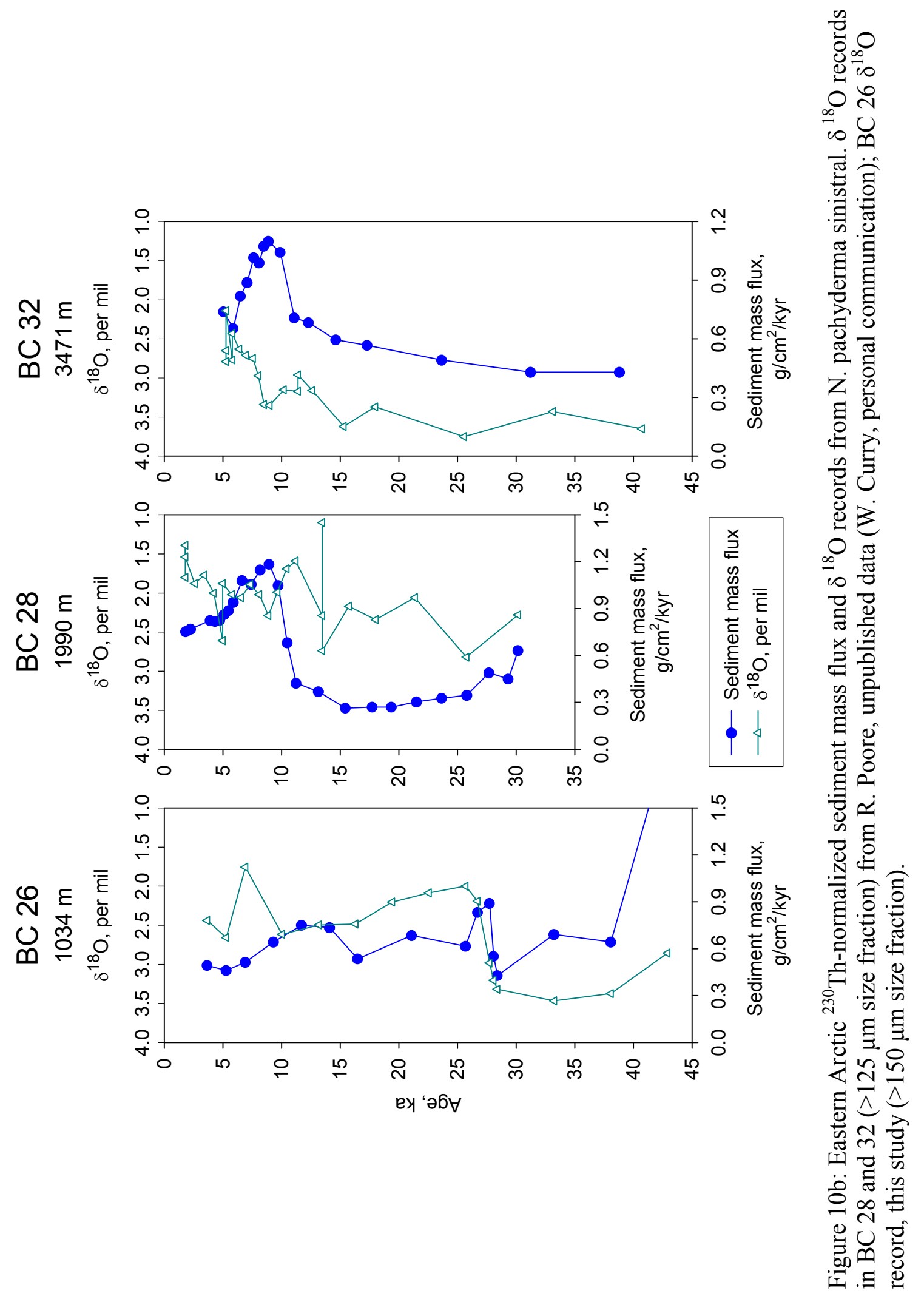




\title{
Chapter 4
}

\section{Extensive deglacial sediment redistribution in the Western Arctic as determined by excess thorium-230}

\begin{abstract}
We have measured excess thorium-230 $\left({ }^{230} \mathrm{Th}_{\mathrm{xs}}\right)$, in cores from the Western Arctic (Mendeleev Ridge and Makarov Basin) to determine changes in vertical particle flux and lateral sediment deposition at the end of the last glaciation. The deglacial sections of these cores show a transition from low to high vertical particle rain rates, which may be indicative of environmental changes such as more open waters at the sea surface. In addition, the ${ }^{230} \mathrm{Th}_{\mathrm{xs}}$ inventories within the core deglacial sections are too high to have resulted from local ${ }^{230} \mathrm{Th}$ production in the water column alone, and the independent estimates of total sediment accumulation rates also outpace estimated vertical particle mass fluxes at this time. This suggests that deglacial changes in upper ocean processes were accompanied by a major redistribution of sediments at depths between $1 \mathrm{~km}$ and $3 \mathrm{~km}$ along the Mendeleev Ridge and Makarov Basin floor. Possible reasons for this sediment focusing event include destabilization of sediments at the shelf-slope break as sea level began to rise, and changes to the deep topographically-driven currents in the Amerasian Basin that promoted sediment remobilization and transport in nepheloid layers.
\end{abstract}




\section{Introduction}

The last deglaciation in the Arctic, following the Last Glacial Maximum (LGM), was a time of rapid and dramatic response to global climate change. As ice sheets collapsed, meltwater and icebergs flooded the surface of the Arctic Ocean, sea level began to rise and flood the broad exposed Siberian shelves, and inflows of Pacific and Atlantic water across the Bering Strait and the Barents shelf resumed. Leads and seasonally open areas appeared in the thinning perennial ice cover, allowing primary productivity to resume and thrive. These changes have been documented in paleoceanographic records from sediment cores in the central Arctic basins. Planktonic foraminifera from deglacial-age sediments show depletions in $\delta{ }^{18} \mathrm{O}$, ascribed to glacial meltwater from the decaying Laurentide Ice Sheet (Poore et al., 1999a; Hall and Chan, 2004). In the central deep basins, sedimentation rates jump by an order of magnitude at the deglaciation, up from $\mathrm{mm} / \mathrm{kyr}$ rates typical of the LGM in this region (Darby et al., 1997; Poore et al., 1999a,b).

These sedimentation rate increases coincide with changes in ${ }^{230} \mathrm{Th}$ content in

several cores from the Amerasian Basin. ${ }^{230} \mathrm{Th}$, produced approximately at constant rate in the water column by uranium decay (Henderson and Anderson, 2003), is rapidly removed to the sediments by adsorption to sinking particles. In much of the world ocean, the rate of ${ }^{230} \mathrm{Th}$ removal by burial at the seafloor roughly balances the rate of its production in the local water column above, making ${ }^{230} \mathrm{Th}$ measurements in sediments useful for estimating vertical particle fluxes as well as sediment redistribution along the 
seafloor (Suman and Bacon, 1989; Francois et al., 1990, 2004). Records of ${ }^{230} \mathrm{Th}_{\mathrm{xs}}$ (excess ${ }^{230} \mathrm{Th}$, unsupported by ${ }^{234} \mathrm{U}$ decay within the sediments) from box cores in the Western Arctic suggest that this assumption appears to be valid in the Arctic during Holocene and glacial times (Hoffmann and McManus, 2007).

However, the deglacial sections of these cores contained more ${ }^{230} \mathrm{Th}_{\mathrm{xs}}$ than could have been produced locally above the core sites during the time that the deglacial sediments were deposited. This suggests that other processes must be involved in producing the sedimentary ${ }^{230} \mathrm{Th}_{\mathrm{xs}}$ signals in these cores: either lateral transport of

${ }^{230} \mathrm{Th}_{\mathrm{xs}}$-bearing particles from elsewhere to the core sites, or lateral transport of ${ }^{230} \mathrm{Th}$ in the water column from elsewhere in the basin. Here we present radioisotope data from five Amerasian Basin deep sea cores, revealing major sediment redistribution associated with deglacial ice breakup and sea level rise. A sharp rise in sedimentation, accompanying planktonic foraminiferal records of increased meltwater input and productivity, suggests that sediments may have been remobilized, transported, and redeposited on the sea floor as surface conditions changed. We examine the deglacial sections of these box cores in detail, relating vertical and lateral sedimentation fluxes to climatic influences at the surface through planktonic stable isotopic measurements and abundance.

\section{Materials and Methods}

The cores in this study (Table 1) were taken during the 1994 R.V. Polar Sea Arctic Ocean Section cruise, at sites on the Mendeleev Ridge and the floor of the 
Makarov Basin in the deep western Arctic (map, Figure 1). The sediments consist of brown muds, containing large numbers of foraminifera in the later deglacial and Holocene sections but mostly barren in the glacial sections. These core sites sit beneath the Beaufort Gyre surface circulation (Poore et al., 1999a), and in modern times were icecovered year-round until recent years (Fetterer et al., 2002).

\section{Core chronologies}

Age models for cores $\mathrm{BC}$ 08, 16, 17, and 19 were constructed by interpolation between radiocarbon dates measured on polar planktonic foraminifer N. Pachyderma sin. (Poore et al., 1999b). These dates were all obtained on the same subcores in which we measured ${ }^{230} \mathrm{Th}$. The age model for BC 20 was constructed by the same method from dates published by Darby et al. (1997). Although the dates for BC 20 were determined on a different subcore than we used for our ${ }^{230} \mathrm{Th}$ measurements, records of coarse fraction weight percent from both subcores are similar (Appendix Figure A.1), suggesting that there is little significant stratigraphic difference between the subcores and that the age model is appropriate for our subcore. Dates were corrected for a reservoir age of 440 years (Darby et al., 1997) with an additional $\Delta \mathrm{R}=250$ years (Mangerud \& Gulliksen, 1975), to account for the possibility of impeded air-sea gas exchange due to sea ice. Changes in the reservoir age of Arctic surface waters with time are still unknown, so we have applied this correction to all our ages. We calibrated radiocarbon dates younger than 22 kyr using the Calib 5.0.2 program (Stuiver et al., 2005) and the INTCAL 2004 calibration data set (Hughen et al., 2004). Older dates outside of the INTCAL calibration 
range were converted to calendar ages using the calibration program of Fairbanks et al. (2005).

${ }^{230}$ Th measurements and corrections

For ${ }^{230} \mathrm{Th}$ measurements, cores PLS-94 BC 08, 16, and 20 were sampled in halfcm slices at 1-cm intervals, and BC 17 at half-cm intervals for a higher-resolution record. Samples were processed by methods from Choi et al. (2001) and analyzed on a ThermoFinnegan Element2 inductively-coupled plasma mass spectrometer. Corrections for supported ${ }^{230}$ Th activity and radiodecay since deposition were applied as in Gherardi et al. (2005). ${ }^{230} \mathrm{Th}_{\mathrm{xs}}$ data for core BC 19 are from Huh et al. (1997). ${ }^{230} \mathrm{Th}$-normalized sediment mass flux $\mathrm{F}$ (figure 3 ) was calculated according to the equation $\mathrm{F}=\beta \mathrm{z} /{ }^{230} \mathrm{Th}_{\mathrm{xs}}$, (Francois et al., 2004) where $\beta$ is the production rate of ${ }^{230} \mathrm{Th}$ in seawater $(0.0267$ $\left.\mathrm{dpm} / \mathrm{m}^{3} / \mathrm{kyr}\right), \mathrm{z}$ is the water depth of the site $(\mathrm{m})$, and our reported $\mathrm{F}$ is in units of $\mathrm{g} / \mathrm{cm}^{2} / \mathrm{kyr}$. This equation assumes a balance between local production and removal to sediments of ${ }^{230} \mathrm{Th}$.

Focusing factors, $\Psi$ (Figure 2), were calculated between radiocarbon-dated horizons according to the equation of Suman and Bacon (1989): $\Psi=\left(\int{ }^{230} \mathrm{Th}_{\mathrm{xs}} * \rho \mathrm{dz}\right) / \beta$ $\left(t_{1}-t_{2}\right)$ integrated between depths $z_{1}$ and $z_{2}$ in the core; where ${ }^{230}{ }^{2} h_{x s}$ is the age-corrected sample concentration in $\mathrm{dpm} / \mathrm{g}, \rho$ is bulk sediment density in $\mathrm{g} / \mathrm{cm}^{3}, \beta$ is the production rate of ${ }^{230} \mathrm{Th}$ in the water column at the site in $\mathrm{dpm} /\left(\mathrm{cm}^{2} * \mathrm{kyr}\right)$, and $\mathrm{t}_{1}$ and $\mathrm{t}_{2}$ are the ages of radiocarbon-dated horizons $\mathrm{z}_{1}$ and $\mathrm{z}_{2}$. A value of $\Psi=1$ indicates no net lateral transport of Th-bearing sediment; values higher than 1 indicate net lateral import of sediment to the site, as determined by the presence of more ${ }^{230} \mathrm{Th}_{\mathrm{xs}}$ in the sediments than 
could have been produced locally in the water column during the time those sediments were deposited.

We calculated uncertainty estimates from replicate measurements of ${ }^{230} \mathrm{Th}$; the average standard deviation $\sigma$ between replicates is $2.5 \%$ of the mean of the replicates (Appendix Table A.6). Machine error accounts for less than 1\% of variability on our samples, and variability in our decay correction for ${ }^{230} \mathrm{Th}$ is less than $3 \%$ for age errors up to $2 \mathrm{kyr}$.

\section{Other methods}

Two sets of stable isotopic data (figure 3) have been generated on samples of foraminifera from the PLS-94 box cores, sampled at $1-\mathrm{cm}$ intervals. $\delta{ }^{18} \mathrm{O}$ results published in Poore et al. (1999b) were measured on samples of $6 \mathrm{~N}$. pachyderma sin. from the $>125 \mu \mathrm{m}$ size fraction. New $\delta^{18} \mathrm{O}$ results were measured on samples of $\sim 10$ specimens from the 180-212 $\mu \mathrm{m}$ size fraction (W. Curry, unpublished data). All stable isotopes were analysed on a Finnigan MAT 253 after the procedures of Ostermann and Curry (2000). For the unpublished Curry data, up to 10 replicate measurements were available from each depth interval. These values were averaged for each sample (Appendix Table A.4); standard error for these multiple $\delta^{18} \mathrm{O}$ measurements ranged from 0.04 to 0.20 permil. Sediment density was determined by Huh et al. (1997) on different subcores of $\mathrm{BC} 08,16,17$ and 20 than were used for our ${ }^{230} \mathrm{Th}$ measurements. Mass accumulation rate (MAR), an estimate of total (vertical and lateral) sedimentation rate independent of ${ }^{230} \mathrm{Th}$ measurements, was calculated by multiplying the linear 
sedimentation rate determined between pairs of radiocarbon-dated horizons by the average density of samples between the dated horizons.

\section{Results}

${ }^{230} \mathrm{Th}_{\mathrm{xs}}$ concentration profiles in all cores show a decrease downcore from the sediment-water interface to minimum values just above a strong subsurface peak (fig. 2). In all cores this peak is substantially larger than the coretop ${ }^{230} \mathrm{Th}_{\mathrm{xs}}$ concentration. The lowest ${ }^{230} \mathrm{Th}_{\mathrm{xs}}$ values above the peaks correspond to sediments deposited during the deglaciation $(\sim 15-10 \mathrm{ka})$, while the peaks correspond to times of extremely low sedimentation rate, independently determined by radiocarbon dates, coincident with the Last Glacial Maximum (24-18 ka). The thickness of the deglacial interval varies, and is generally thicker nearer to the continental slope: $2 \mathrm{~cm}$ in BC 19, $4 \mathrm{~cm}$ in BC 20,6 cm in

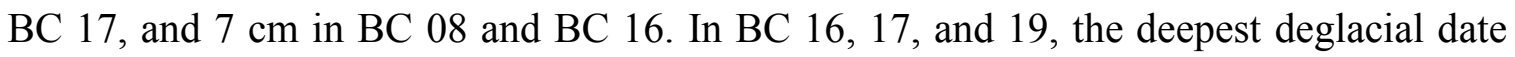
coincides with the peak in ${ }^{230} \mathrm{Th}_{\mathrm{xs}}$ or comes just above the peak. ${ }^{230} \mathrm{Th}_{\mathrm{xs}}$ concentrations in sediments deposited during this interval thus drop rapidly from high values to low values. Focusing factors calculated between deglacial-dated horizons at all five sites show evidence for deposition of laterally-transported thorium-bearing sediments coincident with the deglacial-dated sections. In $\mathrm{BC} 08$ on the Arliss Plateau, the shallowest core $(1047 \mathrm{~m})$ and the core nearest to the continental slope, an additional interval of strong lateral sediment delivery is seen at $\sim 8 \mathrm{ka}$.

${ }^{230}$ Th-normalized mass fluxes (figure 3, Appendix Table A.5) are very low in the glacial section of all five cores, consistent with the low glacial sedimentation rates found 
in cores from across the Central Arctic as inferred from radiocarbon dating (Poore et al, 1999 a, b; Darby et al., 1997, Norgaard-Pedersen et al., 1998, 2003). These fluxes begin to rise at the start of the deglacial section of each core, and attain maximum values during the deglacial, except in $\mathrm{BC} 20$ where high fluxes coincide with the deepest deglacial sample. MARs (Appendix Table A.5) are very high during the deglaciation in all five cores, and substantially higher than ${ }^{230}$ Th-normalized sediment mass fluxes during these intervals, consistent with lateral supply of ${ }^{230}$ Th-bearing sediments to these sites.

The oxygen stable isotope composition of the polar planktonic foraminifer $N$. pachyderma sin. reflects near-surface water conditions such as temperature and salinity. In the Arctic, modern-day $\delta^{18} \mathrm{O}$ appears to reflect spatial gradients in subsurface water masses (Spielhagen et al., 1994), but in the past this proxy was strongly affected by isotopically-depleted meltwater input from terrestrial ice sheets (Poore et al., 1999a; Stein et al., 1994, Spielhagen et al., 1994). In the Western Arctic, depletions in $\delta{ }^{18} \mathrm{O}$ (figure 3 ) and $\delta^{13} \mathrm{C}$ (Poore et al., 1999a,b) appear during the deglacial, most likely linked to meltwater input from the collapsing Laurentide Ice Sheet (Hall and Chan, 2004). The lowest values occur simultaneously or just before the rise in ${ }^{230} \mathrm{Th}$-normalized sediment flux in each core (Figure 3).

\section{Discussion}

Rapid sedimentation by increased particle fluxes from the surface is associated with low ${ }^{230} \mathrm{Th}$ concentrations in the accumulating sediment, while slow vertical sedimentation is associated with high ${ }^{230} \mathrm{Th}$ concentrations. In cores $\mathrm{BC} 08,16,17$, and 
19, the records of ${ }^{230} \mathrm{Th}_{\mathrm{xs}}$ show a rapid drop in ${ }^{230} \mathrm{Th}_{\mathrm{xs}}$ concentration in samples taken upcore from the base of the deglacial dated section (Figure 2). In BC 20 the drop from high glacial ${ }^{230} \mathrm{Th}$ concentrations to low deglacial values concentration occurs at the base of the deglacial, coincident with the earliest deglacial-age radiocarbon date, rather than slightly above the base of the deglacial. This indicates a rapid increase in vertical particle flux to these sites and consequent dilution of ${ }^{230} \mathrm{Th}$ scavenged from the water column. However, inventories of ${ }^{230} \mathrm{Th}_{\mathrm{xs}}$ between the dated horizons indicate that, despite low concentrations, nevertheless ${ }^{230} \mathrm{Th}_{\mathrm{xs}}$ accumulated more rapidly at each of our sites than it was produced in the water above the sites. This can be seen in the focusing factors calculated for these cores (Figure 2), which show the proportion of ${ }^{230} \mathrm{Th}_{\mathrm{xs}}$ present in samples to the local production.

\section{Lateral sediment transport}

Our records of ${ }^{230} \mathrm{Th}$ deposition at Western Arctic sites during the deglaciation outpacing local water column production strongly suggest that lateral transport of sediments was a major sedimentation process at that time. In BC 20 , in which the entire deglacial section is characterized by low ${ }^{230} \mathrm{Th}$ concentrations, approximately $47 \%$ of the ${ }^{230} \mathrm{Th}$ present is not accounted for by local production (Table 1). In the other four cores, between $63 \%$ (BC 19) and $82 \%$ (BC 16) of the ${ }^{230} \mathrm{Th}_{\mathrm{xs}}$ present in the deglacial sections cannot be accounted for through local ${ }^{230} \mathrm{Th}$ production in the water column (Table 1). ${ }^{230} \mathrm{Th}$ concentration drops rapidly above the base of the deglacial in the other four cores (figure 2), which could be due either to bioturbation causing mixing of high ${ }^{230} \mathrm{Th}$ glacial sediments with low- ${ }^{230} \mathrm{Th}$ deglacial sediments, or due to remobilization and redeposition 
of high- ${ }^{230} \mathrm{Th}$ glacial sediments. If we assume, as a sensitivity test, that high ${ }^{230} \mathrm{Th}$ concentrations at the base of the deglacial are a result of bioturbation and assume that low ${ }^{230} \mathrm{Th}$ deglacial values from each core represent a true deglacial thorium signal undisturbed by bioturbation, we find that water column production can account for 45$63 \%$ of the estimated deglacial inventory. In either case, a lateral supply of ${ }^{230} \mathrm{Th}_{\mathrm{xs}}$ must account for the rest of the thorium inventory.

In addition to using thorium budgets to estimate the amount of ${ }^{230} \mathrm{Th}$ that must have been delivered laterally to our sites, we can also use different means of calculating sediment deposition at our sites to estimate the proportion of sediment that must have been delivered laterally. ${ }^{230} \mathrm{Th}$-normalized sediment mass fluxes estimate the rate of accumulation of vertically-delivered sediment particles at the seafloor. Mass accumulation rates, calculated from sediment density and the linear sedimentation rate derived from radiocarbon dating, provide an estimate of total sediment input to the seafloor completely independent of ${ }^{230} \mathrm{Th}$. Comparing the highest ${ }^{230} \mathrm{Th}$-normalized mass fluxes from the deglacial in each core to deglacial MARs indicates that vertical fluxes represent between $14 \%$ and $28 \%$ of the total sediment accumulation (Table 1), averaging $21 \%$. Thus, the majority of sediment present in the deglacially-dated interval at each site appears to be supplied by lateral sediment focusing. This falls within the general proportion range as our various estimates of lateral ${ }^{230} \mathrm{Th}$ supply relative to total ${ }^{230} \mathrm{Th}$ inventory. In $\mathrm{BC} 08$, a second lateral transport event in the early Holocene, around $8 \mathrm{kyr}$, consists of sediment virtually all supplied by lateral rather than vertical transport, as inferred from measured ${ }^{230} \mathrm{Th}$ sediment content compared to production. These events do 
not have sharply defined erosive bases, suggesting that they do not simply represent turbidite deposits, which are known to be common on the floors of the deep Arctic basins (Grantz et al., 1996). Their well-defined excess ${ }^{230} \mathrm{Th}$ contents may also indicate a nonturbiditic origin, as turbidites deposit sediments extremely rapidly, making it less likely that particles could re-equilibrate with dissolved deep water ${ }^{230} \mathrm{Th}$ before final deposition.

These results all suggest that a major event of sediment redistribution occurred in the western Makarov Basin during the deglaciation, which affected cores at a number of depths along the Arliss Plateau, Mendeleev Ridge, and on the Wrangel Abyssal Plain. What could have caused such a wide-ranging redistribution event? One possibility is that as sea level rose due to melting ice sheets, it began to flood the edges of the wide, exposed Siberian shelves (e.g. Bauch et al., 2005), destabilizing long-dry sediments and allowing them to move down the slopes. Our sites are not far from the slope of the East Siberian Sea, making such a sediment source reasonable. Poore et al. (1999a) suggested that a meltwater event in the Western Arctic at the deglacial may be connected to Meltwater Pulse 1a (Fairbanks, 1989), a rapid rise in sea level at $\sim 14$ kyr. Although this early sea level rise likely drowned only a small percentage of the exposed shelves (Bauch et al., 2005), the area that it did flood would be at or near the shelf-slope break: the area of the shelves closest to our sites, and with the steepest topography (hence possibly the most potential for sediment destabilization and downslope transport.) The subaerially exposed shelves contained large amounts of permafrost, the thawing of which under newly-risen seas might contribute to destabilization (Are et al., 1999). Delta sediments deposited at the shelf edge by the major Siberian rivers, which flowed throughout the late 
glacial (Kleiber and Niessen, 1999), also could be a source of easily mobilized terrigenous materials.

However, although the shelves might supply sediment, they cannot have supplied the extra thorium we find in every core. Shallow sediments have very little ${ }^{230} \mathrm{Th}_{\mathrm{xs}}$ associated with them, due to the very small water column above them in which to produce ${ }^{230} \mathrm{Th}$, and due to generally high rates of sedimentation which would dilute any ${ }^{230} \mathrm{Th}$ that was deposited there. Thorium must have been transported to our sites in one of two ways: either adsorbed to sediment particles, or in dissolved form in the water column. In the case of the first possibility, if the sediments we find in our cores did come from the shelves, they may have traveled downslope and out to our sites while reequilibrating with ${ }^{230} \mathrm{Th}$ along the way, importing thorium from the water column along their travel path to our sites. Another possibility is that ${ }^{230} \mathrm{Th}$-bearing sediments at all depths along the side of the slope and ridge were redistributed laterally, synchronous with deposition or shortly thereafter. Some change to circulation at all depths in the Makarov Basin, or slope destabilization propagating downwards to deep waters, would be required to move all these sediments at the same time. Grain size analyses of these cores may help to understand deep water motion at these sites in future research.

Could the extra ${ }^{230} \mathrm{Th}$ present in these samples have been transported as dissolved ${ }^{230} \mathrm{Th}$ in the water column, the second possibility, rather than adsorbed to laterallymoving sediments? Net import of ${ }^{230} \mathrm{Th}$ usually only occurs in regions with large particle concentration gradients in the water column, such as near margins (Anderson et al., 1983; Henderson et al., 1999). Most of our sites are well away from the continental slope, and 
underlie waters that if anything seem more likely to export ${ }^{230} \mathrm{Th}$ rather than import it. Bacon et al. (1989) suggested that ${ }^{230} \mathrm{Th}$ was inefficiently scavenged at their site on the Alpha Ridge, allowing for the possibility of export from some regions of the Arctic basins. However, we can think of no reason why our sites in particular should be the final scavenging sites for massive amounts of dissolved imported ${ }^{230} \mathrm{Th}$. Furthermore, ${ }^{231} \mathrm{~Pa} /{ }^{230} \mathrm{Th}$ measurements at these sites (Chapter 5 ) show no elevation of the more easilytransported ${ }^{231} \mathrm{~Pa}$ over ${ }^{230} \mathrm{Th}$, which we would expect to see were these cores experiencing water column transport and boundary scavenging.

Particle fluxes, $\delta^{18} \mathrm{O}$, and implications for the surface environment

Although much of the sediment dated to the deglaciation appears to be transported to these sites from elsewhere in the basin, our ${ }^{230} \mathrm{Th}$-normalized vertical sediment mass fluxes indicate that vertical particle fluxes increased as well during the deglaciation. The thorium-normalized particle fluxes (figure 3) rise in conjunction with a number of indicators of surface change. Deglacial planktonic foraminiferal $\delta{ }^{18} \mathrm{O}$ and $\delta{ }^{13} \mathrm{C}$ in the Western Arctic appear to be largely driven by inputs of freshwater to the surface ocean, which may have become trapped in the region by the Beaufort Gyre surface circulation pattern (Poore et al., 1999a). When the ice sheets supplying the isotopically-depleted meltwater disappeared in the Holocene, Western Arctic planktonic $\delta{ }^{18} \mathrm{O}$ became more enriched, contrary to the global oceanic pattern of post-glacial isotopic depletion. Depletions in deglacial polar planktonic foraminiferal $\delta{ }^{18} \mathrm{O}$ and $\delta{ }^{13} \mathrm{C}$ (figure 3) above the glacial and Holocene signals, reported in BC 16, 17, and 19 in Poore et al. (1999a) have been interpreted as indicating very high input to the Beaufort Gyre of glacial meltwater, 
most likely from the Laurentide Ice Sheet (Hall and Chan, 2004). Increased input of icerafted grains from sources abutting the Laurentide Ice Sheet to locations across the Arctic, including the site of BC 16, has been found to occur at this time as well (Darby et al., 2002), suggesting increased input of icebergs to the surface of the Arctic. Further evidence for surface oceanographic changes comes from planktonic foraminiferal abundance: numbers of $N$. pachyderma sin. per gram of sediment increase in our cores starting at the deglacial (Poore et al. 1999a\&b, Darby et al., 1997), indicative of improved conditions for productivity such as more open water in among the ice floes, and gradually increasing insolation at these high latitudes.

The increase we infer in vertical particle fluxes to the seafloor at the deglaciation thus could be due to several factors. Terrigenous particle input may have increased from rivers now swollen from ice sheet melting (Hall and Chan, 2004), and from armadas of newly calved icebergs following collapses of the near-sea ice sheets (Darby et al., 2002). Some sediments from the newly-flooded shelf-slope break could have been advected out into the central basins at the surface, to sink as part of the local particle flux. Breakup of the perennial thick sea ice/land ice mix that covered the Arctic during the glacial, and subsequent increases in open water conditions, may have allowed primary productivity to grow and increased the vertical particle flux. Loosening of the ice pack may also have allowed for more ice movement around the surface of the Arctic, carrying larger amounts of IRD into the center of the basin (Bradley and England, 2008). Furthermore, if water temperatures beneath the largely ice-covered surface rose, perhaps from increased input of warm Atlantic waters across the newly flooded Barents Sea, this could increase the 
melting rate of icebergs and sea ice and speed the release of IRD. Many processes thus may have acted together to produce the increased vertical sedimentation flux we see in the Western Arctic at the deglaciation.

\section{Conclusions}

We measured ${ }^{230} \mathrm{Th}_{\mathrm{xs}}$ in five cores from the Mendeleev Ridge and Makarov Basin, Western Arctic, to examine patterns of vertical and lateral sediment deposition during the last deglaciation. Rates of ${ }^{230} \mathrm{Th}_{\mathrm{xs}}$ burial in sediments during the deglacial indicate a major sediment redeposition event in the Makarov Basin at this time, affecting depths from $1 \mathrm{~km}$ to $>3 \mathrm{~km}$. A possible source for the laterally transported sediments is the wide continental shelf north of Siberia, which was flooded by rising seas as the ice sheets collapsed. However, sediments on shallow shelves are likely to have low ${ }^{230} \mathrm{Th}_{\mathrm{xs}}$ concentrations, suggesting that sediments imported to our sites either re-equilibrated with water column ${ }^{230} \mathrm{Th}$ during their transit to our sites, or that the transported sediments originated deeper on the continental slope. Vertical sedimentary fluxes also increased during this time, most likely due to a combination of changes at the surface which allowed for increased input of terrigenous material and biological productivity. 


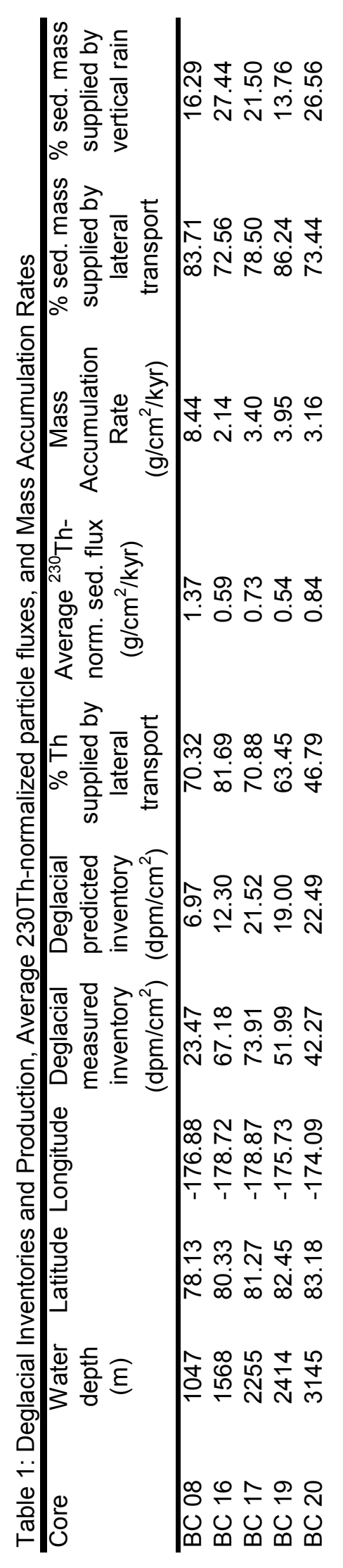




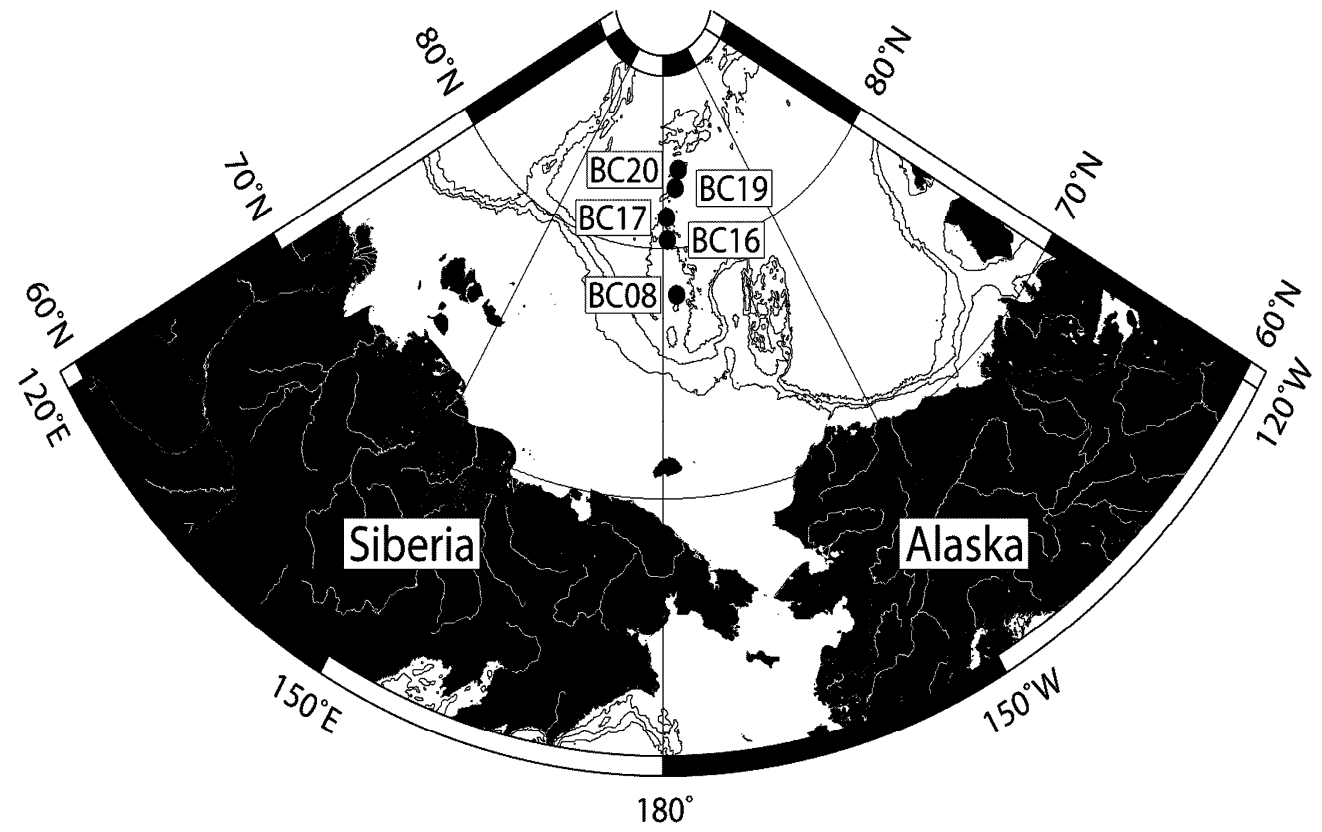

Figure 1: Amerasian Basin PLS-94 box core locations used in this study: PLS-94 BC 08 $(1000 \mathrm{~m}, 78.13 \mathrm{~N}, 176.88 \mathrm{~W}), \mathrm{BC} 16(1533 \mathrm{~m}, 80.33 \mathrm{~N}, 178.72 \mathrm{~W}), \mathrm{BC} 17(2217 \mathrm{~m}, 81.27 \mathrm{~N}$, $178.87 \mathrm{~W}), \mathrm{BC} 19(2400 \mathrm{~m}, 82.45 \mathrm{~N}, 175.73 \mathrm{~W})$ and $\mathrm{BC} 20(3145 \mathrm{~m}, 83.18 \mathrm{~N}, 174.09 \mathrm{~W})$. 


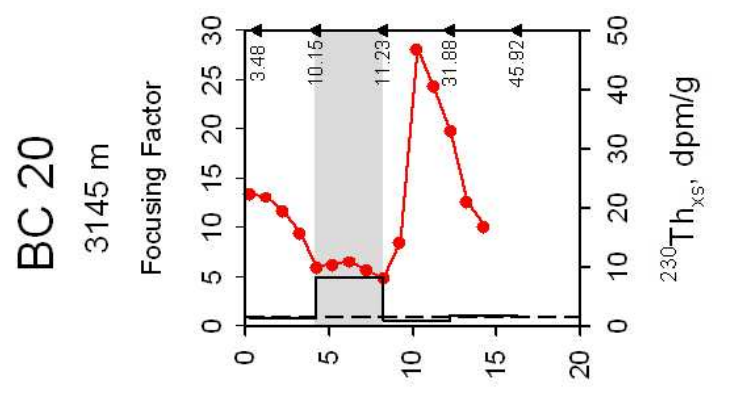

过菅

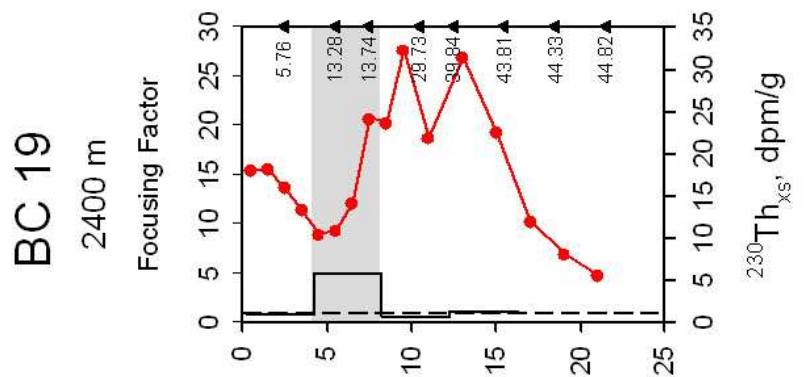

츨 응

은

氙 잉

0 壱

:

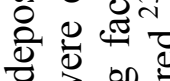

ए 00

氜 $\frac{\pi}{\pi}$

$\lambda$ 近

ฮั

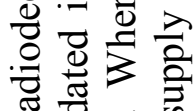

ज्ञ

ᄒํํ요
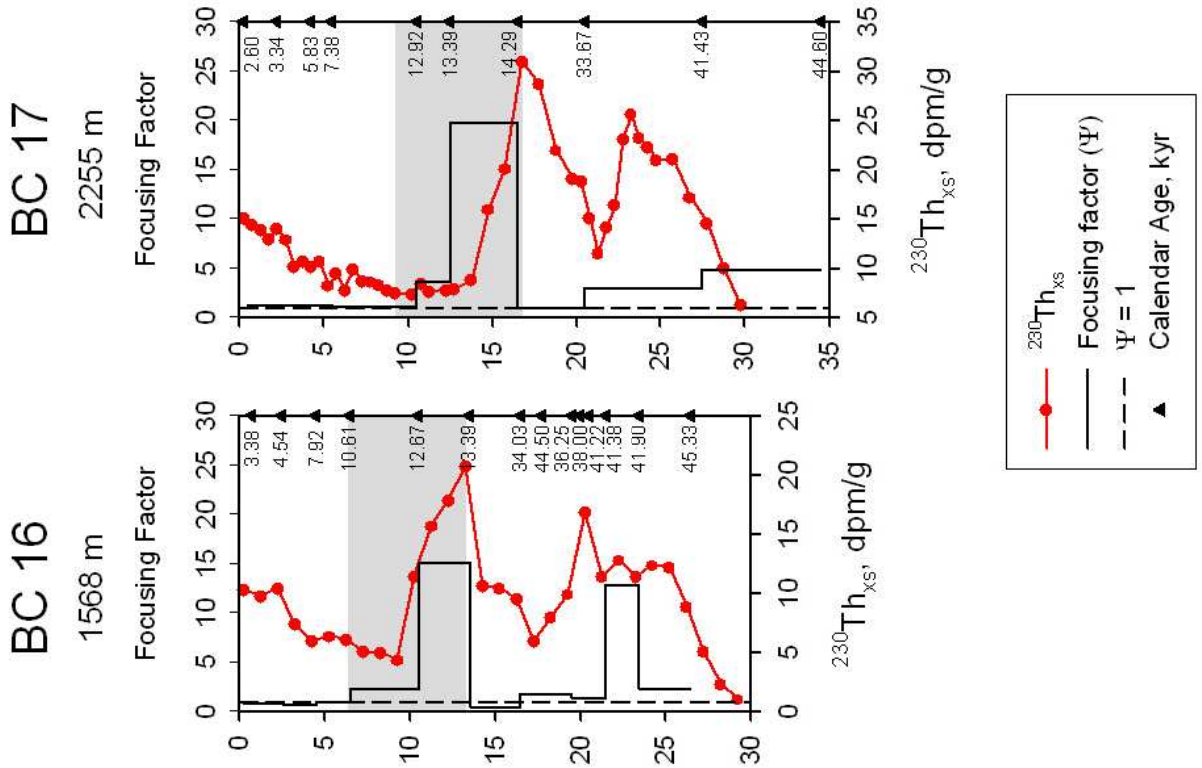

귱 흉.

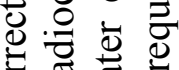

ठํㅓㄴ

की $\overline{8}$ 중

ह

흥유

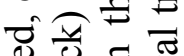

过需

르워

ฮี 휴ㅇㅝㅠ

氙产

.

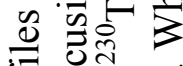

은 홍

an $\dot{0}$

.융ㅎㅀ

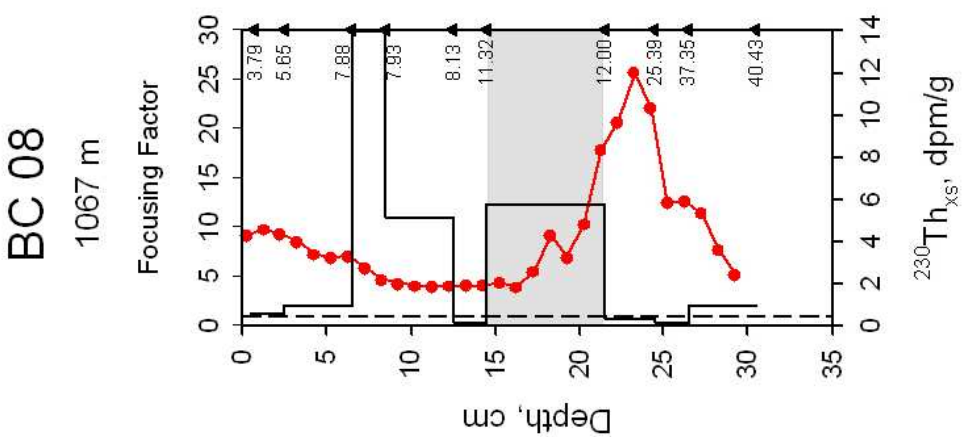

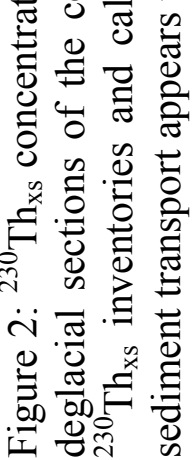



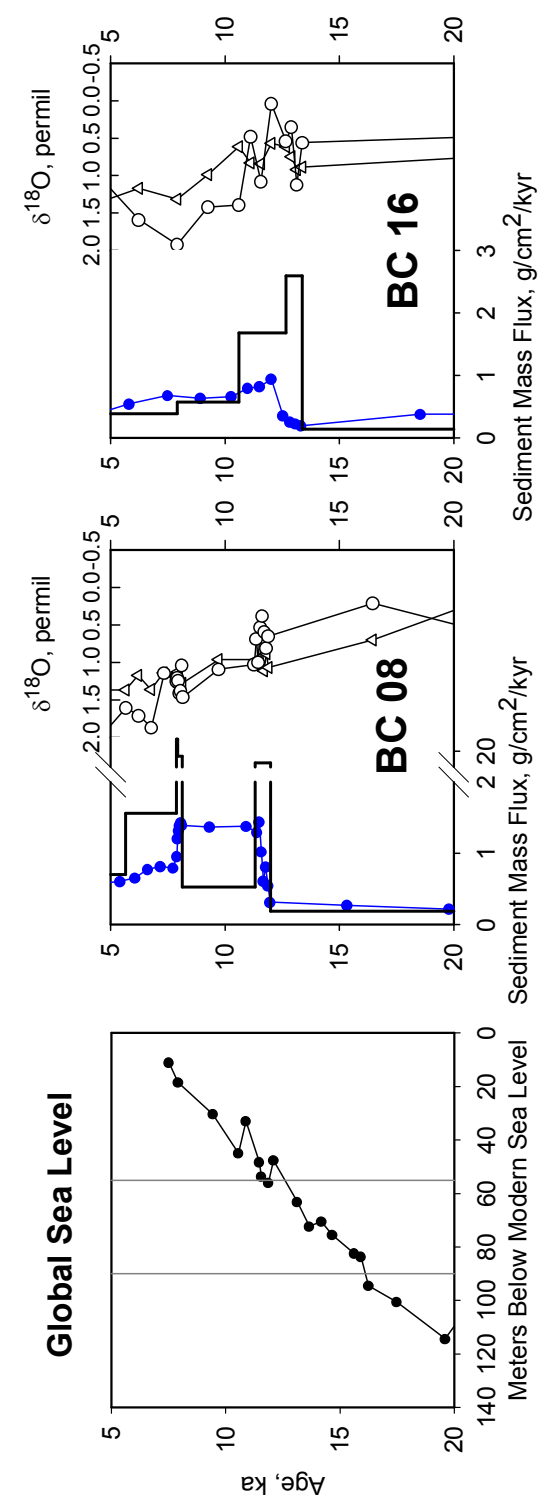
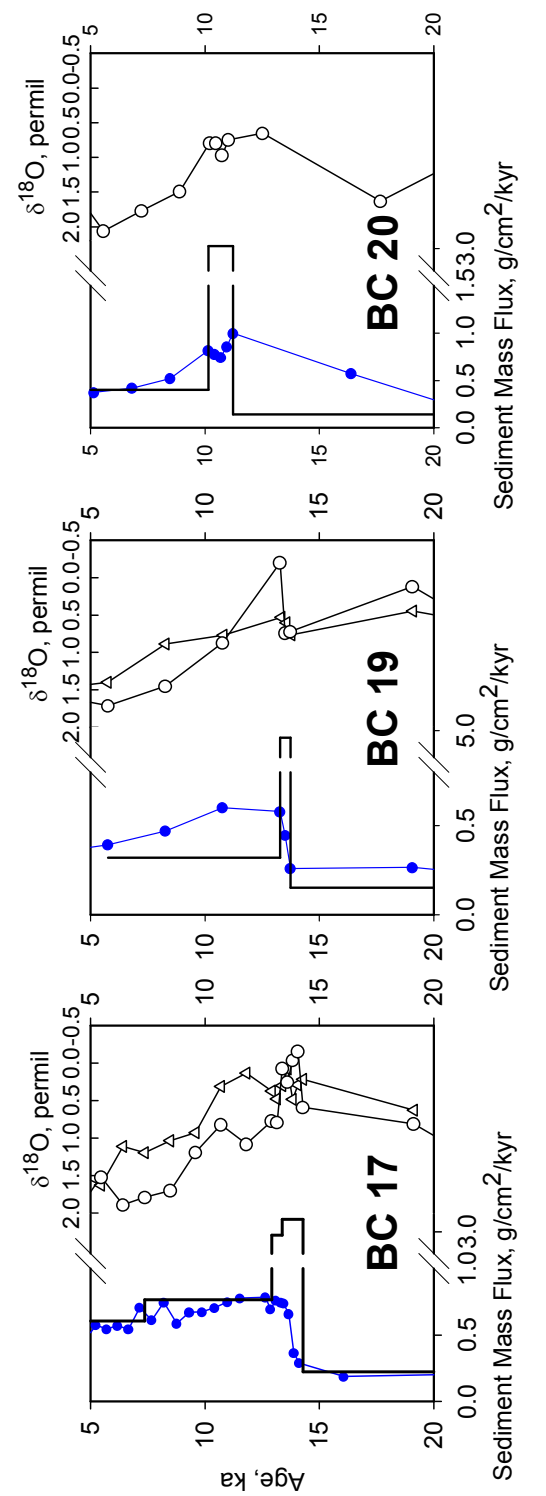

$\bar{\Xi}$

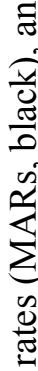

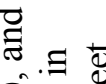

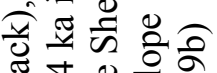

ป \&

की

त क त

$\sum \mathbb{D}_{0} \mathbb{0}$

पे 0 元分

전

ธี . ฐ

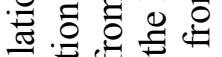

证

궁

లु

क 80 .

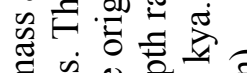

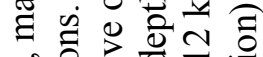

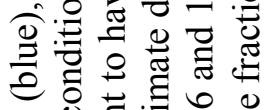

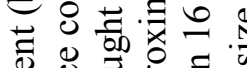

छ

害票芯

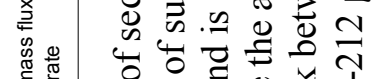

है

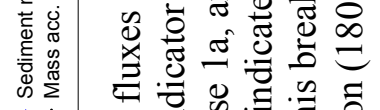

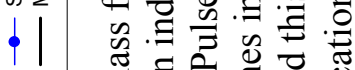

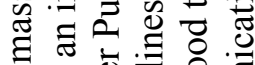

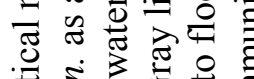

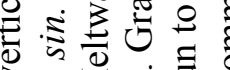

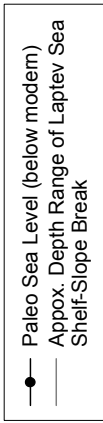

$>\sum \stackrel{0}{0}$

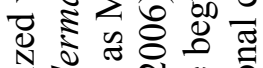

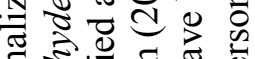

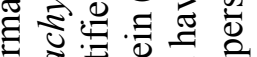

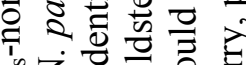

‘

E

导 胥

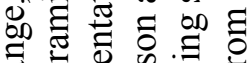

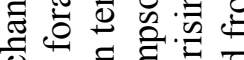

ఠ

己 흔

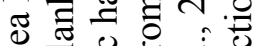

क

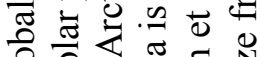

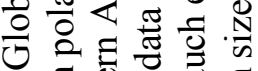

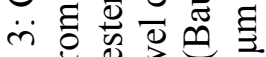

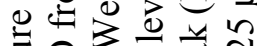

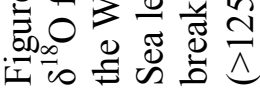




\section{References}

Anderson, R.F., Bacon, M.P., Brewer, P.G., 1983. Removal of ${ }^{230} \mathrm{Th}$ and ${ }^{231} \mathrm{~Pa}$ at ocean margins. Earth Planet. Sci. Lett., v. 66, p. 73-90.

Are, F.E., 1999. The role of coastal retreat for sedimentation in the Laptev Sea. In: Kassens, H., Bauch, H.A., Dmitrenko, I., Eicken, H., Hubberten, H.-W., Melles, M., Thiede, J., Timokhov, L. (eds.), Land-Ocean Systems in the Siberian Arctic: Dynamics and History. Springer-Verlag, Berlin, 1999, 287-295.

Bacon, M.P., Huh, C.-A., Moore, R.M., 1989. Vertical profiles of some natural radionuclides over the Alpha Ridge, Arctic Ocean. Earth Planet. Sci. Lett. 95, 1522.

Bauch, H.A., Mueller-Lupp, T., Taldenkova, E., Spielhagen, R.F., Kassens, H., Grootes, P.M., Thiede, J., Heinemeier, J., Petryashov, V.V., 2005. Chronology of the Holocene transgression at the North Siberian margin. Global Planet. Change 31, 125-139.

Bradley, R.S., England, J.H., 2008. The Younger Dryas and the sea of ancient ice. Quat. Res. In press.

Choi, M.S., R. Francois, K. Sims, M.P. Bacon, S. Brown-Leger, A.P. Fleer, L. Ball, D. Schneider, S. Pichat, 2001. Rapid determination of ${ }^{230} \mathrm{Th}$ and ${ }^{231} \mathrm{~Pa}$ in seawater by desolvated micro-nebulization Inductively Coupled Plasma magnetic sector mass spectrometry. Marine Chemistry v. 76, p. 99-112.

Clough, L.M., Ambrose, W.G., Cochran, J.K., Barnes, C., Renaud, P.E., Aller, R.C., 1997. Infaunal density, biomass and bioturbation in the sediments of the Arctic Ocean. Deep-Sea Res. II 44, 1683-1704.

Darby, D.A., Bischof, J.F., Spielhagen, R.F., Marshall, S.A., Herman, S.W., 2002. Arctic ice export events and their potential impact on global climate during the late Pleistocene. Paleoceanography 17, 10.1029/2001PA000639.

Darby, D.A., Bischof, J.F., Jones, G.A., 1997. Radiocarbon chronology of depositional regimes in the western Arctic Ocean. Deep-Sea Res. II 44, 17451757.

Fairbanks, R.G., 1989. A 17,000-year glacio-eustatic sea level record: Influence of glacial melting rates on the Younger Dryas event and deep-ocean circulation, Nature 342, 637-642.

Fairbanks, R.G., Mortlock, R.A., Chiu, T.-C., Cao, L., Kaplan, A., Guilderson, T.P., Fairbanks, T.W., Bloom, A.L., 2005. Marine radiocarbon calibration curve spanning 0 to 50,000 years B.P. based on paired ${ }^{230} \mathrm{Th} /{ }^{234} \mathrm{U} /{ }^{238} \mathrm{U}$ and ${ }^{14} \mathrm{C}$ dates on pristine corals. Quat. Sci. Rev. 24, 1781-1796.

Fetterer, F., K. Knowles, W. Meier, and M. Savoie. 2002, updated 2008. Sea Ice Index. Boulder, Colorado USA: National Snow and Ice Data Center. Digital media.

Francois, R., Bacon, M.P., Suman, D.O., 1990. Thorium $-{ }^{230}$ profiling in deep sea sediments: High-resolution records of flux and dissolution of carbonate in the equatorial Atlantic during the last 24,000 years. Paleoceanography 5, 761-787. 
Francois, R., Frank, M., Rutgers van der Loeff, M.M., Bacon, M.P., 2004. ${ }^{230} \mathrm{Th}$ normalization: An essential tool for interpreting sedimentary fluxes during the late Quaternary. Paleoceanography 19, PA1018, doi:10.1029/2003PA000939.

Gherardi, J.-M., Labeyrie, L., McManus, J.M., Francois, R., Skinner, L.C., Cortijo, E., 2005. Evidence from the Northeastern Atlantic basin for variability in the rate of the meridional overturning circulation through the last deglaciation. Earth Planet. Sci. Lett., v. 240, p. 710-723.

Grantz, A., Phillips, R.L., Mullen, M.W., Starratt, S.W., Jones, G.A., Naidu, A.S.,Finney, B.P., 1996. Character, paleoenvironment, rate of accumulation, and evidence for seismic triggering of Holocene turbidites, Canada Abyssal Plain, Arctic Ocean. Mar. Geol. 133, 51-73

Hall, J.J. and L.-H. Chan, 2004. Ba/Ca in Neogloboquadrina pachyderma as an indicator of deglacial meltwater discharge into the western Arctic Ocean. Paleoceanography v. 19, PA1017, doi:10.1029/2003PA000910.

Henderson, G.M., C. Heinze, R.F. Anderson, and A.M.E. Winguth, 1999. Global distribution of the ${ }^{230} \mathrm{Th}$ flux to ocean sediments constrained by GCM modeling. Deep-Sea Research I v. 46, p. 1861-1893.

Henderson, G.M., Anderson, R.F., 2003. The U-series toolbox for paleoceanography. Rev. Mineral. Geochem. 52, 493-531.

Hoffmann, S.S. and J.F. McManus, 2007. Is There a ${ }^{230}$ Thorium Deficit in Arctic Sediments? Earth Planet. Sci. Lett. v. 258, p. 516-527.

Hughen, K.A., Baillie, M.G.L., Bard, E., Bayliss, A., Beck, J.W., Bertrand, C.J.H., Blackwell, P.G., Buck, C.E., Burr, G.S., Cutler, K.B., Damon, P.E., Edwards, R.L., Fairbanks, R.G., Friedrich, M., Guilderson, T.P., Kromer, B., McCormac, F.G., Manning, S.W., Bronk Ramsey, C., Reimer, P.J., Reimer, R.W., Remmele, S., Southon, J.R., Stuiver, M., Talamo, S., Taylor, F.W., van der Plicht, J., Weyhenmeyer, C.E., 2004. Marine04 Marine radiocarbon age calibration, 26 - 0 ka BP. Radiocarbon 46, 1059-1086.

Huh, C.-A. , Pisias, N.G., Kelley, J.M., Maiti, T.C., Grantz, A., 1997. Natural radionuclides and plutonium in sediments from the western Arctic Ocean: sedimentation rates and pathways of radionuclides. Deep-Sea Res. II 44, 1725 1743.

Kleiber, H.P., Niessen, F., 1999. Late Pleistocene paleoriver channels on the Laptev Sea Shelf - implications from sub-bottom profiling. In: Kassens, H., Bauch, H.A., Dmitrenko, I., Eicken, H., Hubberten, H.-W., Melles, M., Thiede, J., Timokhov, L. (Eds.), Land-Ocean Systems in the Siberian Arctic: Dynamics and History. Springer-Verlag, New York, p. 635-656.

Mangerud, J., Gulliksen, S., 1975. Apparent radiocarbon ages of recent marine shells from Norway, Spitsbergen, and Arctic Canada. Quat. Res. 5 (1975) 263-273.

Norgaard-Pedersen, N., R.F. Spielhagen, J. Thiede, and H. Kassens, 1998. Central Arctic surface ocean environment during the past 80,000 years. Paleoceanography v. 13, p. 193-204. 
Norgaard-Pedersen, N., R.F. Spielhagen, H. Erlenkeuser, P.M. Grootes, J. Heinemeier, and J. Knies, 2003. Arctic Ocean during the Last Glacial Maximum: Atlantic and polar domains of surface water mass distribution and ice cover. Paleoceanography v. 18, 1063 doi:10.1029/2002PA000781.

Ostermann, D.R., Curry, W.B., 2000. Inter-lab mass spectrometer calibration programs. IGBP PAGES/World Data Center A for Paleoclimatology Data Contribution Series \#1999-065. NOAA/NGDC Paleoclimatology Program, Boulder CO.

Poore, R.Z., Osterman, L., Curry, W.B., Phillips, R.L., 1999a. Late Pleistocene and Holocene meltwater events in the western Arctic Ocean. Geology 27, 759-762.

Poore, R.Z., Ostermann, D.R., McGeehin, J., 1999b. Stable isotope data and AMS 14C dates from Arctic Ocean Section 1994 surface sediment transect and box core samples from the Mendeleyev Ridge area. USGS Open-File Report 99-48.

Spielhagen,R.F., Erlenkeuser, H., 1994. Stable oxygen and carbon isotopes in planktic foraminifers from Arctic Ocean surface sediments: reflection of the low salinity surface water layer. Mar. Geol. v. 119, p. 227-250.

Stein, R., S.-I. Nam, C. Schubert, C. Vogt, D. Futterer, and J. Heinemeier, 1994. The last deglaciation event in the eastern central Arctic Ocean. Science v. 264, p. 692-696.

Stuiver, M., Reimer, P.J., Reimer, R.W., 2005. Calib 5.0, WWW Program and Documentation.

Suman, D.O., Bacon, M.P., 1989. Variations in Holocene sedimentation in the North American Basin determined from ${ }^{230} \mathrm{Th}$ measurements. Deep-Sea Res. 36, 869878.

Thompson, W., Goldstein, S., 2006. A radiometric calibration of the SPECMAP timescale. Quat. Sci. Rev. v. 25, p. 3207-3215. 


\title{
Chapter 5
}

\section{${ }^{231}$ Pa Deposition and Export in the Central Arctic Since the Last Glaciation}

\begin{abstract}
The radionuclides ${ }^{231} \mathrm{~Pa}$ and ${ }^{230} \mathrm{Th}$, produced in the water column and removed from the ocean by particle scavenging and burial in sediments, offer a means for paleoceanographers to examine past dynamics of both water column and sedimentary processes. We present the first high-resolution, radiocarbon-dated downcore records of sedimentary ${ }^{231} \mathrm{~Pa} /{ }^{230} \mathrm{Th}$ from the Arctic Ocean, in a transect from the Makarov Basin (Western Arctic) to the Nansen Basin (Eastern Arctic) to determine regional and temporal patterns of ${ }^{231} \mathrm{~Pa}$ deposition and export from the central basins. Low ratios indicate that ${ }^{231} \mathrm{~Pa}$ was exported from all sites during the late glacial period (35-15 ky), with export decreasing during the deglaciation (15-11 ky). ${ }^{231} \mathrm{~Pa} /{ }^{230} \mathrm{Th}$ measurements in cores from three continental slope sites show no evidence for a ${ }^{231} \mathrm{~Pa}$ sink related to boundary scavenging on the continental slopes. Holocene ${ }^{231} \mathrm{~Pa} /{ }^{230} \mathrm{Th}$ ratios show a strong variation by depth, with strong export of ${ }^{231} \mathrm{~Pa}$ at deep sites but little or no export at shallow sites, a result which echoes findings for the South Atlantic and the Pacific. The Central Arctic thus appears fundamentally similar to other ocean basins in its ${ }^{231} \mathrm{~Pa}$ dynamics, despite its peculiar qualities of sea ice cover, low particle flux, and relatively isolated deep waters.
\end{abstract}

\section{Introduction}

The radionuclides ${ }^{231} \mathrm{~Pa}$ and ${ }^{230} \mathrm{Th}$ are of interest to paleoceanographers because they preserve in sediments a record of both water column and sedimentation processes. These nuclides are produced by radiodecay of ${ }^{235} \mathrm{U}$ and ${ }^{234} \mathrm{U}$, respectively, which are well-mixed and conservative in seawater. Because $U$ is conservative in oxygenated 
seawater, and thus present in the bulk of the ocean at the same concentration and in the same isotopic ratio, its daughter nuclides ${ }^{231} \mathrm{~Pa}$ and ${ }^{230} \mathrm{Th}$ are produced at constant rates and at a constant ratio to each other of 0.093 in any given volume of seawater (Henderson and Anderson, 2003). Thorium and protactinium are both particle-reactive, and leave the water column by adsorption to sinking particles and subsequent burial in sediments (Bacon and Anderson, 1982). Thorium in particular is so particle-reactive that for much of the world ocean, the local rate of ${ }^{230} \mathrm{Th}$ removal to sediments approximately balances its local rate of production in the water column, determined by the depth of the water column (Anderson et al., 1983a, Yu et al., 2001). This behavior makes "excess" ${ }^{230} \mathrm{Th}$ $\left({ }^{230} \mathrm{Th}_{\mathrm{xs}}\right),{ }^{230} \mathrm{Th}$ derived from the water column and unsupported by $\mathrm{U}$ decay within the crystal lattice of the sediments, a useful proxy to which records of other chemical species or sedimentary components can be normalized to determine their fluxes (Bacon, 1984; Francois et al., 1990; Francois et al., 2004).

$\mathrm{Pa}$ is less particle-reactive than $\mathrm{Th}$, and consequently has a longer residence time in the water column before it is removed to sediments (Anderson et al., 1983a; Yu et al., 2001). This allows ${ }^{231} \mathrm{~Pa}$ to be transported away from regions of low particle flux (and thus low scavenging potential) and exported to regions of higher particle flux or different particle composition (Anderson et al., 1983b). Export of ${ }^{231} \mathrm{~Pa}$ can occur either by water mass advection, as is thought to occur in the North Atlantic (e.g. Moran et al., 2002), or by eddy diffusion, as is thought to occur in the Pacific (Yang et al., 1986). Normalized to ${ }^{230} \mathrm{Th}_{\mathrm{xs}},{ }^{231} \mathrm{~Pa}_{\mathrm{xs}}$ measurements in sediment cores can give information on local scavenging and particle fluxes, as well as regional ${ }^{231} \mathrm{~Pa}$ transport by advection and eddy diffusion. Its half-life of 32.76 kyr allows reconstruction of $\mathrm{Pa}_{\mathrm{xs}}{ }^{230} \mathrm{Th}_{\mathrm{xs}}$ records from sediments of the past $150 \mathrm{kyr}$ (e.g. Thomas et al., 2007). (Note that all sedimentary ${ }^{231} \mathrm{~Pa}{ }^{230} \mathrm{Th}$ ratios referred to henceforward in this paper are ratios of the excess activity of these nuclides.) ${ }^{231} \mathrm{~Pa} /{ }^{230} \mathrm{Th}$ records have been used in the Atlantic as a dynamic tracer of deep water circulation and residence time in the North Atlantic (Yu et al., 1996; McManus et al., 2004; Gherardi et al., 2005, Hall et al., 2006), as a tracer of bottom water inflow in the Indian Ocean (Thomas et al., 2007), and as a proxy of diatom productivity in the Pacific 
and the Southern Ocean (Kumar et al., 1993; Asmus et al., 1994; Bradtmiller et al., 2006), since opal scavenges ${ }^{231}$ Pa very efficiently (Chase et al., 2002).

Few studies of sedimentary ${ }^{231} \mathrm{~Pa}$ have been undertaken in the Arctic. It was thought that particle scavenging in this low-sedimentation-rate basin was too weak to efficiently remove dissolved ${ }^{230} \mathrm{Th}$ from the water column at a rate in balance with its production (e.g. Bacon et al., 1989; Huh et al., 1997). If sediments had a ${ }^{230} \mathrm{Th}_{\mathrm{xs}}$ deficit, then ${ }^{230} \mathrm{Th}_{\mathrm{xs}}$ could not be used as a constant flux proxy or as a normalizer for ${ }^{231} \mathrm{~Pa}_{\mathrm{xs}}$, making interpretation of ${ }^{231} \mathrm{~Pa}_{\mathrm{xs}}$ records difficult. However, Hoffmann and McManus (2007) found that little or no ${ }^{230} \mathrm{Th}_{\mathrm{xs}}$ deficit appeared in sediments from the Makarov Basin and Mendeleev Ridge in the last $35 \mathrm{kyr}$. This finding allows us to use sedimentary ${ }^{230} \mathrm{Th}$ as a normalizing factor in the Arctic, encouraging the use of ${ }^{231} \mathrm{~Pa}$ as a tracer of water column and sedimentation processes.

The water column behavior of ${ }^{231} \mathrm{~Pa}$ and ${ }^{230} \mathrm{Th}$ can be modeled by a reversibleexchange model (Nozaki et al., 1981; Bacon and Anderson, 1982), in which nuclides produced in seawater adsorb to and desorb from sinking particles. At steady state, this model predicts a linear increase in dissolved concentrations of both nuclides with water depth, such that the highest concentrations of dissolved ${ }^{230} \mathrm{Th}$ and ${ }^{231} \mathrm{~Pa}$ are found in the deepest parts of the basins. The slope of this linear increase reflects the scavenging rate at the sampled site, as well as the sinking rate of particles carrying scavenged nuclides. Rapid increase in concentration with depth implies a slower scavenging rate, whereas a small gradient between surface and deep concentrations implies rapid scavenging. Both small and steep gradients can be consistent with locally balanced production and burial of ${ }^{230} \mathrm{Th}$. Water column studies of dissolved and particulate ${ }^{230} \mathrm{Th}$ and ${ }^{231} \mathrm{~Pa}$ suggest variable particle scavenging rates in different regions of the Arctic. At the Alpha Ridge and in the Makarov Basin, high water column concentrations of dissolved ${ }^{230} \mathrm{Th}$ and ${ }^{231} \mathrm{~Pa}$ suggest that particle fluxes are small and residence times are long, up to 55 years for ${ }^{230} \mathrm{Th}$ and 250 years for ${ }^{231} \mathrm{~Pa}$ (Bacon et al., 1989; Scholten et al., 1995; Edmonds et al., 2004). However, in the Nansen and Amundsen Basins, as well as in the Beaufort Sea, residence times for ${ }^{231} \mathrm{~Pa}$ and ${ }^{230} \mathrm{Th}$ are comparable to those elsewhere in the world (Scholten et al., 
1995, Edmonds et al., 1998; Edmonds et al., 2004, Trimble et al., 2004). These results give us a picture of ${ }^{231} \mathrm{~Pa}$ and ${ }^{230} \mathrm{Th}$ dynamics in the present-day ocean.

Our understanding of the past behavior of these nuclides, however, has so far been extremely limited. One downcore record of ${ }^{231} \mathrm{~Pa} /{ }^{230} \mathrm{Th}$ in the Arctic exists from the Alpha Ridge (Ku and Broecker, 1967); although it is relatively low-resolution and has no age control, it shows ratios of ${ }^{231} \mathrm{~Pa}{ }^{230} \mathrm{Th}$ lower than the production ratio in seawater of 0.093. Moran et al. (2005) measured ${ }^{231} \mathrm{~Pa}$ and ${ }^{230} \mathrm{Th}$ in coretop sediments from numerous locations in a transect from the Chukchi Sea to the Nansen Basin, showing that ratios lower than the production ratio dominated the Arctic seafloor, with an average ratio of 0.06. This held true even near the continental slope of the Chukchi Sea, where higher ratios were expected due to larger sources of particles from terrigenous sources and higher productivity. That study concluded that no basin/margin fractionation of ${ }^{231} \mathrm{~Pa}$ and ${ }^{230} \mathrm{Th}$ was apparent, and that roughly $39 \%$ of ${ }^{231} \mathrm{~Pa}$ produced in the Arctic Ocean is exported today.

To investigate whether this pattern of low ratios in the basins of the Arctic Ocean, indicating net ${ }^{231} \mathrm{~Pa}$ export from the Arctic Ocean, has persisted through the large-scale climate changes associated with glacial/interglacial cycles, we measured seven highresolution records of ${ }^{231} \mathrm{~Pa} /{ }^{230} \mathrm{Th}$ in box cores taken in a transect from the Arliss Plateau and Mendeleev Ridge in the Amerasian Basin, across the Lomonosov Ridge, to the Nansen Basin in the Eastern Arctic. These data allow us to address the questions:

i. Has export of ${ }^{231} \mathrm{~Pa}$ from the Central Arctic basins in the water column occurred during different climatic periods, including the Last Glacial Maximum, the last termination, and the Holocene?

ii. Where is this exported ${ }^{231} \mathrm{~Pa}$ finally buried? Does it leave the Arctic?

iii. Does ${ }^{231} \mathrm{~Pa}$ give us information on particle fluxes and scavenging, to complement records of ${ }^{230}$ Th-normalized particle mass flux?

iv. Are regional or depth-related patterns of ${ }^{231} \mathrm{~Pa}$ deposition apparent, and what might influence them? 


\section{Materials and Methods}

Seven box cores from the 1994 Arctic Ocean Section cruise of the $R / V$ Polar Sea (PL-94-AR) were chosen to give a regional transect from the Mendeleev Ridge to the Gakkel Ridge (Figure 1, Table 1), sampling the western, central, and eastern Arctic, and a range of water depths $(\sim 1-3 \mathrm{~km})$ in the Makarov Basin. Cores PL-94-AR BC 08, 16, 17, and 20 from the Mendeleev Ridge and Makarov Basin (Western Arctic) lie underneath the Beaufort Gyre surface circulation, while cores BC 26, 28 and 32 from the Lomonosov Ridge and Nansen Basin (Eastern Arctic) lie beneath the Transpolar Drift, which transports surface water and ice across the basin to the Fram Strait. The cores consist of brown muds, with varying foraminifer and lithic grain contents. Individual samples in several cores from continental slopes in the Amerasian and Eurasian Basins, PL-91-AR 21-8BC, PL-91-AR 14-4PG, and PL-93-AR 19BC, were analyzed to examine the possibility of boundary scavenging of ${ }^{231} \mathrm{~Pa}$.

\section{Radionuclide analyses}

Cores were sampled in half-cm slices every $1 \mathrm{~cm}$; BC 17 was sampled every half$\mathrm{cm}$ for a higher-resolution record. Sediments were spiked with ${ }^{233} \mathrm{~Pa}$ and ${ }^{229} \mathrm{Th}$ for isotope dilution analysis, and digested in $\mathrm{HClO}_{4}, \mathrm{HF}$, and $\mathrm{HNO}_{3}$ according to methods in Choi et al. (2001). Aliquots were removed and spiked with ${ }^{236} \mathrm{U}$ and ${ }^{229} \mathrm{Th}$ for measurement of ${ }^{238} \mathrm{U}$ and ${ }^{232} \mathrm{Th}$. The rest of the digested samples were separated into Th and $\mathrm{Pa}$ fractions by anion-exchange column chromatography, and analyzed on a ThermoFinnegan Element 2 inductively-coupled plasma mass spectrometer. ${ }^{238} \mathrm{U}$ and ${ }^{232} \mathrm{Th}$ measurements were used to estimate supported ${ }^{230} \mathrm{Th}$ and ${ }^{231} \mathrm{~Pa}$ activity within the crystal lattice and ingrown activity from authigenic U. Excess values were corrected for radiodecay since the time of deposition according to radiocarbon-derived age models.

Uncertainty associated with ICPMS analysis is estimated to be less than $2 \%$ for both ${ }^{231} \mathrm{~Pa}$ and ${ }^{230} \mathrm{Th}$ analyses. Uncertainty in our age models, used in corrections for radioactive decay since deposition, produces uncertainty in age-corrected ${ }^{231} \mathrm{~Pa} /{ }^{230} \mathrm{Th}$ ratios of less than $3 \%$ for age errors up to $2 \mathrm{kyr}$. Using replicate ${ }^{230} \mathrm{Th}$ data from samples in $\mathrm{BC} 28$ and 32, and replicate ${ }^{231} \mathrm{~Pa}$ data from samples in $\mathrm{BC} 28$, we calculated an 
average sigma ${ }^{231} \mathrm{~Pa} /{ }^{230} \mathrm{Th}$ of 0.0045 , excluding two apparent outliers with large sigmas (see Appendix Table A.6, Figure A.2). On average, the sigma ${ }^{231} \mathrm{~Pa} /{ }^{230} \mathrm{Th}$ was $\sim 8 \%$ of the mean ${ }^{231} \mathrm{~Pa}{ }^{230} \mathrm{Th}$ of our replicates, indicating that uncertainty associated with replication is greater than that associated with machine error or age error.

\section{Core chronologies}

Radiocarbon dates, measured on samples of the polar planktonic foraminifera $N$. pachyderma sinistral, for $\mathrm{BC} 08,16$, and 17 are from Poore et al. (1999b), from the same subcores as our nuclide records, and for BC 20 are from Darby et al. (1997). Although stratigraphy can vary by several $\mathrm{cm}$ between subcores of the same box core, our coarse fraction weight percent record matches the published Darby et al. record quite well, suggesting little stratigraphic offset between their subcore and ours (Appendix Figure A.1). Dates for cores BC 28 and 32 are from R. Poore, unpublished data (W. Curry, personal communication). Dates from $\mathrm{BC} 26$ are new to this study and were analyzed by the NOSAMS facility at WHOI on $N$. pachyderma sinistral. Radiocarbon ages were converted to calendar years using the Calib 5.2 program (Stuiver and Reimer, 2005) and INTCAL 04 marine calibration dataset (Hughen et al., 2004) for ages younger than 22 kyr, and the calibration of Fairbanks et al. (2005) for older ages. A reservoir age of 690 years (440 years, as in Poore et al. (1999a,b) and Darby et al. (1997), plus a 250 year $\Delta \mathrm{R}$ to account for the likely influence of sea ice on air-sea gas exchange (Mangerud and Gulliksen, 1975) was applied to all ages. Age models were constructed by linear interpolation between these calibrated dates.

\section{Results}

Our ${ }^{231} \mathrm{~Pa},{ }^{230} \mathrm{Th},{ }^{232} \mathrm{Th}$, and ${ }^{238} \mathrm{U}$ measurements, as well as ${ }^{231} \mathrm{~Pa} /{ }^{230} \mathrm{Th}$ ratios, are presented in Appendix Table A.3. ${ }^{231} \mathrm{~Pa} /{ }^{230} \mathrm{Th}$ ratios are graphed in figure 2 on a depth scale and in figure 3 on an age scale.

Western Arctic, Mendeleev Ridge to Makarov Basin Floor (BC 08, 16, 17, 20)

${ }^{231} \mathrm{~Pa}{ }^{230} \mathrm{Th}$ ratios were measured in samples from four cores in the Western Arctic, in water depths ranging from 1047 to $3110 \mathrm{~m}$. Previous work on these cores has 
shown that a major event of sediment redistribution occurred at the deglaciation (15-11 kyr.) We discuss ${ }^{231} \mathrm{~Pa} /{ }^{230} \mathrm{Th}$ in these cores in three climate regimes: the late glacial (35$15 \mathrm{ka})$, the deglacial (15-11 ka) and the Holocene (11 ka-present).

In BC 08 at $1047 \mathrm{~m}$ on the Arliss Plateau, one sample gives a ratio similar to the production ratio prior to $35 \mathrm{ka}$. Between 35 and $12 \mathrm{ka}$, ratios are substantially lower $(\sim 0.07$, Table 1$)$ than the production ratio, beginning to rise at $\sim 12 \mathrm{ka}$ in the deglacial interval in the core, within a sediment layer thought to have been deposited largely by lateral sediment transport (Chapters 3 and 4). Above this layer, ratios hover slightly below the production ratio for $5 \mathrm{~cm}$, jumping again within a second layer deposited by lateral transport at $8 \mathrm{ka}$. Ratios remain at or slightly above the production ratio for the remainder of the Holocene section above this event.

Somewhat deeper along the flank of the Mendeleev Ridge, at 1568 m, BC 16 also shows very low ratios $(\sim 0.04)$ prior to $35 \mathrm{ka}$. Ratios lie below the production ratio in the late glacial and the early deglacial sections (averaging 0.063 ), jumping to the production ratio in the late deglacial and remaining near production, with some variation through the Holocene.

At $2255 \mathrm{~m}, \mathrm{BC} 17$ shows a record of ${ }^{231} \mathrm{~Pa} /{ }^{230} \mathrm{Th}$ entirely below the production ratio. Ratios are lowest ( $\sim 0.034)$ in the glacial section older than $35 \mathrm{kyr}$, rising slightly to late glacial values of $\sim 0.057$ (Table 1), and rising again between 13 and $11 \mathrm{ka}$. Highest ratios in this core (up to 0.082) occur in the late deglacial and early Holocene, and then taper off slightly into the later Holocene.

Our deepest core in the Western Arctic, BC 20, lies on the floor of the Makarov Basin at $3110 \mathrm{~m}$. Here too, $\mathrm{Pa} / \mathrm{Th}$ ratios are always well below the production ratio, averaging 0.05 in the late glacial, with a very small peak at the end of the deglacial and a subsequent fall into the mid-Holocene.

Eastern Arctic, Lomonosov Ridge and Nansen Basin (BC 26, 28, 32)

We measured ${ }^{231} \mathrm{~Pa} /{ }^{230} \mathrm{Th}$ in three cores from the Eastern Arctic, Eurasian Basin, at depths from $1034 \mathrm{~m}$ to $3471 \mathrm{~m}$. Unlike our cores from the Western Arctic, no evidence 
of a major sediment redistribution event at the deglacial is found in these cores. However, glacial-age inventories of ${ }^{230} \mathrm{Th}_{\mathrm{xs}}$ (Chapter 3, figure 4a) suggest that winnowing may possibly have removed sediments from BC 26 at the crest of the Lomonosov Ridge and from BC 32 in the deep Nansen Basin.

BC 26, sitting atop the Lomonosov Ridge at $1034 \mathrm{~m}$ water depth, has almost no ${ }^{231} \mathrm{~Pa}_{\mathrm{xs}}$ or ${ }^{230} \mathrm{Th}_{\mathrm{xs}}$ in the deeper part of the core, below $18 \mathrm{~cm}$. Low concentrations below $15.5 \mathrm{~cm}$ (43 ka) produce high and variable ${ }^{231} \mathrm{~Pa} /{ }^{230} \mathrm{Th}$ ratios. Above $15 \mathrm{~cm}$ in the core, excess nuclide concentrations are higher and give more reliable ratios. Ratios are variable but lie beneath the production ratio throughout the glacial section of the core, transitioning sharply at $7.5 \mathrm{~cm}$ (between dates of $27.7 \mathrm{ka}$ at $8.5 \mathrm{~cm}$ and $16.5 \mathrm{ka}$ at $6.5 \mathrm{~cm}$ ) to values near the production ratio. All samples above this transition, representing the deglacial and Holocene, are at or near the production ratio.

Nearby, at 1990 m on the Amundsen Basin flank of the Lomonosov Ridge, BC 28 gives lower-than-production ratios $(\sim 0.058)$ within its late glacial section. The highest ratios in this core, approaching the production ratio, occur in the late deglacial and early Holocene sections, and fall off slightly into the late Holocene, with a jump in the coretop.

BC 32, at $3471 \mathrm{~m}$ on the floor of the Nansen Basin, not far from the Gakkel Ridge, shows consistently low $\mathrm{Pa} / \mathrm{Th}$ ratios around 0.05 , well below the production ratio, for the last 40 kyr. No change between glacial, deglacial, and Holocene samples can be discerned.

Coretop and shallow samples from several cores on the continental margins of the Arctic were analyzed for ${ }^{231} \mathrm{~Pa}{ }^{230} \mathrm{Th}$ (Table 2, coretops or uppermost samples plotted in Figure 5). The two shallower cores analyzed, PL-91-AR 21-08BC from $1345 \mathrm{~m}$ on the slope north of Svalbard and PL-93-AR 19BC on the Alaskan slope at $2060 \mathrm{~m}$, give ${ }^{231} \mathrm{~Pa}^{230} \mathrm{Th}$ results near to or somewhat below the production ratio, while the deepest core, PL-91-AR 14-4PG, from $4021 \mathrm{~m}$ at the foot of the slope north of Franz-Josef Land gives ratios much lower than production. No age model is available for these cores; thus these ratios, unlike those from our dated Central Arctic box cores, are not corrected for decay since deposition. 


\section{Discussion}

\section{History of late glacial, deglacial, and Holocene Pa deposition}

\section{i. Late glacial records}

Across the Makarov, Amundsen and Nansen Basins, we find low ${ }^{231} \mathrm{~Pa} /{ }^{230} \mathrm{Th}$ ratios in late glacial sediments. In the deepest, oldest sediments measured in BC 16 and 17 , ratios are quite low, $<0.04$; this may be due to insufficient age control. Many of the glacial-age radiocarbon dates measured on these cores are older than five half-lives of ${ }^{14} \mathrm{C}$, resulting in large uncertainty for these ages. If the bottoms of our records are significantly older than our age models based on these ${ }^{14} \mathrm{C}$ dates suggest, the correction we apply for radioactive decay of excess ${ }^{231} \mathrm{~Pa}$ and ${ }^{230} \mathrm{Th}$ since deposition would be too small, resulting in artificially lowered ${ }^{231} \mathrm{~Pa} /{ }^{230} \mathrm{Th}$ ratios. Late glacial sediments between 35 and $15 \mathrm{ka}$ give ratios lower than the production ratio, between 0.049 and 0.070 , in all seven cores. In all cores but $\mathrm{BC} 26$, the ${ }^{231} \mathrm{~Pa} /{ }^{230} \mathrm{Th}$ ratios between $\sim 30$ and $15 \mathrm{ka}$ in each core are remarkably uniform (Figure 3). Sedimentation rates in the central Arctic were extremely low during late glacial times (Darby et al., 1997; Norgaard-Pedersen et al., 1998, 2003; Poore et al., 1999a and b), on the order of mm/kyr. Any bioturbative mixing which occurred in these sediments might work to homogenize the few-cm-thick late glacial section. However, ${ }^{230} \mathrm{Th}_{\mathrm{xs}}$ and ${ }^{231} \mathrm{~Pa}_{\mathrm{xs}}$ themselves are not homogenized through the late glacial interval in every core (Appendix Table A.3; ${ }^{230} \mathrm{Th}_{\mathrm{xs}}$ profiles in Chapter 3, Figure 2), so the constant ratios in this interval appear to be an actual signal of essentially constant proportion of ${ }^{231} \mathrm{~Pa}$ export at each site between 35 and $15 \mathrm{ka}$. The percent of local ${ }^{231} \mathrm{~Pa}$ relative to ${ }^{230} \mathrm{Th}$ missing from the sediments and therefore presumably exported in the water column during the late glacial varies between 24 and $47 \%$ (Table 1, Figure 4), averaging about 35-38\% in the Amerasian and Eurasian Basins (by comparison, export of ${ }^{231} \mathrm{~Pa}$ from the North Atlantic is estimated at 50-70\% ( $\mathrm{Yu}$ et al., 1996)). Export of ${ }^{231} \mathrm{~Pa}$ is strongly related to depth in the water column (Figure 4), see below for further discussion of this trend. Percent export was calculated by subtracting the measured ${ }^{231} \mathrm{~Pa} /{ }^{230} \mathrm{Th}$ ratio from the production ratio and dividing the difference by 
the production ratio. This method assumes that deposition of ${ }^{230} \mathrm{Th}$ is in balance with production of ${ }^{230} \mathrm{Th}$.

\section{ii. Deglacial records}

Ratios rise at the deglaciation in all Western Arctic (Amerasian Basin) cores (BC $08,16,17$, and 20), in BC 26, and in BC 28 at the very end of the deglacial and start of the Holocene. In the Western Arctic cores and $\mathrm{BC} 28$, the ratios rise but remain less than the production ratio, indicating continuing but reduced export of ${ }^{231} \mathrm{~Pa}$ in the water column at this time. ${ }^{231} \mathrm{~Pa}$ export from the central Arctic between 15 and $11 \mathrm{ka}$ based on these cores is on average about $25 \%$ of production (Table 1, Figure 4 ). As in the late glacial, deeper sites bury less ${ }^{231} \mathrm{~Pa}$ relative to production than shallow sites, but in our deglacial samples this relationship is even more pronounced. In BC 26, the measured ${ }^{231} \mathrm{~Pa} /{ }^{230} \mathrm{Th}$ ratio jumps at the end of the glacial to the production ratio, and remains at the production ratio throughout the deglacial and Holocene. This change in ratio, which occurs at $7.25 \mathrm{~cm}$ depth in the core, is bracketed by radiocarbon dates of $25.7 \mathrm{ka}$ at 8.25 $\mathrm{cm}$, and $16.5 \mathrm{ka}$ at $6.25 \mathrm{~cm}$ (Figure 1). The exact timing of this change within that $9 \mathrm{kyr}$ span is therefore unknown; however, the abruptness of the change and the very low apparent sedimentation rate could suggest a possible sedimentation hiatus between 8.25 and $7.25 \mathrm{~cm}$. This interval shows a deficit of ${ }^{230} \mathrm{Th}_{\mathrm{xs}}$ inventory relative to water column production (Chapter 3), consistent with such a hiatus. Only BC 32, the deepest core studied and the closest to the Fram Strait, shows no notable change in ${ }^{231} \mathrm{~Pa} /{ }^{230} \mathrm{Th}$ between the late glacial and deglaciation.

In the Western Arctic cores and $\mathrm{BC} 28$, the deglacial rise in ratio accompanies a rise in ${ }^{230} \mathrm{Th}$-normalized particle mass flux (Figure 3). Although ${ }^{231} \mathrm{~Pa} /{ }^{230} \mathrm{Th}$ and thoriumnormalized mass fluxes are not independent variables, both being calculated with ${ }^{230} \mathrm{Th}_{\mathrm{xs}}$ in the denominator, it is nevertheless intriguing that at times of greater particle flux and greater sedimentation rate such as the deglacial, ${ }^{231} \mathrm{~Pa} /{ }^{230} \mathrm{Th}$ ratios also rise (discussed further below). This would be consistent with an increase in scavenging efficiency of ${ }^{231} \mathrm{~Pa}$ due to an increase in particle fluxes (more particles in the water column are available to scavenge the dissolved ${ }^{231} \mathrm{~Pa}$ ). 
In the Makarov Basin (cores BC 08, 16, 17, and 20), a major deglacial event of sediment redistribution and focusing is found in records of vertical and lateral sediment accumulation, as determined from ${ }^{230} \mathrm{Th}_{\mathrm{xs}}$ measurements (Chapter 4). ${ }^{231} \mathrm{~Pa} /{ }^{230} \mathrm{Th}$ ratios within these laterally-transported sediments are variable in behavior (Figure 2), showing both peaks and intervals of constant ratio in $\mathrm{BC} 08$ (Figure 2, 21-14 cm) and 16 (Figure 2, 13-7 cm), and small variability in $\mathrm{BC} 17$ and 20 (Figure 2, 16-10 $\mathrm{cm}$ and 8-4 cm respectively). The sediments that were transported to these sites at the deglaciation may have come from the continental shelf and slope, remobilizing in response to rising sea level, and scavenged ${ }^{231} \mathrm{~Pa}$ and ${ }^{230} \mathrm{Th}$ from the water during their transit to our sites. As we do not know their exact path or source, we are not able to interpret changes in ratio within these sediment layers. However, the average ${ }^{231} \mathrm{~Pa} /{ }^{230} \mathrm{Th}$ ratios of these sediments may nevertheless reflect regional scavenging patterns of these nuclides in the Makarov Basin, due to the re-equilibration of the nuclides on the particles with ambient ${ }^{231} \mathrm{~Pa}$ and ${ }^{230} \mathrm{Th}$ water column concentrations during transport across the basin.

\section{iii. Holocene records}

Following the deglacial, several trends appear in our ${ }^{231} \mathrm{~Pa} /{ }^{230} \mathrm{Th}$ records. In $\mathrm{BC}$ 17,20 , and $28,{ }^{231} \mathrm{~Pa}{ }^{230} \mathrm{Th}$ ratios gradually drop slightly from the deglacial and early Holocene peaks (Figure 3). This may reflect lowered particle fluxes and hence lowered scavenging efficiency once deglacial sea level rise and collapse of the Laurentide and Kara-Barents Ice Sheets were complete (Chapter 3), changes in dominant particle types, or changes in ventilation and residence times of Arctic deep waters. In BC 32, ratios remained well below the production ratio, similar to its late glacial and deglacial record, indicating unchanged export of $\sim 50 \%$ of locally-produced ${ }^{231} \mathrm{~Pa}$ (Table 1, Figure 4) from this deep site in the Nansen Basin.

In $\mathrm{BC} 08$ and 16, however, ratios increased to around the production ratio during the Holocene (figure 3), while in $\mathrm{BC} 26$ ratios remained at or near the production ratio following the deglacial. These cores are our shallowest, from depths of 1-1.5 km. Holocene ratios are essentially invariant and at or slightly above the production ratio in $\mathrm{BC} 08$, following a second interval of sediment focusing in that core at $8 \mathrm{ka}$. Measured 
${ }^{231} \mathrm{~Pa}{ }^{230} \mathrm{Th}$ stays at the production ratio in $\mathrm{BC} 26$ with only one slight drop at $6 \mathrm{ka}$, while in $\mathrm{BC} 16{ }^{231} \mathrm{~Pa} /{ }^{230} \mathrm{Th}$ values hover around the production ratio in the early Holocene and drop very slightly at $5 \mathrm{ka}$.

Holocene export of ${ }^{231} \mathrm{~Pa}$ from the central Arctic varies more with water depth than late-glacial export: in the water column above $1.5 \mathrm{~km}$, little export occurs; between 1.5 and $2.5 \mathrm{~km}$ roughly one third of ${ }^{231} \mathrm{~Pa}$ production is exported rather than buried locally, and in the deepest waters up to half of locally-produced ${ }^{231} \mathrm{~Pa}$ is exported (Table 1, Figure 4).

\section{Factors controlling export and burial of ${ }^{231} \mathrm{~Pa}$}

vi. Particle fluxes to the Central Arctic seafloor

A number of processes have been suggested to control the distribution of ${ }^{231} \mathrm{~Pa}$ and ${ }^{230} \mathrm{Th}$ in the water column and their removal to the seafloor. The flux of sinking particles in the water column could affect the efficiency of ${ }^{231} \mathrm{~Pa}$ scavenging (Lao et al., 1992, 1993), although it appears to matter less for scavenging of ${ }^{230} \mathrm{Th}$ (Henderson et al., 1999; Yu et al., 2001; Siddall et al., 2008). The more particles are present in seawater, the more likely an atom of ${ }^{231} \mathrm{~Pa}$ will adsorb to one of them, rather than remaining in the water column.

The shapes of our ${ }^{231} \mathrm{~Pa} /{ }^{230} \mathrm{Th}$ records and ${ }^{230} \mathrm{Th}$-normalized mass fluxes resemble each other (Figure 3), suggesting a possible relationship between the two. In general, ${ }^{231} \mathrm{~Pa}^{230} \mathrm{Th}$ ratios and particle fluxes are both low during the late glacial and rise during the deglacial at most sites. Several Holocene records break this pattern: in BC 08, 16, and 26 particle fluxes drop or stay low while ${ }^{231} \mathrm{~Pa}{ }^{230} \mathrm{Th}$ reaches maximum values. ${ }^{231} \mathrm{~Pa}^{230} \mathrm{Th}$ and ${ }^{230} \mathrm{Th}$-normalized mass fluxes are not independent variables, as both normalize an input to the seafloor to measured ${ }^{230} \mathrm{Th}_{\mathrm{xs}}$. However, a comparison between the two variables may prove useful: when the measured concentration of ${ }^{230} \mathrm{Th}_{\mathrm{xs}}$ increases or decreases in a core record, due to changes in sedimentation rate, ${ }^{231} \mathrm{~Pa}$ should also correspondingly increase or decrease because it too is likely to be concentrated in the sediments by adsorption onto scant quantities of particles, or diluted by large particle 
influxes. Variations in the response of ${ }^{231} \mathrm{~Pa}$ scavenging to changes in particle fluxes, i.e. the extent to which ${ }^{231} \mathrm{~Pa}$ was concentrated in the sediments by the same fluxes that scavenged ${ }^{230} \mathrm{Th}$, may therefore be revealed by the relationship between ${ }^{231} \mathrm{~Pa} /{ }^{230} \mathrm{Th}$ and mass fluxes.

We plot ${ }^{231} \mathrm{~Pa} /{ }^{230} \mathrm{Th}$ against ${ }^{230} \mathrm{Th}$-normalized sediment mass flux in each core (Figure 5) along with linear least-squares fits to define the relationships between these variables. We find that, despite similarities between the shapes of the ${ }^{231} \mathrm{~Pa} /{ }^{230} \mathrm{Th}$ and ${ }^{230}$ Th-normalized mass flux records in many cores, changes in mass flux appear to account for a small proportion of total ${ }^{231} \mathrm{~Pa} /{ }^{230} \mathrm{Th}$ variability in most of our cores. BC 17 at intermediate depth in the Makarov Basin alone shows a relatively strong relationship $\left(\mathrm{n}=48, \mathrm{r}^{2}=0.53\right)$. BC 26 shows a negative correlation between particle flux and ${ }^{231} \mathrm{~Pa}{ }^{230} \mathrm{Th}$; however, this data would probably be better described by separate, essentially flat trends for the higher deglacial/Holocene ${ }^{231} \mathrm{~Pa} /{ }^{230} \mathrm{Th}$ values and lower late glacial ${ }^{231} \mathrm{~Pa} /{ }^{230} \mathrm{Th}$ values. At all sites other than $\mathrm{BC} 17$, particle flux can be considered a weak or minimal influence on ${ }^{231} \mathrm{~Pa} /{ }^{230} \mathrm{Th}$ ratios.

v. Particle type and fractionation between ${ }^{231} \mathrm{~Pa}$ and ${ }^{230} \mathrm{Th}$

Particle type is a very strong control on ${ }^{231} \mathrm{~Pa}$ scavenging and burial: biogenic opal scavenges ${ }^{231} \mathrm{~Pa}$ as efficiently as it does ${ }^{230} \mathrm{Th}$, while lithogenic and carbonate particles preferentially scavenge ${ }^{230} \mathrm{Th}$ relative to ${ }^{231} \mathrm{~Pa}$ (Anderson et al., 1983a; Chase et al., 2002.) Oceanic regions of high diatom productivity, such as the Southern Ocean and the equatorial Pacific, therefore act as sinks of ${ }^{231} \mathrm{~Pa}$ (Kumar et al., 1995; Asmus et al., 1999, Bradtmiller et al., 2007).

The observed ratio increases in our cores could therefore be due to changes in particle type, if diatom fluxes increased at the deglaciation. As seawater is undersaturated with respect to silica, dissolution is expected to remove diatoms from the sedimentary record in regions of low sedimentation rate such as the Arctic. A deep sediment trap in the Canada Basin at 3000 m collected little biogenic mineral material (Hwang et al., 2008), including small amounts of Si that could be derived from biogenic opal in some samplings (S. Manganini, personal communication) suggesting that little opal may reach 
the seafloor in the center of the deeper basins, and that what does reach the basins may well be laterally transported, rather than vertically and thus may only scavenge ${ }^{231} \mathrm{~Pa}$ from certain parts of the water column. Measurements of biogenic silica weight $\%$ on $\sim 2-5$ samples each from our cores BC 08, 16, 17, 26, 28 and 32 (Appendix Table A.8, figure A.4) gave values between 3 and $6 \%$, with no apparent pattern related to the water depth of the core or to the measured ${ }^{231} \mathrm{~Pa}{ }^{230} \mathrm{Th}$ of the samples. We therefore cannot yet say with certainty whether opal contributed to enhanced scavenging of ${ }^{231} \mathrm{~Pa}$ at our sites. vi. Boundary scavenging

The phenomenon of boundary scavenging reflects the influence of both particle flux and particle type. Effects of boundary scavenging can be seen in maps of ${ }^{231} \mathrm{~Pa} /{ }^{230} \mathrm{Th}$ in the Pacific Ocean (Yang et al., 1986): sediments lying beneath the particle-starved central gyres show low ratios, indicating ${ }^{231} \mathrm{~Pa}$ export. Near the continental margins, where productivity is high, diatoms are plentiful, and lithogenic particle sources abound, sedimentary ${ }^{231} \mathrm{~Pa} /{ }^{230} \mathrm{Th}$ ratios are higher than the production ratio, indicating ${ }^{231} \mathrm{~Pa}$ import (Yang et al., 1986). This basin/margin fractionation was predicted to occur in the Arctic (Huh et al., 1997; Edmonds et al., 2004; Moran et al., 2005) due to low sedimentation rates in the central basins (Darby et al., 1997; Norgaard-Pedersen et al., 1998; Poore et al., 1999a,b) and higher particle fluxes near the continental slopes and shelves (e.g. Fahl and Nöthig, 2007). Residence times of water masses in the deep Arctic basins, based on radiocarbon content of the deep waters, are estimated at 250 years in the Eurasian Basin and 450 years in the Canadian Basin (Schlosser et al., 1997). Residence times calculated for ${ }^{231} \mathrm{~Pa}$ in the Arctic vary between 125 years in the Eurasian Basin, 110 years in the Beaufort Sea, and 250 years in the Makarov Basin (Scholten et al., 1995; Edmonds et al., 1998). Residence times of ${ }^{231} \mathrm{~Pa}$ are thus similar to or shorter than residence times of water masses in the isolated deep Arctic basins. These timescales could allow for advective export of ${ }^{231} \mathrm{~Pa}$ in a ventilated intermediate water or diffusive export in an unventilated and isolated deep water mass, to transport ${ }^{231} \mathrm{~Pa}$ away from the central basin to the continental slope (Anderson et al., 1983b). 
However, no sedimentary evidence for boundary scavenging has yet been found in the Arctic Ocean. ${ }^{231} \mathrm{~Pa}^{230} \mathrm{Th}$ ratios measured in coretops on the Chukchi Slope fell below the production ratio (Moran et al., 2005), even in coretop samples which displayed very high ${ }^{230} \mathrm{Th}$-normalized mass flux estimates. We measured ${ }^{231} \mathrm{~Pa} /{ }^{230} \mathrm{Th}$ in individual samples from several continental slope cores around the perimeter of the deep Arctic basins, to expand the hunt for exported ${ }^{231} \mathrm{~Pa}$ beyond the Chukchi Sea. PL-93-AR 19BC was selected from the Amerasian Basin, at $2060 \mathrm{~m}$ on the Beaufort Sea slope north of the Mackenzie Delta. From the Eurasian Basin, we selected two cores : PL-91-AR 21-8BC at $1345 \mathrm{~m}$ on the slope north of Franz-Josef Land, and PL-91-AR 14-4PG from $4021 \mathrm{~m}$ at the foot of the slope north of Svalbard (locations mapped in Figure 1; coordinates and results in Table 2). No age models exist for these cores: 19BC on the Beaufort Sea slope contains no carbonate fossils to produce a stratigraphy (W. Curry, personal communication), the deep Eurasian Basin core 14-4PG contains small numbers of forams in layers interspersed with barren zones (S. Hoffmann, unpublished data), and no stratigraphic work has yet been done on the shallow Eurasian Basin core 21-8BC. We therefore arbitrarily picked samples from near the coretops and downcore, to measure for ${ }^{231} \mathrm{~Pa}{ }^{230} \mathrm{Th}$ ratios. Ratios significantly above the production ratio would indicate that a core site sits in a regional sink for ${ }^{231} \mathrm{~Pa}$; however, we find no evidence for such a sink at our sites. The shallow Nansen Basin site PL-91-AR 21-8BC gives ratios that are close to or slightly above the production ratio, the intermediate-depth Beaufort Sea site PL-93-AR 19BC gives ratios somewhat below production, while the deep Nansen Basin core gives ratios well below the production ratio (Table 2, Figure 6). ${ }^{230}$ Th-normalized fluxes calculated for these samples are higher than those found in the central Arctic (compare fluxes in Table 2 with Central Arctic fluxes in Figure 3); these slope sites do not appear to lack for particles to scavenge radionuclides. The ratios measured at these sites are higher than those measured at sites of comparable depth elsewhere in the Arctic (Figure 6), perhaps because of the higher particle fluxes. These three slope cores nevertheless show a decrease in ratio with increasing water depth, similar to the pattern seen in the central basin cores. The ratio/depth gradient for these cores is flatter than the central 
basin gradient: less ${ }^{231} \mathrm{~Pa}$ is exported relative to production at this depth near the slope than is exported from our basin sites. Even so, the fact that ${ }^{231} \mathrm{~Pa}$ is exported at all indicates that at this site the continental slope is not acting as a sink for ${ }^{231} \mathrm{~Pa}$ according to our data.

A possible complication arises if the tops of these cores are significantly older than modern: decay of ${ }^{231} \mathrm{~Pa}$ and ${ }^{230} \mathrm{Th}$ since deposition, uncorrected in our analysis of these samples, could lead to artificially low estimations of the originally-deposited sedimentary ratios. However, if the uppermost samples in the shallow Eurasian slope core were assumed to have been deposited with ${ }^{231} \mathrm{~Pa} /{ }^{230} \mathrm{Th}$ ratios $\sim 30 \%$ above the production ratio (as a sink of ${ }^{231} \mathrm{~Pa}$ ), the age of the samples would have to be $\sim 20 \mathrm{kyr}$. (By comparison, the oldest dated Arctic coretop known to us is $\sim 5 \mathrm{ka}$, at BC 32 ). While many stretches of the Arctic continental slope have yet to be analyzed for ${ }^{231} \mathrm{~Pa} /{ }^{230} \mathrm{Th}$, and thus could hide the sought-for sink of ${ }^{231} \mathrm{~Pa}$ exported from the central basins, nevertheless it is interesting that all current ${ }^{231} \mathrm{~Pa} /{ }^{230} \mathrm{Th}$ measurements from the Arctic marginal regions (11 sites from Moran et al., 3 from this study) indicate no preferential scavenging or import of ${ }^{231} \mathrm{~Pa}$. This result, combined with our evidence for ${ }^{231} \mathrm{~Pa}$ export from deep Arctic core sites over the past $35 \mathrm{kyr}$, suggests that export out of the Arctic basins in the water column may be a possible route for ${ }^{231} \mathrm{~Pa}$ (Moran et al., 2005).

vii. Water depth and ${ }^{231} \mathrm{~Pa}{ }^{230}$ Th ratios

Our findings of low Holocene ${ }^{231} \mathrm{~Pa} /{ }^{230} \mathrm{Th}$ ratios in cores from deep sites such as BC 20 and 32, and high ratios in cores from shallow sites such as BC 08, 16 and 26 suggest a relationship between water depth and sedimentary ${ }^{231} \mathrm{~Pa} /{ }^{230} \mathrm{Th}$. Moran et al. (2005) measured ${ }^{231} \mathrm{~Pa} /{ }^{230} \mathrm{Th}$ in coretop sediments at various depths in a transect from the Chukchi Shelf to the Nansen Basin, providing an excellent dataset for comparison with our own profiles (Figure 6, Table 3). Several of these coretop measurements were analyzed on the same box cores as our records, though not on the same subcores. Our coretop results for cores BC 08 and 26 are higher than those measured by Moran et al. on coretops from the same box cores (Table 3); this may be due to slight differences in 
stratigraphy between subcores of a box core. Coretop coarse fraction weight percent measurements and counts of planktonic foraminiferal tests from separate subcores of the same box core gave different values for several Western Arctic cores (Darby et al., 1997; Poore et al., 1999b), confirming the possibility of such coretop stratigraphic differences in our records. We find better agreement between the two data sets at sites BC 16, 17 and 32.

A third set of coretop data (Scholten et al., 1995), largely from depths between 3.5 and $4.5 \mathrm{~km}$ in the Eurasian Basin (deeper than our cores), gives ratios between 0.05 and 0.09 (Appendix, Figure A.3). These fall outside the trend we see in our own data and the Moran et al. (2005) coretops. A slight relation between depth and ratio appears between 3.5 and $4.5 \mathrm{~km}$ in the Scholten et al. coretop values (slope $=-0.0265$ ratio units $/ \mathrm{km}, \mathrm{r}^{2}=0.34$ ) but this accounts for much less of the variability in that data set than the ratio/depth regression accounts for in both the Moran et al. samples and our samples. Furthermore, the ratio/depth regression for these deep cores would predict a ratio of 0.18 for very shallow samples, a ratio much larger than any so far observed in the Arctic. It is possible that these data reflect nepheloid layer scavenging near the seafloor in the deepest parts of the basin.

Both the Moran et al. dataset and our coretop measurements show a strong trend towards lower ${ }^{231} \mathrm{~Pa} /{ }^{230} \mathrm{Th}$ with greater water depth (Figure 5). Linear regressions calculated for each set give different slopes for the relationship $(\delta$ ratio $/ \delta$ depth $(\mathrm{km})=-0.0076+/$ 0.002 for the Moran et al. data and $-0.0175+/-0.004$ for our data), which may be due to the differences in the measured coretop ratios at the shallowest sites (BC 08 and 26) between the two datasets. Interestingly, the slope of the ratio/depth relationship in our coretop measurements is very close to that calculated for coretops at various depths in the South Atlantic Ocean (Figure 7), as well as in the Pacific Ocean, and Arabian Sea (Scholten et al., 2008), although the ratios in the Arctic are generally lower at any given depth than in other basins. This suggests that the ratio/depth relationship we observe in the Arctic may not be driven primarily by circumstances specific to the Arctic such as low regional particle fluxes or slow ventilation of deep basin water masses. Scholten et 
al. (2008) suggest changes in dominant particle type as a possible explanation of their data: sinking biogenic opal is susceptible to dissolution, so more opal bearing ${ }^{231} \mathrm{~Pa}$ may reach shallow sites than deep sites that require longer sinking times through undersaturated seawater to reach. A rough comparison between approximate dissolved silica and the conservative properties of temperature, salinity, and density anomaly (Swift et al., 1997) in the near-seafloor water column at our sites does not show a strong signature of silica dissolution relative to all three conservative properties (Appendix figure A.5), although there are hints of some addition of dissolved silica at sites BC 17 and 20 in the temperature and density plots. More thorough analysis of the bottle data will be needed to fully determine the impact of silica dissolution on the water column.

More study of opal fluxes and preservation in the deep Arctic basins will be required before we will know if this model of ${ }^{231} \mathrm{~Pa}$ deposition at shallow and deep sites could be responsible for the patterns we see in our records. However, the need to balance the ${ }^{231} \mathrm{~Pa}$ budget in the Arctic remains: ${ }^{231} \mathrm{~Pa}$ produced deep in the water column of the central basins is exported, but we do not know where it is finally removed from the water column.

Although the ratio/depth relationship we see for the Holocene is robust and apparently a global phenomenon, this relationship must have been quite different in the past at our sites. Late glacial sediments were deposited with ${ }^{231} \mathrm{~Pa} /{ }^{230} \mathrm{Th}$ ratios lower than the production ratio in all of our seven records. Average ${ }^{231} \mathrm{~Pa} /{ }^{230} \mathrm{Th}$ ratios in our cores for the late glacial, deglacial, and Holocene times are shown versus water depth in Figure 7. The late glacial ratio/depth gradient is flatter than the Holocene gradient, with a $\delta$ ratio / $\delta$ depth $(\mathrm{km})$ slope of -0.0077 (compared to -0.0192 ), but the trend of lower ratios with greater depths remains.

If water depth is a strong predictor of sedimentary ${ }^{231} \mathrm{~Pa} /{ }^{230} \mathrm{Th}$ the world over (Scholten et al., 2008), the question raised by our Arctic cores may not be why shallower ${ }^{231} \mathrm{~Pa}^{230} \mathrm{Th}$ ratios are high during the Holocene, so different from the low ratios otherwise typical of the basin (Moran et al., 2005), but rather why their ratios are so low during the late glacial. One possible answer is that the sharply reduced particle supply at that time, 
as seen in ${ }^{230} \mathrm{Th}$-normalized mass fluxes and radiocarbon age-derived sedimentation rates, may have reduced scavenging efficiency. Another possibility is that the dominant particle type during the late glacial differed from that of today. At the Last Glacial Maximum, it is thought that thick ice with few leads covered the surface of the Arctic Ocean (Darby et al., 1997; Norgaard-Pedersen et al., 2003; Bradley and England, 2008), strongly reducing primary productivity. If diatom productivity decreased, the biogenic opal flux would also dwindle, leaving a tiny particle flux dominated by terrigenous particles, which strongly fractionate between ${ }^{231} \mathrm{~Pa}$ and ${ }^{230} \mathrm{Th}$. Restoration of open water in leads and seasonally ice-free areas following the glacial could then lead to increased opal fluxes and less fractionation between the nuclides, resulting in higher sedimentary ratios where opal reached the seafloor.

viii. Export from the Arctic Basins

To estimate ${ }^{231} \mathrm{~Pa}$ budgets for the deep Arctic Ocean basin as a whole (Table 4), we used the hypsometric study of Jakobsson (2002) to estimate the volume of water in the deep Arctic basin in $500 \mathrm{~m}$ increments over the depth of the entire water column (0$4500 \mathrm{~m}$ ). We multiplied the volume of water in each $500 \mathrm{~m}$ layer by the production rate of ${ }^{231} \mathrm{~Pa}$ to estimate the amount of ${ }^{231} \mathrm{~Pa}$ produced in each layer. We then used our linear regressions of ${ }^{231} \mathrm{~Pa} /{ }^{230} \mathrm{Th}$ with depth for the Holocene, deglacial, and glacial to calculate $\%{ }^{231} \mathrm{~Pa}$ export relative to water depth, calculated the export \% associated with each $500 \mathrm{~m}$-thick layer at its midpoint depth, and multiplied this by the total ${ }^{231} \mathrm{~Pa}$ produced in each layer, to produce estimates of the total amount of ${ }^{231} \mathrm{~Pa}$ that is being lost from the water of the central Arctic. During the Holocene, this estimated export represents $30 \%$ of production (Table 4), while during the glacial our calculated export is $41 \%$ of production.

${ }^{231} \mathrm{~Pa}$ is today being exported from deep waters in the Arctic basins, and in the past was exported at all depths. So far no evidence exists that it is removed at the boundaries of the Arctic basins. Therefore, we must consider export out of the Arctic as a possible way to account for this missing protactinium. As the bulk of dissolved and particulate ${ }^{231} \mathrm{~Pa}$ in the water column is found in the deeper waters (Scholten et al., 1995; Edmonds et al., 1998; Edmonds et al., 2004), the conduit for export must be the Fram 
Strait, the only deepwater passage between the Arctic and the rest of the world ocean. Moran et al. (2005) calculated an estimated modern export through Fram Strait of $\sim 39 \%$ of the total ${ }^{231} \mathrm{~Pa}$ production of the Arctic Ocean (similar to our export estimates above), based on ${ }^{231} \mathrm{~Pa}$ concentrations in the water column below $1000 \mathrm{~m}$ and an outflow rate of 2 Sv. Their estimate of total export to the Atlantic agrees well with our estimates of ${ }^{231} \mathrm{~Pa}$ export away from our intermediate and deep sites during the Holocene, which range between 26 and 50\%. In light of this, it is interesting to note that our record nearest Fram Strait, from BC 32 in the Nansen Basin, shows continuous strong export of $\sim 50 \%$ of its local ${ }^{231} \mathrm{~Pa}$ production over the last $35 \mathrm{ka}$. Our downcore records suggest that the magnitude of ${ }^{231} \mathrm{~Pa}$ export to the high North Atlantic, if it does indeed occur, would have been increased relative to today during the late glacial, and reduced during the deglacial. Downcore sedimentary ${ }^{231} \mathrm{~Pa} /{ }^{230} \mathrm{Th}$ records from the Nordic Seas and Fram Strait could help resolve this question by showing whether imported ${ }^{231} \mathrm{~Pa}$ is buried in these regions during the glacial.

\section{Conclusions}

i. The magnitude of ${ }^{231} \mathrm{~Pa}$ export away from the central regions of the deep Arctic has varied with oceanographic and climatic changes over the course of the glacial/deglacial/Holocene transitions of the last $35 \mathrm{ka}$. The greatest export occurred during the late glacial, and the smallest export during the deglaciation. However, there has been continuous net export from the deep central basins over the timespan of our records.

ii. Boundary scavenging has not been observed in any of our samples, suggesting that the continental slopes do not serve as a sink for ${ }^{231} \mathrm{~Pa}$ from the central basins. Instead, ${ }^{231} \mathrm{~Pa}$ may be exported in intermediate and deep waters through Fram Strait to the high North Atlantic.

iii. Our records suggest only a weak relationship between particle mass flux and sedimentary ${ }^{231} \mathrm{~Pa} /{ }^{230} \mathrm{Th}$. We do not yet know whether particle scavenging efficiency and fractionation, due to changes in biogenic opal flux, may have driven observed changes in our records. 
iv. A strong relationship to water depth is seen in our Holocene ${ }^{231} \mathrm{~Pa} /{ }^{230} \mathrm{Th}$ records, which is weaker but still present in late glacial records. Shallow cores are likely to show higher ${ }^{231} \mathrm{~Pa} /{ }^{230} \mathrm{Th}$ ratios, while deep cores show low ratios, possibly due to dissolution and remineralization of sinking ${ }^{231} \mathrm{~Pa}$-bearing biogenic particles in the water column. 


\section{References}

Anderson, R.F., Bacon, M.P., Brewer, P.G., 1983a. Removal of ${ }^{230} \mathrm{Th}$ and ${ }^{231} \mathrm{~Pa}$ from the open ocean. Earth Planet. Sci. Lett. 62, 7-23.

Anderson, R.F., Bacon, M.P., Brewer, P.G., 1983b. Removal of ${ }^{230} \mathrm{Th}$ and ${ }^{231} \mathrm{~Pa}$ at ocean margins. Earth Planet. Sci. Lett., v. 66, p. 73-90.

Asmus, T., Frank, M., Koschmeider, C., Frank, N., Gersonde, R., Kuhn, G., Mangini, A., 1999. Variations of biogenic particle flux in the southern Atlantic section of the Subantarctic Zone during the late Quaternary: Evidence from sedimentary ${ }^{231} \mathrm{~Pa}_{\mathrm{ex}}$ and ${ }^{230} \mathrm{Th}_{\mathrm{ex}}$. Marine Geology, v. 159, p. 63-78.

Bacon, M.P., Anderson. R.F., 1982. Distribution of thorium isotopes between dissolved and particulate forms in the deep sea, Journal of Geophysical Research v. 87, p. 2045-2056.

Bacon, M.P., 1984. Glacial to interglacial changes in carbonate and clay sedimentation in the Atlantic Ocean estimated from ${ }^{230} \mathrm{Th}$ measurements. Isotope Geoscience v. 2, p. 97-11.

Bacon, M.P., C.-A. Huh, and R.M. Moore, 1989. Vertical profiles of some natural radionuclides over the Alpha Ridge, Arctic Ocean. Earth and Planetary Science Letters v. 95, p. 15-22.

Bradley, R.S., England, J.H., 2008. The Younger Dryas and the sea of ancient ice. Quat. Res. In press.

Bradtmiller. L.I., R. F. Anderson, M.Q. Fleisher and L. H. Burckle, 2007. Opal burial in the equatorial Atlantic Ocean over the last 30kyr: implications for glacialinterglacial changes in the ocean silicon cycle. Paleoceanography, 22, PA4216, doi:10.1029/2007PA001443

Chase, Z., Anderson, R.F., Fleischer, M.Q., Kubik, P.W., 2002. The influence of particle composition and particle flux on scavenging of $\mathrm{Th}, \mathrm{Pa}$ and $\mathrm{Be}$ in the ocean. Earth Planet. Sci. Lett., v. 204, p. 215-229.

Choi, M.S., R. Francois, K. Sims, M.P. Bacon, S. Brown-Leger, A.P. Fleer, L. Ball, D. Schneider, S. Pichat, 2001. Rapid determination of ${ }^{230} \mathrm{Th}$ and ${ }^{231} \mathrm{~Pa}$ in seawater by desolvated micro-nebulization Inductively Coupled Plasma magnetic sector mass spectrometry. Marine Chemistry v. 76, p. 99-112.

Darby, D.A., J.F. Bischof, and G.A. Jones, 1997. Radiocarbon chronology of depositional regimes in the western Arctic Ocean. Deep-Sea Research II v. 44, p. 1745-1757.

Edmonds, H.N., S.B. Moran, J.A. Hoff, J.N. Smith, and R.L. Edwards, 1998. Protactinium- ${ }^{231}$ and Thorium- ${ }^{230}$ abundances and high scavenging rates in the Western Arctic Ocean. Science v. 280, p. 405-407.

Edmonds, H.N., S.B. Moran, H. Cheng, R.L. Edwards, 2004. ${ }^{230} \mathrm{Th}$ and ${ }^{231} \mathrm{~Pa}$ in the Arctic Ocean: implications for particle fluxes and basin-scale $\mathrm{Th} / \mathrm{Pa}$ fractionation. Earth and Planetary Science Letters v. 227, p. 155-167.

Fahl, K. and Nöthig, E.-M., 2007. Lithigenic and biogenic particle fluxes on the Lomonosov Ridge (central Arctic Ocean) and their relevance for sediment accumulation: Vertical vs. lateral transport. Deep-Sea Research I v. 54, p. 12561272. 
Fairbanks, R.G., Mortlock, R.A., Chiu, T.-C., Cao, L., Kaplan, A., Guilderson, T.P., Fairbanks, T.W., Bloom, A.L., 2005. Marine radiocarbon calibration curve spanning 0 to 50,000 years B.P. based on paired ${ }^{230} \mathrm{Th} /{ }^{234} \mathrm{U} /{ }^{238} \mathrm{U}$ and ${ }^{14} \mathrm{C}$ dates on pristine corals. Quat. Sci. Rev. 24, 1781-1796.

Francois, R., M.P. Bacon, and D.O. Suman, 1990. Thorium ${ }^{230}$ profiling in deep sea sediments: High-resolution records of flux and dissolution of carbonate in the equatorial Atlantic during the last 24,000 years. Paleoceanography v. 5, p. 761787.

Francois, R., M. Frank, M.M. Rutgers van der Loeff, and M.P. Bacon, $2004 .{ }^{230} \mathrm{Th}$ normalization: An essential tool for interpreting sedimentary fluxes during the late Quaternary. Paleoceanography v. 19, PA1018, doi:10.1029/2003PA000939.

Gherardi, J.-M., Labeyrie, L., McManus, J.M., Francois, R., Skinner, L.C., Cortijo, E., 2005. Evidence from the Northeastern Atlantic basin for variability in the rate of the meridional overturning circulation through the last deglaciation. Earth Planet. Sci. Lett., v. 240, p. 710-723.

Hall, I.R., Moran, S.B., Zahn, R., Knutz, P.C., Shen, C.-C., Edwards, R.L., 2006. Accelerated drawdown of meridional overturning in the late-glacial Atlantic triggered by transient pre-H event freshwater perturbation. Geophys. Res. Lett., v. 333, L16616, doi:10.1029/2006GL026239.

Henderson, G.M., C. Heinze, R.F. Anderson, and A.M.E. Winguth, 1999. Global distribution of the ${ }^{230} \mathrm{Th}$ flux to ocean sediments constrained by GCM modeling. Deep-Sea Research I v. 46, p. 1861-1893.

Henderson, G.M., Anderson, R.F., 2003. The U-series toolbox for paleoceanography. Rev. Mineral. Geochem. 52, 493-531.

Hoffmann, S.S. and J.F. McManus, 2007. Is There a ${ }^{230}$ Thorium Deficit in Arctic Sediments? Earth Planet. Sci. Lett. v. 258, p. 516-527.

Hughen, K.A., Baillie, M.G.L., Bard, E., Bayliss, A., Beck, J.W., Bertrand, C.J.H., Blackwell, P.G., Buck, C.E., Burr, G.S., Cutler, K.B., Damon, P.E., Edwards, R.L., Fairbanks, R.G., Friedrich, M., Guilderson, T.P., Kromer, B., McCormac, F.G., Manning, S.W., Bronk Ramsey, C., Reimer, P.J., Reimer, R.W., Remmele, S., Southon, J.R., Stuiver, M., Talamo, S., Taylor, F.W., van der Plicht, J., Weyhenmeyer, C.E., 2004. Marine04 Marine radiocarbon age calibration, 26 - 0 ka BP. Radiocarbon 46, 1059-1086.

Huh, C.-A., N.G. Pisias, J.M. Kelley, T.C. Maiti, and A. Grantz, 1997. Natural radionuclides and plutonium in sediments from the western Arctic Ocean: sedimentation rates and pathways of radionuclides. Deep-Sea Research II v. 44, p. 1725-1743.

Hwang, J., Eglinton, T.I., Krishfield, R.A., Manganini, S.J., Honjo, S., 2008. Lateral organic carbon supply to the deep Canada Basin. Geophys. Res. Lett. v. 35, L11607, doi:10.1029/2008GL034271.

Jakobsson, M., 2002, Hypsometry and volume of the Arctic Ocean and its constituent seas, Geochemistry Geophysics Geosystems, v. 3, no. 2.

Ku, T.-L., Broecker, W.S., 1967. Rates of sedimentation in the Arctic Ocean. Prog. Oceanog. 4, 95-104. 
Kumar, N., R. Gwiazda, R.F. Anderson, and P.N. Froelich, $1993 .{ }^{231} \mathrm{~Pa} /{ }^{230} \mathrm{Th}$ ratios in sediments as a proxy for past changes in Southern Ocean productivity. Nature v. 362 , p. 45-48.

Lao, Y., Anderson, R.F., Broecker, W.S., Trumbore, S.E., Hofmann, H.J., Wolfli, W., 1992. Transport and burial rates of Be-10 and $\mathrm{Pa}^{231}$ in the Pacific Ocean during the Holocene period. Earth Planet. Sci. Lett., v. 113, p. 173-189.

Lao, Y., Anderson, R.F., Broecker, W.S., Hofmann, H.J., Wolfli, W., 1993. Particulate fluxes of $\mathrm{Th}^{2}{ }^{230}, \mathrm{~Pa}^{2}{ }^{231}$ and $\mathrm{Be}-10$ in the northeastern Pacific Ocean. Geochim. Cosmochim. Acta, v. 57, p. 205-217.

Mangerud, J., Gulliksen, S., 1975. Apparent radiocarbon ages of recent marine shells from Norway, Spitsbergen, and Arctic Canada. Quat. Res. 5 (1975) 263-273.

McManus, J.F., Francois, R., Gherardi, J.-M., Keigwin, L.D., Brown-Leger, S., 2004. Collapse and rapid resumption of Atlantic meridional circulation linked to deglacial climate changes. Nature 428, 834-837.

Moran, S.B., Shen, C.-C., Edmonds, H.N., Weinstein, S.E., Smith, J.N., Edwards, R.L., 2002. Dissolved and particulate ${ }^{231} \mathrm{~Pa}$ and ${ }^{230} \mathrm{Th}$ in the Atlantic Ocean: constraints on intermediate/deep water age, boundary scavenging, and ${ }^{231} \mathrm{~Pa} /{ }^{230} \mathrm{Th}$ fractionation. Earth Planet. Sci. Lett. 203, 999-1014.

Moran, S.B., Shen, C.-C., Edwards, R.L., Edmonds, H.N., Scholten, J.C., Smith, J.N., $\mathrm{Ku}, \mathrm{T} . \mathrm{-L} ., 2005 .{ }^{231} \mathrm{~Pa}$ and ${ }^{230} \mathrm{Th}$ in surface sediments of the Arctic Ocean: Implications for ${ }^{231} \mathrm{~Pa} /{ }^{230} \mathrm{Th}$ fractionation, boundary scavenging, and advective export. Earth Planet. Sci. Lett., v. 234, p. 235-248.

Norgaard-Pedersen, N., R.F. Spielhagen, J. Thiede, and H. Kassens, 1998. Central Arctic surface ocean environment during the past 80,000 years. Paleoceanography v. 13, p. 193-204.

Norgaard-Pedersen, N., R.F. Spielhagen, H. Erlenkeuser, P.M. Grootes, J. Heinemeier, and J. Knies, 2003. Arctic Ocean during the Last Glacial Maximum: Atlantic and polar domains of surface water mass distribution and ice cover. Paleoceanography v. 18, 1063 doi:10.1029/2002PA000781.

Nozaki, Y., Horibe, Y., Tsubota, H., 1981. The water column distributions of thorium isotopes in the Western North Pacific. Earth Planet. Sci. Lett. v. 54, p. 203-216.

Poore, R.Z., Osterman, L., Curry, W.B., Phillips, R.L., 1999a. Late Pleistocene and Holocene meltwater events in the western Arctic Ocean. Geology 27, 759-762.

Poore, R.Z., Ostermann, D.R., McGeehin, J., 1999b. Stable isotope data and AMS ${ }^{14} \mathrm{C}$ dates from Arctic Ocean Section 1994 surface sediment transect and box core samples from the Mendeleyev Ridge area. USGS Open-File Report 99-48.

Schlosser, P., Kromer, B., Ekwurzel, B., Bönisch,G., McNichol, A., Schneider, R., von Reden, K., Östlund, H.G., Swift, J.H., 1997. The first trans-Arctic ${ }^{14} \mathrm{C}$ section: Comparison of the mean ages of the deep waters in the Eurasian and Canadian basins of the Arctic Ocean. Nucl.Instrum. Methods, 123B, 431-437.

Scholten, J.C., M.M. Rutgers van der Loeff, and A. Michel, 1995. Distribution of ${ }^{230} \mathrm{Th}$ and ${ }^{231} \mathrm{~Pa}$ in the water column in relation to the ventilation of the deep Arctic basins. Deep-Sea Research II v. 42, p. 1519-1531.

Scholten, J.C., Fietzke, J., Mangini, A., Garbe- Schönberg, C.-D., Eisenhauer, A., 
Schneider, R., Stoffers, P., 2008. Advection and scavenging: Effects on ${ }^{230}$ Th and

${ }^{231} \mathrm{~Pa}$ distribution off Southwest Africa. Earth Planet. Sci. Lett., v. 271, p. 159169.

Siddall, M., Henderson, G.M., Edwards, N.R., Frank, M., Müller, S., Stocker, T.F., Joos, F., 2005. ${ }^{231} \mathrm{~Pa} /{ }^{230} \mathrm{Th}$ fractionation by ocean transport, biogenic particle flux and particle type. Earth Planet. Sci. Lett., v. 237, p. 135-155.

Stuiver, M., Reimer, P.J., Reimer, R.W., 2005. Calib 5.0, WWW Program and Documentation.

Swift, J.H., Jones, E.P., Aagaard, K., Carmack, E.C., Hingston, M., MacDonald, R.W., McLaughlin, F.A., Perkin, R.G., 1997. Waters of the Makarov and Canada Basins. Deep-Sea Research II v. 44, p. 1503-1530.

Thomas, A.L., Henderson, G.M., McCave, I.N., 2007. Constant bottom water flow into the Indian Ocean for the past $140 \mathrm{ka}$ indicated by sediment ${ }^{231} \mathrm{~Pa} /{ }^{230} \mathrm{Th}$ ratios. Paleoceanography, v. 22, PA4210, doi:10.1029/2007PA001415.

Trimble, S.M., M. Baskaran, D. Porcelli, 2004. Scavenging of thorium isotopes in the Canada Basin of the Arctic Ocean. Earth and Planetary Science Letters v. 222, p. 915-932.

Yang, H.-S., Nozaki, Y., Sakai, H., Masuda, A., 1986. The distribution of ${ }^{230}$ Th and ${ }^{231} \mathrm{~Pa}$ in the deep-sea surface sediments of the Pacific Ocean. Geochim. Cosmochim. Acta, v. 50, p. 81-89.

Yu, E.-F., R. Francois, and M.P. Bacon, 1996. Similar rates of modern and last-glacial ocean thermohaline circulation inferred from radiochemical data. Nature v. 379, p. 689-694.

Yu, E.-F., R. Francois, M.P. Bacon, and A.P. Fleer, 2001. Fluxes of ${ }^{230} \mathrm{Th}$ and ${ }^{231} \mathrm{~Pa}$ to the deep sea: implications for the interpretation of excess ${ }^{230} \mathrm{Th}$ and ${ }^{231} \mathrm{~Pa} /{ }^{230} \mathrm{Th}$ profiles in sediments. Earth and Planetary Science Letters v. 191, p. 219- ${ }^{230}$. 


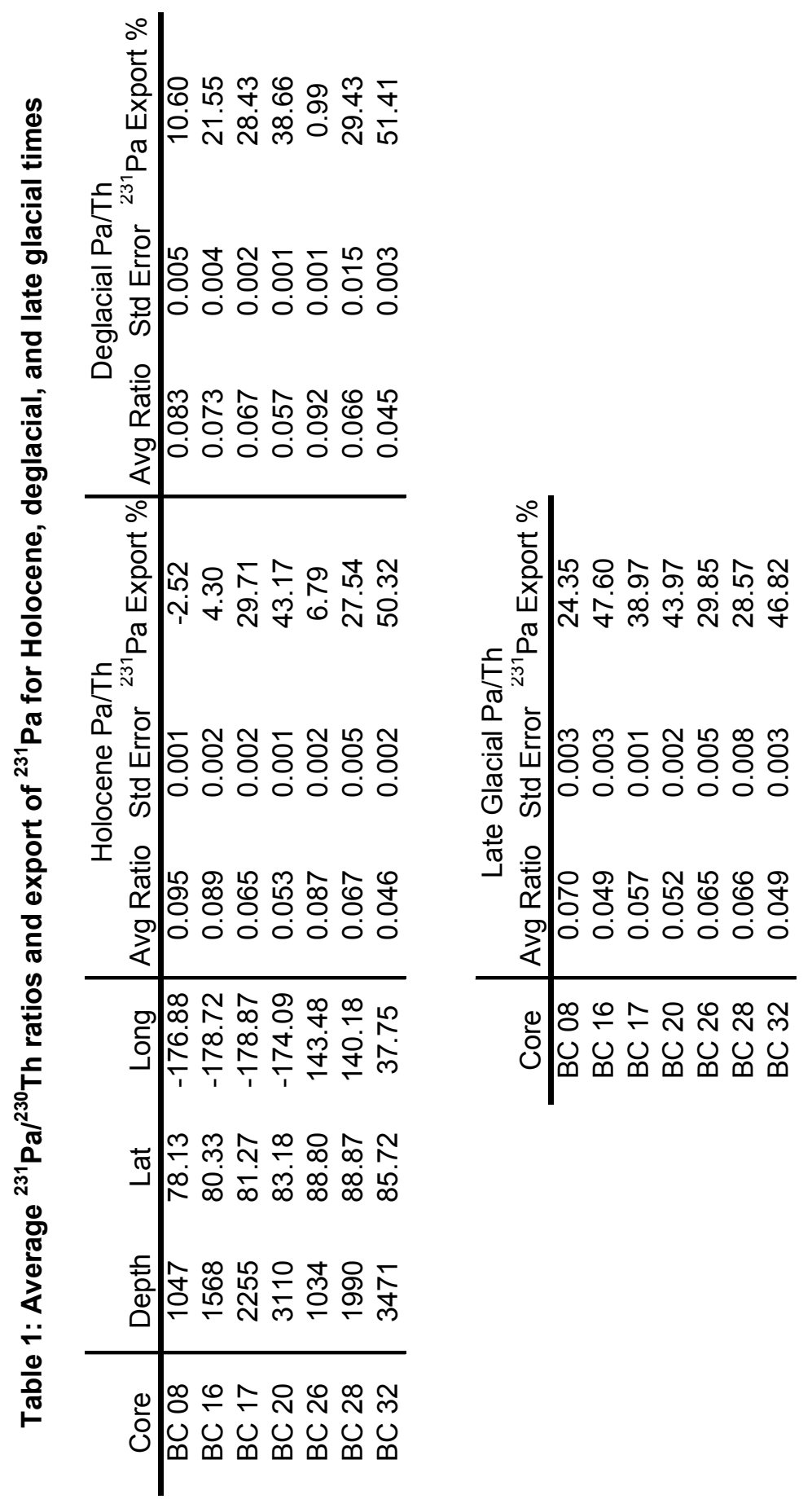


Table $2: \mathrm{Pa} / \mathrm{Th}$ in Samples from Continental Slope Sites

PL-91-AR $1345 \mathrm{~m}$ water depth

21-8BC $\quad 82.66 \mathrm{~N} \quad 47.89 \mathrm{E}$

\begin{tabular}{ccc} 
& ${ }^{231} \mathrm{~Pa} /$ & \\
Sample $(\mathrm{cm})$ & ${ }^{230} \mathrm{Th}$ & Mass flux \\
\hline 5 & 0.087 & 4.94 \\
21 & 0.096 & 4.84
\end{tabular}

PL-91-AR $\quad 4021 \mathrm{~m}$ water depth

14-4PG $\quad 84.95 \mathrm{~N} 38.99 \mathrm{E}$

\begin{tabular}{ccc} 
& ${ }^{231} \mathrm{~Pa} /$ & \\
Sample $(\mathrm{cm})$ & ${ }^{230} \mathrm{Th}$ & Mass flux \\
\hline 0 & 0.060 & 4.11 \\
10 & 0.057 & 5.12 \\
20 & 0.049 & 3.44
\end{tabular}

PL-93-AR $2060 \mathrm{~m}$ water depth

$19 \mathrm{BC} \quad 71.28 \mathrm{~N} 147.35 \mathrm{~W}$

\begin{tabular}{ccc} 
& ${ }^{231} \mathrm{~Pa} /$ & \\
Sample $(\mathrm{cm})$ & ${ }^{230} \mathrm{Th}$ & Mass flux \\
\hline 0 & 0.084 & 5.72
\end{tabular}

$\begin{array}{lll}10 & 0.078 & 5.30\end{array}$ 
Table 3: Comparison of Coretop ${ }^{231} \mathrm{~Pa} /{ }^{230} \mathrm{Th}$, This Study and Moran et al. (2005)

\begin{tabular}{|c|c|c|c|}
\hline \multicolumn{2}{|c|}{ This Study } & \multicolumn{2}{|c|}{ Moran et al. (2005) } \\
\hline Core & ${ }^{231} \mathrm{~Pa} /{ }^{230} \mathrm{Th}$ & Core & $\mathrm{a} /{ }^{230} \mathrm{Th}$ \\
\hline BC 08 & 0.093 & PS-8 & 0.071 \\
\hline BC 16 & 0.088 & PS-16 & 0.088 \\
\hline BC 17 & 0.050 & PS-17 & 0.057 \\
\hline BC 26 & 0.087 & PS-26 & 0.078 \\
\hline BC 32 & 0.053 & LSL-36 & 0.051 \\
\hline
\end{tabular}




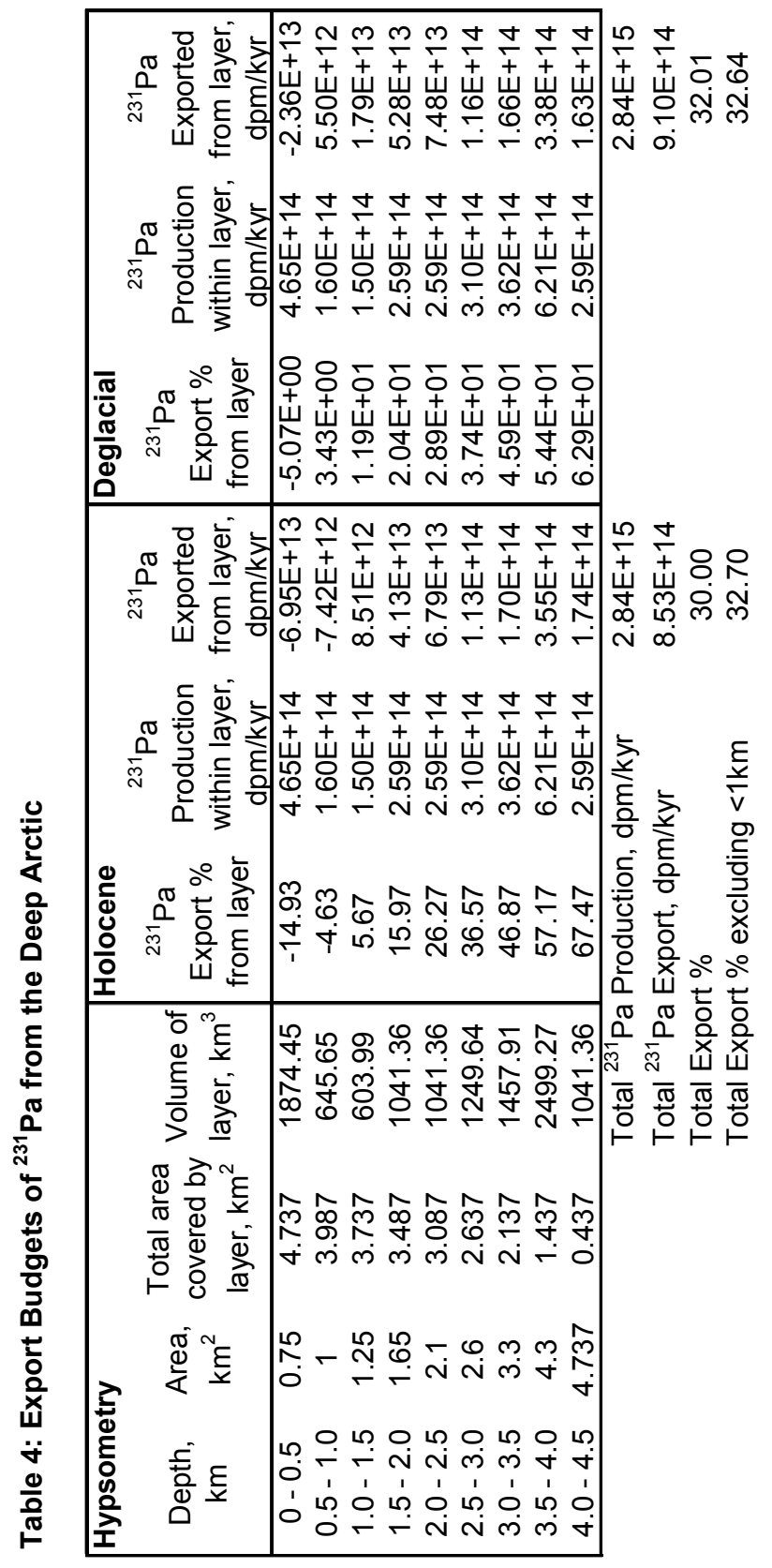

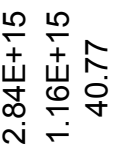

बढ ते

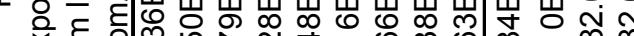

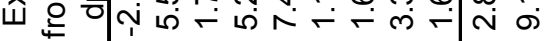

元

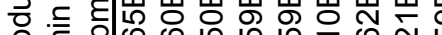

带诨

잉ㅇㅇㅎㅎㅎㅎㅎㅎㅎ

岸山岀山س

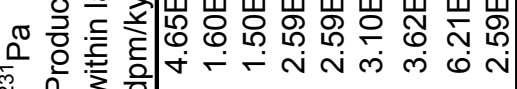

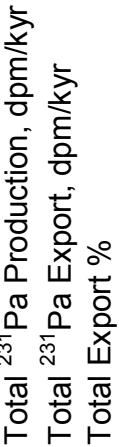

\begin{tabular}{|c|c|}
\hline 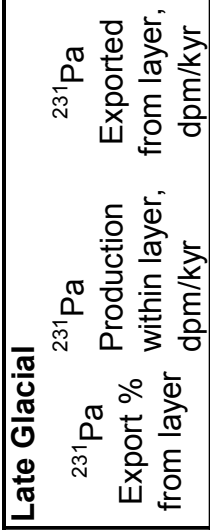 & 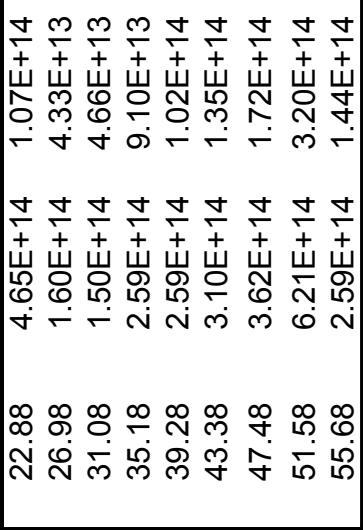 \\
\hline 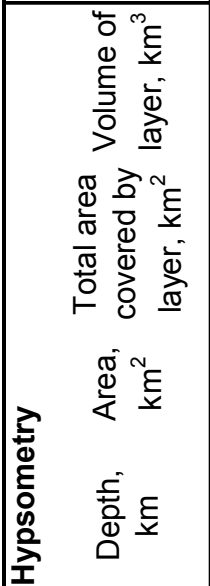 & 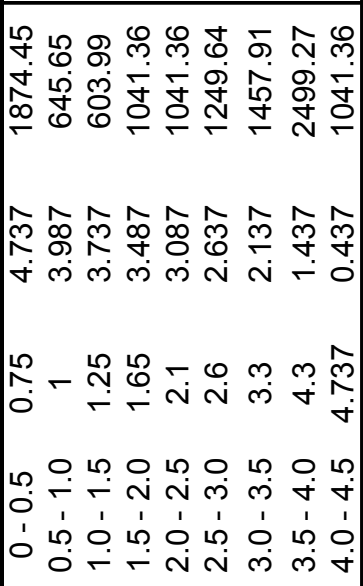 \\
\hline
\end{tabular}




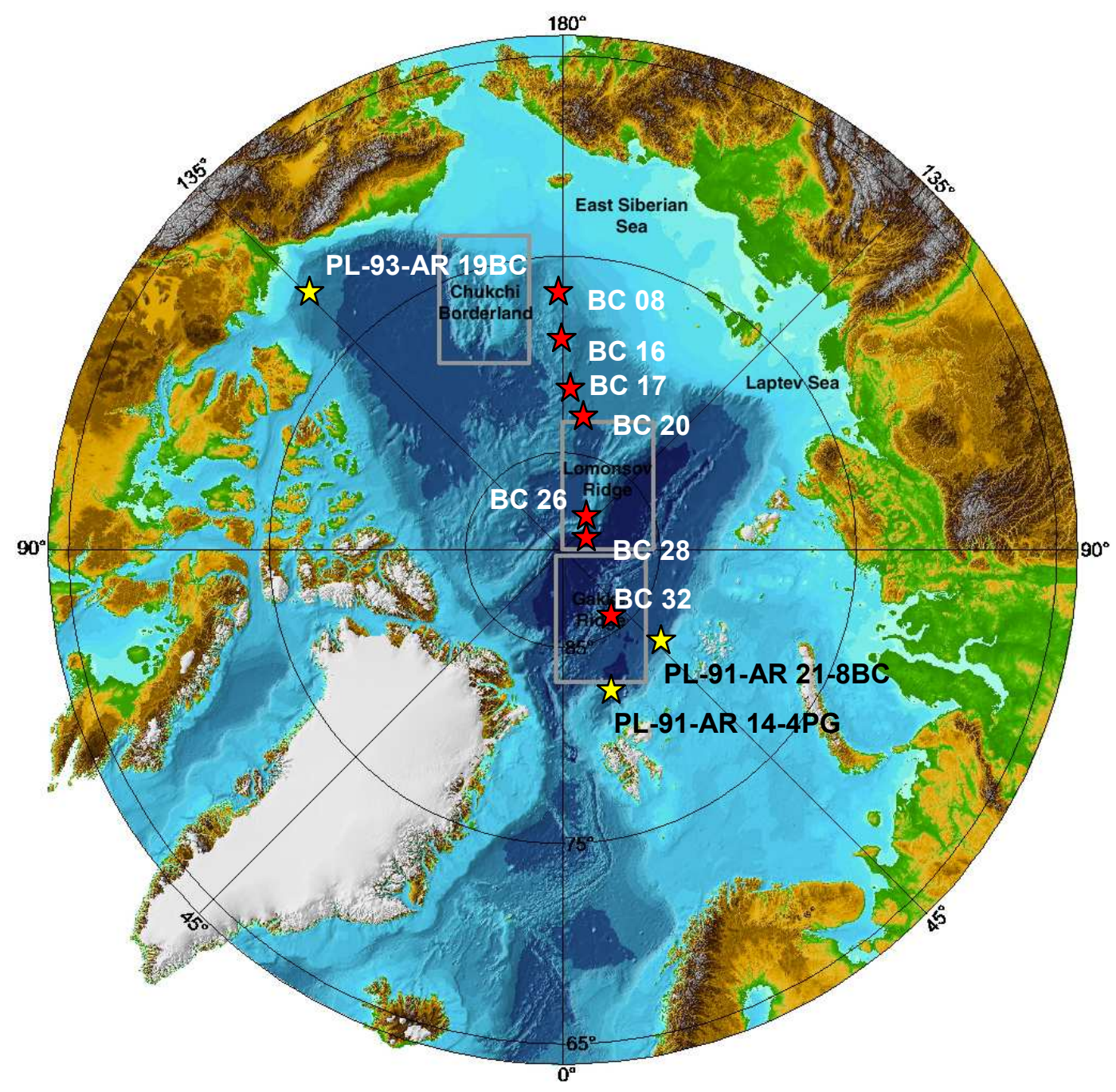

Figure 1: Map of sites discussed in this paper. Red stars indicate locations of our downcore records from PL-94-AR box cores, whose core coordinates and water depths are given in Table 1. Yellow stars indicate locations of samples investigated for evidence of boundary scavenging, whose core coordinates and water depths are given in Table 2. 


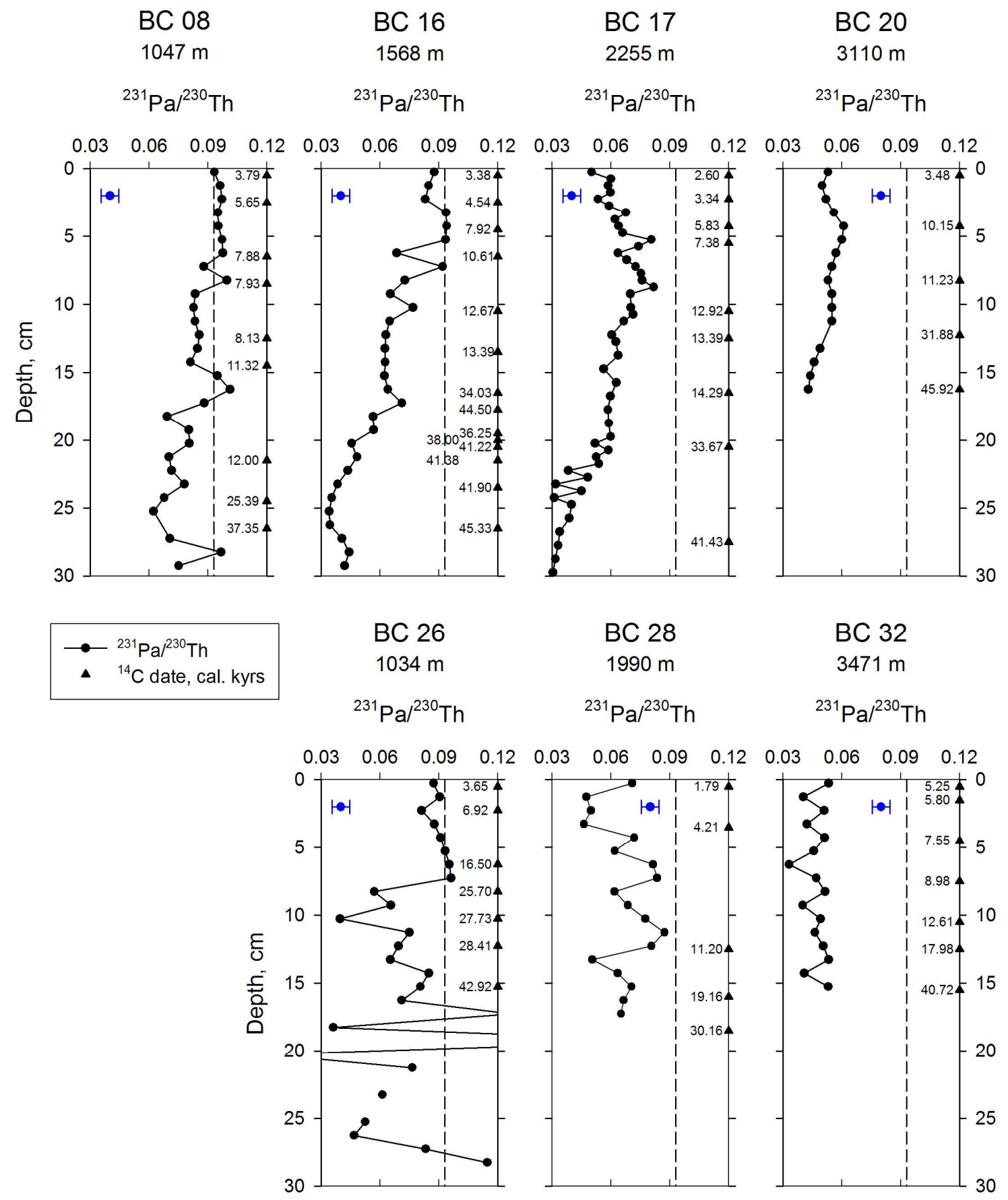

Figure 2: Box core records of ${ }^{231} \mathrm{~Pa} /{ }^{230} \mathrm{Th}$ excess activity ratios and calibrated radiocarbon ages in kyr, from the Amerasian Basin (top) and Eurasian Basin (bottom), plotted by depth in the core. Blue points with error bars depict average range of uncertainty associated with replicate ${ }^{231} \mathrm{~Pa} /{ }^{230} \mathrm{Th}$ standard deviation. 


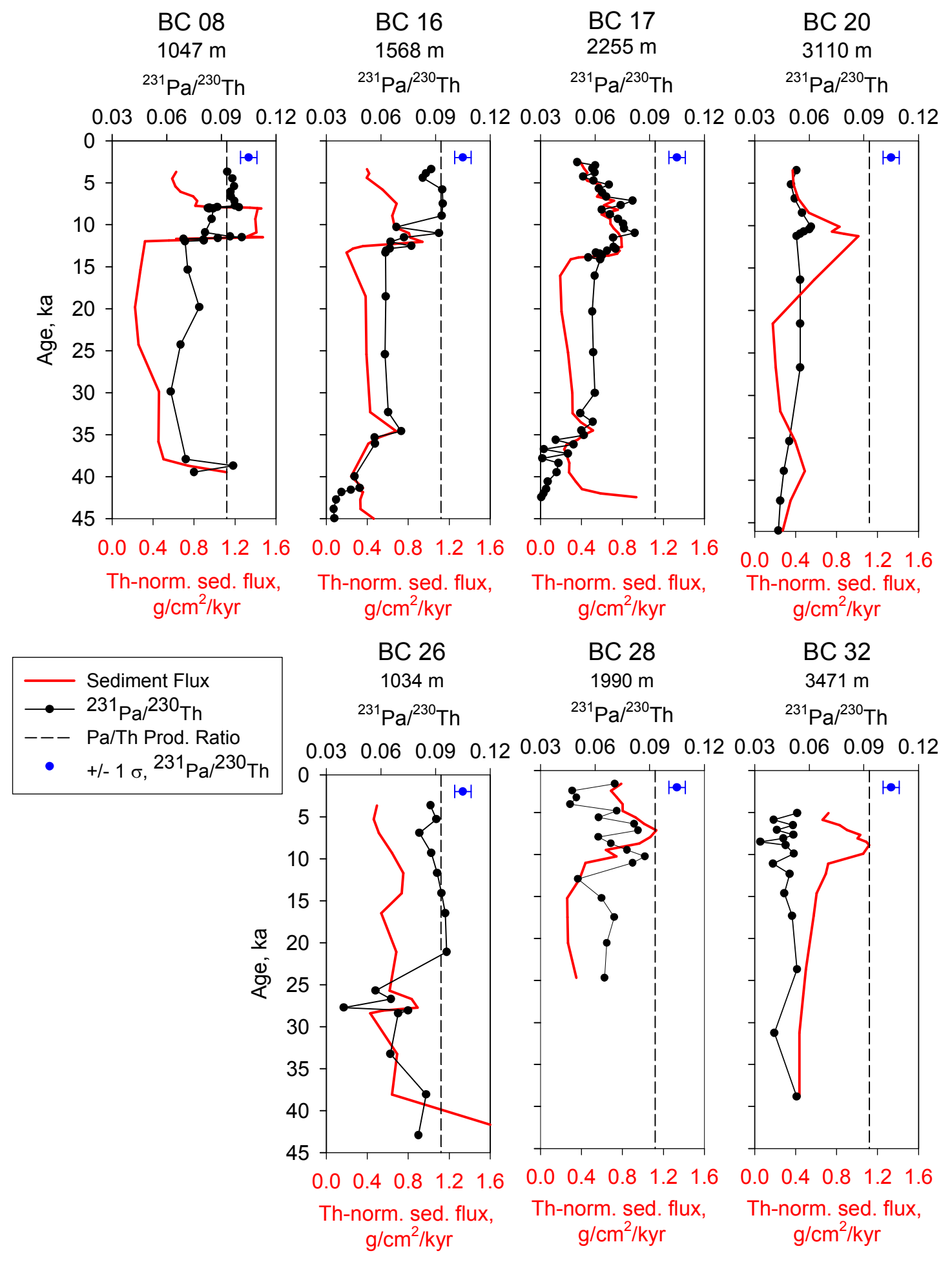

Figure 3: ${ }^{231} \mathrm{~Pa} /{ }^{230} \mathrm{Th}$ excess activity ratios and ${ }^{230} \mathrm{Th}$-normalized sediment mass fluxes, plotted by modeled age in kyr. Blue points with error bars depict average range of uncertainty associated with replicate ${ }^{231} \mathrm{~Pa} /{ }^{230} \mathrm{Th}$ standard deviation. 


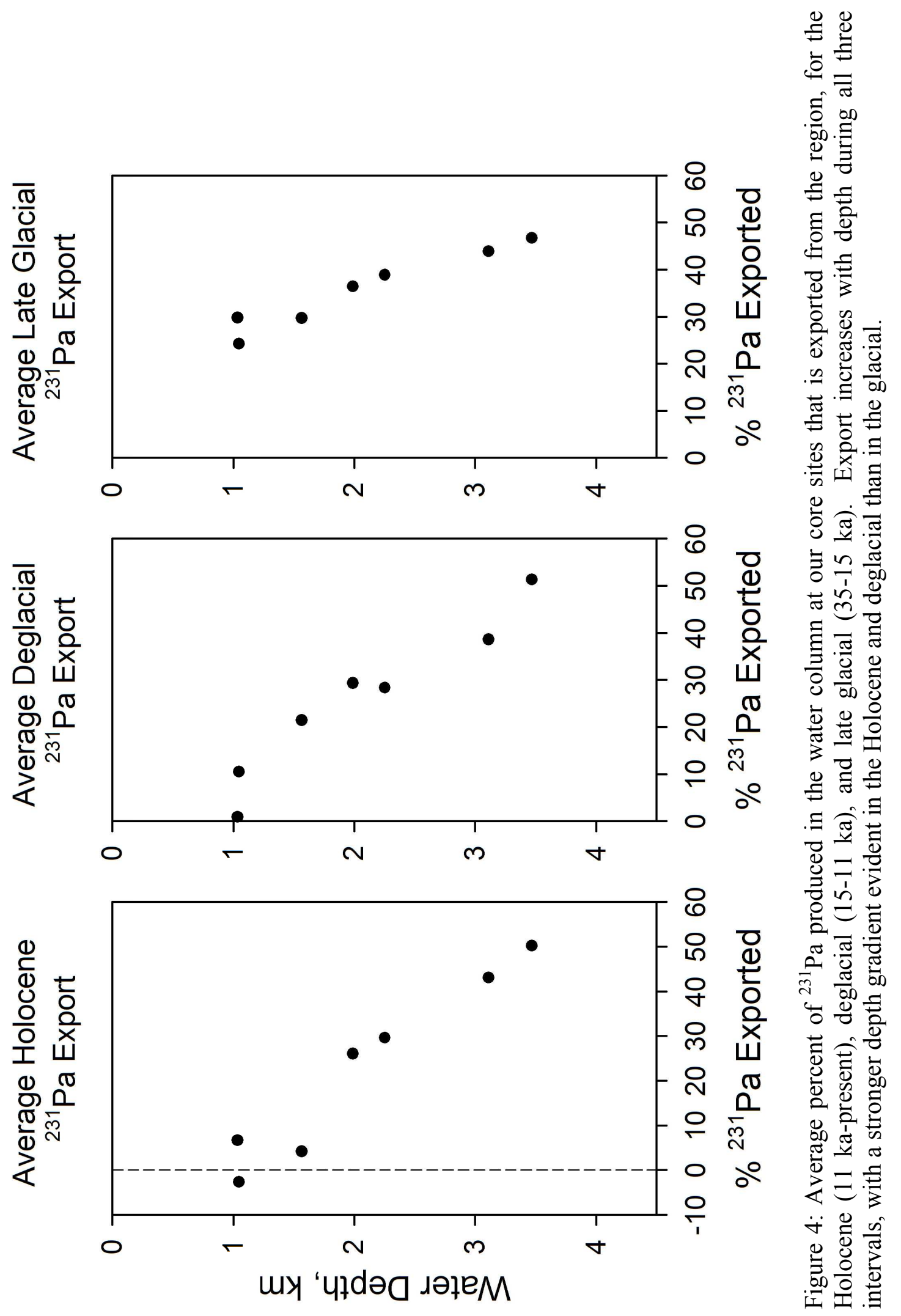




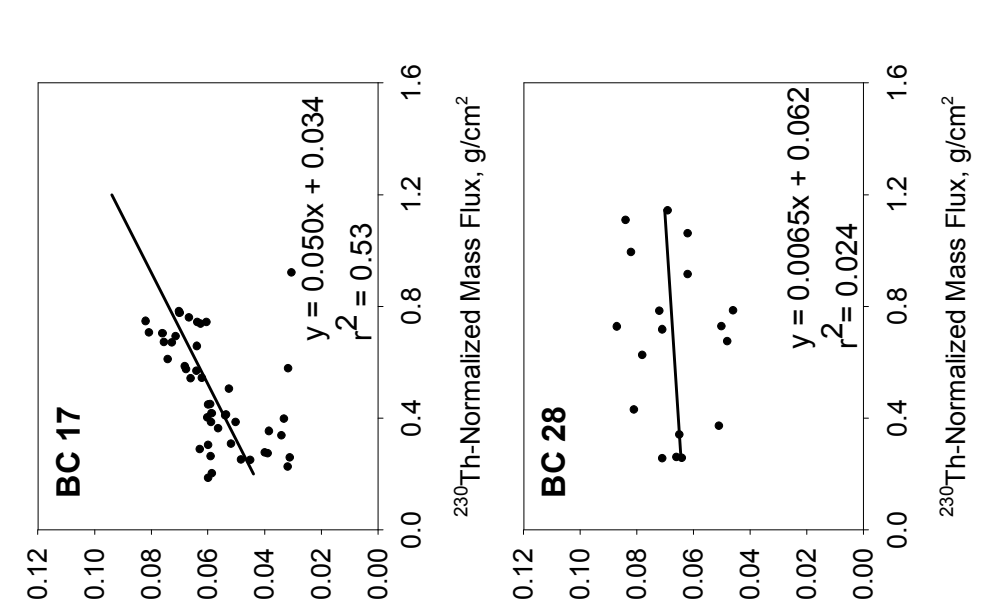

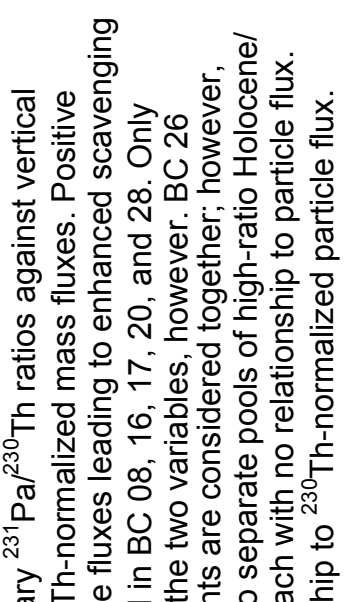

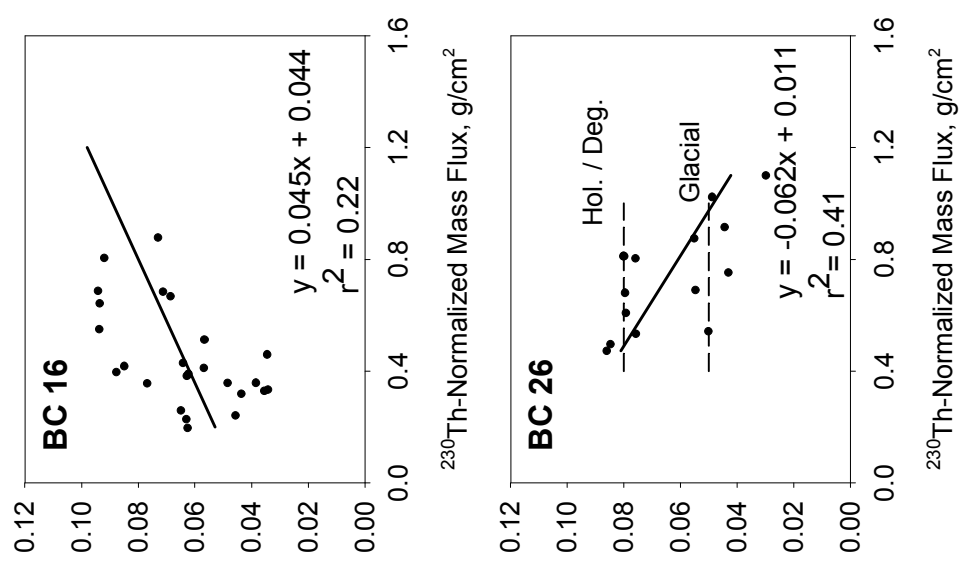

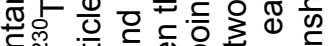

ब

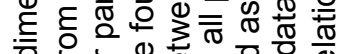

论

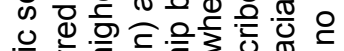

헌

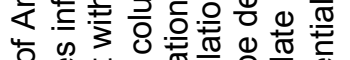

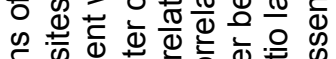

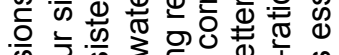

के

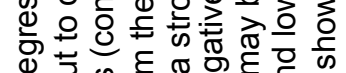

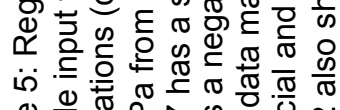

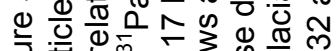

运密
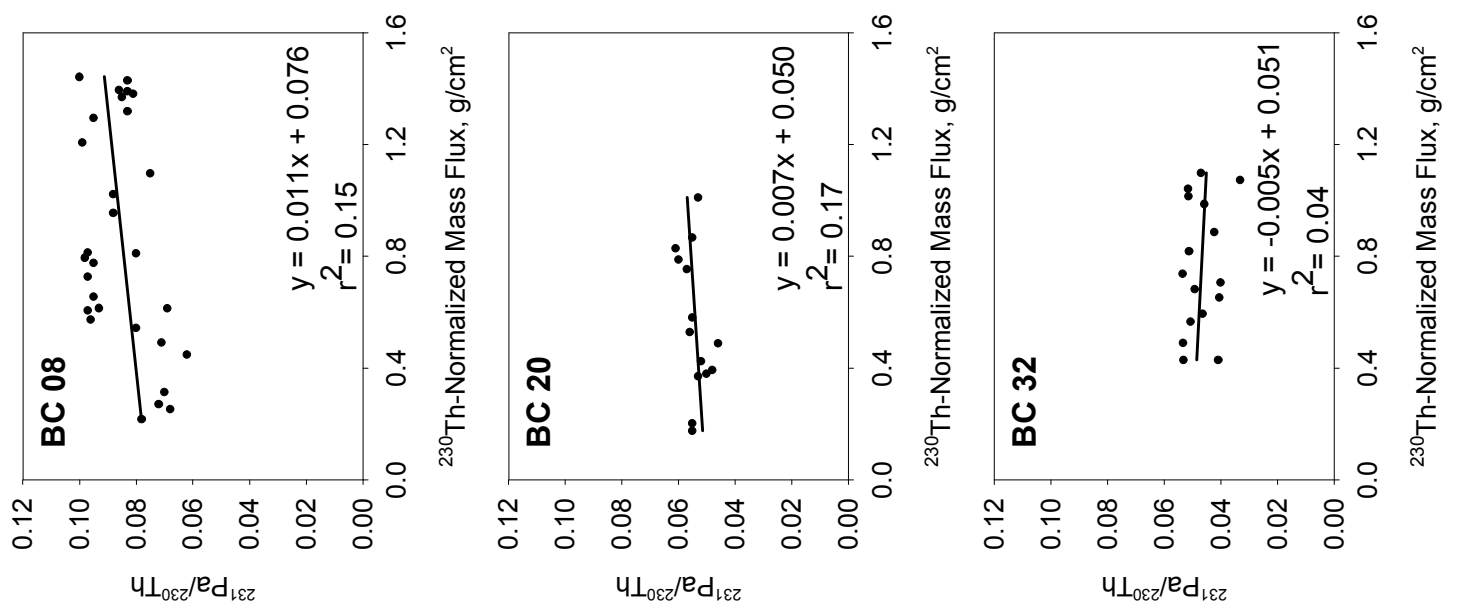


\section{Arctic Coretop ${ }^{231} \mathrm{~Pa} /{ }^{230} \mathrm{Th}$ Values from Moran et al. (2005), This Study}

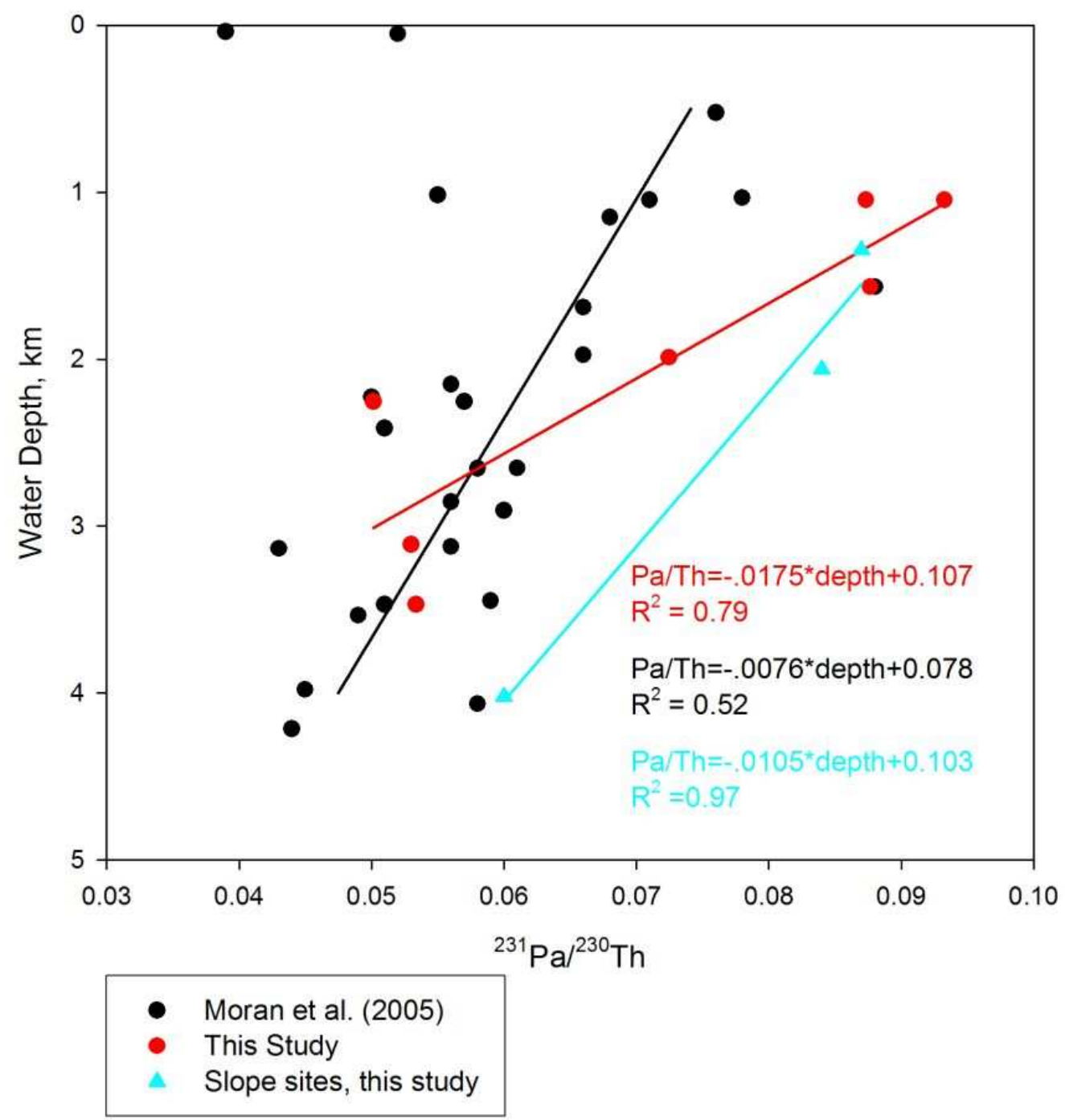

Figure 6: Comparison of Arctic coretop ${ }^{231} \mathrm{~Pa} /{ }^{230} \mathrm{Th}$ excess activity values from this study and from Moran et al. (2005). Linear regression of the Moran et al. data excludes two very shallow shelf sites. The equation of the trend for the combined data sets of Moran et al. and our Central Arctic cores is ${ }^{231} \mathrm{~Pa} /{ }^{230} \mathrm{Th}=-0.0098 * \operatorname{depth}(\mathrm{km})+0.0852$, with an $\mathrm{r}^{2}$ of 0.54. Our samples from continental slope sites give higher ratios than either our central basin sites or the Moran et al. slope sites, but show a similar decrease in ratio with increasing water depth. These sites also do not show evidence for import of ${ }^{231} \mathrm{~Pa}$ from the central basins. 


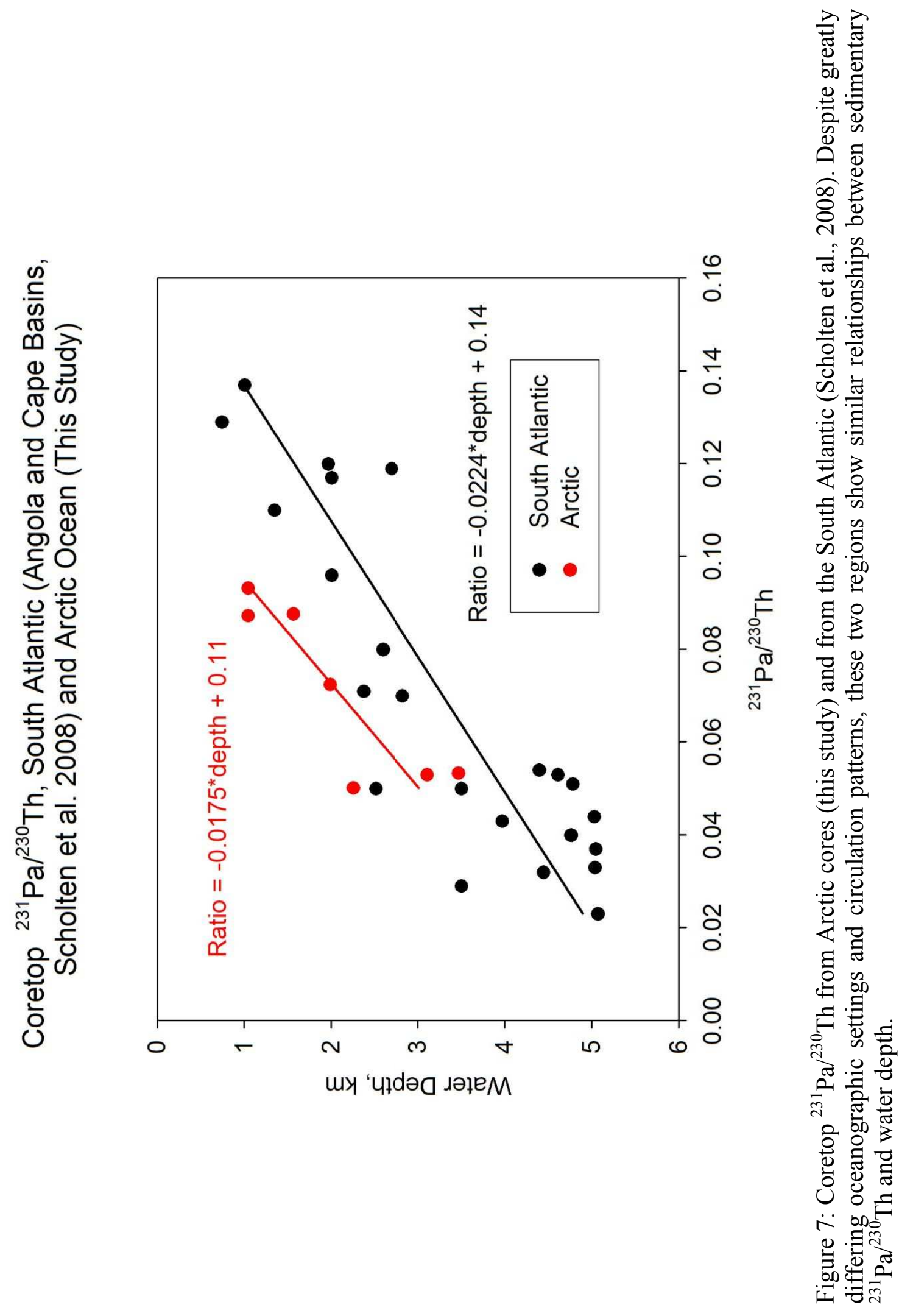




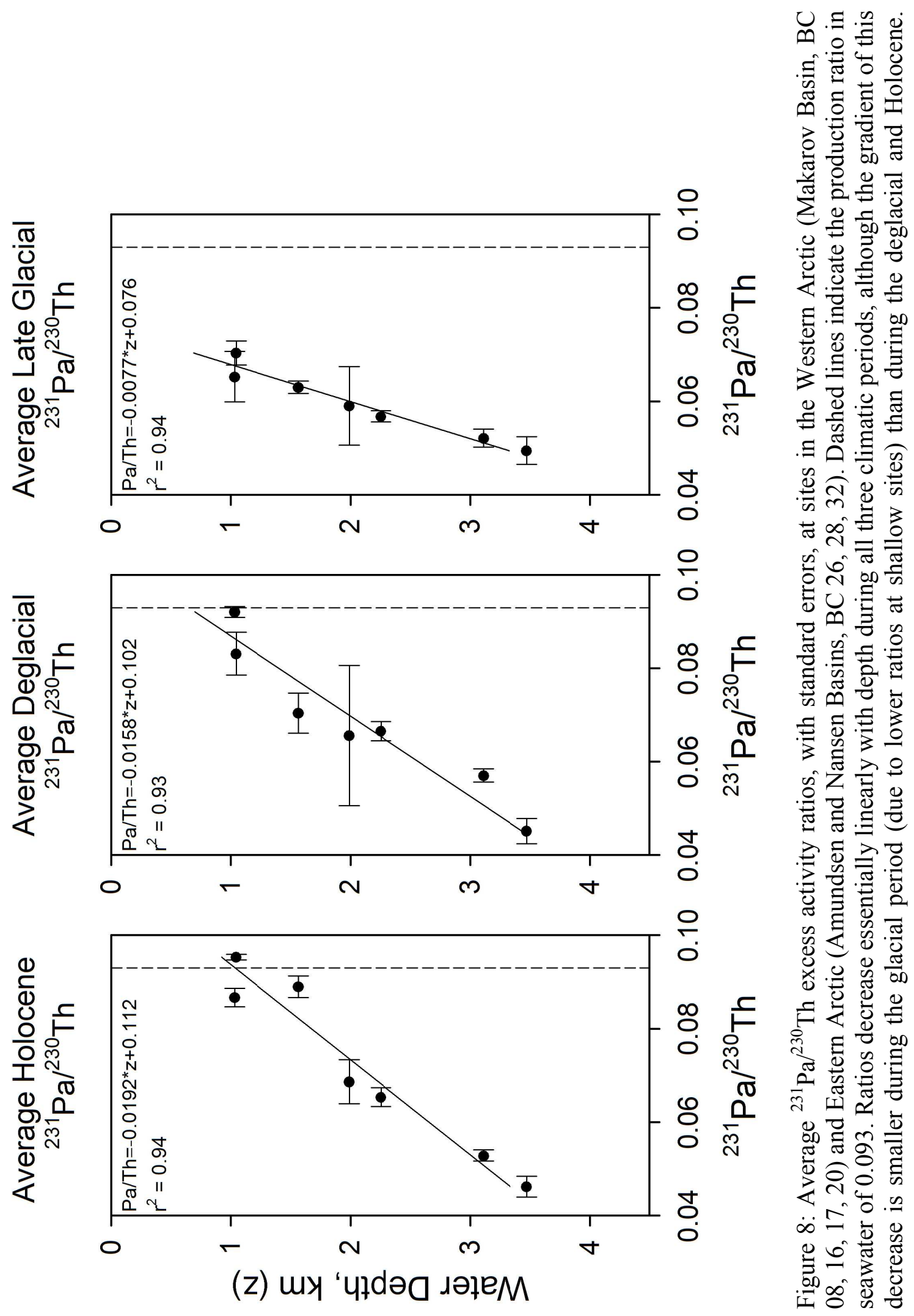




\section{Appendix}

Table A.1 Core Locations and Water Depth:

\begin{tabular}{cccc} 
Core & Depth $(\mathrm{m})$ & Latitude & Longitude \\
\hline PL-94-AR & & & \\
BC 08 & 1047 & 78.13 & -176.88 \\
BC 16 & 1568 & 80.33 & -178.72 \\
BC 17 & 2255 & 81.27 & -178.87 \\
BC 19 & 2414 & 82.45 & -175.73 \\
BC 20 & 3145 & 83.18 & -174.09 \\
BC 26 & 1034 & 88.80 & 143.48 \\
BC 28 & 1990 & 88.87 & 140.18 \\
BC 32 & 3471 & 85.72 & 37.75 \\
& & & \\
PL-91-AR & & & \\
21-8BC & 1345 & 82.66 & 47.89 \\
14-4PG & 4021 & 84.95 & 38.99 \\
PL-93-AR & & & \\
19BC & 2060 & 71.28 & 147.35
\end{tabular}


Table A.2 Radiocarbon Dates and Calibrated Ages

\begin{tabular}{cccccc} 
Core & $\begin{array}{c}\text { Depth, } \\
\text { cm }\end{array}$ & $\begin{array}{c}14 C \text { Date } \\
\text { (kyr) }\end{array}$ & + +/- & $\begin{array}{c}\text { Calibrated } \\
\text { Age (kyr) }\end{array}$ & + /- \\
\hline BC 08 & & & & & \\
& 0.5 & 4130 & 50 & 3793 & 146 \\
& 2.5 & 5580 & 50 & 5650 & 117 \\
& 6.5 & 7700 & 50 & 7875 & 109.5 \\
& 8.5 & 7760 & 50 & 7931 & 112.5 \\
& 12.5 & 7960 & 50 & 8128 & 132 \\
& 14.5 & 10630 & 50 & 11324 & 120.5 \\
& 21.5 & 10960 & 50 & 12018 & 245 \\
& 24.5 & 21740 & 100 & 25388 & 546 \\
& 26.5 & 33110 & 280 & 37349 & 320 \\
& 34.5 & 35580 & 350 & 40428 & 378 \\
BC 16 & & & & & \\
& 0.25 & 3780 & 40 & 3375 & 104 \\
& 2.5 & 4680 & 50 & 4543 & 157 \\
& 4.5 & 7750 & 50 & 7921 & 110 \\
& 6.5 & 10050 & 50 & 10614 & 127 \\
& 10.5 & 11300 & 60 & 12666 & 214 \\
& 13.5 & 12250 & 60 & 13389 & 148.5 \\
& 16.5 & 29680 & 170 & 34032 & 226 \\
& 17.75 & 41250 & 850 & 44501 & 769 \\
& 19.5 & 33810 & 350 & 36252 & 377 \\
& 20 & 31930 & 280 & 38001 & 318 \\
& 20.5 & 36610 & 480 & 41216 & 462 \\
& 21.5 & 36890 & 570 & 41382 & 531 \\
& 23.5 & 37770 & 580 & 41904 & 532 \\
& 26.5 & 42310 & 980 & 45325 & 875 \\
& & & & & \\
& 0.25 & 3150 & - & 2619 & 141.5 \\
& 5.5 & 7150 & 50 & 7375 & 99.5 \\
& 10.5 & 11690 & 50 & 12924 & 93 \\
& 12.5 & 12250 & 50 & 13386 & 132 \\
& 16.5 & 13040 & 50 & 14287 & 308 \\
& 20.5 & 29400 & 110 & 33671 & 186 \\
& 27.5 & 36970 & 280 & 41433 & 298 \\
& 34.5 & 41480 & 460 & 44595 & 451 \\
& & & & &
\end{tabular}


Table A.2 Radiocarbon Dates and Calibrated Ages (ctd.)

\begin{tabular}{cccccc} 
Core & $\begin{array}{c}\text { Depth, } \\
\mathrm{cm}\end{array}$ & $\begin{array}{c}14 \mathrm{C} \text { Date } \\
\text { (kyr) }\end{array}$ & $+/-$ & $\begin{array}{c}\text { Calibrated } \\
\text { Age }(\mathrm{kyr})\end{array}$ & $+/-$ \\
\hline BC 19 & 2.5 & 5680 & 50 & 5764 & 123 \\
& 5.5 & 12120 & 60 & 13283 & 112.5 \\
& 7.5 & 12570 & 60 & 13742 & 151 \\
& 10.5 & 25410 & 190 & 29731 & 303 \\
& 12.5 & 35120 & 410 & 39836 & 437 \\
& 15.5 & 40260 & 780 & 43812 & 705 \\
& 18.5 & 41000 & 840 & 44330 & 761 \\
& 21.5 & 41680 & 930 & 44819 & 836
\end{tabular}

$\begin{array}{ccccccc}\text { BC 20 } & 0.25 & 3880 & 25 & 3482 & 85 & \text { a } \\ & 4.25 & 9580 & 35 & 10148 & 108.5 & a \\ & 8.25 & 10550 & 40 & 11231 & 77.5 & \text { a } \\ & 12.25 & 27700 & 140 & 31883 & 215 & \text { a } \\ & 16.25 & 43000 & 500 & 45917 & 477 & a\end{array}$

$\begin{array}{cccccc}\text { BC 26 } & 0.25 & 4020 & 35 & 3654 & 115 \\ & 2.25 & 6720 & 40 & 6915 & 128.5 \\ & 6.25 & 14500 & 70 & 16495 & 388.5 \\ & 8.25 & 22100 & 150 & 25696 & 240 \\ & 10.25 & 23800 & 120 & 27732 & 193 \\ & 12.25 & 24400 & 110 & 28408 & 184 \\ & 15.25 & 38600 & 320 & 42916 & 324\end{array}$

$\begin{array}{ccccccc}\text { BC 28 } & 0.5 & 2250 & 50 & 1790 & 143 & \mathrm{a} \\ & 3.5 & 4400 & 50 & 4210 & 171 & \mathrm{~b} \\ & 12.5 & 10480 & 60 & 11200 & 106 & \mathrm{~b} \\ & 16 & 16810 & 60 & 19160 & 190 & \mathrm{~b} \\ & 18.5 & 25970 & 140 & 30160 & 201 & \mathrm{~b} \\ \text { BC 32 } & 1.5 & 5680 & 50 & 5800 & 125 & \mathrm{~b} \\ & 4.5 & 7330 & 50 & 7550 & 98 & \mathrm{~b} \\ & 7.5 & 8790 & 50 & 8980 & 142 & \mathrm{~b} \\ & 10.5 & 11300 & 50 & 12610 & 290 & \mathrm{~b} \\ & 12.5 & 15700 & 70 & 17980 & 281 & \mathrm{~b} \\ & 15.5 & 36210 & 470 & 40720 & 461 & \mathrm{~b}\end{array}$
a. Data from Darby et al. (1997)
b. Unpublished data from R. Poore (W. Curry, personal communication) 


\section{BC 20 Coarse Fraction in Two Subcores: \\ Darby et al. (1997) and This Study}

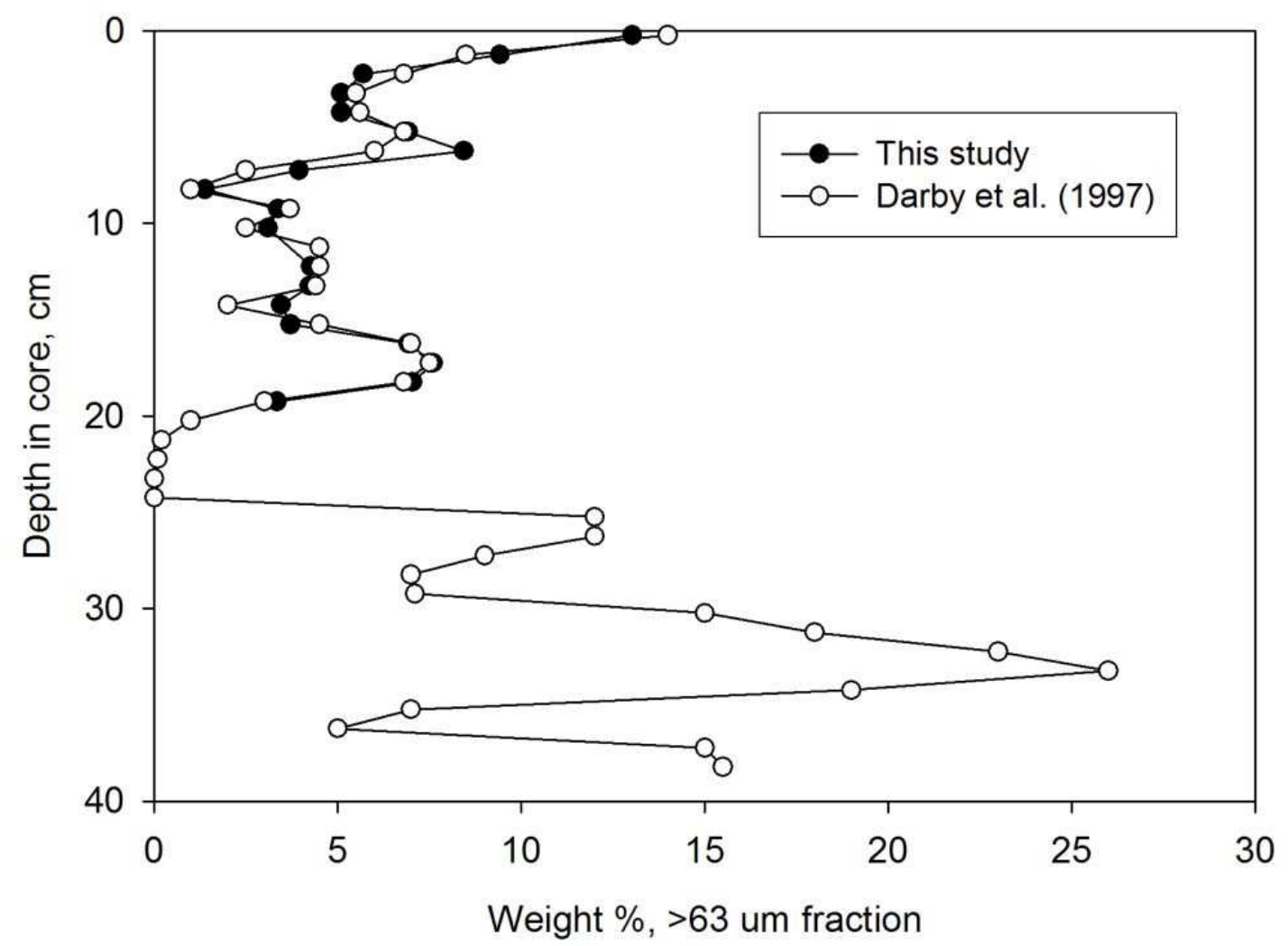

Figure A.1: Coarse ( $>63 \mathrm{um}$ ) fraction weight percent in radiocarbon-dated subcore of BC 20 (Darby et al., 1997) and in subcore analyzed for ${ }^{230} \mathrm{Th}$ and ${ }^{231} \mathrm{~Pa}$ (this study). The records are very similar, suggesting no major stratigraphic offsets between the two subcores. 
Table A.3 Nuclide Measurements, all cores

\section{BC $08 \quad 1047 \mathrm{~m}$}

\begin{tabular}{|c|c|c|c|c|c|c|c|c|c|}
\hline $\begin{array}{c}\text { depth } \\
\mathrm{cm}\end{array}$ & $\begin{array}{c}\text { Age } \\
\text { ky }\end{array}$ & $\begin{array}{l}{ }^{231} \mathrm{~Pa} \\
\mathrm{dpm} / \mathrm{g}\end{array}$ & $\begin{array}{l}{ }^{230} \mathrm{Th} \\
\mathrm{dpm} / \mathrm{g}\end{array}$ & $\begin{array}{r}{ }^{238} \mathrm{U} \\
\mathrm{dpm} / \mathrm{g} \\
\end{array}$ & $\begin{array}{l}{ }^{32} \mathrm{Th} \\
\mathrm{pm} / \mathrm{g}\end{array}$ & $\begin{array}{c}{ }^{238} \mathrm{U}^{232} \mathrm{~T} \\
\text { ratio }\end{array}$ & $\begin{array}{r}{ }^{231} \mathrm{~Pa}_{\mathrm{xs} 0} \\
\mathrm{dpm} / \mathrm{g}\end{array}$ & $\begin{array}{r}{ }^{230} \mathrm{Th}_{\mathrm{xs} 0} \\
\mathrm{dpm} / \mathrm{g}\end{array}$ & $\begin{array}{r}{ }^{231} \mathrm{~Pa}_{\mathrm{xs} 0} / \\
{ }^{230} \mathrm{Th}_{\mathrm{xs} 0}\end{array}$ \\
\hline 0.25 & 3.70 & 0.43 & 5.47 & 1.44 & 2.25 & 0.64 & 0.40 & 4.26 & 0.093 \\
\hline 1.25 & 4.49 & 0.46 & 5.79 & 1.51 & 2.36 & 0.64 & 0.44 & 4.56 & 0.096 \\
\hline 2.25 & 5.42 & 0.44 & 5.60 & 1.59 & 2.49 & 0.64 & 0.42 & 4.31 & 0.097 \\
\hline 3.25 & 6.07 & 0.40 & 5.29 & 1.59 & 2.51 & 0.63 & 0.38 & 3.99 & 0.095 \\
\hline 4.25 & 6.62 & 0.35 & 4.67 & 1.63 & 2.49 & .66 & 0.32 & 3.37 & 0.095 \\
\hline 5.25 & 7.18 & 0.34 & 4.54 & 1.79 & 2.52 & 0.71 & 0.31 & 3.22 & 0.097 \\
\hline 6.25 & 7.74 & 0.34 & 4.58 & 1.86 & 2.53 & 0.74 & 0.32 & 3.29 & 0.098 \\
\hline 7.25 & 7.90 & 0.28 & 4.19 & 1.91 & 2.71 & 0.70 & 0.24 & 2.74 & 0.088 \\
\hline 8.25 & 7.92 & 0.26 & 3.68 & 1.91 & 2.75 & .70 & 0.21 & 2.17 & 0.100 \\
\hline 9.25 & 7.97 & 0.22 & 3.49 & 1.80 & 2.72 & .66 & 0.16 & 1.98 & 0.083 \\
\hline 10.25 & 8.02 & 0.21 & 3.54 & 1.95 & 2.97 & 0.66 & 0.15 & 1.88 & 0.083 \\
\hline 11.25 & 8.07 & 0.21 & 3.45 & 1.80 & 2.89 & 0.62 & 0.15 & 1.83 & 0.083 \\
\hline 12.25 & 8.07 & 0.21 & 3.38 & 1.61 & 2.73 & 0.59 & 0.16 & 1.88 & 0.086 \\
\hline 13.25 & 9.33 & .21 & 3.39 & 1.56 & 2.74 & 0.57 & 0.16 & 1.91 & 0.085 \\
\hline 14.25 & 10.92 & 0.20 & 3.33 & 1.58 & 2.68 & 0.59 & 0.15 & 1.89 & 0.081 \\
\hline 15.25 & 11.40 & 0.23 & 3.53 & 1.73 & 2.82 & 0.61 & 0.19 & 2.02 & 0.095 \\
\hline 16.25 & 11.49 & 0.22 & 3.33 & 1.65 & 2.83 & 0.58 & 0.18 & 1.82 & 0.101 \\
\hline 17.25 & 11.59 & 0.25 & 4.03 & 1.70 & 2.88 & 0.59 & 0.22 & 2.56 & 0.088 \\
\hline 18.25 & 11.69 & 0.24 & 3.93 & 0.09 & 0.17 & 0.55 & 0.30 & 4.26 & 0.069 \\
\hline 19.25 & 11.78 & 0.28 & 4.64 & 1.75 & 2.88 & 0.61 & 0.26 & 3.23 & 0.080 \\
\hline 20.25 & 11.88 & 0.38 & 6.00 & 1.61 & 2.81 & 0.57 & 0.39 & 4.80 & 0.080 \\
\hline 21.25 & 11.98 & 0.46 & 7.59 & 0.15 & 0.25 & 0.60 & 0.58 & 8.31 & 0.070 \\
\hline 22.25 & 15.35 & 0.58 & 21 & 1.7 & 3.04 & 0.58 & 0.69 & 9.64 & 0.072 \\
\hline 23.25 & 19.81 & 0.70 & 11.76 & 1.68 & 2.92 & 0.58 & 0.93 & 11.98 & 0.078 \\
\hline 24.25 & 24.27 & 0.49 & 9.90 & 1.60 & 2.71 & 0.59 & 0.70 & 10.31 & 0.068 \\
\hline 25.25 & 29.87 & 0.26 & 5.79 & 1.44 & 2.20 & 0.65 & 0.36 & 5.83 & 0.062 \\
\hline 26.25 & 35.85 & & 5.6 & 1.4 & 2.23 & 0.64 & & 5.89 & \\
\hline 27.25 & 37.93 & 0.2 & 5.3 & 1.5 & 2.70 & 0.59 & 0.38 & 5.32 & 0.070 \\
\hline 28.25 & 38.70 & 0.2 & 4.27 & 1.80 & 2. & 0.61 & 0.35 & 3.59 & 0.097 \\
\hline 29.25 & 39.47 & 16 & 3.48 & 1.78 & 2.96 & 0.60 & 0.18 & 2.39 & 0.075 \\
\hline
\end{tabular}


Table A.3 Nuclide Measurements, all cores (continued)

\section{BC $16 \quad 1568 \mathrm{~m}$}

\begin{tabular}{|c|c|c|c|c|c|c|c|c|c|}
\hline $\begin{array}{l}\text { depth } \\
\mathrm{cm}\end{array}$ & $\begin{array}{c}\text { Age } \\
\text { ky }\end{array}$ & $\begin{array}{l}{ }^{231} \mathrm{~Pa} \\
\mathrm{dpm} / \mathrm{g}\end{array}$ & $\begin{array}{l}{ }^{230} \mathrm{Th} \\
\mathrm{dpm} / \mathrm{g}\end{array}$ & $\begin{array}{l}{ }^{238} \mathrm{U} \\
\mathrm{dpm} / \mathrm{g}\end{array}$ & $\begin{array}{l}{ }^{232} \mathrm{Th} \\
\mathrm{dpm} / \mathrm{g}\end{array}$ & $\begin{array}{l}{ }^{238} \mathrm{U} /{ }^{232} \mathrm{Tr} \\
\text { ratio }\end{array}$ & $\begin{array}{l}{ }^{231} \mathrm{~Pa}_{\mathrm{xs} 0} \\
\mathrm{dpm} / \mathrm{g}\end{array}$ & $\begin{array}{r}{ }^{230} \mathrm{Th}_{\mathrm{xs} 0} \\
\mathrm{dpm} / \mathrm{g}\end{array}$ & $\begin{array}{l}{ }^{231} \mathrm{~Pa}_{\mathrm{xs} 0} / \\
{ }^{230} \mathrm{Th}_{\mathrm{xs} 0}\end{array}$ \\
\hline 0.25 & 38 & 0.91 & 11.43 & 1.68 & 2.36 & 0.71 & 0.90 & 10.29 & 0.088 \\
\hline 1.25 & 3.89 & 0.83 & 10.89 & 1.70 & 2.30 & 0.74 & 0.83 & 9.77 & 0.084 \\
\hline 2.25 & 4.41 & 0.78 & 10.45 & 1.82 & 2.33 & 0.78 & 0.83 & 10.38 & 0.084 \\
\hline 3.25 & 5.81 & 0.69 & 8.56 & 1.80 & 2.46 & 0.73 & 0.70 & 7.43 & 0.094 \\
\hline 4.25 & 7.50 & 55 & 7.12 & 1.74 & 2.49 & .70 & 0.56 & 5.95 & 0.094 \\
\hline 5.25 & 8.93 & 0.57 & 7.59 & 1.77 & 2.49 & 0.71 & 0.59 & 6.36 & 0.092 \\
\hline 6.25 & 10.28 & 0.43 & 7.49 & 1.76 & 2.61 & 0.67 & 0.42 & 6.12 & 0.068 \\
\hline 7.25 & .00 & 0.44 & 6.05 & 1.67 & 2.58 & 06 & 0.47 & 5.07 & 0.093 \\
\hline 8.25 & 51 & 0.63 & 5.78 & 1.88 & 2.93 & 64 & 36 & 4.99 & 0.073 \\
\hline 9.25 & .02 & 0.26 & 4.19 & 1.84 & 2.93 & 1.63 & 0.28 & 4.35 & 0.065 \\
\hline 10.25 & 12.54 & 0.75 & 11.81 & 1.93 & 3.27 & 0.59 & 0.88 & 11.46 & 0.078 \\
\hline 11.25 & 12.85 & 0.85 & 15.59 & 1.85 & 3.13 & .59 & 1.02 & 15.71 & 0.065 \\
\hline 12.25 & 13.09 & 0.93 & 17.43 & 1.90 & 3.14 & 61 & 13 & 17.90 & 0.063 \\
\hline 13.25 & 13.33 & 1 & 19.91 & 0.99 & 1.6 & 6 & 1.30 & 20.74 & 0.062 \\
\hline 14.25 & 18.55 & 0.53 & 10.56 & 1.69 & 2.59 & 0.65 & 0.67 & 10.64 & 0.063 \\
\hline 15.25 & 25.43 & 0.46 & 9.94 & 1.75 & 2.73 & 0.64 & 0.65 & 10.46 & 0.062 \\
\hline 16.25 & 32.31 & & 8.74 & 1.72 & 2.77 & .62 & 0.61 & 9.52 & 0.064 \\
\hline 17.25 & 99 & & 5.99 & 1.72 & 2.74 & .63 & 42 & 5.97 & 0.071 \\
\hline 18.25 & 35.33 & 0 & 7.43 & 1.74 & 2.71 & 0.64 & 0.45 & 7.97 & 0.057 \\
\hline 19.25 & 36.07 & 84 & 8.85 & 1.77 & 2.78 & 0.64 & 0.56 & 9.93 & 0.057 \\
\hline 20.25 & 39.98 & 0.39 & 12.98 & 1.47 & 2.08 & 0.71 & 0.77 & 16.84 & 0.046 \\
\hline 21.25 & 41.3 & & 8.87 & 1.29 & 1.76 & 0.7 & 0.55 & 11.43 & 0.048 \\
\hline 22.25 & .58 & & 9.87 & 1. & 1.7 & 7 & 0.56 & 12.81 & 0.044 \\
\hline 23.25 & 41.84 & 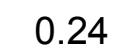 & 8.93 & 1.32 & 1.84 & 0.72 & 0.44 & 11.39 & 0.038 \\
\hline 24.25 & 42.74 & 0.24 & 9.63 & 1.44 & 2.01 & 0.72 & 0.44 & 12.37 & 0.035 \\
\hline 25.25 & 43.85 & & 9.66 & 1.67 & 2.33 & 0.72 & 0.42 & 12.25 & 0.034 \\
\hline 26.25 & 44.96 & & 7.39 & 1.69 & 2.38 & 0.71 & 0.31 & 8.88 & 0.034 \\
\hline 27.25 & & & 58 & 1.66 & 2.27 & 0.73 & 0.21 & 5.09 & 0.041 \\
\hline 28.25 & & & 2.85 & 1.59 & 2.28 & 0.70 & 0.11 & 2.34 & 0.044 \\
\hline 29.25 & & 00 & 2.08 & 1.56 & 2.22 & 0.70 & 0.04 & 1.03 & 0.042 \\
\hline
\end{tabular}


Table A.3 Nuclide Measurements, all cores (continued)

BC $17 \quad 2255 \mathrm{~m}$

\begin{tabular}{|c|c|c|c|c|c|c|c|c|c|}
\hline $\begin{array}{c}\text { depth } \\
\mathrm{cm}\end{array}$ & $\begin{array}{c}\text { Age } \\
\text { ky }\end{array}$ & $\begin{array}{l}{ }^{231} \mathrm{~Pa} \\
\mathrm{dpm} / \mathrm{g}\end{array}$ & $\begin{array}{l}{ }^{230} \mathrm{Th} \\
\mathrm{dpm} / \mathrm{g}\end{array}$ & $\begin{array}{l}{ }^{238} \mathrm{U} \\
\mathrm{dpm} / \mathrm{g}\end{array}$ & ${ }^{332} \mathrm{Th}$ & $\begin{array}{c}{ }^{238} \mathrm{U} /{ }^{232} \mathrm{Th} \\
\text { ratio }\end{array}$ & $\begin{array}{r}{ }^{231} \mathrm{~Pa}_{\mathrm{xs} 0} \\
\mathrm{dpm} / \mathrm{g}\end{array}$ & $\begin{array}{r}{ }^{230} \mathrm{Th}_{\mathrm{xs} 0} \\
\mathrm{dpm} / \mathrm{g}\end{array}$ & $\begin{array}{l}{ }^{231} \mathrm{~Pa}_{\mathrm{xs} 0} / \\
{ }^{230} \mathrm{Th}_{\mathrm{xs} 0}\end{array}$ \\
\hline 0.25 & 2.55 & 0.78 & 16.16 & 1.69 & 2.40 & 0.71 & 0.76 & 15.06 & 0.050 \\
\hline 0.75 & 2.93 & 0.89 & 15.54 & 1.77 & 2.42 & 0.73 & 0.87 & 14.47 & 0.060 \\
\hline 1.25 & 3.31 & 0.83 & 14.97 & 1.79 & 2.44 & 0.73 & 0.81 & 13.91 & 0.059 \\
\hline 1.75 & 3.79 & 0.78 & 13.98 & 1.77 & 2.45 & 0.73 & 0.77 & 12.95 & 0.060 \\
\hline 2.25 & 4.27 & 0.71 & 14.03 & 0.57 & 0.80 & 71 & 0.75 & 14.09 & 0.053 \\
\hline 2.75 & 4.75 & 0.76 & 13.83 & 1.76 & 2.45 & 0.72 & 0.76 & 12.91 & 0.059 \\
\hline 3.25 & 5.22 & 0.68 & 11.16 & 1.79 & 2.51 & 0.72 & 0.68 & 10.12 & 0.068 \\
\hline 3.75 & 5.70 & 0.66 & 11.71 & 1.78 & 2.56 & 0.69 & 0.66 & 10.70 & 0.062 \\
\hline 4.25 & 6.18 & 0.65 & 11.21 & 1.78 & 2.58 & 69 & 0.65 & 10.21 & 0.064 \\
\hline 4.75 & 6.66 & 0.69 & 11.60 & 1.74 & 2.53 & 0.69 & 0.71 & 10.71 & 0.066 \\
\hline 5.25 & 7.14 & 0.65 & 9.45 & 1.82 & 2.86 & 0.64 & 0.66 & 8.25 & 0.081 \\
\hline 5.75 & 7.67 & 0.67 & 10.43 & 1.78 & 2.57 & 0.69 & 0.70 & 9.51 & 0.074 \\
\hline 6.25 & 8.21 & 0.51 & 9.18 & 1.82 & 3.20 & .57 & 0.50 & 7.82 & 0.064 \\
\hline 6.75 & 8.76 & 0.63 & 10.72 & 1.84 & 2.59 & 0.71 & 0.68 & 9.93 & 0.068 \\
\hline 7.25 & 9.32 & 0.59 & 9.43 & 1.62 & 2.40 & 0.67 & 0.63 & 8.68 & 0.073 \\
\hline 7.75 & 9.87 & 0.60 & 9.48 & 1.73 & 2.58 & 0.67 & 0.65 & 8.66 & 0.075 \\
\hline 8.25 & 10.43 & 0.58 & 9.10 & 1.80 & 2.61 & 0.69 & 0.63 & 8.27 & 0.076 \\
\hline 8.75 & 10.98 & 0.58 & 8.60 & 1.74 & 2.57 & 0.68 & 0.64 & 7.79 & 0.082 \\
\hline 9.25 & 11.54 & 0.48 & 8.26 & 1.66 & 2.4 & 0.67 & 0.52 & 7.50 & 0.070 \\
\hline 9.75 & 12.09 & 0.52 & & 1.65 & 2.56 & 0.65 & 0.58 & & \\
\hline 10.25 & 12.65 & 0.47 & 8.21 & 1.70 & 2.62 & 65 & 0.52 & 7.44 & 0.070 \\
\hline 10.75 & 12.87 & 0.53 & 9.02 & 1.71 & 2.5 & .67 & 0.60 & 8.39 & 0.071 \\
\hline 11.25 & 13.10 & 0.46 & 8.42 & 1.69 & 2.6 & 0.63 & 0.51 & 7.66 & 0.067 \\
\hline 11.75 & 13.21 & 0.51 & & 1.81 & 2.96 & 0.61 & 0.57 & & \\
\hline 12.25 & 13.33 & 0.43 & 8.51 & 1.70 & 2.60 & 0.65 & 0.47 & 7.83 & 0.060 \\
\hline 12.75 & 13.44 & 0.45 & 8.60 & 1.75 & 2.70 & .65 & 0.49 & 7.90 & 0.063 \\
\hline 13.75 & 13.67 & 0.50 & 9.51 & 1.71 & 2.85 & .60 & 0.56 & 8.84 & 0.064 \\
\hline 14.75 & 13.89 & 0.76 & 15.96 & 1.84 & 3.16 & 0.58 & 0.90 & 15.96 & 0.056 \\
\hline 15.75 & 14.12 & 1.03 & 19.55 & 1.78 & 3.14 & 0.57 & 1.26 & 20.10 & 0.063 \\
\hline 16.75 & 16.08 & 1.41 & 28.72 & 1.92 & 3.29 & 0.58 & 1.85 & 31.00 & 0.060 \\
\hline 17.75 & 20.34 & 1.18 & 25.67 & 1.80 & 3. & 0.57 & 1.68 & 28.66 & 0.06 \\
\hline 18.75 & 25.19 & 0.85 & 19.23 & 1.7 & 2. & 0.61 & 1.30 & 21.99 & 0.06 \\
\hline 19.75 & 30.04 & 0.70 & 16.43 & 1.77 & 3. & 0.55 & 1.14 & 19.11 & 0.06 \\
\hline 20.25 & 32.46 & 0.58 & 15.79 & 1.81 & 3.00 & 0.60 & 0.97 & 18.80 & 0.05 \\
\hline 20.75 & 33.48 & 0.52 & 12.89 & 1.76 & 2.5 & 0.59 & 0.89 & 15.07 & 0.06 \\
\hline 21.25 & 34.50 & 0.38 & 10.21 & 1.84 & 2.95 & 0.62 & 0.60 & 11.52 & 0.05 \\
\hline
\end{tabular}


Table A.3 Nuclide Measurements, all cores (continued)

\section{BC $17 \quad 2255$ m (continued)}

\begin{tabular}{cccccccccc} 
depth & Age & ${ }^{231} \mathrm{~Pa}$ & ${ }^{230} \mathrm{Th}$ & ${ }^{238} \mathrm{U}$ & ${ }^{232} \mathrm{Th}$ & ${ }^{238} \mathrm{U} /{ }^{232} \mathrm{Th}^{231} \mathrm{~Pa}_{\mathrm{xs} 0}{ }^{230} \mathrm{Th}_{\mathrm{xs} 0}{ }^{231} \mathrm{~Pa}_{\mathrm{xs} 0} /$ \\
cm & ky & dpm/g & dpm/g & dpm/g & dpm/g & ratio & dpm/g & dpm/g & ${ }^{230} \mathrm{Th}_{\mathrm{xs} 0}$ \\
\hline & & & & & & & & & \\
21.75 & 35.06 & 0.44 & 11.98 & 1.71 & 2.85 & 0.60 & 0.76 & 14.18 & 0.054 \\
22.25 & 35.61 & 0.38 & 13.59 & 1.82 & 2.85 & 0.64 & 0.63 & 16.41 & 0.038 \\
22.75 & 36.17 & 0.60 & 18.27 & 1.65 & 2.82 & 0.58 & 1.11 & 23.07 & 0.048 \\
23.25 & 36.72 & 0.45 & 20.00 & 1.68 & 2.72 & 0.62 & 0.82 & 25.67 & 0.032 \\
23.75 & 37.27 & 0.55 & 18.05 & 1.61 & 2.53 & 0.64 & 1.05 & 23.22 & 0.045 \\
24.25 & 37.83 & 0.39 & 17.38 & 1.71 & 2.55 & 0.67 & 0.69 & 22.35 & 0.031 \\
24.75 & 38.38 & 0.45 & 16.31 & 1.70 & 2.50 & 0.68 & 0.84 & 20.98 & 0.040 \\
25.75 & 39.49 & 0.43 & 16.27 & 1.71 & 2.53 & 0.68 & 0.82 & 21.11 & 0.039 \\
26.75 & 40.60 & 0.32 & 13.42 & 1.71 & 2.54 & 0.67 & 0.58 & 17.17 & 0.034 \\
27.75 & 41.46 & 0.27 & 11.54 & 1.79 & 2.59 & 0.69 & 0.48 & 14.62 & 0.033 \\
28.75 & 42.00 & 0.20 & 8.38 & 1.78 & 2.55 & 0.70 & 0.32 & 10.07 & 0.032 \\
29.75 & 42.45 & 0.16 & 5.86 & 1.80 & 2.50 & 0.72 & 0.19 & 6.32 & 0.030
\end{tabular}


Table A.3 Nuclide Measurements, all cores (continı

\begin{tabular}{|c|c|c|c|c|}
\hline BC 19 & & $2414 \mathrm{~m}$ & & \\
\hline $\begin{array}{c}\text { depth } \\
\mathrm{cm}\end{array}$ & $\begin{array}{l}\text { Age } \\
\text { ky }\end{array}$ & $\begin{array}{l}{ }^{230} \mathrm{Th} \\
\mathrm{dpm} / \mathrm{g}\end{array}$ & $\begin{array}{l}{ }^{232} \mathrm{Th} \\
\mathrm{dpm} / \mathrm{g}\end{array}$ & $\begin{array}{r}{ }^{230} \mathrm{Th}_{\mathrm{xs} 0} \\
\mathrm{dpm} / \mathrm{g}\end{array}$ \\
\hline 0.5 & 0.75 & 19.40 & 2.45 & 19.85 \\
\hline 1.5 & 3.26 & 19.18 & 2.58 & 19.64 \\
\hline 2.5 & 5.76 & 16.78 & 2.69 & 17.20 \\
\hline 3.5 & 8.27 & 14.00 & 2.66 & 14.34 \\
\hline 4.5 & 10.78 & 10.98 & 2.49 & 11.23 \\
\hline 5.5 & 13.28 & 11.10 & 2.75 & 11.38 \\
\hline 6.5 & 13.51 & 13.82 & 2.67 & 14.16 \\
\hline 7.5 & 13.74 & 23.10 & 3.22 & 23.79 \\
\hline 8.5 & 19.07 & 21.32 & 2.60 & 21.83 \\
\hline 9.5 & 24.40 & 27.52 & 2.93 & 28.27 \\
\hline 11 & 32.26 & 17.63 & 3.20 & 18.15 \\
\hline 13 & 40.21 & 23.85 & 3.99 & 24.73 \\
\hline 15 & 41.71 & 16.99 & 2.58 & 17.39 \\
\hline 17 & 43.21 & 9.73 & 2.80 & 9.99 \\
\hline 19 & 44.41 & 6.97 & 2.52 & 7.13 \\
\hline 21 & 44.74 & 5.16 & 2.37 & 5.28 \\
\hline 23 & & 4.60 & 2.57 & \\
\hline 25 & & 4.47 & 2.65 & \\
\hline 27 & & 4.07 & 3.03 & \\
\hline 29 & & 6.24 & 2.81 & \\
\hline 31 & & 3.33 & 2.27 & \\
\hline 33 & & 6.67 & 2.82 & \\
\hline 35 & & 4.83 & & \\
\hline
\end{tabular}


Table A.3 Nuclide Measurements, all cores (continued)

\section{BC $20 \quad 3110 \mathrm{~m}$}

\begin{tabular}{|c|c|c|c|c|c|c|c|c|c|}
\hline $\begin{array}{l}\text { depth } \\
\mathrm{cm}\end{array}$ & $\begin{array}{c}\text { Age } \\
\text { ky }\end{array}$ & $\begin{array}{l}{ }^{231} \mathrm{~Pa} \\
\mathrm{dpm} / \mathrm{g}\end{array}$ & $\begin{array}{l}{ }^{230} \mathrm{Th} \\
\mathrm{dpm} / \mathrm{g}\end{array}$ & $\begin{array}{c}{ }^{238} \mathrm{U} \\
\mathrm{dpm} / \mathrm{g}\end{array}$ & $\begin{array}{l}{ }^{232} \mathrm{Th} \\
\mathrm{dpm} / \mathrm{g}\end{array}$ & $\begin{array}{l}{ }^{8} \mathrm{U}{ }^{232} \mathrm{~T} \\
\text { ratio }\end{array}$ & $\begin{array}{r}{ }^{231} \mathrm{~Pa}_{\mathrm{xs} 0} \\
\mathrm{dpm} / \mathrm{g}\end{array}$ & $\begin{array}{r}{ }^{230} \mathrm{Th}_{\mathrm{xs} 0} \\
\mathrm{dpm} / \mathrm{g}\end{array}$ & $\begin{array}{l}{ }^{231} \mathrm{~Pa}_{\mathrm{xs} 0} / \\
{ }^{230} \mathrm{Th}_{\mathrm{xs} 0}\end{array}$ \\
\hline 0.25 & 48 & 1.17 & 23.08 & 1.65 & 2.31 & 0.71 & 1.18 & 22.39 & 0.053 \\
\hline 1.2 & 15 & 1.05 & 22.26 & 1.62 & 2.34 & 0.69 & 1.10 & 21.87 & 0.050 \\
\hline 2.25 & 682 & 0.95 & 19.81 & 1.73 & 2.52 & 0.68 & 1.02 & 19.48 & 0.052 \\
\hline 3. & 8. & 81 & 0.10 & 1.80 & 63 & 68 & .88 & 8 & 0.056 \\
\hline 4.25 & 15 & .56 & .67 & 1.5 & 2.55 & .59 & 61 & 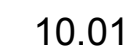 & 0.061 \\
\hline 5.25 & & 0.58 & .13 & 1.64 & 2.58 & .63 & 0.63 & 10.53 & 0.060 \\
\hline 6.25 & 69 & 57 & .51 & 1.57 & 2.56 & 61 & 0.62 & 11.00 & 0.057 \\
\hline 7.25 & & 50 & & 175 & 83 & 62 & .53 & 9.55 & 0.055 \\
\hline 8.2 & & & & 1 & 3.01 & .60 & 0.44 & 8.2 & 0.053 \\
\hline 9.25 & 16 & 0.64 & 1.07 & 1. & 2.95 & .61 & 0.78 & 4.28 & 0.055 \\
\hline 10.25 & 6 & 4 & & 1. & 3. & & 2.60 & 4 & 0.055 \\
\hline 11.25 & 26.72 & & & 1.8 & 3. & 60 & 2.25 & 40.62 & 0.055 \\
\hline 12. & & & & & & & & 0 & \\
\hline 13.25 & & & & & & & 1. & 1 & 0.049 \\
\hline 14.25 & $3 \varepsilon$ & & & & & 0.6 & 0.78 & 5 & 0.046 \\
\hline 15.25 & 42.41 & 50 & & 1.7 & 2.7 & 0.62 & 1.05 & 23.73 & 0.044 \\
\hline 16.2 & 4 & 56 & & 1.66 & 2.11 & 0.61 & 1.30 & 30.14 & 0.043 \\
\hline
\end{tabular}


Table A.3 Nuclide Measurements, all cores (continued)

BC $26 \quad 1034 \mathrm{~m}$

\begin{tabular}{cccccccccc} 
depth & Age & ${ }^{231} \mathrm{~Pa}$ & ${ }^{230} \mathrm{Th}$ & ${ }^{238} \mathrm{U}$ & ${ }^{232} \mathrm{Th}$ & ${ }^{238} \mathrm{U} /{ }^{232} \mathrm{Th}$ & ${ }^{231} \mathrm{~Pa}_{\mathrm{xs} 0}{ }^{230} \mathrm{Th}_{\mathrm{xs} 0}{ }^{231} \mathrm{~Pa}_{\mathrm{xs} 0} /$ \\
$\mathrm{cm}$ & ky & dpm/g & dpm/g & dpm/g & dpm/g & ratio & dpm/g & dpm/g & ${ }^{230} \mathrm{Th}_{\mathrm{xs} 0}$ \\
\hline & & & & & & & & & \\
0.25 & 3.65 & 0.50 & 6.51 & 1.45 & 2.12 & 0.68 & 0.47 & 5.41 & 0.087 \\
1.25 & 5.28 & 0.53 & 6.81 & 1.47 & 2.17 & 0.68 & 0.52 & 5.78 & 0.091 \\
2.25 & 6.92 & 0.43 & 6.30 & 1.57 & 2.38 & 0.66 & 0.42 & 5.19 & 0.081 \\
3.25 & 9.31 & 0.37 & 5.27 & 1.58 & 2.40 & 0.66 & 0.36 & 4.15 & 0.088 \\
4.25 & 11.71 & 0.32 & 4.71 & 1.58 & 2.51 & 0.63 & 0.32 & 3.55 & 0.091 \\
5.25 & 14.10 & 0.32 & 4.71 & 1.56 & 2.50 & 0.63 & 0.34 & 3.63 & 0.093 \\
6.25 & 16.50 & 0.40 & 5.69 & 1.50 & 2.35 & 0.64 & 0.47 & 4.98 & 0.095 \\
7.25 & 21.10 & 0.31 & 4.67 & 1.49 & 2.39 & 0.62 & 0.37 & 3.90 & 0.096 \\
8.25 & 25.70 & 0.21 & 4.87 & 1.55 & 2.36 & 0.66 & 0.25 & 4.33 & 0.057 \\
9.25 & 26.71 & 0.19 & 3.90 & 1.48 & 2.25 & 0.66 & 0.21 & 3.20 & 0.066 \\
10.25 & 27.73 & 0.13 & 3.77 & 1.56 & 2.33 & 0.67 & 0.12 & 3.00 & 0.040 \\
11.25 & 28.07 & 0.27 & 5.17 & 1.48 & 2.32 & 0.64 & 0.36 & 4.84 & 0.075 \\
12.25 & 28.41 & 0.30 & 6.15 & 1.46 & 2.26 & 0.64 & 0.43 & 6.22 & 0.069 \\
13.25 & 33.24 & 0.19 & 4.20 & 1.48 & 2.26 & 0.66 & 0.25 & 3.86 & 0.065 \\
14.25 & 38.08 & 0.22 & 4.33 & 1.48 & 2.26 & 0.65 & 0.35 & 4.15 & 0.085 \\
15.25 & 42.92 & 0.10 & 2.00 & 1.19 & 1.69 & 0.71 & 0.11 & 1.38 & 0.081 \\
16.25 & & 0.08 & 1.74 & 1.47 & 2.15 & 0.68 & 0.05 & 0.70 & 0.071 \\
17.25 & & 0.18 & 3.08 & 1.55 & 2.29 & 0.68 & 0.34 & 2.70 & 0.126 \\
18.25 & & 0.08 & 1.76 & 1.56 & 2.19 & 0.71 & 0.02 & 0.57 & 0.036 \\
19.25 & & 0.07 & 1.38 & 1.45 & 1.92 & 0.76 & 0.03 & 0.21 & 0.213 \\
20.25 & & 0.05 & 1.24 & 1.31 & 1.45 & 0.90 & 0.00 & 0.41 & 0.003 \\
21.25 & & 0.06 & 1.15 & 1.26 & 1.47 & 0.85 & 0.04 & 0.42 & 0.077 \\
22.25 & & 0.06 & 1.11 & 1.23 & 1.59 & 0.77 & 0.02 & 0.11 & -0.349 \\
23.25 & & 0.05 & 0.97 & 1.18 & 1.30 & 0.91 & 0.01 & 0.15 & 0.061 \\
24.25 & & 0.05 & 1.05 & 1.22 & 1.44 & 0.85 & 0.00 & 0.14 & -0.003 \\
25.25 & & 0.05 & 1.10 & 1.16 & 1.30 & 0.89 & 0.02 & 0.36 & 0.052 \\
26.25 & & 0.06 & 1.09 & 1.29 & 1.37 & 0.94 & 0.01 & 0.25 & 0.047 \\
27.25 & & 0.06 & 1.07 & 1.33 & 1.40 & 0.95 & 0.04 & 0.36 & 0.083 \\
28.25 & & 0.06 & 1.10 & 1.36 & 1.45 & 0.94 & 0.05 & 0.36 & 0.115
\end{tabular}


Table A.3 Nuclide Measurements, all cores (continued)

\begin{tabular}{|c|c|c|c|c|c|c|c|c|c|}
\hline BC 28 & & $90 \mathrm{~m}$ & & & & & & & \\
\hline $\begin{array}{c}\text { depth } \\
\mathrm{cm}\end{array}$ & $\begin{array}{c}\text { Age } \\
\text { ky }\end{array}$ & $\begin{array}{l}{ }^{231} \mathrm{~Pa} \\
\mathrm{dpm} / \mathrm{g}\end{array}$ & $\begin{array}{l}{ }^{230} \mathrm{Th} \\
\mathrm{dpm} / \mathrm{g}\end{array}$ & $\begin{array}{l}{ }^{238} \mathrm{U} \\
\mathrm{dpm} / \mathrm{g}\end{array}$ & $\begin{array}{l}{ }^{232} \mathrm{Th} \\
\mathrm{dpm} / \mathrm{g}\end{array}$ & $\begin{array}{c}{ }^{238} \mathrm{U} /{ }^{232} \mathrm{Th} \\
\text { ratio }\end{array}$ & $\begin{array}{r}{ }^{231} \mathrm{~Pa}_{\mathrm{xs} 0} \\
\mathrm{dpm} / \mathrm{g}\end{array}$ & $\begin{array}{r}{ }^{230} \mathrm{Th}_{\mathrm{xs} 0} \\
\mathrm{dpm} / \mathrm{g}\end{array}$ & $\begin{array}{l}{ }^{231} \mathrm{~Pa}_{\mathrm{xs} 0} / \\
{ }^{230} \mathrm{Th}_{\mathrm{xs} 0}\end{array}$ \\
\hline 0.25 & 1.59 & 0.53 & 8.03 & 1.73 & 2.45 & 0.71 & 0.48 & 6.72 & 0.071 \\
\hline 1.25 & 2.40 & 0.42 & 9.02 & 1.68 & 2.44 & 0.69 & 0.37 & 7.71 & 0.047 \\
\hline 2.25 & 3.20 & 0.40 & 8.43 & 1.74 & 2.48 & 0.70 & 0.35 & 7.12 & 0.050 \\
\hline 3.25 & 4.01 & 0.35 & 7.89 & 1.71 & 2.49 & 0.69 & 0.31 & 6.62 & 0.046 \\
\hline 4.25 & 4.79 & 0.50 & 7.89 & 1.75 & 2.54 & 0.69 & 0.48 & 6.62 & 0.072 \\
\hline 5.25 & 5.57 & 0.38 & 6.91 & 1.76 & 2.62 & 0.67 & 0.35 & 5.72 & 0.062 \\
\hline 6.25 & 6.35 & 0.45 & 6.56 & 1.64 & 2.69 & 0.61 & 0.43 & 5.24 & 0.082 \\
\hline 7.25 & 7.12 & 0.41 & 6.03 & 1.54 & 2.71 & 0.57 & 0.39 & 4.70 & 0.084 \\
\hline 8.25 & 7.90 & 0.33 & 6.13 & 1.70 & 2.59 & 0.66 & 0.31 & 4.95 & 0.062 \\
\hline 9.25 & 8.68 & 0.39 & 6.63 & 1.65 & 2.91 & 0.57 & 0.38 & 5.51 & 0.069 \\
\hline 10.25 & 9.45 & 0.53 & 7.70 & 0.06 & 0.12 & 0.54 & 0.65 & 8.32 & 0.078 \\
\hline 11.25 & 10.23 & 0.58 & 8.21 & 1.66 & 2.80 & 0.59 & 0.62 & 7.15 & 0.087 \\
\hline 12.25 & 11.01 & 0.85 & 12.74 & 1.68 & 3.00 & 0.56 & 0.97 & 12.10 & 0.081 \\
\hline 13.25 & 12.91 & 0.64 & 14.55 & 2.14 & 3.53 & 0.61 & 0.70 & 13.88 & 0.051 \\
\hline 14.25 & 15.18 & 1.03 & 19.72 & 2.19 & 3.48 & 0.63 & 1.29 & 20.35 & 0.064 \\
\hline 15.25 & 17.45 & 1.10 & 19.41 & 2.12 & 3.47 & 0.61 & 1.42 & 20.18 & 0.071 \\
\hline 16.25 & 20.53 & 0.86 & 16.60 & 0.15 & 0.26 & 0.58 & 1.32 & 19.86 & 0.066 \\
\hline 17.25 & 24.66 & 0.67 & 13.87 & 1.67 & 2.97 & 0.56 & 0.99 & 15.14 & 0.065 \\
\hline
\end{tabular}


Table A.3 Nuclide Measurements, all cores (continued)

\section{BC $32 \quad 3471 \mathrm{~m}$}

\begin{tabular}{|c|c|c|c|c|c|c|c|c|c|}
\hline $\begin{array}{c}\text { depth } \\
\mathrm{cm}\end{array}$ & $\begin{array}{c}\text { Age } \\
\text { ky }\end{array}$ & $\begin{array}{l}{ }^{231} \mathrm{~Pa} \\
\mathrm{dpm} / \mathrm{g}\end{array}$ & $\begin{array}{l}{ }^{230} \mathrm{Th} \\
\mathrm{dpm} / \mathrm{g}\end{array}$ & $\begin{array}{l}{ }^{238} \mathrm{U} \\
\mathrm{dpm} / \mathrm{g}\end{array}$ & $\begin{array}{l}{ }^{232} \mathrm{Th} \\
\mathrm{dpm} / \mathrm{g}\end{array}$ & $\begin{array}{l}{ }^{238} \mathrm{U} /{ }^{232} \mathrm{Tr} \\
\quad \text { ratio }\end{array}$ & $\begin{array}{r}{ }^{231} \mathrm{~Pa}_{\mathrm{xs} 0} \\
\mathrm{dpm} / \mathrm{g}\end{array}$ & $\begin{array}{r}{ }^{230} \mathrm{Th}_{\mathrm{xs} 0} \\
\mathrm{dpm} / \mathrm{g}\end{array}$ & $\begin{array}{l}{ }^{231} \mathrm{~Pa}_{\mathrm{xs} 0} / \\
{ }^{230} \mathrm{Th}_{\mathrm{xs} 0}\end{array}$ \\
\hline 0.25 & 5.06 & 0.68 & 13.72 & 1.48 & 2.24 & 0.66 & 0.69 & 12.96 & 0.053 \\
\hline 1.25 & 5.88 & 0.57 & 14.73 & 1.55 & 2.29 & 0.68 & 0.57 & 14.08 & 0.040 \\
\hline 2.25 & 6.51 & 0.57 & 12.04 & 1.58 & 2.41 & 0.66 & 0.57 & 11.24 & 0.051 \\
\hline 3.25 & 7.07 & 0.45 & 11.21 & 1.60 & 2.49 & 0.64 & 0.44 & 10.36 & 0.042 \\
\hline 4.25 & 7.64 & 0.46 & 9.95 & 1.57 & 2.49 & 0.63 & 0.46 & 9.06 & 0.051 \\
\hline 5.25 & 8.08 & 0.43 & 10.19 & 1.70 & 2.55 & 0.67 & 0.43 & 9.31 & 0.046 \\
\hline 6.25 & 8.48 & 0.31 & 9.45 & 1.61 & 2.52 & 0.64 & 0.28 & 8.57 & 0.033 \\
\hline 7.25 & 8.88 & 0.39 & 9.18 & 1.52 & 2.43 & 0.63 & 0.39 & 8.37 & 0.047 \\
\hline 8.25 & 9.89 & 0.44 & 9.66 & 1.61 & 2.65 & 0.61 & 0.45 & 8.83 & 0.051 \\
\hline 9.25 & 11.10 & 0.49 & 13.47 & 1.70 & 2.86 & 0.59 & 0.52 & 13.00 & 0.040 \\
\hline 10.25 & 12.31 & 0.60 & 13.94 & 1.78 & 3.17 & 0.56 & 0.66 & 13.46 & 0.049 \\
\hline 11.25 & 14.62 & 0.61 & 15.50 & 1.82 & 3.29 & 0.55 & 0.72 & 15.45 & 0.046 \\
\hline 12.25 & 17.31 & 0.66 & 15.86 & 1.90 & 3.34 & 0.57 & 0.82 & 16.22 & 0.051 \\
\hline 13.25 & 23.67 & 0.70 & 17.10 & 1.90 & 3. & 0.57 & 1.00 & 18.73 & 0.053 \\
\hline 14.25 & 31.25 & 0.54 & 18.05 & 1.79 & 3.25 & 0.55 & 0.88 & 21.43 & 0.041 \\
\hline 15.25 & 38.83 & & & 1.65 & 3.03 & 0.55 & 1.14 & 1.43 & 0.053 \\
\hline
\end{tabular}


Table A.4: Stable Isotopic Measurements, $\delta^{13} \mathrm{C}$ and $\delta^{18} \mathrm{O}$

BC 08

$1047 \mathrm{~m}$

Poore et al. (1999 a,b), >125 um Size Fraction

\begin{tabular}{|c|c|c|c|c|c|}
\hline $\begin{array}{c}\text { depth } \\
\mathrm{cm}\end{array}$ & $\begin{array}{l}\delta^{13} \mathrm{C} \\
\text { permil }\end{array}$ & $\begin{array}{c}\delta^{18} \mathrm{O} \\
\text { permil }\end{array}$ & $\begin{array}{c}\text { depth } \\
\mathrm{cm}\end{array}$ & $\begin{array}{c}\delta^{13} \mathrm{C} \\
\text { permil }\end{array}$ & $\begin{array}{c}\delta^{18} \mathrm{O} \\
\text { permil }\end{array}$ \\
\hline 0.5 & 0.97 & 1.86 & 13.5 & 0.15 & 0.66 \\
\hline 0.5 & 1.16 & 1.76 & 13.5 & 0.47 & 1.52 \\
\hline 0.5 & 1.16 & 1.84 & 14.5 & 0.26 & 1.03 \\
\hline 0.5 & 1.22 & 1.72 & 14.5 & 0.19 & 1.02 \\
\hline 0.5 & 1.26 & 1.80 & 15.5 & 0.04 & 0.44 \\
\hline 1.5 & 0.82 & 1.95 & 15.5 & 0.16 & 0.64 \\
\hline 1.5 & 0.92 & 1.90 & 15.5 & 0.14 & 0.97 \\
\hline 2.5 & 0.70 & 1.34 & 16.5 & 0.33 & 1.52 \\
\hline 2.5 & 1.20 & 1.87 & 16.5 & 0.20 & 0.47 \\
\hline 3.5 & 0.73 & 1.62 & 17.5 & 0.22 & 0.43 \\
\hline 3.5 & 1.06 & 1.80 & 17.5 & 0.54 & 0.63 \\
\hline 4.5 & 0.94 & 1.93 & 18.5 & 0.25 & -0.14 \\
\hline 4.5 & 1.18 & 1.81 & 18.5 & 0.13 & 0.90 \\
\hline 5.5 & 0.33 & 0.76 & 19.5 & 0.24 & 0.49 \\
\hline 5.5 & 0.88 & 0.94 & 19.5 & 0.08 & 0.69 \\
\hline 5.5 & 1.14 & 1.72 & 20.5 & 0.25 & 0.89 \\
\hline 6.5 & 0.58 & 0.87 & 20.5 & 0.17 & 0.72 \\
\hline 6.5 & 0.78 & 1.16 & 21.5 & 0.26 & 1.19 \\
\hline 6.5 & 1.09 & 1.71 & 21.5 & 0.13 & 0.11 \\
\hline 7.5 & 0.64 & 0.84 & 22.5 & 0.08 & -0.15 \\
\hline 7.5 & 0.47 & 1.57 & 22.5 & 0.18 & 0.57 \\
\hline 8.5 & 0.49 & 1.27 & 23.5 & 0.10 & 0.57 \\
\hline 8.5 & 0.91 & 1.79 & 24.5 & 0.16 & 0.38 \\
\hline 8.5 & 0.38 & 0.66 & 25.5 & 0.42 & 1.07 \\
\hline 9.5 & 0.49 & 0.98 & 26.5 & 0.42 & 1.28 \\
\hline 9.5 & 0.77 & 1.78 & 27.5 & 0.21 & 1.51 \\
\hline 9.5 & 0.94 & 1.46 & 28.5 & 0.07 & 1.29 \\
\hline 10.5 & 0.29 & 0.90 & 29.5 & 0.06 & 1.39 \\
\hline 10.5 & 0.61 & 1.67 & 30.5 & 0.20 & 0.50 \\
\hline 10.5 & 0.79 & 1.25 & 31.5 & 0.14 & 0.87 \\
\hline 10.5 & 0.86 & 1.68 & 32.5 & 0.59 & 1.44 \\
\hline 11.5 & 0.28 & 0.86 & 33.5 & 0.70 & 1.31 \\
\hline 11.5 & 0.29 & 0.87 & 34.5 & 0.81 & 1.31 \\
\hline 11.5 & 0.91 & 1.38 & 35.5 & 0.90 & 1.40 \\
\hline 12.5 & 0.60 & 1.35 & 35.5 & 0.99 & 2.11 \\
\hline 12.5 & 0.75 & 1.29 & 36.5 & 1.22 & 2.14 \\
\hline 12.5 & 0.83 & 1.74 & 37.5 & 1.45 & 3.12 \\
\hline
\end{tabular}


Table A.4: Stable Isotopic Measurements, $\delta^{13} \mathrm{C}$ and $\delta^{18} \mathrm{O}$ (ctd.)

BC 08 $1047 \mathrm{~m}$

Curry (unpublished data), 180-212 $\mu \mathrm{m}$ Size Fraction

\begin{tabular}{ccc}
$\begin{array}{c}\text { depth } \\
\mathrm{cm}\end{array}$ & $\begin{array}{c}\delta^{13} \mathrm{C} \\
\text { permil }\end{array}$ & $\begin{array}{c}\delta^{18} \mathrm{O} \\
\text { permil }\end{array}$ \\
\hline 0.5 & 0.56 & 1.63 \\
1.0 & 0.54 & 1.43 \\
1.5 & 0.54 & 1.37 \\
2.5 & 0.57 & 1.37 \\
3.5 & 0.56 & 1.17 \\
4.5 & 0.57 & 1.36 \\
5.5 & 0.59 & 1.14 \\
6.5 & 0.62 & 1.20 \\
7.5 & 0.66 & 1.16 \\
8.5 & 0.66 & 1.13 \\
9.5 & 0.67 & 1.23 \\
10.5 & 0.66 & 1.32 \\
11.5 & 0.67 & 1.34 \\
12.5 & 0.66 & 1.28 \\
13.5 & 0.66 & 0.96 \\
15.5 & 0.67 & 0.96 \\
16.5 & 0.68 & 1.06 \\
17.5 & 0.68 & 0.70 \\
18.5 & 0.65 & 1.11 \\
19.5 & 0.63 & 0.88 \\
20.5 & 0.60 & 1.07 \\
22.5 & 0.63 & 0.70 \\
23.5 & 0.62 & 0.20
\end{tabular}

Values averaged from $\sim 10$ measurements per sample (W. Curry, personal communication) 
Table A.4: Stable Isotopic Measurements, $\delta^{13} \mathrm{C}$ and $\delta^{18} \mathrm{O}$ (ctd.)

BC 16

$1568 \mathrm{~m}$

Poore et al. (1999 a,b), >125 $\mu \mathrm{m}$ Size Fraction

\begin{tabular}{|c|c|c|c|c|c|}
\hline $\begin{array}{c}\text { depth } \\
\mathrm{cm}\end{array}$ & $\begin{array}{c}\delta^{13} \mathrm{C} \\
\text { permil }\end{array}$ & $\begin{array}{c}\delta^{18} \mathrm{O} \\
\text { permil }\end{array}$ & $\begin{array}{c}\text { depth } \\
\mathrm{cm}\end{array}$ & $\begin{array}{l}\delta^{13} \mathrm{C} \\
\text { permil }\end{array}$ & $\begin{array}{c}\delta^{18} \mathrm{O} \\
\text { permil }\end{array}$ \\
\hline 0.5 & 1.16 & 1.65 & 31.5 & 1.13 & 3.19 \\
\hline 0.5 & 1.17 & 1.89 & 32.5 & 0.86 & 3.09 \\
\hline 0.5 & 1.36 & 1.74 & 33.5 & 0.99 & 3.13 \\
\hline 1.5 & 1.34 & 1.41 & 34.5 & 0.59 & 1.72 \\
\hline 2.5 & 1.13 & 1.02 & 35.5 & 0.93 & 2.75 \\
\hline 3.5 & 1.11 & 1.59 & 36.5 & 0.79 & 2.37 \\
\hline 3.5 & 1.16 & 1.92 & 36.5 & 0.80 & 2.25 \\
\hline 4.5 & 1.10 & 1.42 & 37.5 & 0.58 & 2.45 \\
\hline 5.5 & 0.89 & 1.39 & & & \\
\hline 6.5 & 0.94 & 0.48 & & & \\
\hline 7.5 & 0.64 & 1.08 & & & \\
\hline 8.5 & 0.43 & 0.04 & & & \\
\hline 9.5 & 0.17 & 0.54 & & & \\
\hline 10.5 & 0.25 & 0.35 & & & \\
\hline 11.5 & 0.12 & 1.12 & & & \\
\hline 12.5 & 0.22 & 0.56 & & & \\
\hline 13.5 & 0.35 & 0.49 & & & \\
\hline 14.5 & 0.37 & 1.04 & & & \\
\hline 15.5 & 0.10 & 1.29 & & & \\
\hline 15.5 & 0.12 & 1.43 & & & \\
\hline 16.5 & 0.20 & 1.27 & & & \\
\hline 17.5 & 0.36 & 1.59 & & & \\
\hline 18.5 & 0.55 & 1.60 & & & \\
\hline 19.5 & 0.63 & 1.27 & & & \\
\hline 20.5 & 0.84 & 1.27 & & & \\
\hline 20.5 & 0.89 & 1.57 & & & \\
\hline 21.5 & 1.03 & 2.00 & & & \\
\hline 22.5 & 1.35 & 2.80 & & & \\
\hline 23.5 & 1.14 & 2.80 & & & \\
\hline 24.5 & 1.25 & 3.02 & & & \\
\hline 25.5 & 1.25 & 2.99 & & & \\
\hline 26.5 & 1.06 & 2.79 & & & \\
\hline 26.5 & 1.12 & 2.74 & & & \\
\hline 28.5 & 1.14 & 2.91 & & & \\
\hline 29.5 & 0.98 & 2.40 & & & \\
\hline 29.5 & 1.04 & 3.19 & & & \\
\hline 30.5 & 0.95 & 2.40 & & & \\
\hline
\end{tabular}


Table A.4: Stable Isotopic Measurements, $\delta^{13} \mathrm{C}$ and $\delta^{18} \mathrm{O}$ (ctd.)

BC 16

$1568 \mathrm{~m}$

Curry (unpublished data), 180-212 $\mu \mathrm{m}$ Size Fraction

\begin{tabular}{ccc}
$\begin{array}{c}\text { depth } \\
\mathrm{cm}\end{array}$ & $\begin{array}{c}\delta^{13} \mathrm{C} \\
\text { permil }\end{array}$ & $\begin{array}{c}\delta^{18} \mathrm{O} \\
\text { permil }\end{array}$ \\
\hline 0.5 & 0.87 & 1.81 \\
1.0 & 0.73 & 1.39 \\
1.5 & 0.86 & 1.68 \\
2.5 & 0.72 & 1.35 \\
3.5 & 0.69 & 1.17 \\
4.5 & 0.68 & 1.31 \\
5.5 & 0.39 & 0.99 \\
6.5 & 0.28 & 0.61 \\
7.5 & 0.20 & 0.83 \\
8.5 & 0.30 & 0.84 \\
9.5 & 0.20 & 0.57 \\
10.5 & 0.20 & 0.61 \\
11.5 & 0.18 & 0.75 \\
12.5 & 0.03 & 0.92 \\
13.5 & 0.32 & 0.88 \\
14.5 & 0.14 & 0.76
\end{tabular}

Values averaged from $\sim 10$ measurements per sample (W. Curry, personal communication) 
Table A.4: Stable Isotopic Measurements, $\delta^{13} \mathrm{C}$ and $\delta^{18} \mathrm{O}$ (ctd.)

BC 17

$2255 \mathrm{~m}$

Poore et al. (1999 a,b), >125 $\mu \mathrm{m}$ Size Fraction

\begin{tabular}{|c|c|c|c|c|c|}
\hline $\begin{array}{c}\text { depth } \\
\mathrm{cm}\end{array}$ & $\begin{array}{c}\delta^{13} \mathrm{C} \\
\text { permil }\end{array}$ & $\begin{array}{c}\delta^{18} \mathrm{O} \\
\text { permil }\end{array}$ & $\begin{array}{c}\text { depth } \\
\mathrm{cm}\end{array}$ & $\begin{array}{l}\delta^{13} \mathrm{C} \\
\text { permil }\end{array}$ & $\begin{array}{c}\delta^{18} \mathrm{O} \\
\text { permil }\end{array}$ \\
\hline 0.5 & 1.19 & 1.62 & 35.5 & 1.01 & 2.96 \\
\hline 0.5 & 1.28 & 1.40 & 36.5 & 1.24 & 3.40 \\
\hline 0.5 & 1.31 & 1.55 & & & \\
\hline 1.5 & 1.12 & 1.80 & & & \\
\hline 2.5 & 1.22 & 1.93 & & & \\
\hline 3.5 & 1.11 & 1.52 & & & \\
\hline 4.5 & 1.05 & 1.89 & & & \\
\hline 5.5 & 0.89 & 1.79 & & & \\
\hline 6.5 & 0.77 & 1.70 & & & \\
\hline 7.5 & 0.92 & 1.19 & & & \\
\hline 8.5 & 0.89 & 0.82 & & & \\
\hline 9.5 & 0.43 & 1.08 & & & \\
\hline 10.5 & 0.07 & 0.77 & & & \\
\hline 11.5 & 0.10 & 0.79 & & & \\
\hline 12.5 & 0.18 & 0.07 & & & \\
\hline 13.5 & 0.20 & 0.25 & & & \\
\hline 14.5 & 0.19 & -0.04 & & & \\
\hline 15.5 & 0.11 & -0.16 & & & \\
\hline 16.5 & 0.28 & 0.59 & & & \\
\hline 17.5 & 0.16 & 0.81 & & & \\
\hline 18.5 & 0.13 & 1.66 & & & \\
\hline 19.5 & 0.14 & 0.98 & & & \\
\hline 20.5 & 0.09 & 0.70 & & & \\
\hline 21.5 & 0.50 & -0.06 & & & \\
\hline 22.5 & 0.74 & 1.03 & & & \\
\hline 23.5 & 0.78 & 1.12 & & & \\
\hline 24.5 & 0.86 & 1.66 & & & \\
\hline 25.5 & 0.72 & 1.55 & & & \\
\hline 26.5 & 0.87 & 2.28 & & & \\
\hline 27.5 & 1.11 & 2.43 & & & \\
\hline 28.5 & 1.12 & 2.85 & & & \\
\hline 29.5 & 1.15 & 2.97 & & & \\
\hline 30.5 & 1.10 & 2.64 & & & \\
\hline 31.5 & 1.11 & 2.83 & & & \\
\hline 32.5 & 1.02 & 2.58 & & & \\
\hline 33.5 & 1.07 & 2.77 & & & \\
\hline 34.5 & 0.97 & 2.98 & & & \\
\hline
\end{tabular}


Table A.4: Stable Isotopic Measurements, $\delta^{13} \mathrm{C}$ and $\delta^{18} \mathrm{O}$ (ctd.)

BC 17

$2255 \mathrm{~m}$

Curry (unpublished data), 180-212 $\mu \mathrm{m}$ Size Fraction

\begin{tabular}{ccc}
$\begin{array}{c}\text { depth } \\
\mathrm{cm}\end{array}$ & $\begin{array}{c}\delta^{13} \mathrm{C} \\
\text { permil }\end{array}$ & $\begin{array}{c}\delta^{18} \mathrm{O} \\
\text { permil }\end{array}$ \\
\hline 0.5 & 0.81 & 1.72 \\
1.0 & 0.92 & 1.80 \\
1.5 & 0.76 & 1.48 \\
2.5 & 0.75 & 1.50 \\
3.5 & 0.78 & 1.63 \\
4.5 & 0.68 & 1.11 \\
5.5 & 0.53 & 1.19 \\
6.5 & 0.51 & 1.04 \\
7.5 & 0.47 & 0.92 \\
8.5 & 0.34 & 0.31 \\
9.5 & 0.20 & 0.13 \\
10.5 & 0.04 & 0.37 \\
11.5 & -0.01 & 0.47 \\
12.5 & -0.03 & 0.30 \\
13.5 & -0.03 & 0.08 \\
14.5 & 0.06 & 0.48 \\
15.5 & 0.00 & 0.29 \\
16.5 & 0.04 & 0.22 \\
17.5 & -0.03 & 0.63
\end{tabular}

Values averaged from $\sim 10$ measurements per sample (W. Curry, personal communication) 
Table A.4: Stable Isotopic Measurements, $\delta^{13} \mathrm{C}$ and $\delta^{18} \mathrm{O}$ (ctd.)

BC 19

$2414 \mathrm{~m}$

Poore et al. (1999 a,b), >125 $\mu \mathrm{m}$ Size Fraction

\begin{tabular}{|c|c|c|c|c|c|}
\hline $\begin{array}{c}\text { depth } \\
\mathrm{cm}\end{array}$ & $\begin{array}{c}\delta^{13} \mathrm{C} \\
\text { permil }\end{array}$ & $\begin{array}{c}\delta^{18} \mathrm{O} \\
\text { permil }\end{array}$ & $\begin{array}{c}\text { depth } \\
\mathrm{cm}\end{array}$ & $\begin{array}{c}\delta^{13} \mathrm{C} \\
\text { permil }\end{array}$ & $\begin{array}{l}\delta^{18} \mathrm{O} \\
\text { permil }\end{array}$ \\
\hline 0.5 & 1.06 & 1.66 & 31.5 & 0.40 & -0.84 \\
\hline 0.5 & 1.16 & 1.76 & 32.5 & 0.72 & 1.18 \\
\hline 0.5 & 1.26 & 1.68 & 33.5 & 0.69 & 2.47 \\
\hline 0.5 & 1.28 & 1.68 & 34.5 & 0.62 & 2.28 \\
\hline 1.5 & 1.10 & 1.56 & 35.5 & 0.60 & 1.54 \\
\hline 2.5 & 0.82 & 1.71 & 36.5 & 0.34 & 2.90 \\
\hline 3.5 & 0.84 & 1.45 & 36.5 & 0.50 & 2.44 \\
\hline 4.5 & 0.49 & 0.87 & & & \\
\hline 5.5 & 0.27 & -0.20 & & & \\
\hline 6.5 & 0.17 & 0.71 & & & \\
\hline 6.5 & 0.17 & 0.77 & & & \\
\hline 7.5 & 0.17 & 0.72 & & & \\
\hline 8.5 & 0.24 & 0.12 & & & \\
\hline 9.5 & 0.09 & 1.07 & & & \\
\hline 10.5 & 0.10 & 1.13 & & & \\
\hline 11.5 & 0.27 & 0.83 & & & \\
\hline 12.5 & 0.69 & 1.05 & & & \\
\hline 13.5 & 0.63 & 1.27 & & & \\
\hline 14.5 & 0.90 & 1.40 & & & \\
\hline 15.5 & 0.89 & 1.48 & & & \\
\hline 15.5 & 0.97 & 1.77 & & & \\
\hline 16.5 & 1.02 & 2.33 & & & \\
\hline 17.5 & 0.99 & 2.08 & & & \\
\hline 18.5 & 0.94 & 2.84 & & & \\
\hline 19.5 & 1.03 & 2.66 & & & \\
\hline 20.5 & 1.17 & 3.09 & & & \\
\hline 21.5 & 1.12 & 2.60 & & & \\
\hline 22.5 & 0.93 & 2.57 & & & \\
\hline 23.5 & 1.03 & 2.45 & & & \\
\hline 24.5 & 0.95 & 2.13 & & & \\
\hline 25.5 & 0.77 & 1.33 & & & \\
\hline 26.5 & 0.72 & 1.04 & & & \\
\hline 27.5 & 0.69 & 1.94 & & & \\
\hline 28.5 & 0.30 & 1.01 & & & \\
\hline 29.5 & 0.47 & 1.80 & & & \\
\hline 29.5 & 0.62 & 1.58 & & & \\
\hline 30.5 & 0.42 & 0.92 & & & \\
\hline
\end{tabular}


Table A.4: Stable Isotopic Measurements, $\delta^{13} \mathrm{C}$ and $\delta^{18} \mathrm{O}$ (ctd.)

BC 19

$2414 \mathrm{~m}$

Curry (unpublished data), 180-212 $\mu \mathrm{m}$ Size Fraction

\begin{tabular}{ccc}
$\begin{array}{c}\text { depth } \\
\mathrm{cm}\end{array}$ & $\begin{array}{c}\delta^{13} \mathrm{C} \\
\text { permil }\end{array}$ & $\begin{array}{c}\delta^{18} \mathrm{O} \\
\text { permil }\end{array}$ \\
\hline 0.5 & 0.80 & 1.56 \\
1 & 0.68 & 1.30 \\
1.5 & 0.72 & 1.49 \\
2.5 & 0.60 & 1.40 \\
3.5 & 0.53 & 0.89 \\
4.5 & 0.20 & 0.77 \\
5.5 & 0.08 & 0.53 \\
6.5 & 0.14 & 0.60 \\
7.5 & 0.04 & 0.76 \\
8.5 & 0.16 & 0.45 \\
9.5 & 0.05 & 0.74
\end{tabular}

Values averaged from 10 measurements per sample (W. Curry, personal communication) 
Table A.4: Stable Isotopic Measurements, $\delta^{13} \mathrm{C}$ and $\delta^{18} \mathrm{O}$ (ctd.)

\section{BC 20 \\ $3110 \mathrm{~m}$}

Poore (unpublished data; W. Curry, personal communication)

$>125$ um Size Fraction

\begin{tabular}{|c|c|c|c|c|c|}
\hline $\begin{array}{c}\text { depth } \\
\mathrm{cm}\end{array}$ & $\begin{array}{c}\delta^{13} \mathrm{C} \\
\text { permil }\end{array}$ & $\begin{array}{c}\delta^{18} \mathrm{O} \\
\text { permil }\end{array}$ & $\begin{array}{c}\text { depth } \\
\mathrm{cm}\end{array}$ & $\begin{array}{c}\delta^{13} \mathrm{C} \\
\text { permil }\end{array}$ & $\begin{array}{c}\delta^{18} \mathrm{O} \\
\text { permil }\end{array}$ \\
\hline 0.5 & 0.24 & -0.31 & 28.5 & 0.50 & 1.92 \\
\hline 0.5 & 1.02 & 1.69 & 29.5 & 0.55 & 1.78 \\
\hline 0.5 & 1.15 & 1.77 & 30.5 & 0.57 & 1.80 \\
\hline 0.5 & 1.15 & 1.84 & 31.5 & 0.56 & 1.22 \\
\hline 0.5 & 1.21 & 1.57 & 32.5 & -0.28 & -0.64 \\
\hline 1.5 & 0.92 & 2.06 & 32.5 & -0.33 & -0.13 \\
\hline 2.5 & 0.92 & 1.77 & 33.5 & -0.44 & -0.83 \\
\hline 3.5 & 0.5 & 1.49 & 34.5 & 0.47 & 2.85 \\
\hline 4.5 & 0.24 & 0.79 & 35.5 & 0.54 & 2.81 \\
\hline 5.5 & 0.08 & 0.79 & 36.5 & 0.11 & 2.68 \\
\hline 6.5 & 0.11 & 1.27 & 36.5 & 0.42 & 3.04 \\
\hline 6.5 & 0.19 & 0.66 & 37.5 & 0.60 & 2.60 \\
\hline 7.5 & -0.03 & 0.52 & 37.5 & 0.69 & 2.40 \\
\hline 7.5 & 0.05 & 0.97 & & & \\
\hline 8.5 & 0.11 & 0.65 & & & \\
\hline 9.5 & -0.03 & 1.63 & & & \\
\hline 10.5 & -0.19 & 0.75 & & & \\
\hline 11.5 & 0.05 & 0.77 & & & \\
\hline 12.5 & 0.33 & 2.05 & & & \\
\hline 13.5 & 0.71 & 0.9 & & & \\
\hline 14.5 & 0.78 & 0.57 & & & \\
\hline 15.5 & 0.61 & 1.38 & & & \\
\hline 16.5 & 0.51 & 1.49 & & & \\
\hline 16.5 & 0.69 & 1.01 & & & \\
\hline 17.5 & 0.76 & 1.71 & & & \\
\hline 18.5 & 0.44 & 1.47 & & & \\
\hline 19.5 & 0.68 & 1.7 & & & \\
\hline 20.5 & 0.72 & 1.67 & & & \\
\hline 21.5 & 0.62 & 1.66 & & & \\
\hline 22.5 & 0.88 & 2.39 & & & \\
\hline 23.5 & 1 & 2.24 & & & \\
\hline 24.5 & 0.71 & 3.01 & & & \\
\hline 25.5 & 0.77 & 2.95 & & & \\
\hline 25.5 & 0.88 & 2.87 & & & \\
\hline 26.5 & 0.8 & 2.9 & & & \\
\hline 27.5 & 0.48 & 0.74 & & & \\
\hline 27.5 & 0.49 & 1.86 & & & \\
\hline
\end{tabular}


Table A.4: Stable Isotopic Measurements, $\delta^{13} \mathrm{C}$ and $\delta^{18} \mathrm{O}$ (ctd.)

\begin{tabular}{ccc} 
BC 26 & \multicolumn{3}{c}{$\mathbf{1 0 3 4} \mathbf{~}$} \\
This study & \multicolumn{3}{c}{} \\
$>150 \mu \mathrm{m}$ & Size Fraction \\
depth & $\delta^{13} \mathrm{C}$ & $\delta^{18} \mathrm{O}$ \\
cm & permil & permil \\
\hline 0.25 & 1.02 & 2.44 \\
0.25 & 1.06 & 2.66 \\
1.25 & 0.85 & 1.75 \\
2.25 & 0.97 & 2.62 \\
3.25 & 1.05 & 2.49 \\
4.25 & 0.65 & 2.48 \\
4.25 & 0.81 & 2.20 \\
5.25 & 0.53 & 2.08 \\
6.25 & 0.58 & 2.00 \\
7.25 & 0.77 & 2.19 \\
8.25 & 1.25 & 2.98 \\
8.25 & 1.32 & 3.20 \\
9.25 & 0.91 & 3.32 \\
10.25 & 1.32 & 3.47 \\
11.25 & 1.10 & 3.37 \\
12.25 & 0.96 & 2.85 \\
13.25 & 0.72 & 2.75 \\
14.25 & 0.90 & 2.89 \\
15.25 & 0.78 & 2.71 \\
16.25 & 0.82 & 2.88 \\
16.25 & 0.80 & 2.90 \\
16.25 & 0.80 & 3.13 \\
17.25 & 0.81 & 2.92 \\
18.25 & 0.73 & 2.85
\end{tabular}


Table A.4: Stable Isotopic Measurements, $\delta^{13} \mathrm{C}$ and $\delta^{18} \mathrm{O}$ (ctd.)

\section{BC 28 \\ $1990 \mathrm{~m}$}

Poore (unpublished data; W. Curry, personal communication)

$>125 \mu \mathrm{m}$ Size Fraction

\begin{tabular}{|c|c|c|c|c|c|}
\hline $\begin{array}{c}\text { depth } \\
\mathrm{cm}\end{array}$ & $\begin{array}{c}\delta^{13} \mathrm{C} \\
\text { permil }\end{array}$ & $\begin{array}{c}\delta^{18} \mathrm{O} \\
\text { permil }\end{array}$ & $\begin{array}{c}\text { depth } \\
\mathrm{cm}\end{array}$ & $\begin{array}{c}\delta^{13} \mathrm{C} \\
\text { permil }\end{array}$ & $\begin{array}{c}\delta^{18} \mathrm{O} \\
\text { permil }\end{array}$ \\
\hline 0.5 & 0.80 & 1.80 & 29.5 & 0.77 & 2.24 \\
\hline 0.5 & 1.01 & 1.39 & 30.5 & 0.72 & 2.69 \\
\hline 0.5 & 1.08 & 1.54 & 31.5 & 0.87 & 2.32 \\
\hline 1.5 & 1.00 & 1.88 & 32.5 & 0.82 & 2.54 \\
\hline 2.5 & 1.04 & 1.77 & 33.5 & 0.88 & 2.95 \\
\hline 3.5 & 0.94 & 2.00 & 34.5 & 0.70 & 2.50 \\
\hline 4.5 & 0.88 & 2.61 & 34.5 & 0.71 & 3.01 \\
\hline 4.5 & 0.89 & 1.88 & 35.5 & 0.69 & 2.68 \\
\hline 5.5 & 0.93 & 2.02 & & & \\
\hline 6.5 & 0.56 & 2.06 & & & \\
\hline 7.5 & 0.72 & 1.89 & & & \\
\hline 8.5 & 0.77 & 2.02 & & & \\
\hline 9.5 & 0.58 & 2.29 & & & \\
\hline 10.5 & 0.50 & 1.99 & & & \\
\hline 11.5 & 0.36 & 1.69 & & & \\
\hline 12.5 & 0.51 & 1.59 & & & \\
\hline 13.5 & 0.23 & 2.29 & & & \\
\hline 13.5 & 0.28 & 1.10 & & & \\
\hline 13.5 & 0.34 & 2.74 & & & \\
\hline 14.5 & 0.63 & 2.17 & & & \\
\hline 15.5 & 0.25 & 2.34 & & & \\
\hline 16.5 & 0.28 & 2.06 & & & \\
\hline 17.5 & 0.33 & 2.82 & & & \\
\hline 18.5 & 0.08 & 2.28 & & & \\
\hline 19.5 & 0.46 & 1.58 & & & \\
\hline 20.5 & 0.36 & 2.31 & & & \\
\hline 21.5 & 0.35 & 1.55 & & & \\
\hline 22.5 & 0.60 & 2.35 & & & \\
\hline 23.5 & 0.71 & 1.75 & & & \\
\hline 24.5 & 0.67 & 2.45 & & & \\
\hline 25.5 & 0.55 & 2.41 & & & \\
\hline 26.5 & 0.77 & 1.26 & & & \\
\hline 27.5 & 0.62 & 2.13 & & & \\
\hline 27.5 & 0.72 & 2.24 & & & \\
\hline 27.5 & 0.74 & 2.16 & & & \\
\hline 28.5 & 0.76 & 2.53 & & & \\
\hline 28.5 & 0.83 & 2.36 & & & \\
\hline
\end{tabular}


Table A.4: Stable Isotopic Measurements, $\delta^{13} \mathrm{C}$ and $\delta^{18} \mathrm{O}$ (ctd.)

BC 28

$1990 \mathrm{~m}$

Curry (unpublished data), 180-212 $\mu \mathrm{m}$ Size Fraction

\begin{tabular}{ccc}
$\begin{array}{c}\text { depth } \\
\text { cm }\end{array}$ & $\begin{array}{c}\delta^{13} \mathrm{C} \\
\text { permil }\end{array}$ & $\begin{array}{c}\delta^{18} \mathrm{O} \\
\text { permil }\end{array}$ \\
\hline 0.5 & 0.81 & 1.87 \\
1 & 0.77 & 1.94 \\
1.5 & 0.85 & 1.92 \\
2.5 & 0.72 & 2.12 \\
3.5 & 0.68 & 2.00 \\
4.5 & 0.75 & 2.17 \\
5.5 & 0.55 & 1.85 \\
6.5 & 0.46 & 2.19 \\
7.5 & 0.44 & 2.14 \\
8.5 & 0.45 & 2.02 \\
9.5 & 0.34 & 2.07 \\
10.5 & 0.17 & 1.89 \\
11.5 & 0.19 & 1.76 \\
12.5 & 0.44 & 2.06 \\
13.5 & -0.04 & 1.74 \\
14.5 & 0.20 & 2.43 \\
15.5 & 0.25 & 2.40 \\
16.5 & 0.07 & 2.46 \\
17.5 & 0.07 & 2.21 \\
18.5 & 0.00 & 1.99 \\
19.5 & 0.19 & 1.73
\end{tabular}

Values averaged from $\sim 10$ measurements per sample (W. Curry, personal communication) 
Table A.4: Stable Isotopic Measurements, $\delta^{13} \mathrm{C}$ and $\delta^{18} \mathrm{O}$ (ctd.)

BC 32

$3471 \mathrm{~m}$

Poore (unpublished data; W. Curry, personal communication)

$>125 \mu \mathrm{m}$ Size Fraction

\begin{tabular}{|c|c|c|}
\hline $\begin{array}{c}\text { depth } \\
\mathrm{cm}\end{array}$ & $\begin{array}{c}\delta^{13} \mathrm{C} \\
\text { permil }\end{array}$ & $\begin{array}{c}\delta^{18} \mathrm{O} \\
\text { permil }\end{array}$ \\
\hline 0.5 & 0.77 & 2.79 \\
\hline 0.5 & 0.87 & 2.65 \\
\hline 0.5 & 0.89 & 2.14 \\
\hline 1.5 & 0.79 & 2.77 \\
\hline 1.5 & 0.81 & 2.43 \\
\hline 2.5 & 0.80 & 2.63 \\
\hline 3.5 & 0.84 & 2.71 \\
\hline 4.5 & 0.84 & 2.75 \\
\hline 5.5 & 0.68 & 2.97 \\
\hline 6.5 & 0.62 & 3.34 \\
\hline 7.5 & 0.57 & 3.35 \\
\hline 8.5 & 0.70 & 3.15 \\
\hline 9.5 & 0.65 & 3.17 \\
\hline 9.5 & 0.67 & 2.96 \\
\hline 10.5 & 0.60 & 3.16 \\
\hline 11.5 & 0.56 & 3.62 \\
\hline 12.5 & 0.62 & 3.37 \\
\hline 13.5 & 0.48 & 3.75 \\
\hline 14.5 & 0.57 & 3.43 \\
\hline 15.5 & 0.48 & 3.65 \\
\hline 16.5 & 0.43 & 3.81 \\
\hline 16.5 & 0.46 & 3.68 \\
\hline 17.5 & 0.24 & 3.79 \\
\hline 18.5 & 0.29 & 4.14 \\
\hline 19.5 & 0.32 & 4.12 \\
\hline 20.5 & 0.26 & 3.65 \\
\hline 21.5 & 0.08 & 2.71 \\
\hline 22.5 & 0.23 & 3.80 \\
\hline 23.5 & 0.15 & 3.75 \\
\hline 24.5 & -0.01 & 3.62 \\
\hline 25.5 & 0.12 & 4.04 \\
\hline 25.5 & 0.25 & 3.79 \\
\hline 26.5 & 0.20 & 3.81 \\
\hline 27.5 & 0.47 & 4.00 \\
\hline 28.5 & 0.65 & 3.76 \\
\hline 29.5 & 0.53 & 3.89 \\
\hline 30.5 & 0.72 & 3.99 \\
\hline
\end{tabular}

\begin{tabular}{ccc}
$\begin{array}{c}\text { depth } \\
\mathrm{cm}\end{array}$ & $\begin{array}{c}\delta^{13} \mathrm{C} \\
\text { permil }\end{array}$ & $\begin{array}{c}\delta^{18} \mathrm{O} \\
\text { permil }\end{array}$ \\
\hline 31.5 & 0.65 & 3.89 \\
32.5 & 0.78 & 4.13 \\
33.5 & 0.69 & 3.49 \\
33.5 & 0.74 & 3.82 \\
34.5 & 0.72 & 3.97 \\
36.5 & 0.71 & 4.22 \\
37.5 & 0.83 & 4.22 \\
38.5 & 0.61 & 3.97 \\
39.5 & 0.76 & 3.42 \\
40.5 & 0.75 & 3.44 \\
41.5 & 0.71 & 3.34 \\
41.5 & 0.74 & 3.38 \\
42.5 & 0.87 & 3.37
\end{tabular}


Table A.4: Stable Isotopic Measurements, $\delta^{13} \mathrm{C}$ and $\delta^{18} \mathrm{O}$ (ctd.)

BC 32

$3471 \mathrm{~m}$

Curry (unpublished data), 180-212 $\mu \mathrm{m}$ Size Fraction

\begin{tabular}{ccc}
$\begin{array}{c}\text { depth } \\
\mathrm{cm}\end{array}$ & $\begin{array}{c}\delta^{13} \mathrm{C} \\
\text { permil }\end{array}$ & $\begin{array}{c}\delta^{18} \mathrm{O} \\
\text { permil }\end{array}$ \\
\hline 0.5 & 0.51 & 2.60 \\
1 & 0.60 & 2.77 \\
1.5 & 0.45 & 2.88 \\
2.5 & 0.49 & 2.77 \\
3.5 & 0.40 & 3.00 \\
4.5 & 0.47 & 3.01 \\
5.5 & 0.27 & 3.21 \\
6.5 & 0.26 & 3.04 \\
7.5 & 0.24 & 3.06 \\
8.5 & 0.21 & 3.10 \\
9.5 & 0.23 & 3.25 \\
10.5 & 0.33 & 3.24 \\
11.5 & 0.26 & 3.39 \\
12.5 & 0.14 & 3.25 \\
13.5 & 0.14 & 3.50 \\
14.5 & 0.18 & 3.57
\end{tabular}

Values averaged from $\sim 10$ measurements per sample (W. Curry, personal communication) 
Table A.5: ${ }^{230}$ Th-Normalized Mass Flux, Mass Accumulation Rate, and Focusing Factors

\section{BC 08}

\begin{tabular}{|c|c|}
\hline $\begin{array}{c}\text { Depth } \\
\mathrm{cm}\end{array}$ & $\begin{array}{c}{ }^{230} \text { Th-norm. } \\
\text { mass flux } \\
\left(\mathrm{g} / \mathrm{cm}^{2} / \mathrm{kyr}\right)\end{array}$ \\
\hline 0.25 & 0.63 \\
\hline 1.25 & 0.59 \\
\hline 2.25 & 0.62 \\
\hline 3.25 & 0.67 \\
\hline 4.25 & 0.79 \\
\hline 5.25 & 0.83 \\
\hline 6.25 & 0.81 \\
\hline 7.25 & 0.97 \\
\hline 8.25 & 1.23 \\
\hline 9.25 & 1.35 \\
\hline 10.25 & 1.42 \\
\hline 11.25 & 1.46 \\
\hline 12.25 & 1.42 \\
\hline 13.25 & 1.40 \\
\hline 14.25 & 1.41 \\
\hline 15.25 & 1.32 \\
\hline 16.25 & 1.47 \\
\hline 17.25 & 1.04 \\
\hline 18.25 & 0.63 \\
\hline 19.25 & 0.83 \\
\hline 20.25 & 0.56 \\
\hline 21.25 & 0.32 \\
\hline 22.25 & 0.28 \\
\hline 23.25 & 0.22 \\
\hline 24.25 & 0.26 \\
\hline 25.25 & 0.46 \\
\hline 26.25 & 0.45 \\
\hline 27.25 & 0.50 \\
\hline 28.25 & 0.74 \\
\hline 29.25 & 1.12 \\
\hline
\end{tabular}

\begin{tabular}{|c|c|c|c|}
\hline Depth & $\begin{array}{c}\text { Calib. Age } \\
\text { ka }\end{array}$ & $\begin{array}{l}\text { Focusing } \\
\text { Factor }\end{array}$ & $\begin{array}{l}\text { Mass Acc. } \\
\text { Rate } \\
\left(\mathrm{g} / \mathrm{cm}^{2} / \mathrm{kyr}\right)\end{array}$ \\
\hline 0.5 & 3.79 & 1.18 & 0.71 \\
\hline 2.5 & 5.65 & 2.06 & 1.57 \\
\hline 6.5 & 7.88 & 29.98 & 32.14 \\
\hline 8.5 & 7.93 & 11.01 & 15.23 \\
\hline 12.5 & 8.13 & 0.38 & 0.53 \\
\hline 14.5 & 11.32 & 12.19 & 8.44 \\
\hline 21.5 & 12.00 & 12.31 & 0.19 \\
\hline 24.5 & 25.39 & 0.76 & 0.15 \\
\hline 26.5 & 37.35 & 0.33 & 1.29 \\
\hline 30.5 & 40.43 & 1.99 & 2.59 \\
\hline 36.5 & 42.93 & & \\
\hline
\end{tabular}


Table A.5: ${ }^{230}$ Th-Normalized Mass Flux, Mass Accumulation Rate, and Focusing Factors (ctd.)

\section{BC 16}

\begin{tabular}{|c|c|c|c|c|c|}
\hline $\begin{array}{l}\text { Depth } \\
\text { cm }\end{array}$ & $\begin{array}{l}{ }^{230} \text { Th-norm. } \\
\text { mass flux } \\
\left(\mathrm{g} / \mathrm{cm}^{2} / \mathrm{kyr}\right)\end{array}$ & $\begin{array}{l}\text { Depth } \\
\text { cm }\end{array}$ & $\begin{array}{c}\text { Calib. Age } \\
\text { ka }\end{array}$ & $\begin{array}{l}\text { Focusing } \\
\text { Factor }\end{array}$ & $\begin{array}{c}\text { Mass Acc. } \\
\text { Rate } \\
\left(\mathrm{g} / \mathrm{cm}^{2} / \mathrm{kyr}\right)\end{array}$ \\
\hline 0.25 & 0.41 & 0.5 & 3.38 & 0.83 & 0.72 \\
\hline 1.25 & 0.43 & 2.5 & 4.54 & 0.77 & 0.39 \\
\hline 2.25 & 0.40 & 4.5 & 7.92 & 0.92 & 0.57 \\
\hline 3.25 & 0.56 & 6.5 & 10.61 & 2.31 & 1.68 \\
\hline 4.25 & 0.70 & 10.5 & 12.67 & 15.05 & 2.60 \\
\hline 5.25 & 0.66 & 13.5 & 13.39 & 0.40 & 0.13 \\
\hline 6.25 & 0.68 & 16.5 & 34.03 & 1.72 & 1.45 \\
\hline 7.25 & 0.83 & 19.5 & 36.25 & 1.32 & 0.44 \\
\hline 8.25 & 0.90 & 21.5 & 41.38 & 12.78 & 4.06 \\
\hline 9.25 & 1.40 & 23.5 & 41.90 & 2.37 & 0.78 \\
\hline 10.25 & 0.37 & 26.5 & 45.33 & & \\
\hline 11.25 & 0.27 & & & & \\
\hline 12.25 & 0.23 & & & & \\
\hline 13.25 & 0.20 & & & & \\
\hline 14.25 & 0.39 & & & & \\
\hline 15.25 & 0.40 & & & & \\
\hline 16.25 & 0.44 & & & & \\
\hline 17.25 & 0.70 & & & & \\
\hline 18.25 & 0.53 & & & & \\
\hline 19.25 & 0.42 & & & & \\
\hline 20.25 & 0.25 & & & & \\
\hline 21.25 & 0.37 & & & & \\
\hline 22.25 & 0.33 & & & & \\
\hline 23.25 & 0.37 & & & & \\
\hline 24.25 & 0.34 & & & & \\
\hline 25.25 & 0.34 & & & & \\
\hline 26.25 & 0.47 & & & & \\
\hline 27.25 & 0.50 & & & & \\
\hline 28.25 & 0.74 & & & & \\
\hline 29.25 & 1.12 & & & & \\
\hline
\end{tabular}


Table A.5: ${ }^{230}$ Th-Normalized Mass Flux, Mass Accumulation Rate, and Focusing Factors (ctd.)

\section{BC 17}

$\begin{array}{cc}\text { Depth } & { }^{230} \text { Th-norm. } \\ \text { mass flux } \\ \text { (g/cm } / \mathrm{kyr})\end{array}$

\begin{tabular}{|c|c|}
\hline $\begin{array}{c}\text { Depth } \\
\mathrm{cm}\end{array}$ & $\begin{array}{c}{ }^{230} \text { Th-norm. } \\
\text { mass flux } \\
\left(\mathrm{g} / \mathrm{cm}^{2} / \mathrm{kyr}\right)\end{array}$ \\
\hline 19.75 & 0.31 \\
\hline 20.75 & 0.39 \\
\hline 21.75 & 0.42 \\
\hline 22.75 & 0.26 \\
\hline 23.75 & 0.25 \\
\hline 24.75 & 0.28 \\
\hline 25.75 & 0.28 \\
\hline 26.75 & 0.34 \\
\hline 27.75 & 0.41 \\
\hline 28.75 & 0.60 \\
\hline 29.75 & 0.96 \\
\hline
\end{tabular}

Focusing Mass Acc.

\begin{tabular}{cccc} 
Depth & Calib. Age & Factor & $\begin{array}{c}\text { Rate } \\
\left(\mathrm{g} / \mathrm{cm}^{2} / \mathrm{kyr}\right)\end{array}$ \\
\hline 0.5 & 2.60 & 1.25 & 0.61 \\
5.5 & 7.38 & 1.10 & 0.77 \\
10.5 & 12.92 & 3.62 & 2.71 \\
12.5 & 13.39 & 19.75 & 4.08 \\
16.5 & 14.29 & 0.96 & 0.22 \\
20.5 & 33.67 & 2.99 & 0.91 \\
27.5 & 41.43 & 4.80 & 2.04 \\
34.5 & 44.60 & &
\end{tabular}


Table A.5: ${ }^{230}$ Th-Normalized Mass Flux, Mass Accumulation Rate, and Focusing Factors (ctd.)

BC 19

\begin{tabular}{cccccc} 
Depth & $\begin{array}{c}{ }^{230} \text { Th-norm. } \\
\text { mass flux } \\
\text { cm }\end{array}$ & $\begin{array}{c}\text { Depth } \\
\left(\mathrm{g} / \mathrm{cm}^{2} / \mathrm{kyr}\right)\end{array}$ & $\begin{array}{c}\text { Calib. Age } \\
\mathrm{cm}\end{array}$ & $\begin{array}{c}\text { Focusing } \\
\text { Factor }\end{array}$ & $\begin{array}{c}\text { Mass Acc. } \\
\text { Rate } \\
\left(\mathrm{g} / \mathrm{cm}^{2} / \mathrm{kyr}\right)\end{array}$ \\
\hline 0.5 & 0.35 & 2.5 & 5.76 & 0.40 & 0.32 \\
1.5 & 0.35 & 5.5 & 13.28 & 4.36 & 3.95 \\
2.5 & 0.39 & 10.5 & 13.74 & 0.19 & 0.15 \\
3.5 & 0.47 & 12.5 & 39.84 & 0.75 & 0.67 \\
4.5 & 0.60 & 15.5 & 43.81 & 5.79 & 4.80 \\
5.5 & 0.58 & 18.5 & 44.33 & 6.13 & 4.30 \\
6.5 & 0.45 & 21.5 & 44.82 & & \\
7.5 & 0.26 & & & & \\
8.5 & 0.27 & & & & \\
9.5 & 0.19 & & & & \\
11 & 0.29 & & & & \\
13 & 0.20 & & & & \\
15 & 0.28 & & & & \\
17 & 0.52 & & & & \\
19 & 0.77 & & & &
\end{tabular}


Table A.5: ${ }^{230}$ Th-Normalized Mass Flux, Mass Accumulation Rate, and Focusing Factors (ctd.)

\section{BC 20}

\begin{tabular}{|c|c|}
\hline $\begin{array}{c}\text { Depth } \\
\mathrm{cm}\end{array}$ & $\begin{array}{c}{ }^{230} \mathrm{Th}- \\
\text { norm. } \\
\text { (g/cm } / \mathrm{kyr})\end{array}$ \\
\hline 0.25 & 0.37 \\
\hline 1.25 & 0.38 \\
\hline 2.25 & 0.43 \\
\hline 3.25 & 0.53 \\
\hline 4.25 & 0.83 \\
\hline 5.25 & 0.79 \\
\hline 6.25 & 0.75 \\
\hline 7.25 & 0.87 \\
\hline 8.25 & 1.01 \\
\hline 9.25 & 0.58 \\
\hline 10.25 & 0.18 \\
\hline 11.25 & 0.20 \\
\hline 12.25 & 0.25 \\
\hline 13.25 & 0.40 \\
\hline 14.25 & 0.49 \\
\hline 15.25 & 0.35 \\
\hline 16.25 & 0.28 \\
\hline
\end{tabular}

\begin{tabular}{cccc} 
Depth & $\begin{array}{c}\text { Calib. Age } \\
\text { cm }\end{array}$ & $\begin{array}{c}\text { Focusing } \\
\text { Factor }\end{array}$ & $\begin{array}{c}\text { Mass Acc. } \\
\text { Rate } \\
\left(\mathrm{g} / \mathrm{cm}^{2} / \mathrm{kyr}\right)\end{array}$ \\
\hline 0.25 & 3.48 & 0.94 & 0.40 \\
4.25 & 10.15 & 4.04 & 3.16 \\
8.25 & 11.23 & 0.48 & 0.14 \\
12.25 & 31.88 & 0.69 & 0.24 \\
16.25 & 45.92 & &
\end{tabular}


Table A.5: ${ }^{230}$ Th-Normalized Mass Flux, Mass Accumulation Rate, and Focusing Factors (ctd.)

\section{BC 26}

\begin{tabular}{|c|c|}
\hline $\begin{array}{c}\text { Depth } \\
\mathrm{cm}\end{array}$ & $\begin{array}{c}{ }^{230} \mathrm{Th}- \\
\text { norm. } \\
\text { (g/cm } / \mathrm{kyr})\end{array}$ \\
\hline 0.25 & 0.49 \\
\hline 1.25 & 0.46 \\
\hline 2.25 & 0.51 \\
\hline 3.25 & 0.64 \\
\hline 4.25 & 0.75 \\
\hline 5.25 & 0.74 \\
\hline 6.25 & 0.54 \\
\hline 7.25 & 0.68 \\
\hline 8.25 & 0.62 \\
\hline 9.25 & 0.83 \\
\hline 10.25 & 0.89 \\
\hline 11.25 & 0.55 \\
\hline 12.25 & 0.43 \\
\hline 13.25 & 0.69 \\
\hline 14.25 & 0.64 \\
\hline 15.25 & 1.93 \\
\hline 16.25 & 3.79 \\
\hline 17.25 & 0.99 \\
\hline 18.25 & 4.72 \\
\hline 19.25 & 12.47 \\
\hline 20.25 & 6.56 \\
\hline 21.25 & 6.38 \\
\hline 22.25 & 23.65 \\
\hline 23.25 & 17.92 \\
\hline 24.25 & 19.21 \\
\hline 25.25 & 7.51 \\
\hline 26.25 & 10.82 \\
\hline 27.25 & 7.32 \\
\hline 28.25 & 7.47 \\
\hline
\end{tabular}

\begin{tabular}{cccc} 
Depth & $\begin{array}{c}\text { Calib. Age } \\
\mathrm{cm}\end{array}$ & $\begin{array}{c}\text { Focusing } \\
\text { Factor }\end{array}$ & $\begin{array}{c}\text { Mass Acc. } \\
\text { Rate } \\
\left(\mathrm{g} / \mathrm{cm}^{2} / \mathrm{kyr}\right)\end{array}$ \\
\hline 0.25 & 3.65 & 0.54 & 0.40 \\
2.25 & 6.92 & 0.73 & 0.44 \\
6.25 & 16.50 & 0.56 & 0.25 \\
8.25 & 25.70 & 0.58 & 1.12 \\
10.25 & 27.73 & 2.61 & 3.52 \\
12.25 & 28.41 & 0.93 & 0.26 \\
15.25 & 42.92 & &
\end{tabular}

Depth Calib. Age Focusing Mass Acc.
Factor 
Table A.5: ${ }^{230}$ Th-Normalized Mass Flux, Mass Accumulation Rate, and Focusing Factors (ctd.)

\section{BC 28}

\begin{tabular}{cccccc} 
Depth & $\begin{array}{c}{ }^{230} \text { Th-norm. } \\
\text { mass flux } \\
\text { cm }\end{array}$ & $\begin{array}{c}\text { Depth } \\
\left(\mathrm{g} / \mathrm{cm}^{2} / \mathrm{kyr}\right)\end{array}$ & $\begin{array}{c}\text { Calib. Age } \\
\mathrm{cm}\end{array}$ & $\begin{array}{c}\text { Focusing } \\
\text { Factor }\end{array}$ & $\begin{array}{c}\text { Mass Acc. } \\
\text { Rate } \\
\left(\mathrm{g} / \mathrm{cm}^{2} / \mathrm{kyr}\right)\end{array}$ \\
\hline 0.25 & 0.79 & 0.5 & 1.79 & 0.60 & 0.68 \\
1.25 & 0.69 & 3.5 & 4.21 & 0.47 & 0.98 \\
2.25 & 0.75 & 12.5 & 11.20 & 3.20 & 0.36 \\
3.25 & 0.80 & 16.0 & 19.16 & 7.66 & 0.19 \\
4.25 & 0.80 & 18.5 & 30.16 & & \\
5.25 & 0.93 & & & & \\
6.25 & 1.01 & & & & \\
7.25 & 1.13 & & & & \\
8.25 & 1.07 & & & & \\
9.25 & 0.96 & & & & \\
10.25 & 0.64 & & & & \\
11.25 & 0.74 & & & & \\
12.25 & 0.44 & & & & \\
13.25 & 0.38 & & & & \\
14.25 & 0.26 & & & & \\
15.25 & 0.26 & & & & \\
16.25 & 0.27 & & & & \\
17.25 & 0.35 & & & & \\
\end{tabular}


Table A.5: ${ }^{230}$ Th-Normalized Mass Flux, Mass Accumulation Rate, and Focusing Factors (ctd.)

\section{BC 32}

\begin{tabular}{|rr}
\multicolumn{1}{|c}{ Depth } & \multicolumn{1}{c}{$\begin{array}{r}{ }^{230} \text { Th- } \\
\text { norm. } \\
\text { (g/cm } / \mathrm{kyr})\end{array}$} \\
\hline 0.25 & 0.72131 \\
1.25 & 0.66351 \\
2.25 & 0.83159 \\
3.25 & 0.9024 \\
4.25 & 1.03138 \\
5.25 & 1.00346 \\
6.25 & 1.09052 \\
7.25 & 1.11642 \\
8.25 & 1.05878 \\
9.25 & 0.71897 \\
10.25 & 0.69412 \\
11.25 & 0.60468 \\
12.25 & 0.576 \\
13.25 & 0.49892 \\
14.25 & 0.43601 \\
15.25 & 0.43612
\end{tabular}

\begin{tabular}{cccc} 
Depth & Calib. Age & $\begin{array}{c}\text { Focusing } \\
\text { Factor }\end{array}$ & $\begin{array}{c}\text { Mass Acc. } \\
\text { Rate } \\
\text { cm }\end{array}$ \\
ka & & $\left.\mathrm{cm}^{2} / \mathrm{kyr}\right)$ \\
\hline 0.5 & 5.26 & & 0.56 \\
1.5 & 5.80 & 1.51 & 1.18 \\
4.5 & 7.55 & 1.53 & 1.57 \\
7.5 & 8.98 & 0.70 & 0.64 \\
10.5 & 12.61 & 0.46 & 0.30 \\
12.5 & 17.98 & 0.22 & 0.11 \\
15.5 & 40.72 & &
\end{tabular}


Table A.6

$\begin{array}{cccccccc}\text { Depth, cm } & \text { Pa 1 } & \text { Pa 2 } & \text { Pa 3 } & \text { Mean Pa } & \text { sigma Pa } & \begin{array}{c}\text { Mean Pa / } \\ \text { Mean Th }\end{array} & \begin{array}{c}\text { Sigma } \\ \text { Pa/Th }\end{array} \\ & & & & & & & \\ 0.25 & 0.58 & 0.53 & & 0.550 & 0.036 & 0.065 & 0.004 \\ 3.25 & & & & & & & \\ 4.25 & & & & & & \\ 5.25 & 0.34 & 0.38 & & 0.363 & 0.029 & 0.052 & 0.004 \\ 6.25 & 0.45 & 0.44 & & 0.446 & 0.002 & 0.070 & 0.003 \\ 7.25 & 0.41 & 0.46 & & 0.437 & 0.036 & 0.071 & 0.006 \\ 8.25 & & & & & & & \\ 9.25 & 0.42 & 0.43 & 0.39 & 0.414 & 0.025 & 0.071 & 0.005 \\ 10.25 & 0.53 & 0.51 & & 0.519 & 0.018 & 0.075 & 0.012 \\ 11.25 & 0.58 & 0.60 & & 0.589 & 0.012 & 0.070 & 0.003 \\ 12.25 & 0.85 & 0.94 & & 0.898 & 0.062 & 0.070 & 0.005 \\ 13.25 & & & & & & & \\ 14.25 & 0.61 & 1.03 & & 0.818 & 0.301 & 0.042 & 0.016 \\ 15.25 & & & & & & & \\ 16.25 & 0.86 & 0.94 & & 0.902 & 0.057 & 0.055 & 0.004 \\ 17.25 & 0.67 & 0.78 & & 0.725 & 0.083 & 0.053 & 0.006\end{array}$

\section{Average Sigma $\mathrm{Pa} / \mathrm{Th}$ \\ 0.0062}

Average, excluding $14.25 \mathrm{~cm}$ Pa flyer 0.0053

Average, excluding $10.25 \mathrm{~cm}$ Th flyer 0.00448 


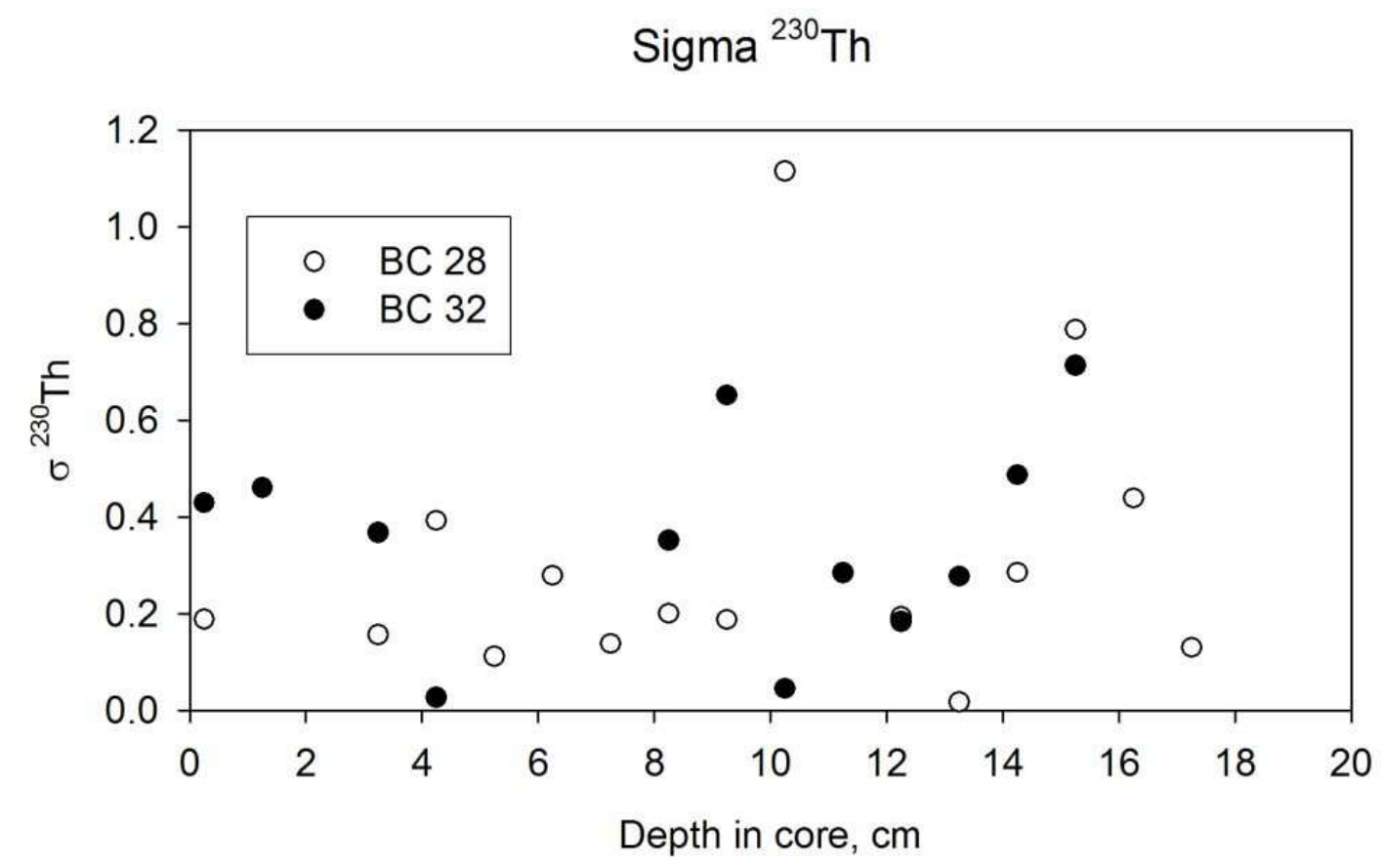

Sigma ${ }^{231} \mathrm{~Pa}$

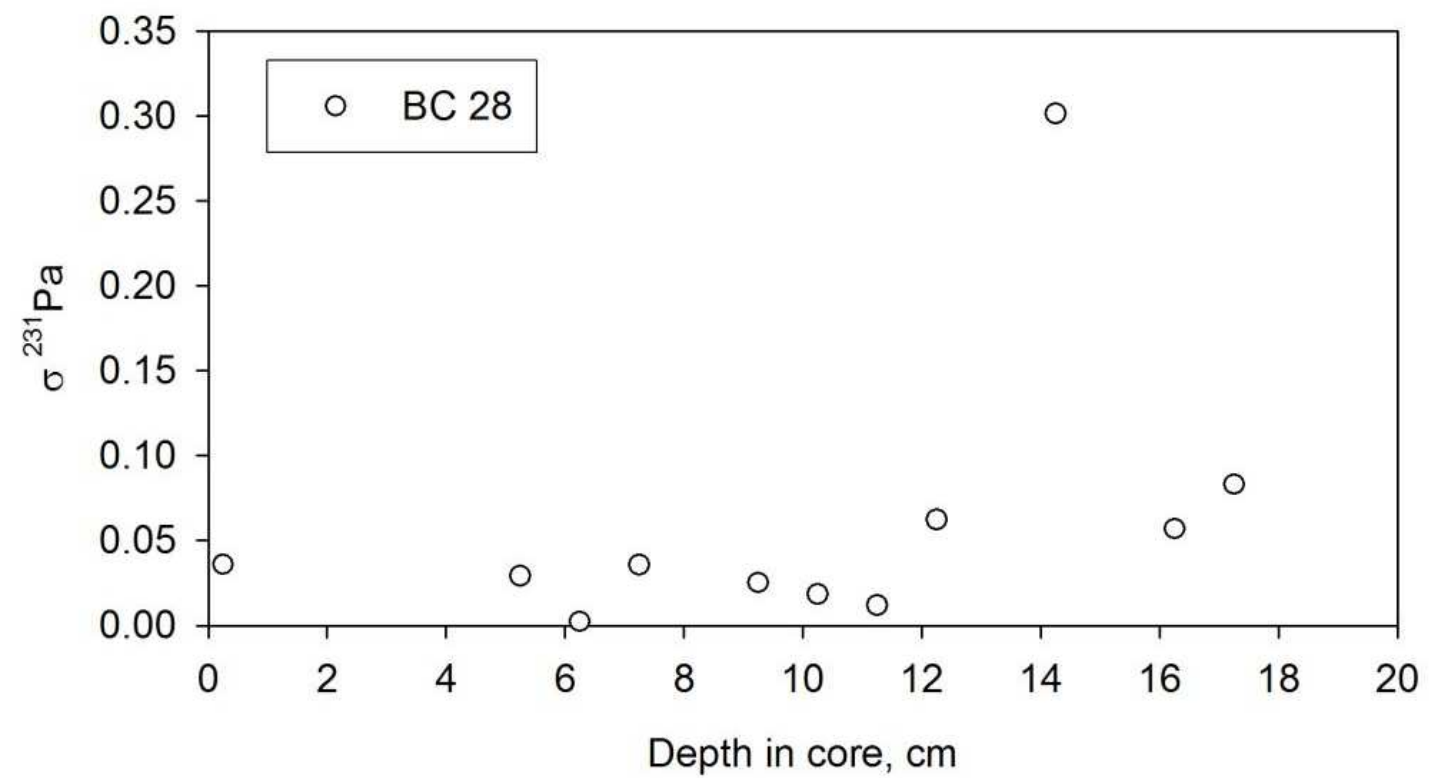

Figure A.2: Replicate Standard Deviations for ${ }^{230} \mathrm{Th}$ and ${ }^{231} \mathrm{~Pa}$, used to calculate average standard deviation for ${ }^{231} \mathrm{~Pa} /{ }^{230} \mathrm{Th}$ ratios. Fyers in ${ }^{230} \mathrm{Th} \mathrm{SD}$ at $10.25 \mathrm{~cm}$ in $\mathrm{BC} 28$, and in ${ }^{231} \mathrm{~Pa}$ SD at $14.25 \mathrm{~cm}$ were excluded from average calculations. 
Table A.7: ${ }^{230}$ Th-normalized Fluxes of Planktonic Foraminifera, BC 07, 16, 17 Neogloboquadrina pachyderma sinistral, > 125 um Counts of planktonic forams from Poore et al. (1999b)

\begin{tabular}{|c|c|c|c|c|c|}
\hline $\begin{array}{c}\text { BC } 08 \\
\text { depth } \\
\mathrm{cm}\end{array}$ & $\begin{array}{l}\text { Planktic Flux } \\
\#^{*} 10^{3} /\left(\mathrm{cm}^{2}\right) \\
\end{array}$ & $\begin{array}{c}\text { BC } 16 \\
\text { depth } \\
\mathrm{cm}\end{array}$ & $\begin{array}{l}\text { Planktic Flux } \\
\#^{*} 10^{3} /\left(\mathrm{cm}^{2}\right) \\
\end{array}$ & $\begin{array}{c}\text { BC } 17 \\
\text { depth } \\
\mathrm{cm}\end{array}$ & $\begin{array}{l}\text { Planktic Flux } \\
\#^{*} 10^{3} /\left(\mathrm{cm}^{2}\right)\end{array}$ \\
\hline 0.50 & 7.86 & 0.50 & 4.59 & 0.50 & 2.81 \\
\hline 1.50 & 6.20 & 1.50 & 5.64 & 1.50 & 2.52 \\
\hline 2.50 & 6.49 & 2.50 & 5.87 & 2.50 & 1.69 \\
\hline 3.50 & 7.71 & 3.50 & 5.26 & 3.50 & 3.33 \\
\hline 4.50 & 9.06 & 4.50 & 6.28 & 4.50 & 2.34 \\
\hline 5.50 & 8.79 & 5.50 & 3.12 & 5.50 & 3.22 \\
\hline 6.50 & 6.41 & 6.50 & 3.69 & 6.50 & 2.32 \\
\hline 7.50 & 4.99 & 7.50 & 1.90 & 7.50 & 1.89 \\
\hline 8.50 & 5.19 & 8.50 & 1.07 & 8.50 & 2.50 \\
\hline 9.50 & 5.08 & 9.50 & 0.68 & 9.50 & 2.34 \\
\hline 10.50 & 4.37 & 10.50 & 0.33 & 10.50 & 2.13 \\
\hline 11.50 & 7.29 & 11.50 & 0.24 & 11.50 & 1.69 \\
\hline 12.50 & 6.80 & 12.50 & 0.18 & 12.50 & 0.67 \\
\hline 13.50 & 1.63 & 13.50 & 0.38 & 13.50 & 0.51 \\
\hline 14.50 & 0.59 & 14.50 & 0.60 & 14.50 & 0.34 \\
\hline 15.50 & 0.17 & 15.50 & 1.10 & 15.50 & 0.17 \\
\hline 16.50 & 0.04 & 16.50 & 0.60 & 16.50 & 0.12 \\
\hline 17.50 & 0.09 & 17.50 & 0.43 & 17.50 & 0.18 \\
\hline 18.50 & 0.10 & 18.50 & 0.57 & 18.50 & 0.18 \\
\hline 19.50 & 1.28 & 19.50 & 1.08 & 19.50 & 0.52 \\
\hline 20.50 & 0.47 & 20.50 & 1.75 & 20.50 & 0.37 \\
\hline 21.50 & 0.26 & 21.50 & 1.38 & 21.50 & 0.52 \\
\hline 22.50 & 0.02 & 22.50 & 1.51 & 22.50 & 0.72 \\
\hline 23.50 & 0.08 & 23.50 & 2.60 & 23.50 & 1.55 \\
\hline 24.50 & 0.22 & 24.50 & 2.96 & 24.50 & 1.54 \\
\hline 25.50 & 0.97 & 25.50 & 5.22 & 25.50 & 1.25 \\
\hline 26.50 & 1.37 & 26.50 & 6.26 & 26.50 & 1.17 \\
\hline 27.50 & 1.01 & 27.50 & 7.79 & 27.50 & 2.14 \\
\hline 28.50 & 0.67 & 28.50 & 6.07 & 28.50 & 3.10 \\
\hline 29.50 & 0.27 & 29.50 & 9.61 & 29.50 & 4.93 \\
\hline
\end{tabular}


Table A.8 Biogenic Silica \% in PL-94-AR Samples

$\begin{array}{ccc}\text { Core } & \text { Depth, cm } & \text { \%Opal } \\ \text { BC 08 } & 1 & 5.63 \\ \text { BC 08 } & 5 & 3.79 \\ \text { BC 08 } & 13 & 5.01 \\ \text { BC 08 } & 24 & 5.57 \\ \text { BC 08 } & 26 & 4.80 \\ \text { BC 17 } & 1 & 5.81 \\ \text { BC 17 } & 5 & 5.51 \\ \text { BC 17 } & 7.5 & 4.67 \\ \text { BC 17 } & 10 & 4.50 \\ \text { BC 17 } & 25.5 & 5.36 \\ \text { BC 16 } & 3.5 & 4.34 \\ \text { BC 16 } & 15.5 & 5.55 \\ \text { BC 26 } & 1 & 4.52 \\ \text { BC 26 } & 6 & 4.13 \\ \text { BC 26 } & 13 & 3.10 \\ \text { BC 28 } & 2 & 5.67 \\ \text { BC 28 } & 11 & 5.48 \\ \text { BC 28 } & 17 & 4.87 \\ \text { BC 32 } & 2 & 5.33 \\ \text { BC 32 } & 10 & 6.31 \\ \text { BC 32 } & 14 & 6.20\end{array}$




\section{Arctic Coretop ${ }^{231} \mathrm{~Pa} /{ }^{230} \mathrm{Th}$ : Scholten et al. (1995), Moran et al. (2005), This Study}

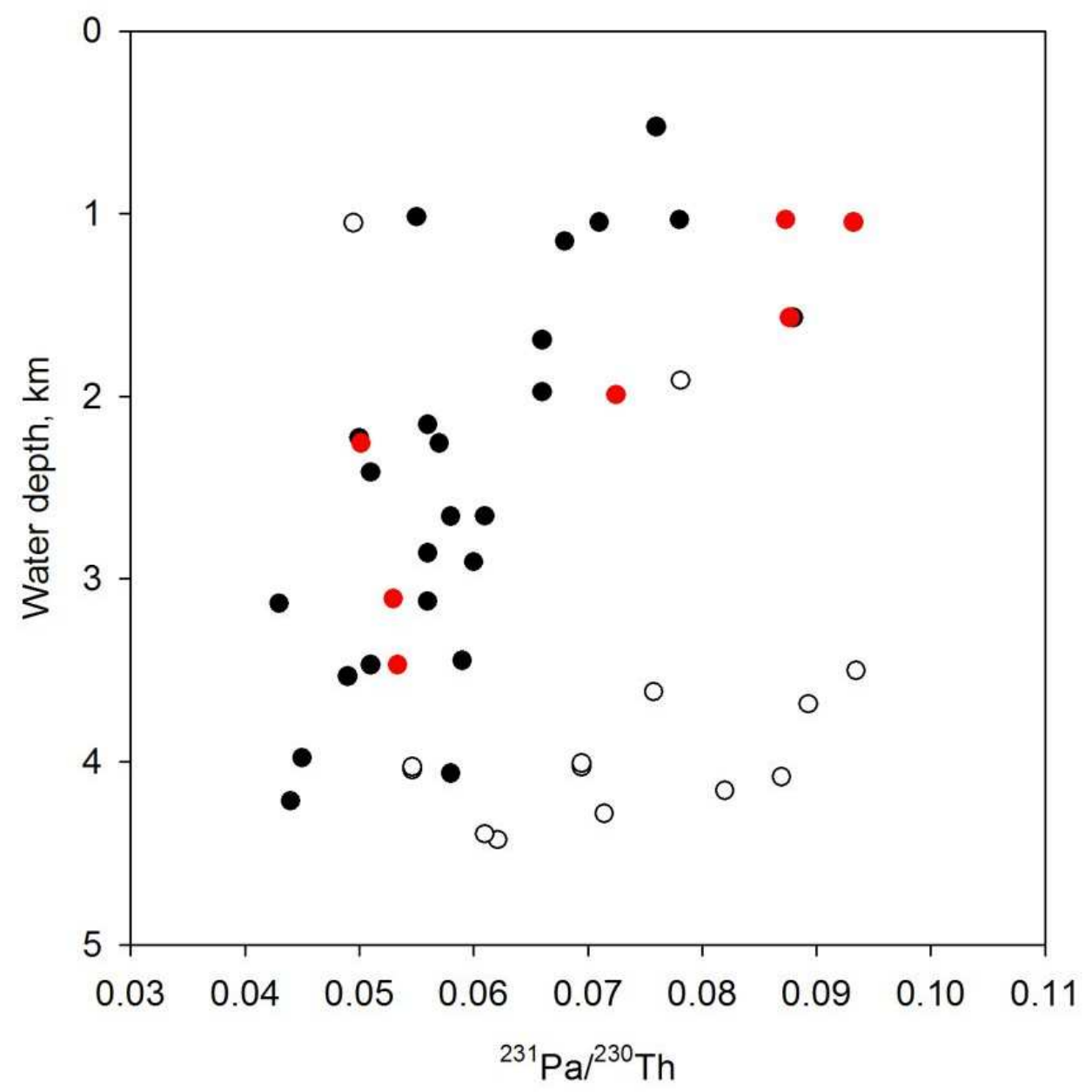

- Scholten et al. (1995)

- Moran et al. (2005)

- This Study

Figure A.3: ${ }^{231} \mathrm{~Pa} /{ }^{230} \mathrm{Th}$ ratios from this study, Moran et al. (2005) and Scholten et al. (1995). The Scholten et al. data, largely from between 3.5 and $4.5 \mathrm{~km}$ (deeper than our deepest site, this study) do not fit the relationship between depth and ratio seen in our data and the Moran et al. data; it is unclear why this is the case. Possibilities include a change in ${ }^{231} \mathrm{~Pa}$ scavenging and burial at $3.5 \mathrm{~km}$, and differences in analytical method (mass spectrometry and alpha-counting.) 


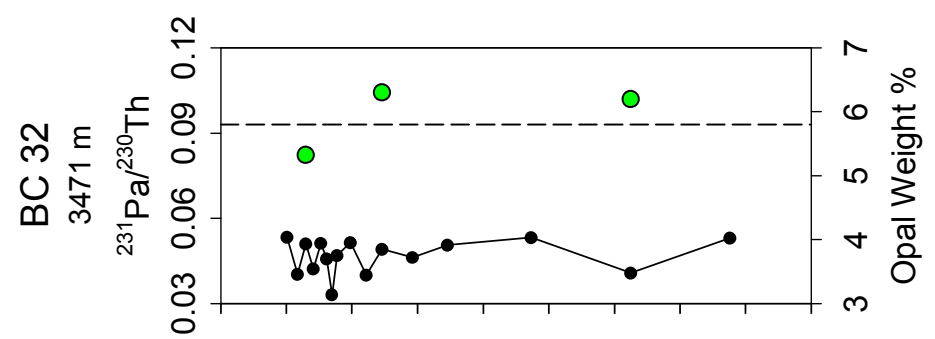

告
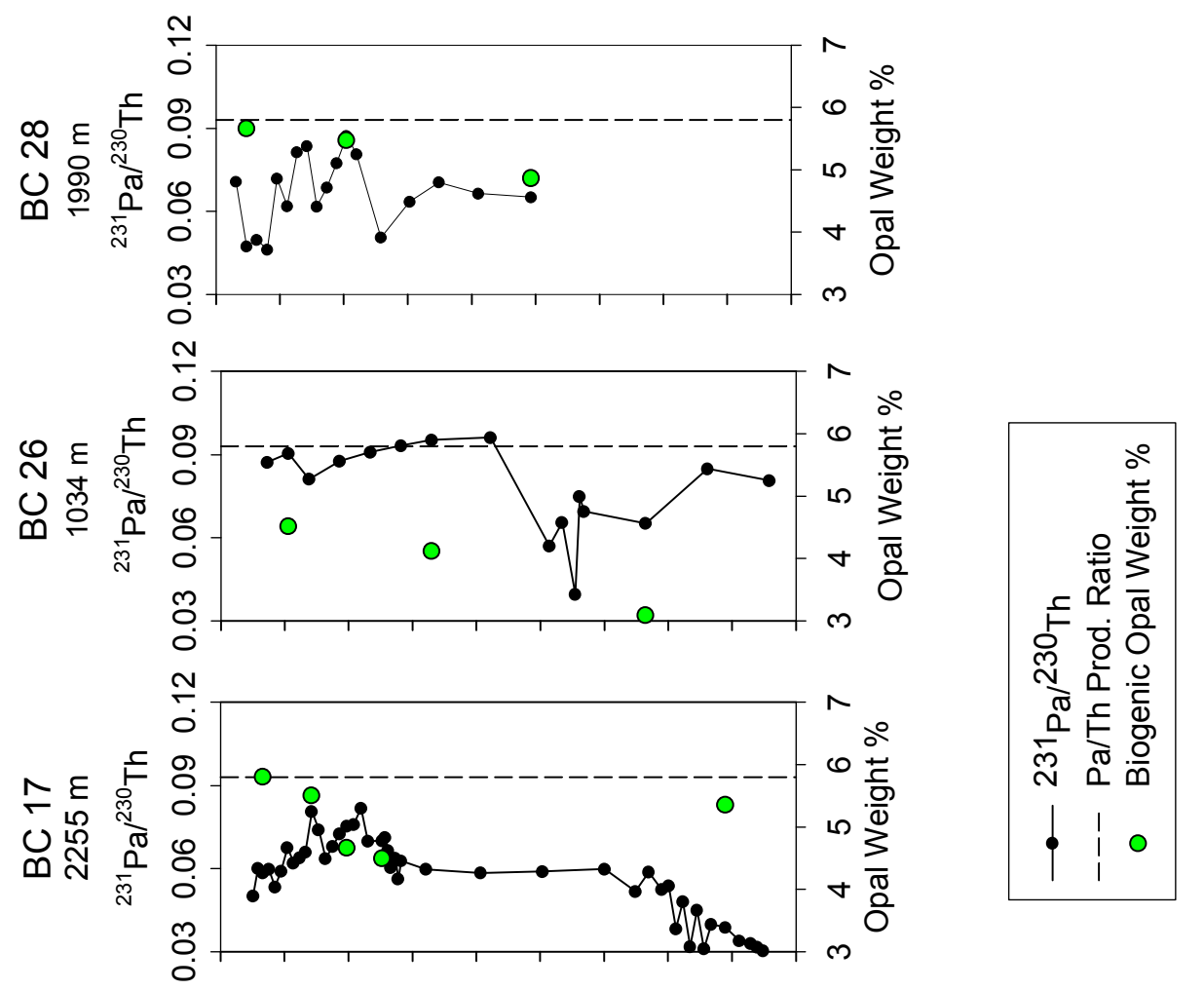

포

उे

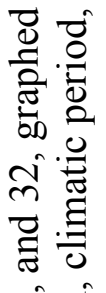

กิ

จำ

N.

N $E$ o

U 음
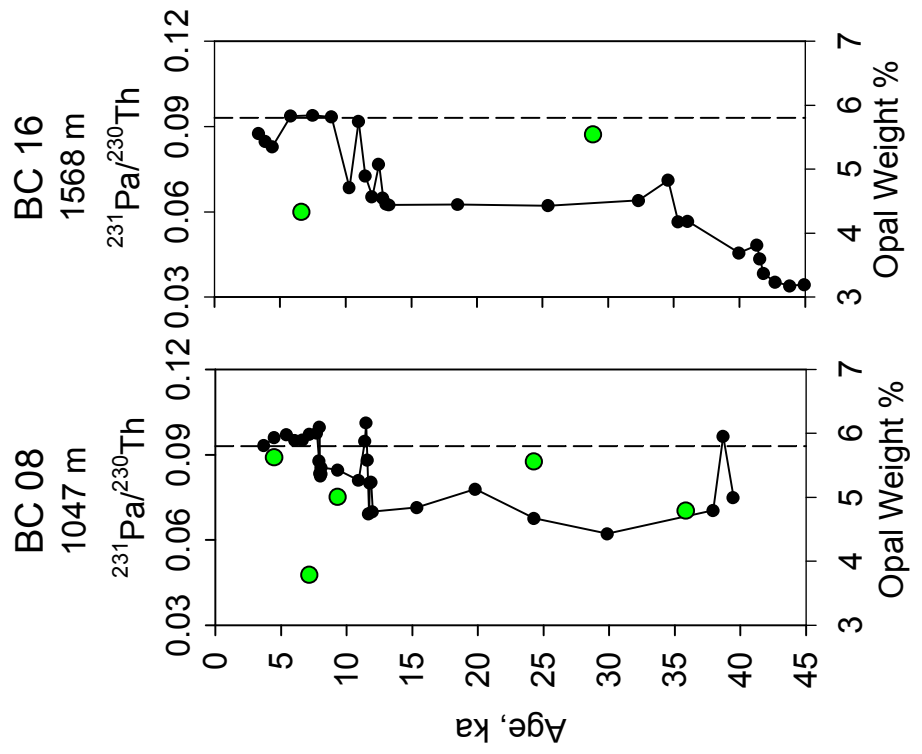

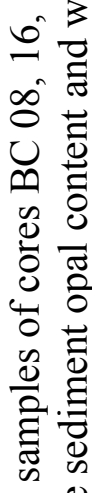

용

过

क

อ

으를

क्ष

एं

능

응 范

. $\frac{0}{0}$

$\infty$

응 ठ․

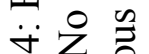

¿

总 


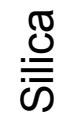

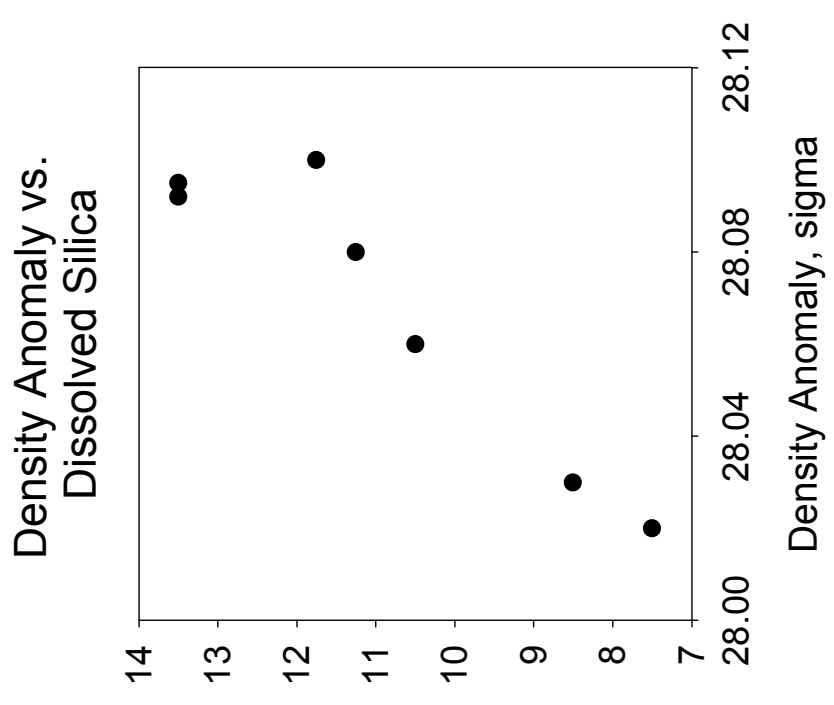

잉

की

○

능 응

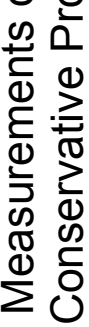

ह

ปั

$\frac{1}{2}$

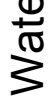
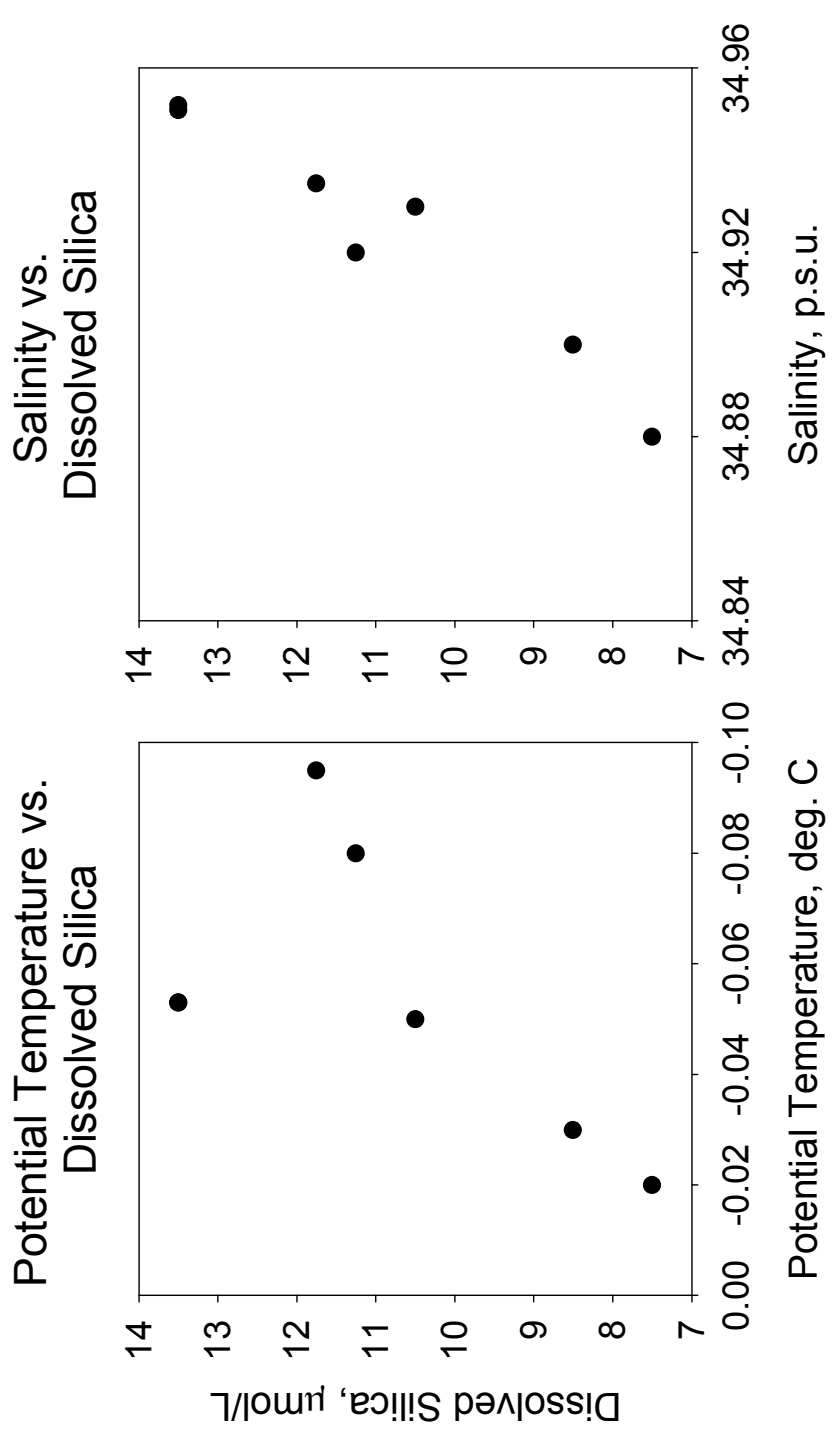

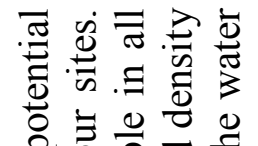

¿

包

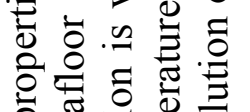

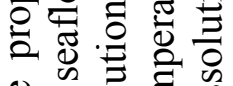

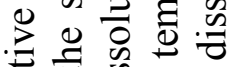

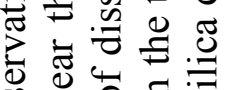

包

융이유

‡

ㅇN으.

호웡

Э.류

츨

总乙的

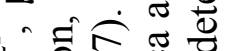

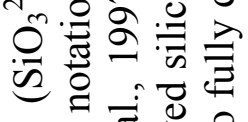

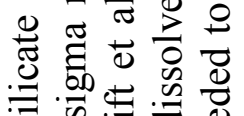

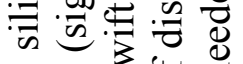

근유

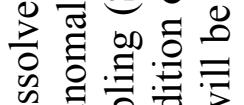

을 卷完

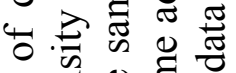

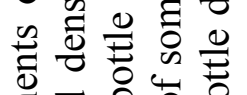

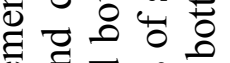

ฮี ప

苛

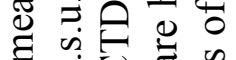

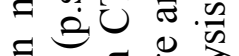

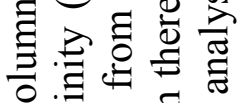

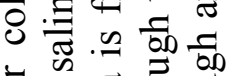

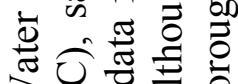

3 0 0

ஸ்

《

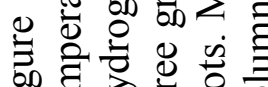

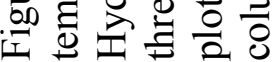

